\title{
The Working Public's Perceptions of Service Dogs: A Phenomenological Investigation of Gatekeepers' Experiences
}

Angela M. Dial

amdial@mix.wvu.edu

Follow this and additional works at: https://researchrepository.wvu.edu/etd

Part of the Other Public Affairs, Public Policy and Public Administration Commons, and the Public Policy Commons

\section{Recommended Citation}

Dial, Angela M., "The Working Public's Perceptions of Service Dogs: A Phenomenological Investigation of Gatekeepers' Experiences" (2019). Graduate Theses, Dissertations, and Problem Reports. 3875.

https://researchrepository.wvu.edu/etd/3875

This Dissertation is protected by copyright and/or related rights. It has been brought to you by the The Research Repository @ WVU with permission from the rights-holder(s). You are free to use this Dissertation in any way that is permitted by the copyright and related rights legislation that applies to your use. For other uses you must obtain permission from the rights-holder(s) directly, unless additional rights are indicated by a Creative Commons license in the record and/ or on the work itself. This Dissertation has been accepted for inclusion in WVU Graduate Theses, Dissertations, and Problem Reports collection by an authorized administrator of The Research Repository @ WVU.

For more information, please contact researchrepository@mail.wvu.edu. 
The Working Public's Perceptions of Service Dogs:

A Phenomenological Investigation

of Gatekeepers’ Experiences

Angela M. Dial

Dissertation submitted to the

Davis College of Agriculture, Natural Resources and Design

at West Virginia University

in partial fulfillment of the requirements

for the degree of

Doctor of Philosophy

in

Human and Community Development

Harry N. Boone, Jr., PhD, Chair

Cindy Beacham, $\mathrm{PhD}$

Katie Baker Jones, $\mathrm{PhD}$

Joy Saab, PhD

Craig Nelson, MID

School of Design and Community Development

Morgantown, West Virginia

2019

Keywords: Accessibility, Americans with Disabilities Act, Air Carrier Access Act, Assistance

Dog, Disability, Fair Housing Act, Gatekeeper, Misrepresentation, Public facility

Service dog, Service dog team

Copyright 2019 Angela M. Dial 


\author{
ABSTRACT \\ The Working Public's Perceptions of Service Dogs: \\ A Phenomenological Investigation \\ of Gatekeepers' Experiences
}

Angela M. Dial

The purpose of this study was to capture the essence of the working public's experiences with, and perceptions of service dogs. The population for the study was the working public of Kentucky, who through their employment, have experienced first-hand the phenomenon. A phenomenological framework informed the research design. Indepth, unstructured interviews were conducted to obtain data. Interview transcriptions were analyzed according to suggestions from Moustakas (1994) and Hycner (1985) regarding phenomenological research. The results of this research study naturally formed into five themes. Findings showed prevalent misunderstandings, confusion and lack of knowledge regarding service dogs, including how to identify a service dog, how to differentiate service dogs from other dogs, uniform and certification or registration expectations, legislation, and the labels used to describe different assistance dogs. Additionally, findings showed exposure to dogs in general, and training procedures, could impact one's perceptions of, and level of comfort around service dogs.

Furthermore, participants identified misrepresentation of a service dog as a primary issue around this topic. Participants placed value in standardization of service dog uniforms and identification processes, as well as the need for increased educational programs across social groups. Based on these findings, recommendations for future research were made to further establish an understanding of the public's perceptions of assistance animals and assistance dog legislation. Recommendations were also made for adaptations and educational opportunities for various social groups. Increased research and education are necessary catalysts for change and further understanding of how to successfully incorporate service dogs into our communities. 


\section{DEDICATION}

This dissertation is dedicated in part, to my grandfather, Dr. John Carline, who, in the midst of innumerable challenges, has steadily exemplified honor, faithfulness, commitment to excellence, and above all, kindness. My grandfather was the first person to teach me about the $\mathrm{PhD}$ process. His influence in my life has helped me see the beauty in teaching, and inspired me to pursue this degree. At 91, he is still learning, writing, and blessing me with his knowledge and experience.

Second, I dedicate this work to all of the dogs who have taught me about the incredible creatures with which we have been blessed on this earth. The inspiration for this research would not have come if not for Ginger, Bailey, Norm, Sarge, and, of course my sweet Gabbie. These dogs have forever changed my life and inspired me to continuously work on creating a world where dogs are respected, valued, and cherished. 


\section{ACKNOWLEDGEMENTS}

This project would not have been possible without the immense amount of guidance, support, and encouragement from so many people. I am profoundly grateful to everyone who has supported me through this process. I could not have attained this goal without you.

To West Virginia University and the School of Design and Community Development, thank you for giving me the opportunity to pursue my graduate education as a teaching assistant. Thank you also to Dr. Kerry Odell, for believing in me and welcoming me into an educational program where I could design such a research study. Your ability to inspire students and encourage your colleagues continues to inspire me as I pursue my educational career. Thank you for being such a positive example in my life.

To Dr. Harry Boone, I cannot thank you enough for being willing to take me under your wing and for believing in me throughout this process. Even with all of the challenges that came along the way, you have been a pillar of support, guidance, and wisdom. I fully believe you are one of the absolute best academic advisors, and it has been a true honor to be one your graduate students. I am forever grateful to have learned from you and I strive to one day be the caliber of a mentor for others that you have been for me. Thank you!

To Dr. Cindy Beacham, there are not enough words to thank you for the constant support and encouragement you have given me from day one. Every single time we have talked, I left with a renewed sense of energy, excitement, encouragement and curiosity. Thank you for teaching me about design thinking, and helping me see things in new ways. I admire you as a teacher, designer, and woman, and I am forever grateful for your mentorship. Also, thank you for always sharing your sweet dogs with me and letting me know they were there to support me on our conference calls. Please give them some highfives and treats and let them know, we made it!

To Dr. Joy Saab, I do not know where I would be without you. You have helped me in more ways than I knew possible. You are an incredible teacher, mentor, woman, and friend. Thank you for your endless support, encouragement, and guidance. You have helped me learn about so many things, including qualitative research, dissertation writing, and how to balance those with my everyday life. Grazie mille!

To Dr. Katie Baker Jones, your attention to detail, and commitment to my work has been so valuable. Thank you for pushing me to see my own biases and for always helping me improve my research design and writing. You have provided me with valuable insight into how my work fits in our industry and what my next steps look like. I thank you for all that you have done for me and all that you have done for the program. West Virginia University is very lucky to have you.

To Craig Nelson, your willingness to help me through this process has been so appreciated. I respect and admire your open-mindedness and grounded approach to research. Your knowledge of the industry has provided me with invaluable insight and 
you have helped me see important connections between educational research and the industry. Thank you!

To the eleven co-researchers in my study, none of this would have been possible without you. Thank you for your time, your participation, and your willingness to share your experiences.

To everyone who helped open my eyes and educate me on service dogs, Dr. Jean Meade, Lindsay Parenti, the Hearts of Gold organization, and my original committee, thank you. You have provided me with invaluable experience that has changed the trajectory of my life.

To my family and friends, thank you for constantly believing in me and encouraging me to pursue my wild dreams and goals. No matter how far I roam, you are always there to welcome me home, and for that, I am so grateful.

To my grad school friends, especially Dawn, Lauren, Hannah, Pariya, Sofija, and Ruchi, you have been the best part of the past five years. Not only have you helped me stay on track but you have made me laugh and stay sane through the craziness of it all. I will forever value your friendship and cherish your incredible minds.

To Beth, you are the definition of a friend. When we were teenagers in Brazil, if you told me that one day we would be talking through my dissertation, I probably would have laughed. Thank you for helping me find solutions, for being my sounding board, and always being up for anything!

Finally, to David, I do not know if I will ever be able to show you how much I appreciate you. You have been my rock and my source of stability through this adventure. You have comforted me when I was frustrated, took care of Gabbie when I was overwhelmed, helped me stay level-headed, celebrated with me, and always made me laugh. Thank you for being my person and loving me. I love you. 


\section{TABLE OF CONTENTS}

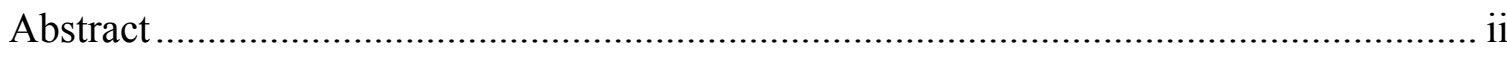

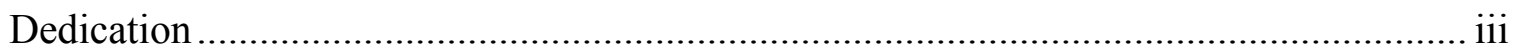

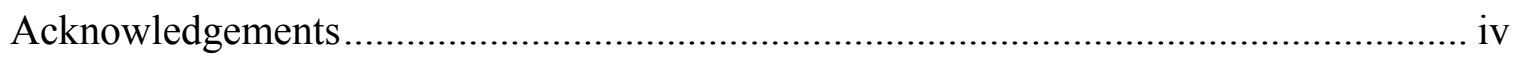

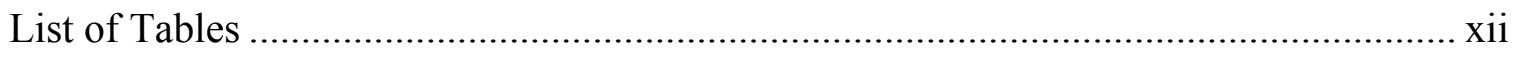

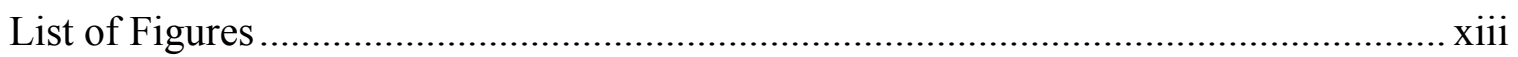

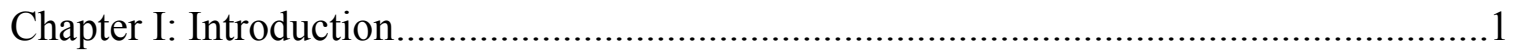

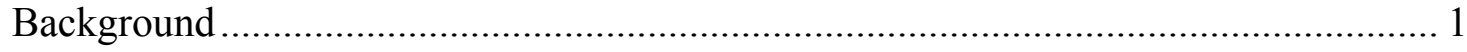

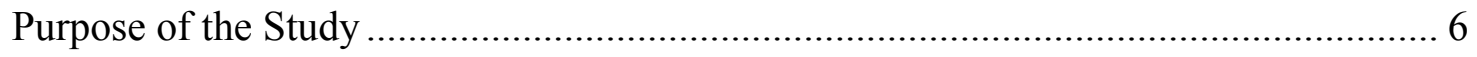

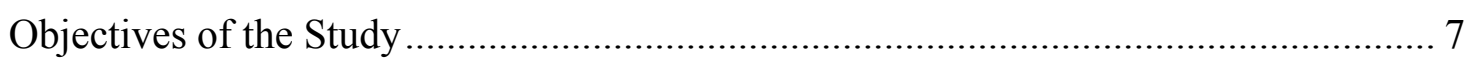

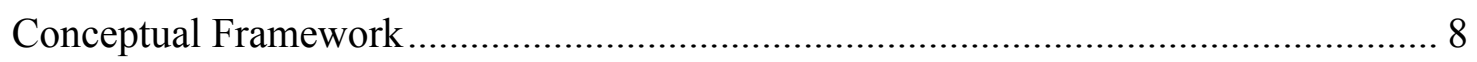

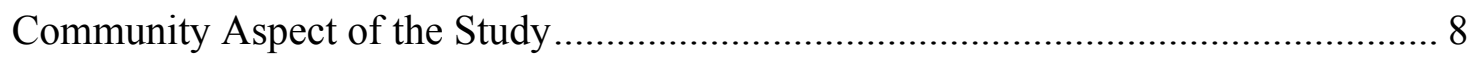

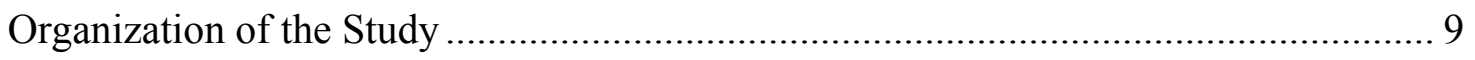

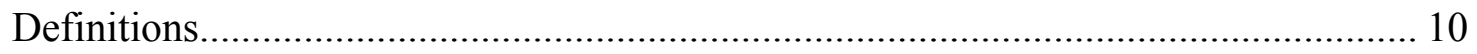

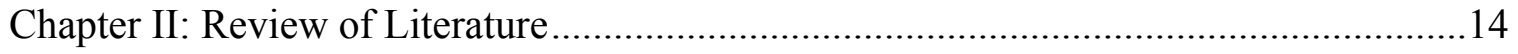

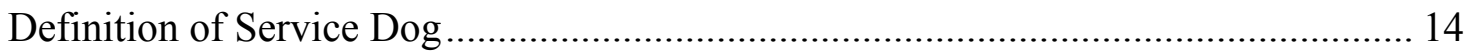

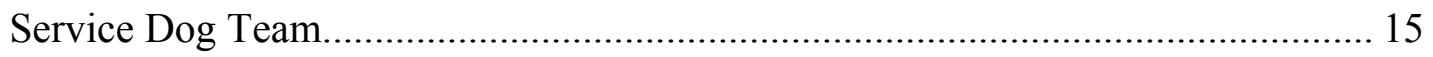

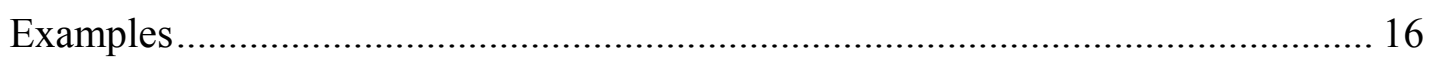

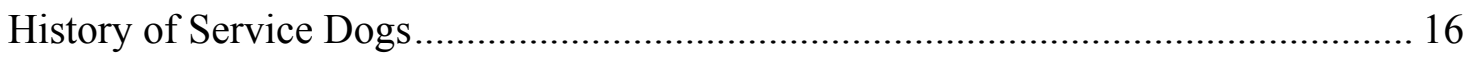

Service Dogs as a Topic of Research.................................................................... 18

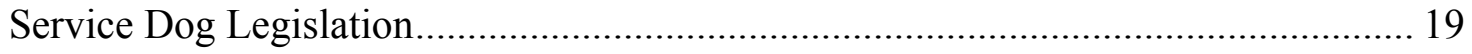

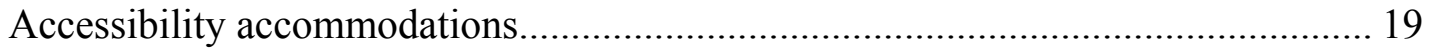

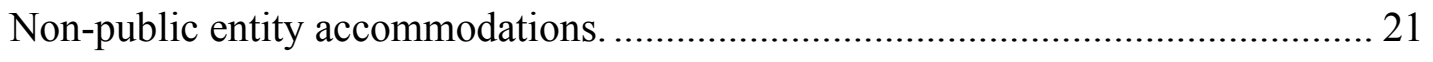

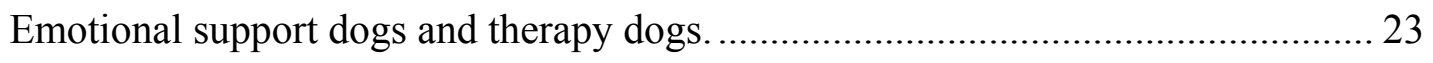

Population, Registration, and Certification............................................................ 23

Federal-to-state and state-to-state discrepancies............................................. 25

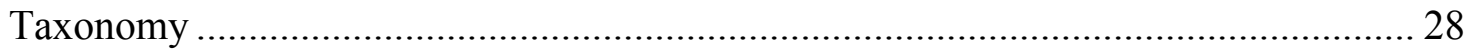

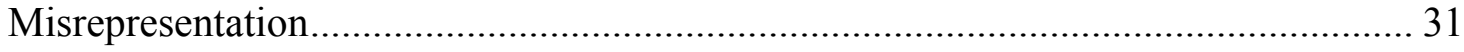

Misrepresentation as studied in empirical research. .......................................... 32

Misrepresentation as presented in the news...................................................... 35

Service Dog Representation in Physical and Digital Communities............................ 37

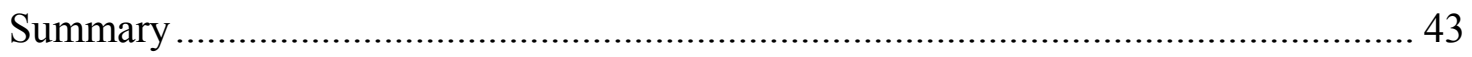

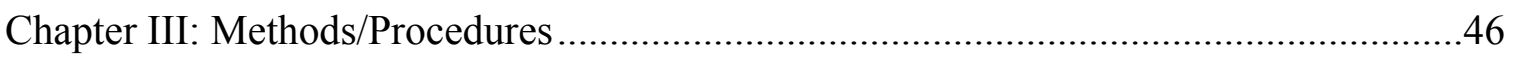

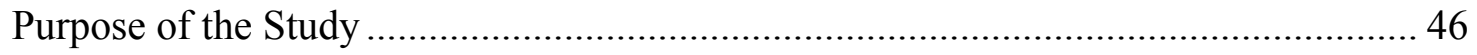

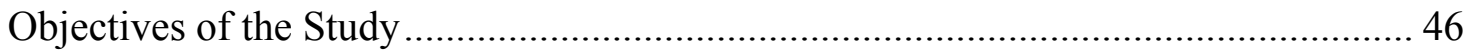


Methodology and Conceptual Framework - Phenomenology ....................................... 47

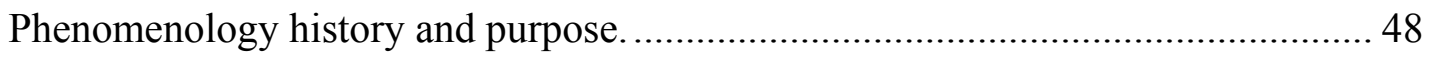

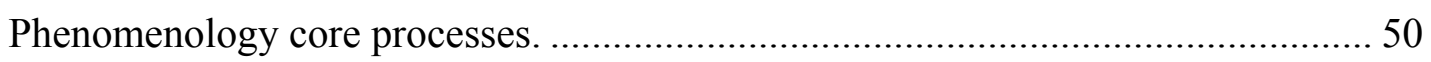

Initial engagement.

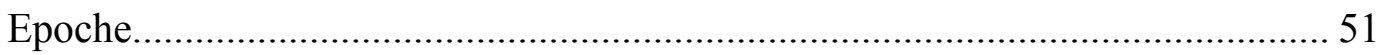

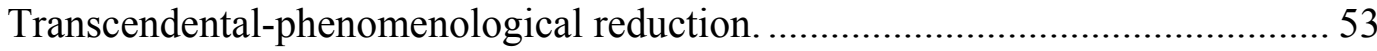

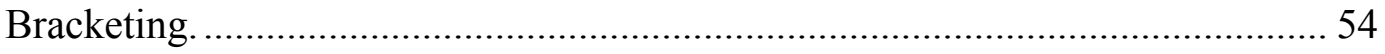

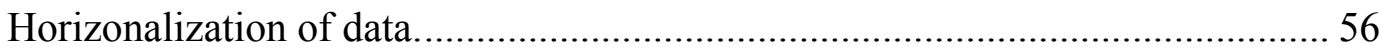

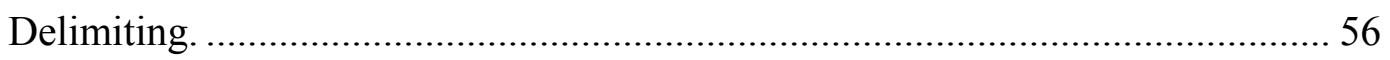

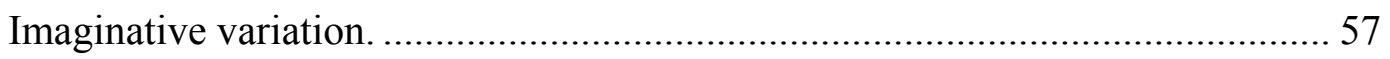

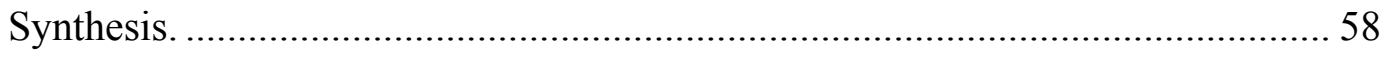

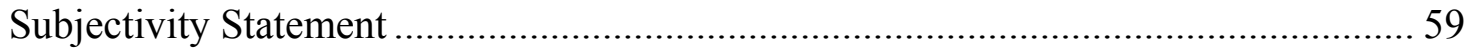

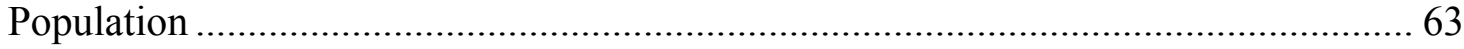

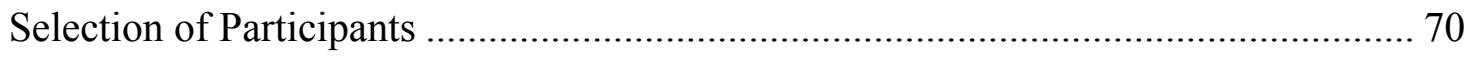

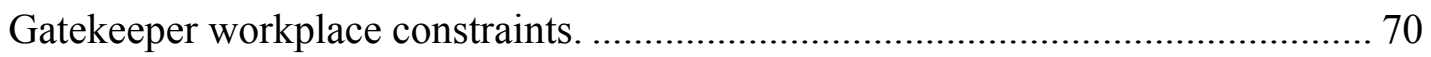

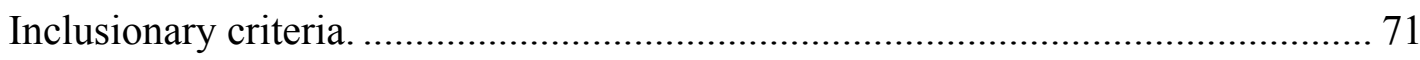

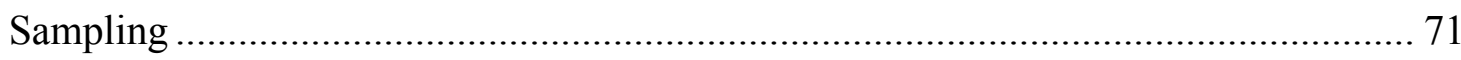

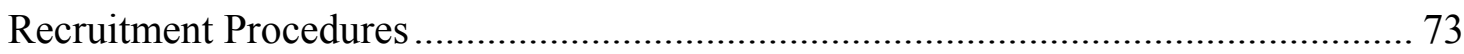

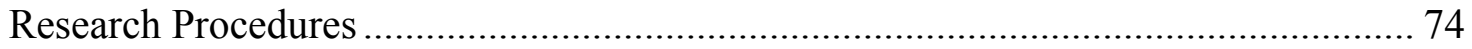

Instructions to co-researchers. ........................................................................... 74

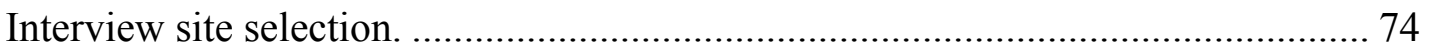

Data collection (interview process). ................................................................... 74

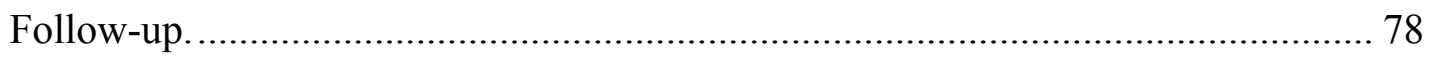

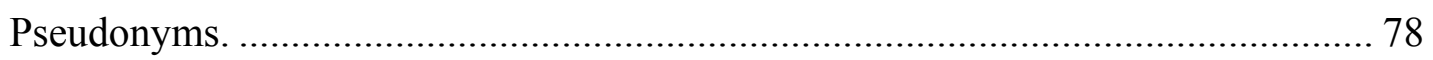

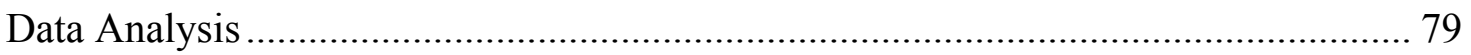

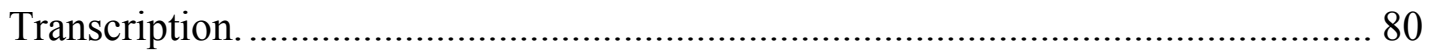

Step 1: Listing and preliminary grouping/horizonalization....................................... 81

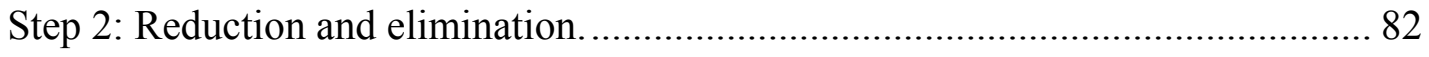

Step 3: Clustering and tentative thematizing of invariant constituents (ICs), .......... 82

Step 4: Final identification of the invariant constituents and themes by application

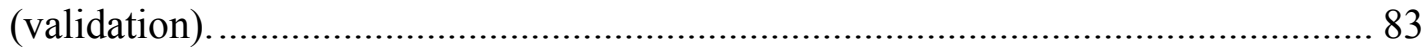

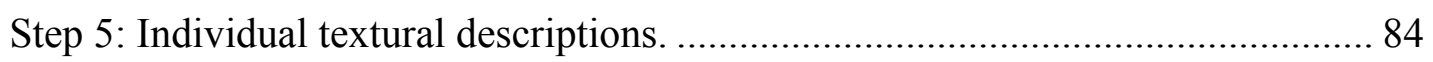

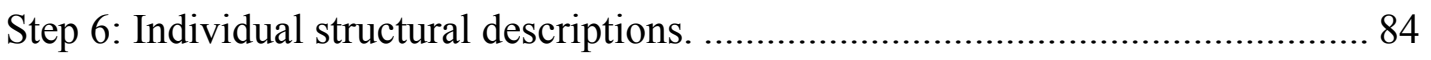

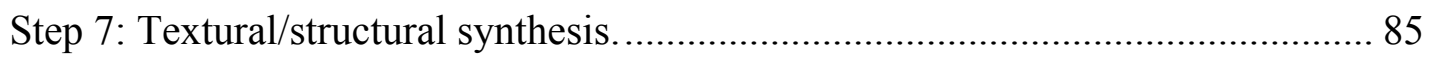

Step 8: Integrated textural/structural description................................................... 86

Credibility, Transferability, Dependability, and Confirmability .................................. 87 


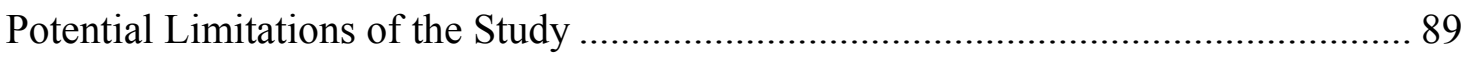

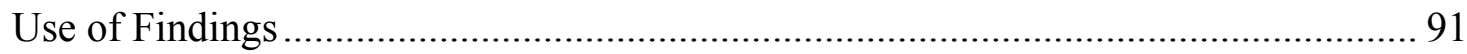

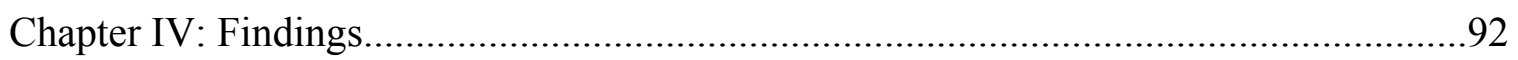

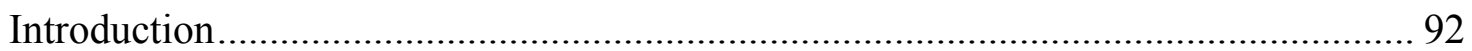

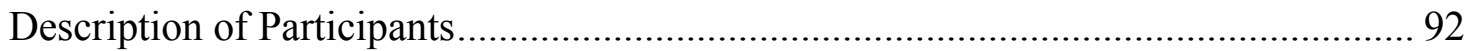

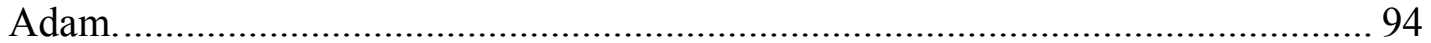

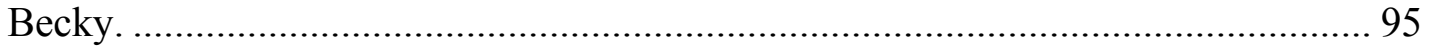

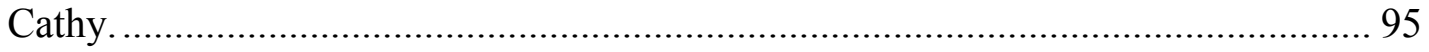

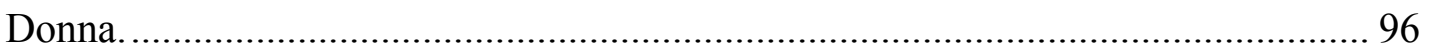

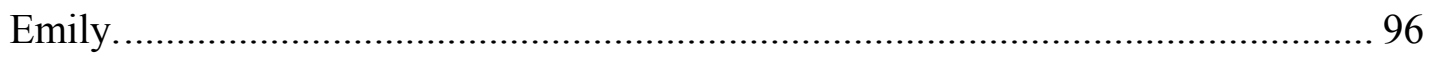

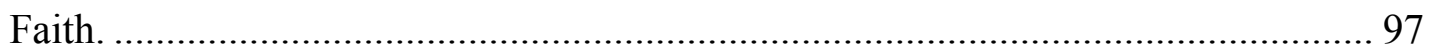

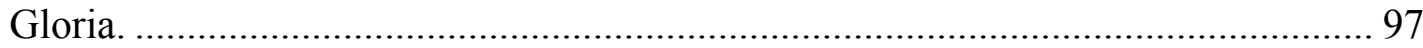

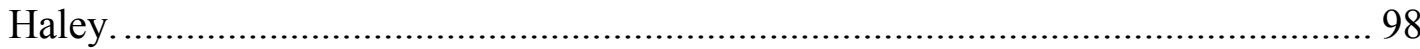

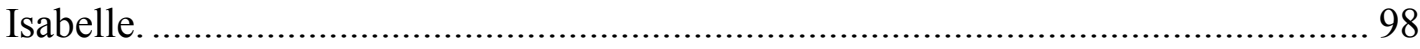

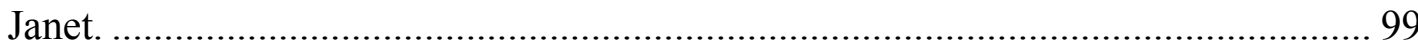

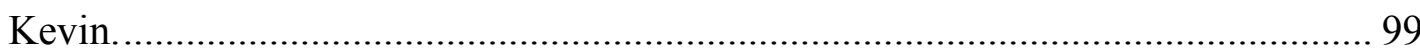

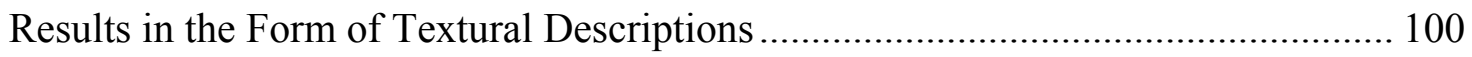

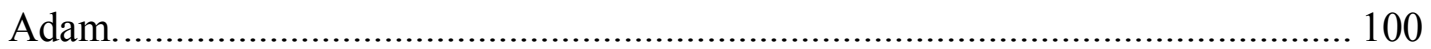

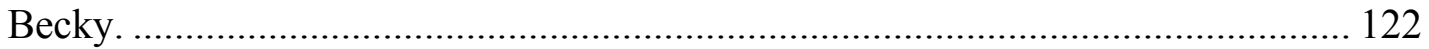

Cathy

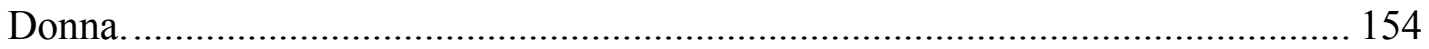

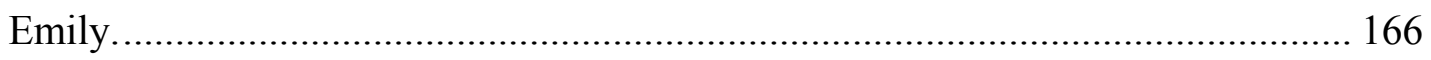

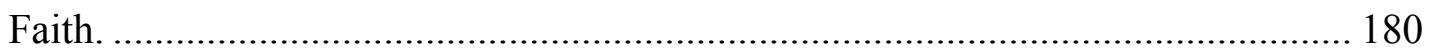

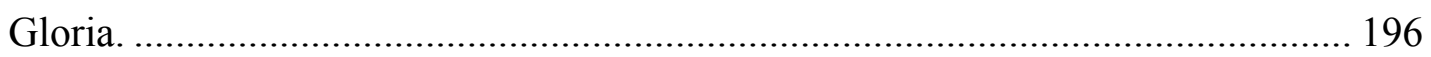

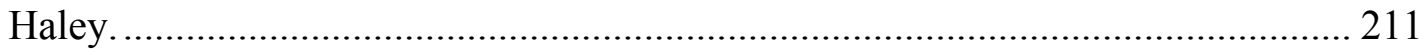

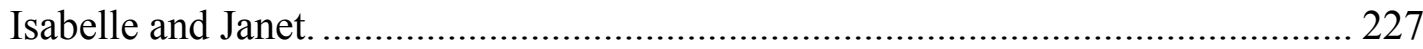

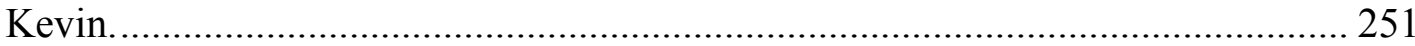

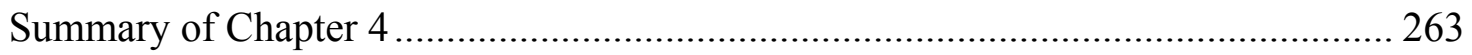

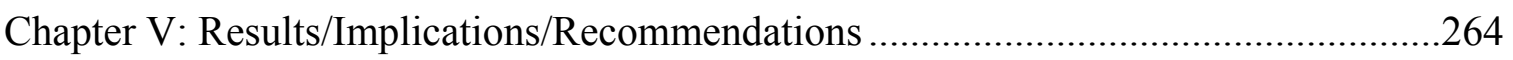

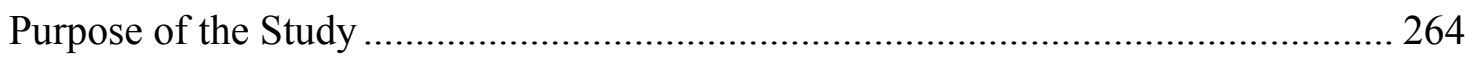

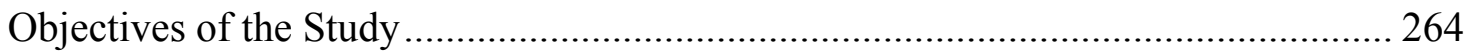

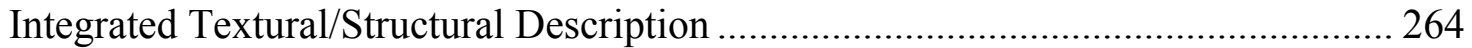

Themes/Conclusions/Interpretations/Implications ……………………………...... 265

Theme 1: Misunderstanding, Confusion, and Lack of Knowledge ........................... 266

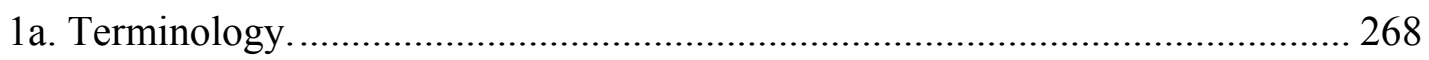

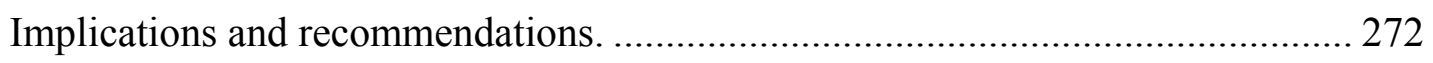




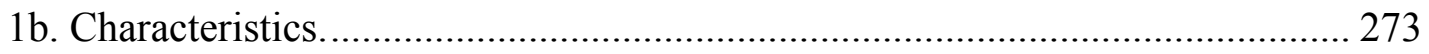

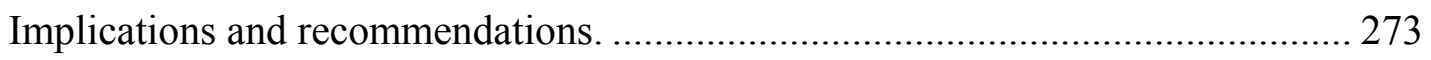

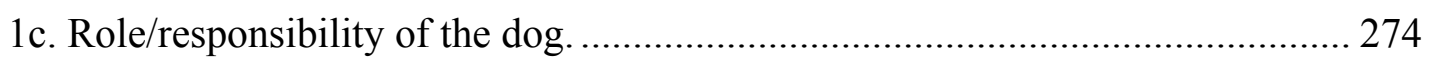

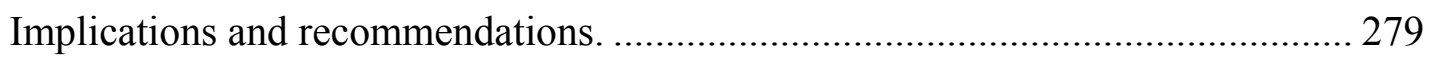

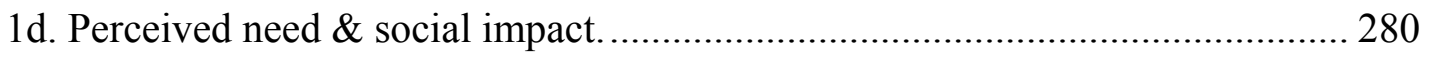

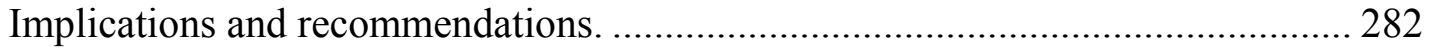

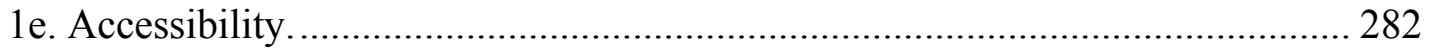

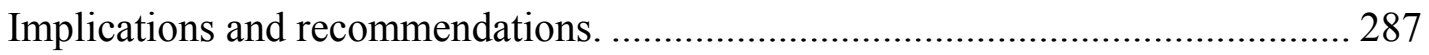

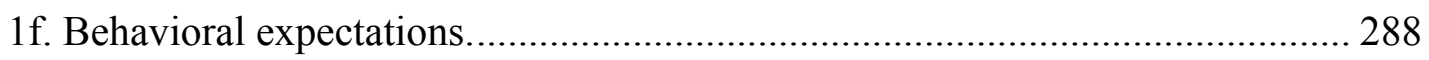

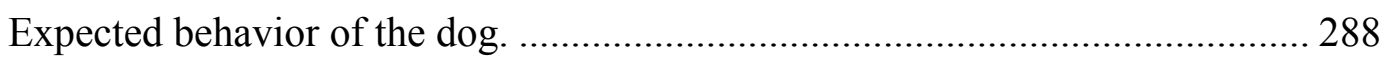

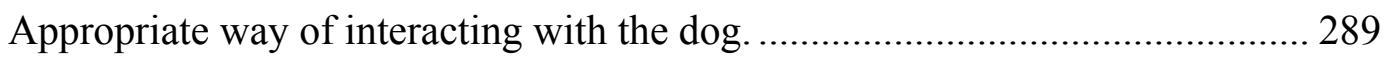

Implications and recommendations............................................................. 290

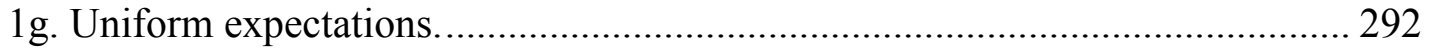

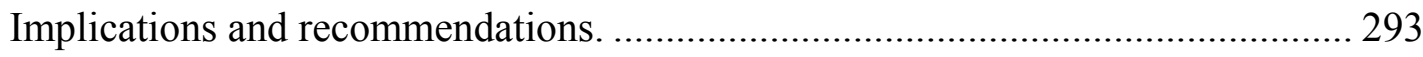

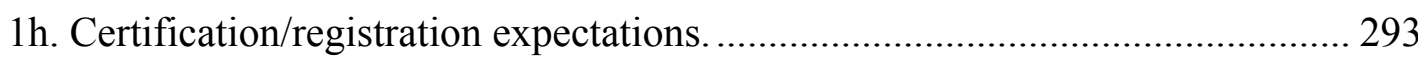

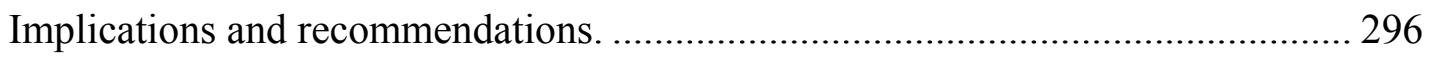

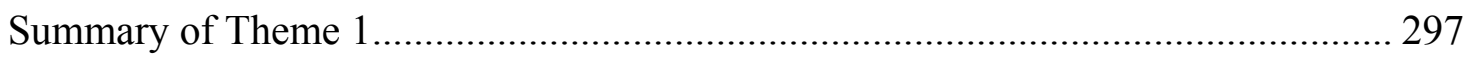

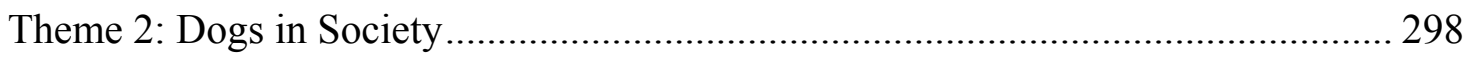

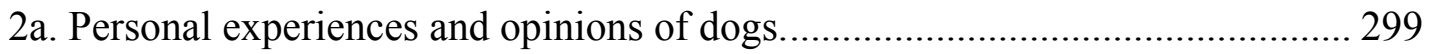

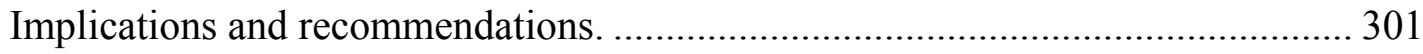

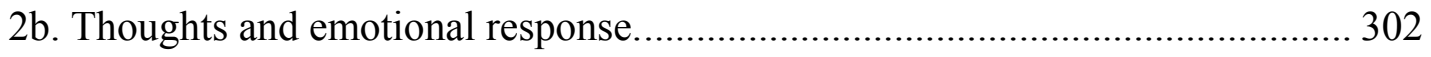

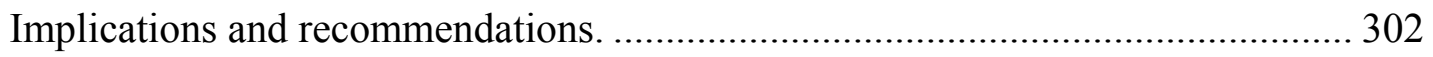

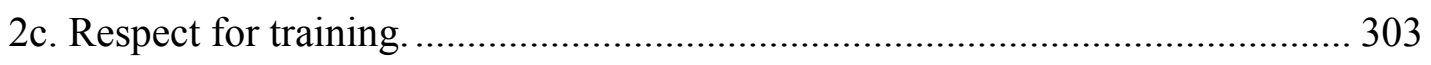

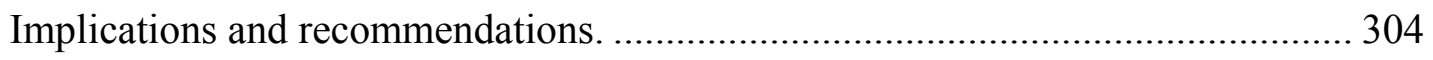

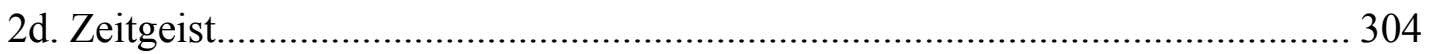

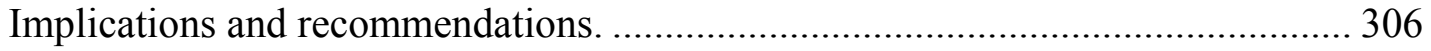

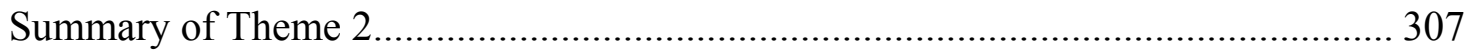

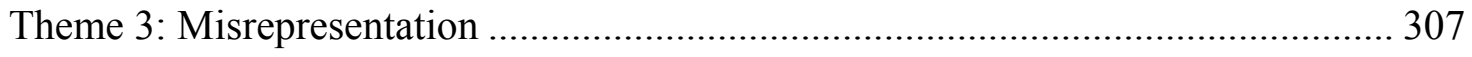

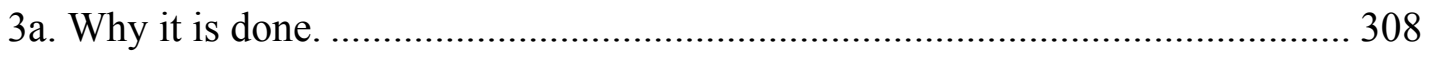

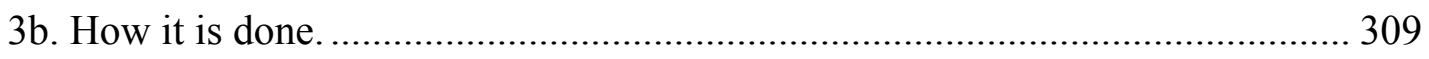

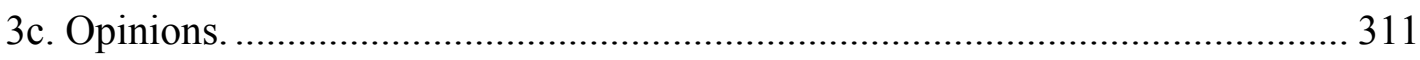

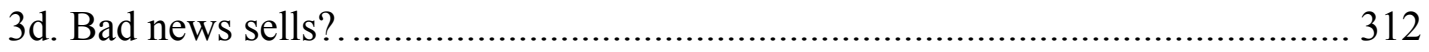

3e. Implications; social/cultural impact and potential harm.................................. 313

Reputation of service dogs and service dog handlers...................................... 313

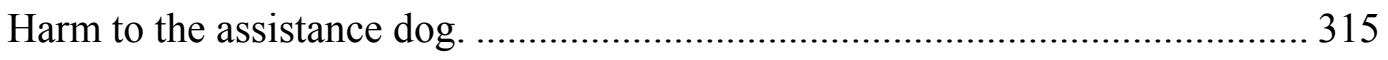

Reputation of the person misrepresenting their dog......................................... 315 


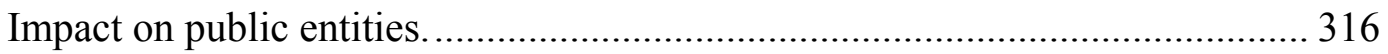

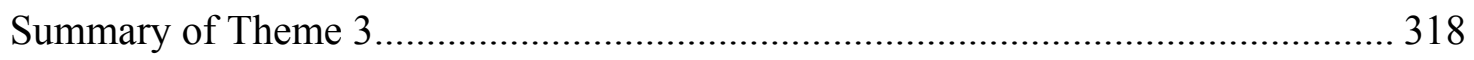

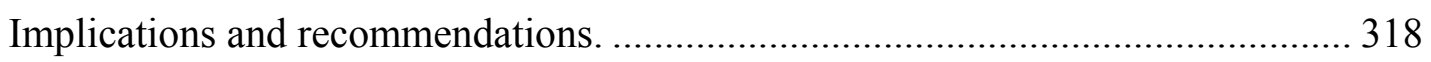

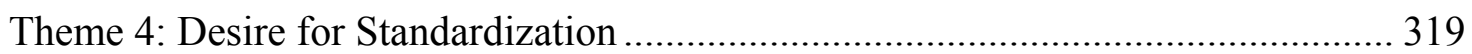

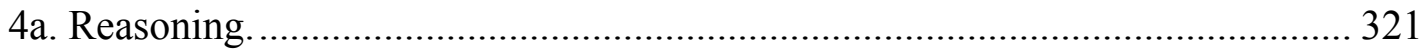

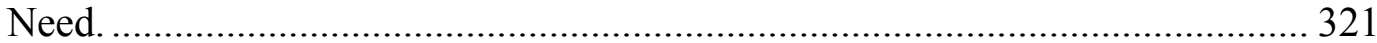

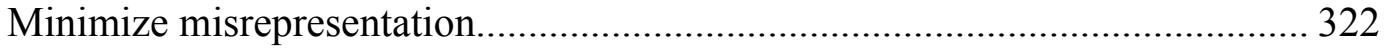

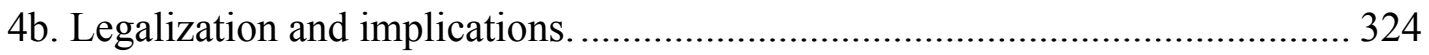

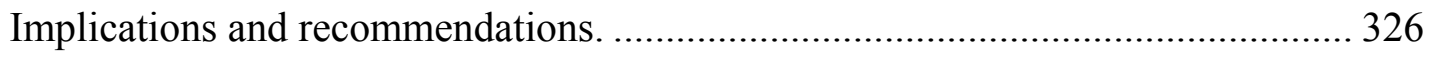

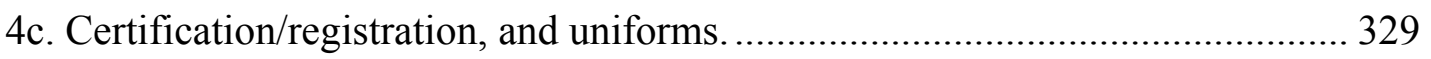

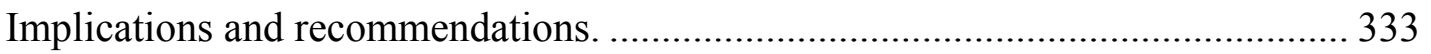

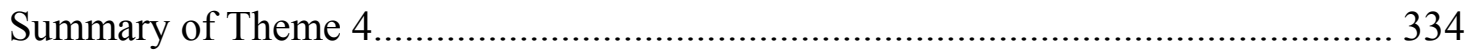

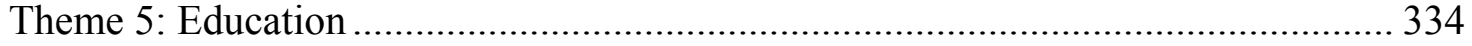

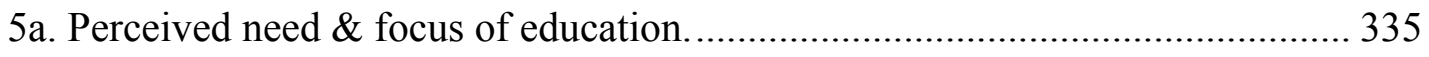

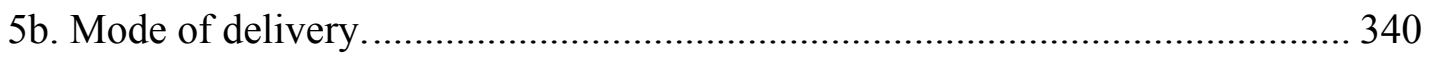

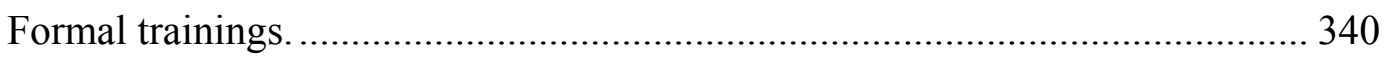

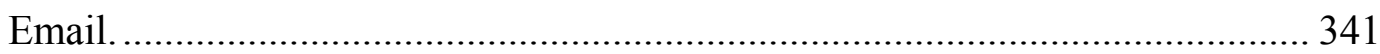

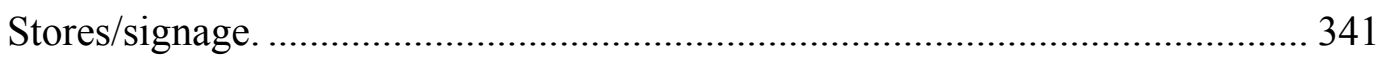

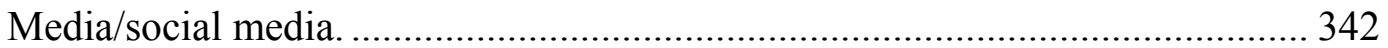

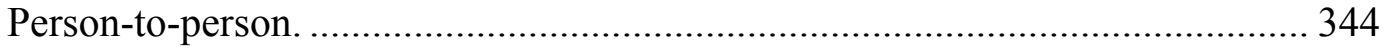

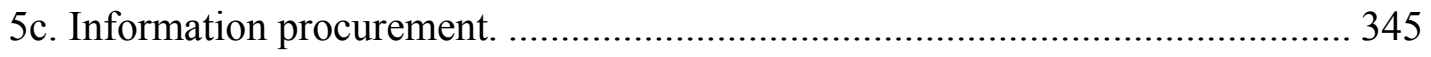

Summary of Theme 5 with Implications and Recommendations................................ 350

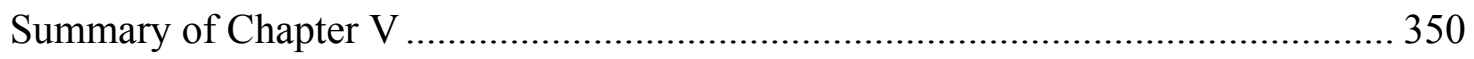

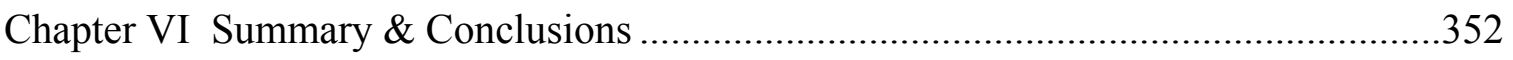

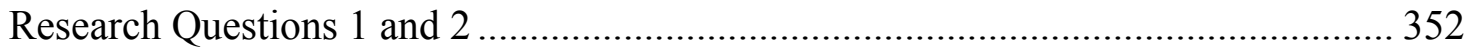

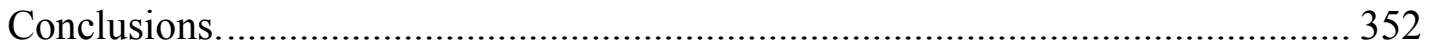

Misunderstanding, confusion, and lack of knowledge....................................... 354

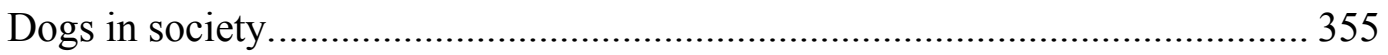

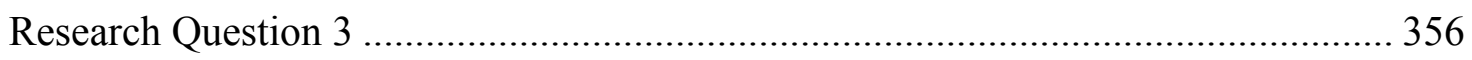

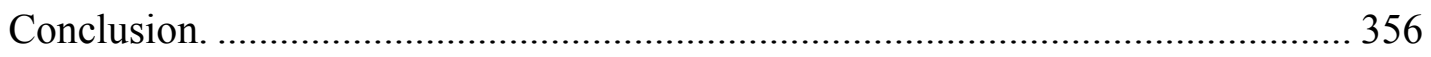

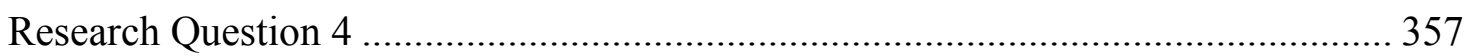

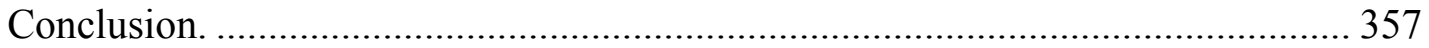

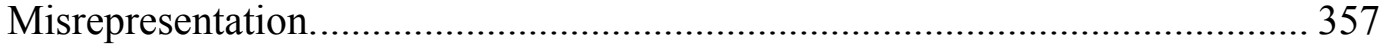

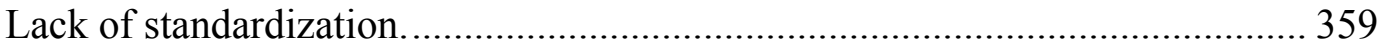

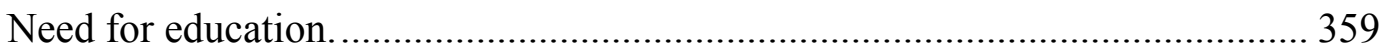

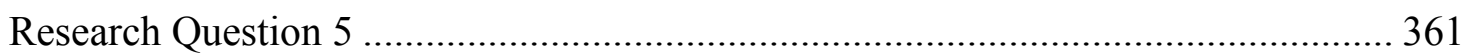




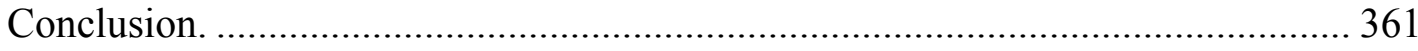

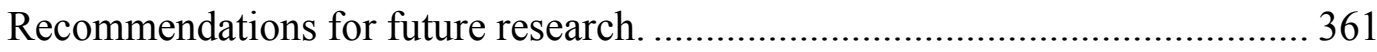

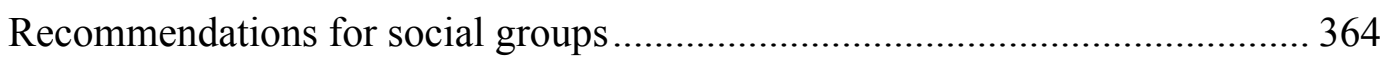

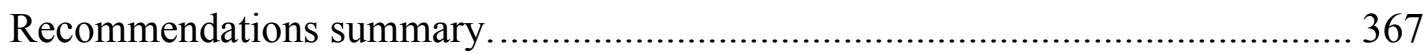

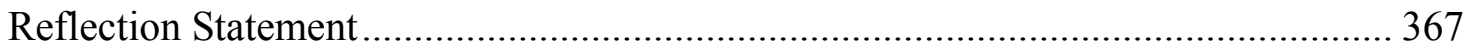

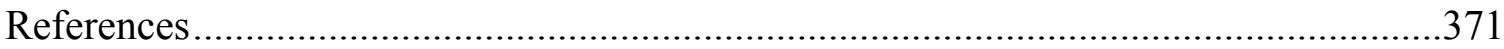

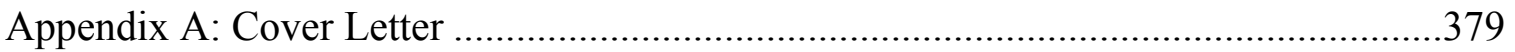

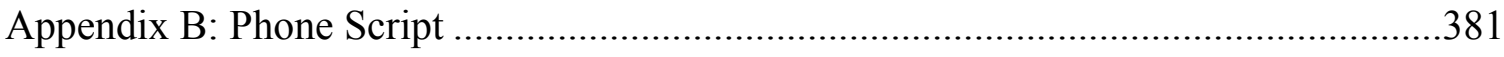

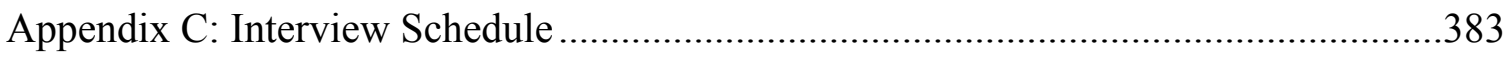

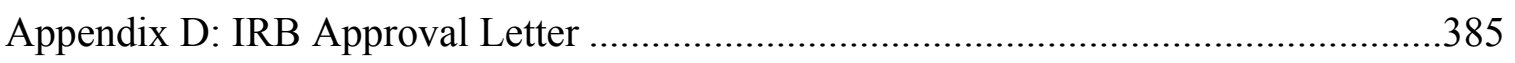

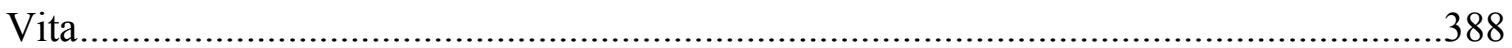




\section{LIST OF TABLES}

1 United States Individual State Expectations for Service Dogs to Wear Orange ...29

2 Comparison of Terminology Used in Service Dog Legislation in Eight

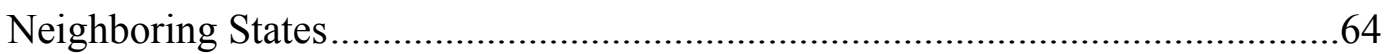

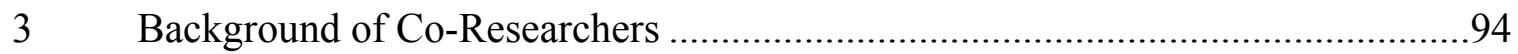

4 Themes and Subthemes of Data Analysis Results............................................353 


\section{LIST OF FIGURES}

1 Emoji. This figure illustrates the disability related digital icons to be released in

2019. (Heasley, 2019)

2 Café sign. This figure illustrates signage the researcher found on a café door in 2018

3 Main themes/conclusions/interpretations/implications of this research study.....265

4 Main theme 1: Misunderstanding, confusion, and lack of knowledge, and related

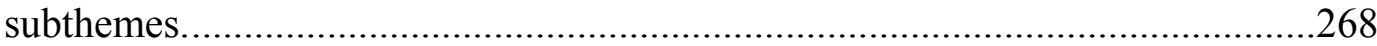

$5 \quad$ Main theme 2: Dogs in society, and related subthemes...................................298

6 Main theme 3: Misrepresentation, and related subthemes.................................308

$7 \quad$ Main theme 4: Desire for standardization, and related subthemes.....................320

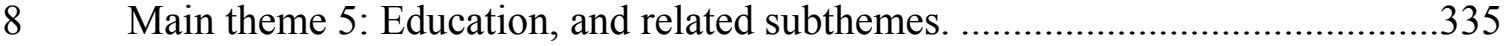




\section{CHAPTER I}

\section{Introduction}

Imagine, it is a sunny, summer afternoon and you are working admissions for a local food and music festival. This annual event brings your community together in a celebration of local restaurants, bands, breweries, and family fun. As part of admissions, you are instructed to offer free dog-daycare services for any attendees who show up with their pet dog. With the exception of service dogs, pets are not allowed in the event outside of the dog-daycare. You have not been given any additional information or training. Do you feel prepared to distinguish service dogs from other dogs?

This scenario, as described by one of the participants in this research study, is an example of what people working in public facilities regularly experience. Facilitation of this interaction was the motivation for this inspection into the working public's perceptions of service dogs.

\section{Background}

Dogs have been assisting humans for hundreds of years with tasks ranging from farming and hunting, to guiding and protecting (Parenti, Foreman, Meade, \& Wirth, 2013). The term "service dog" was coined in 1975 (Blattner, 2015), but evidence of what we call a "service dog" goes back as far as a first century fresco portraying a dog guiding the blind (Blattner, 2015; Fishman, 2003). In 1819, in Vienna, the first known guide dog training manual was published, and in 1929, the first formal United States guide dog training center opened (Blattner, 2015; Cohen, 2011).

A service dog is a canine "trained to do work or perform tasks for people with disabilities" (United States Department of Justice [DOJ], 2011b, p. 1). Examples of ways 
in which service dogs help mitigate disabilities include "guiding people who are blind; alerting people who have disabling auditory loss, seizure disorder or diabetes; and intervening in anxiety-driven or self-destructive behaviors for people with disabling mental illness" (Elliott \& Hogle, 2013, p. 1). Studies have shown service dogs contributed to improvements in their handler's physical, psychological and emotional well-being; and increased their handler's contributions to society (Allen \& Blascovich, 1996; Eddy, Hart, \& Boltz, 1988; Fairman \& Huebner, 2001; Sachs-Ericsson, Hansen, \& Fitzgerald, 2002). Additionally, service dogs have the potential to influence their handler's finances if the dog's assistance eliminates the need for additional paid nurses or attendants (Collins et al., 2006). In general, having a dog, including a service dog, has been linked to higher quality of life (Cutt, Giles-Corti, Knuiman, \& Burke, 2007; Jennings, 1997; Serpell, 1991) and in one study, longer life (Raina, Waltner Toews, Bonnett, Woodward, \& Abernathy, 1999). Today, there are an estimated 4,000 service dogs in the United States of America (Walther et al., 2017).

Passed in 1990, by the United States Department of Justice, the Americans with Disabilities Act [ADA] prohibits discrimination, and guarantees equal rights for individuals with disabilities in the United States (Americans with Disabilities Act [ADA], 1990; Campbell, 2016). Service dog provisions are included in the ADA. One component of these provisions is public accessibility protections (U. S. Department of Justice [DOJ], 2011a). "When accompanied by their handler, who is an individual with a disability, service animals are afforded public access protections" (Parenti et al., 2013, p. 749). State and local governments, business, and nonprofit organizations that serve the public must allow those who have a service dog to keep their dog with them in areas the 
public is normally permitted (DOJ, 2011a). As a group, those whose operations affect public commerce are called public accommodations, facilities, or entities (DOJ, 2011b).

Under the U. S. Department of Justice, individual states may create laws for increased assistance animal access, but they are not allowed to create or enforce laws that are more restrictive than the ADA (ADA, 1990). Nevertheless, more than half of the states in the United States "have laws on the books that narrow the federal definition," and further restrict the laws regarding service dogs (Elliott \& Hogle, 2013, p. 7). In some cases, the state law contradicts the federal legislation (Elliott \& Hogle, 2013).

One example where a state law further restricts the federal is North Carolina's Service Animal Permanent Registration law. The ADA states "mandatory registration of service animals is not permissible under the ADA....covered entities may not require documentation, such as proof that the animal has been certified, trained, or licensed as a service animal, as a condition for entry" (United States Department of Justice [DOJ], 2015, p. 1). However, in North Carolina legislation, residents are required to certify, and register their service dog with the Department of Health and Human Services to receive an ID tag, stamped with a registration number. That ID tag must be shown to obtain public access with their service dog (Wisch, 2016). Also in violation of the ADA, North Carolina's law states that in the event an ID tag is not available, the person must show proof that the animal has been trained as a service dog to qualify for public access (Wisch, 2016). This is just one example of the many conflicting laws in the United States.

Recognizing the Federal-to-state and state-to-state differences, Wisch (2016) created a table highlighting the differences in the laws. The following categories are 
identified as areas of state-to-state discrepancies in Wisch's (2016) table: (a) definitions of assistance animal/service animal; (b) accommodation law; (c) harassment of/interference with a service dog law; (d) driving law; (e) licensing law; and (f) misrepresentation of service animal law. Included in these categories are laws delineating registration, certification, training, licensing and uniform laws. Additional examples of these discrepancies are presented in Chapter II.

In addition to conflicting legislation, variations exist in the terminology used to describe a service dog (Campbell, 2016; Zetwick, 2016). In Delaware, the terms "service dog" and "support animal" are both used to describe a dog who provides assistance to a person with a disability (Wisch, 2016). Georgia's law uses the terms "assistance dog" and "guide dog or service dog"; and in Illinois, "service animal," "guide dog," "hearing ear dog," and "assistance animal" are all used in legal nomenclature regarding service dogs (Wisch, 2016).

As a response to the "inconsistent" vocabulary "across Federal and state statues," Parenti et al. (2013) proposed a "concise taxonomy for classifying assistance animals" (p.745). As Parenti et al. (2013) explained, “...the lack of consistency, and in some cases, ambiguity in the laws and regulations gives rise to legal challenges" (p. 748). "Common court cases involve complaints against public accommodations that refuse access to individuals and their service animals" (Parenti et al., 2013, p. 748). In one example, a woman with PTSD took her service dog into a grocery store, and after another customer complained about the presence of the dog, a manager approached the handler. The woman said the dog was a service dog and though not required, showed a laminated ID card, however, the manager questioned whether there was enough evidence to 
distinguish the dog from a pet, and asked the customer to leave. The woman took the grocery store to court for discrimination and the appellate court found there was sufficient evidence to establish a prima facie case of discrimination against the business for refusing to allow her to shop accompanied by her service dog (Storms v. Fred Meyer Stores, Inc., 2005). This example highlights the concerns over not being able to confirm a service dog's legitimacy or differentiate a service dog from other dogs.

Grocery stores, like in this example, are included in the list of public facilities responsible for adhering to the ADA laws. The owners, managers, and employees of public facilities are the working public who are responsible for allowing or denying a service dog access. In this way, the owners, managers and employees are gatekeepers. As Elliott and Hogle (2013) described, "gatekeepers are expected to make on-the-spot judgements regarding public access for the dogs that are accompanying people who have or who claim to have disabilities" (p. 3). In determining access, gatekeepers are allowed to ask two questions: (a) is the animal required because of a disability; and (b) what work or tasks has the dog been trained to perform (DOJ, 2011a). The person asking the questions is legally not allowed to inquire about the disability, request documentation, ask the dog to perform a task, or make any other qualifying inquires.

Allowing a dog, misrepresented as a service dog, entry to a public facility is risky for business owners. If the dog misbehaves, it could put other patrons at risk, but denying access to a legitimate service dog team puts the public facility in violation of the Americans with Disabilities Act, potentially resulting in a lawsuit (Huss, 2010; DOJ, 2011a). To facilitate this interaction, it is important to understand gatekeepers' experiences, how they make their decisions, and their perceptions of service dogs. It is 
through this understanding, that we can make informed decisions, to address these concerns, and embrace the value of service dogs in our communities.

\section{Purpose of the Study}

Existing research is limited regarding human perceptions of service dogs. Three peer-reviewed articles, and one on-going private organization survey, were identified as closest to the topic of this research study. All four of the identified studies were quantitative surveys. The first of the three studies, looked at the perceptions and experiences people working in university counseling centers had, in regards to emotional support animals (Kogan, Schaefer, Erdman, \& Schoenfeld-Tacher, 2016). The second study looked at the perceptions and experiences people in professional veterinary programs had pertaining to emotional support and service animals (Schoenfeld-Tacher \& Kogan, 2017).

The third research study looked at the public's perceptions of assistance animals, including service dogs, emotional support dogs, and therapy dogs (Schoenfeld-Tacher, Hellyer, Cheung, \& Kogan, 2017). The population for that study was United States adults who did not own any type of assistance animal. The fourth research study was an on-going, private organization survey, found through online research of service dog organizations (The Foundation for Service Dog Support, 2015). The results of the survey did not provide peer reviewed data, however, the survey results provided interesting validation of accessibility issues as experienced by service dog teams.

No studies were found that focused specifically on perceptions of service dogs from the public's perspective. Since service dog teams are allowed access to any public space (DOJ, 2011a), and gatekeepers are responsible for allowing or denying a service 
dog team access to those public spaces (Elliott \& Hogle, 2013), it is important to understand how gatekeepers make their decisions in navigating those social interactions.

The purpose of this study was to understand, through in-depth, unstructured interviews, the working public's experiences with, and perceptions of, service dogs in public places. The results of this study were analyzed to identify the primary aspects of the phenomenon from the gatekeeper's point of view. Additionally, the results of this study identified areas needing further research.

For the purpose of this research study, I chose to refer to the selected participants, or interviewees, as "co-researchers." Kvale and Seidman provided a rationale for this statement, “...'co-researchers'...work with the researcher, not to summon up and state a prior experience like playing a recording, but to jointly explore the participant's experience and co-create a meaningful description" (Kvale and Seidman, as cited in Donalek, 2004, p. 516).

\section{Objectives of the Study}

The objectives of this study are reflected in the following research questions, which were used to guide the study.

1. What are the experiences of the working public with service dogs and service dog teams in public places?

2. How does the working public perceive service dogs?

3. What are the working public's understandings of accessibility regulations as they relate to service dogs and public places?

4. What, if any, are the issues the working public identify in and around this topic? 
5. Based on the data obtained, what are the important issues and areas that need further research?

\section{Conceptual Framework}

To gain the desired understanding, Moustakas' (1994) instructions for conducting a phenomenological inquiry were followed. A phenomenological framework was appropriate for this study because phenomenological designs are often used to "study areas where little is known or to explore sensitive content" (Donalek, 2004, p. 516). Additionally, phenomenological researchers seek to understand how, "complex meanings are built out of simple units of direct experience" (Merriam and Associates, as cited in Ary, Jacobs, Irvine, \& Walker, 2014, p. 502). Moustakas' (1994) and Hycner's (1985) guidelines were followed for data collection and analysis.

\section{Community Aspect of the Study}

As a working member of the public, I have experienced service dog accessibility interactions, as both a gatekeeper and a service dog handler. It is through these experiences, that I have observed the ways in which this phenomenon affects our communities. Regardless of how the dog assists the person in their own home, a disabled person needs to keep their service dog directly with them at all times in public spaces. Restaurants, stores, museums, entertainment venues, offices, and other public spaces, all represent places where people come together as a community to experience life. The ADA governs these public spaces to guarantee equal rights for the disabled in our communities.

Service dogs are one component of our complex societies. When working, the dog can be as important as a wheelchair or a support cane, hence why the ADA includes 
provisions for service dogs. Likewise, business owners, managers, and employees, who work in public spaces, play an important role in community growth and function. People who require service dogs, and members of the working public, all bring value, and diversity to our society.

Since the creation of the ADA, politicians have created laws and guidelines to facilitate the use, and incorporation, of service dogs in our communities. Given the different, and sometimes conflicting laws, as well as the complexity of gatekeeper responsibilities, the room for improvement is apparent. This research study focused on the United States, however legislation confusion regarding service dogs is not confined to the United States. Bremhorst, Mongillo, Howell, and Marinelli (2018) reviewed assistance dog legislation in the European Union and Australia, and concluded, "we lack comprehensive national laws in many countries," and "even if laws covering assistance dogs exist, implementing these laws into practice is far less straightforward" (p. 129). As Bremhorst et al. (2018) explained, “...the clarification of rights covering qualified assistance dogs when they are accompanying their owners would be helpful" (p.129). Research studies like this one, can provide valuable insight, and clarification for moving forward as an inclusive, and united society.

\section{Organization of the Study}

This document is divided into six chapters. The first chapter is this, the introduction, which provides a summarized background of issues related to service dogs and accessibility. This information was used to establish the purpose and development of this research study. 
The second chapter presents a review of the literature that informed this research study. The third chapter describes the methodological framework chosen to guide the research, as well as the data collection, and analysis procedures that were followed. The forth chapter is a presentation of the data collected from the eleven in-depth, unstructured interviews with gatekeepers. Through a phenomenological framework, the data were gathered, interpreted and presented as a series of narratives, each one specific to the interviewee. The fifth chapter, is a presentation of the themes identified in the analysis, within and across all eleven interviews. The discussed themes informed the researcher of the major components identified in the working public's perceptions of service dogs, as told through their experiences, and are this research study's findings. Implications of the findings, recommendations for social groups, and recommendations for future research are also included in chapter five. The sixth, and final chapter, is a summary of the results of this research study.

\section{Definitions}

ADA: Acronym for the Americans with Disabilities Act of 1990 [Pub. L. 101-336], the ADA is "a comprehensive anti-discrimination statute that prohibits discrimination against disabled individuals" (Fitzpatrick, 1991, p. 13).

Assistance animal: Any animal that provides assistance for a human; within this research study, this term is used as an umbrella term for service animals, emotional assistance animals, and therapy animals.

Co-researcher: For the purpose of this research study, I chose to refer to the selected participants, or interviewees, as "co-researchers." Kvale and Seidman provided a rationale for this statement, “...'co-researchers'...work with the researcher, not to 
summon up and state a prior experience like playing a recording, but to jointly explore the participant's experience and co-create a meaningful description" (Kvale and Seidman, as cited in Donalek, 2004, p. 516).

DOJ: Acronym for the United States Department of Justice

Gatekeeper: Gatekeepers are the members of the working public whose position requires them to uphold and enforce these accessibility laws. As used by Elliott and Hogle (2013) in their research on the ethical concerns of service dog accessibility rights,

Gatekeepers are citizens who work as store clerks, security guards, receptionists, and building managers, and who, among their role-related responsibilities, allow or disallow public access for people and their dogs. Gatekeepers are expected to make on-the-spot judgements regarding public access for the dogs that are accompanying people who have or who claim to have disabilities. (p. 3)

Neuman defined a gatekeeper as "someone with the formal or informal authority to control access to a site" (as cited in Groenewald, 2004, p. 46). For the purpose of this study, the term gatekeeper extends to include anyone who is responsible for allowing or denying a service dog team access to a space.

Service dog: Service dogs are not pets. As defined by the United States Department of Justice [DOJ], in the Americans with Disabilities Act (DOJ, 2011a), a service dog is a dog that is individually trained to perform tasks or do work directly related to a disability. With the exception of miniature horses, the DOJ does not include any other species, or assistance animals in their definition of service animals. Therefore, dogs who provide comfort, but do not perform a task or work related to a disability are not service dogs 
according to the ADA. Examples of these dogs are emotional support dogs and therapy dogs.

Service dog team: As defined by Elliott and Hogle (2013), a two or three-member team consisting of a service dog, as defined above, and the person with the disability. The team can be three members if a person's age, or limitations, makes them unable to manage the dog on their own.

Phenomenology: Phenomenological researchers focus on the first person, subjective experiences to answer the question "what is the meaning, structure, and essence of the lived experience of this phenomenon for this person or group of people?" (Patton, 2002, p. 132). Phenomenology is "the study of human experience and of the ways things present themselves to us in and through such experience" (Sokolowski, 2000, p. 2).

Public accommodation, facility or entity: Any State or local government property, private or publicly owned businesses, whose operations affect commerce, and fits into at least one of these twelve categories of public accommodations, as determined by the United States Department of Justice (DOJ, 2011b). Examples of these include restaurants, retail stores, healthcare facilities, schools, entertainment venues, banks, and gas stations. For the purposes of this research study, the words accommodation, facility, and entity, are interchangeable.

Working public: For the purpose of this research study, members of the working public are those whose employment requires them to adhere to the rules and regulations of the Americans with Disabilities Act. Gatekeepers are part of the working public. 


\section{Limitations of the Study}

As previously stated in the definitions, gatekeepers are one part of the working public.

For this research study, the population was limited to gatekeepers. Therefore the terms working public and gatekeepers were used interchangeably. 


\section{CHAPTER II}

\section{Review of Literature}

Starting with the definition of service dogs, the first part of this chapter includes a brief history of service dogs; as well as a presentation of service dogs as a topic of research; service dogs in society; and service dog population, registration, and certification. The second part of this chapter presents information on legislation regarding service dogs, which includes accessibility allowances, and the discrepancies between in federal-to-state, and state-to-state laws. The discussion of service dog legislation introduces the concerns of taxonomy, and varying vocabulary. Lastly, the concern of misrepresentation of service dogs is addressed. The chapter ends with research found on human perceptions of assistance animals. Service dogs assist humans across the world (Bremhorst et al., 2018), however, this research study focused on gatekeeper's experiences with service dogs in the United States of America.

\section{Definition of Service Dog}

The United States Department of Justice [DOJ], Americans with Disabilities Act, defines service animals as, "dogs that are individually trained to do work or perform tasks for people with disabilities," and "the work or task a dog has been trained to provide must be directly related to the person's disability" (DOJ, 2011a, p. 1). Additionally, "the ADA does not restrict the type of dog breeds that can be service animals" (DOJ, 2015, p. 1). Therefore, legally, service dogs can be of any canine breed and size.

This information is found in the section of the ADA titled, "Service animals." According to this definition, with the exception of miniature horses, the DOJ does not include any other species, or assistance animals in their definition of service animals 
(DOJ, 2011a). The exclusion of other species is the result of a 2010 revision of the original 2009 ADA. Also, a result of the 2010 revision, with the intention of "specifically expanding the population of service-dog users who have invisible disabilities," the mandate recognized "psychiatric service dogs" as a type of service dog (Elliott \& Hogle, 2013, p. 2).

The Americans with Disabilities Act (1990) clarified that service dogs "are working animals, not pets," and excluded "dogs whose sole function is to provide comfort or emotional support" (DOJ, 2011a, p. 1). Examples of those are emotional support dogs and therapy dogs. Some researchers argue that emotional support dogs should be included in the ADA's provisions for service dogs because of the ways emotional support dogs ameliorate debilitating emotional strain (Bourland, 2009; Hernandez-Silk, 2018).

Beyond the ADA, the labels used to identify service dogs vary (Parenti et al., 2013). These differences are discussed in detail, later in this chapter, in the taxonomy section, however, since "the ADA is the most commonly cited legislative act in the realm of service animals" (Campbell, 2016, p. 74), for the purposes of this research study, I employed the Department of Justice's definition of a service dog.

\section{Service dog team}

When paired with a human, the service dog and the disabled human become a service dog team. In the event a person's age or limitations make them unable to manage the dog on their own, a third person may be included as part of the team (Elliott \& Hogle, 2013). The person responsible for the dog is commonly referred to as the "handler." A "handler is responsible for caring for and supervising the service animal, which includes 
toileting, feeding, grooming and veterinary care" (DOJ, 2015, p. 2). In the event the service dog team has three members, the physically able person is considered the handler.

\section{Examples.}

Service dogs mitigate disabilities in a variety of ways. Examples include:

guiding people who are blind, alerting people who are deaf, pulling a wheelchair, alerting and protecting a person who is having a seizure, reminding a person with a mental illness to take prescribed medications, [or] calming a person with Post Traumatic Stress Disorder [PTSD] during an anxiety attack. (DOJ, 2011a) Elliott and Hogle (2013) provided the following examples of service dog work: “...alerting people who have...diabetes; providing balance and fetching objects for people who have mobility disabilities; and intervening in anxiety-driven or selfdestructive behaviors for people with disabling mental illness" (p. 1). Service dogs also assist children with autism by protecting the child from environmental hazards, redirecting harmful behaviors, and increasing their overall state of wellness (Burgoyne et al., 2014; Harris \& Sholtis, 2016).

\section{History of Service Dogs}

Service dogs have not always been labeled as "service dogs," but dogs have a long history of assisting humans. The first historical evidence, of what we now call a "service dog," is from a recovered fresco in the small Roman town, Herculaneum. Like Pompeii, Mount Vesuvius' 79AD eruption covered Herculaneum (Cole, 2017). During an archeological excavation, a mural was uncovered which appeared to portray a dog functioning as a guide dog for a blind person (Blattner, 2015; Cole, 2017; Fishman, 2003). Hundreds of years later, in 1702, “...the earliest systematic instruction of guide 
dogs, as helpers of the visually impaired...took place in a Paris hospital for the blind" (Cohen, 2011, para. 2). In 1804, Johann Wilhelm Klein founded the Imperial Royal Institute for the Education of the Blind, in Vienna, Austria, and in 1819, he published one of the first known dog training manuals for coaching guide dogs (Blattner, 2015; Cohen, 2011).

In the United States of America, the first guide dog school for the blind was opened in 1929, named The Seeing Eye (Cohen, 2011). In 1941, a public law was enacted to permit people with seeing eye dogs entrance to Government buildings (Bersani \& Lyman, 2009). In 1975, Dr. Bonita [Bonnie] Bergin was the first to coin the term, 'service dog,' while founding America's first nonprofit service dog training facility, Canine Companions for Independence [CCI], in Santa Rosa, California (Blattner, 2015).

Sixteen years later, in 1986, Assistance Dogs International [ADI], a worldwide coalition of nonprofit assistance dog training programs, was founded (Bergin \& Hogan, 2006; Kegel, 2016). Dr. Bergin, part of the ADI founding team, later participated in the development of the Americans with Disabilities Act of 1990 (Bergin \& Hogan, 2006; Kegel, 2016). The Americans with Disabilities Act, a federal statute, was established to prohibit discrimination, and guarantee equal rights for individuals with disabilities in the United States (ADA, 1990; Campbell, 2016). Provisions for service dogs are included in the ADA.

One aspect of these provisions is public accessibility protections (DOJ, 2011a). In 2010, "after two years of public comment and departmental analysis" (Elliott \& Hogle, 2013 , p. 2), the DOJ revised the ADA with the changes discussed previously to exclude other species and include PTSD service dogs. The 2010 revisions of the ADA provided 
the resulting legislation popularly referenced today (Campbell, 2016). Over the course of this history, service dogs have been a focal point for scholars, state politicians and social groups.

\section{Service Dogs as a Topic of Research}

Since the eighties, studies have been conducted on the human-animal bond (Odendaal, 2000; Willens, 2013). Davis (1992) found that humans are naturally attracted to the sight of dogs (Davis, 1992), and McNicholas and Collis (2000) found that when accompanied by a trained dog, people experienced an increase in public interactions and acknowledgement.

Researchers have also studied the selection, and effectiveness of service dogs as a means of treatment. Weiss and Greenberg (1997) studied service dog selection from animal shelters, and found that coming from a shelter did not inhibit a dog's ability to learn tasks. Winkle, Crowe, and Hendrix (2012) reviewed existing literature on the use of service dogs for people with mobility assistance, and found "there are many anecdotal publications extolling the benefits of working with service dogs" (Winkle, Crowe, \& Hendrix, 2012, p. 54). Yount, Ritchie, Laurent, Chumley, and Olmert (2013) researched the impact of training a service dog while getting treatment for combat-related PTSD. They found participants experienced positive improvements to their mental, emotional and physical wellbeing as a result of participating in the service dog training process.

It was observed, that the majority of the existing research pertaining to service dogs, has been done within the last twenty years. From the available literature, a large amount focused on the effectiveness of service dogs, including the mental, physical, and 
emotional benefits it has on its handler. In the following sections, legislation regarding service dogs is addressed, as well as accessibility accommodations.

\section{Service Dog Legislation}

In addition to the federally mandated, Americans with Disabilities Act of 1990, state-level governments have created legislation on protections, and accommodations for service dogs. Within each law is a description of what defines a service dog, according to that particular piece of legislation. It is important to review current legislation to develop an understanding of the affordances, and boundaries legally established for service dogs. Legislation is discussed as it relates to the main topics of: (a) accessibility accommodations; (b) service dog population, registration, and certification; and (c) the legal discrepancies noted from federal-to-state, and from state-to-state.

\section{Accessibility accommodations.}

The ADA governs public entities. According to the ADA (2010), public entities must allow those who have a service dog [a service dog team] to keep their dog with them in areas the public is normally permitted to go. A public entity, is a facility whose operations affect commerce, and fits into at least one of these twelve categories: (1) places of lodging (hotels, motels, etc.), with the exception of owner-occupied establishments renting fewer than six rooms; (2) establishments serving food or drink (restaurants, bars, etc.); (3) places of exhibition or entertainment (theaters, concert halls, stadiums, etc.); (4) places of public gathering (auditoriums, convention centers, lecture halls, etc.); (5) sales or rental establishments (retail stores, hardware stores, grocery stores, etc.); (6) service establishments (laundromats, banks, gas stations, health-care providers, etc.); (7) public transportation terminals, depots, or stations (not including 
those related to air transportation); (8) places of public display or collection (museums, libraries, galleries, etc.); (9) places of recreation (parks, zoos, amusement parks, etc.); (10) places of education (nursery schools, elementary, secondary, undergraduate, or postgraduate schools, etc.); (11) social service center establishments (day care centers, senior citizens centers, homeless shelters, food banks, etc.); and (12) places of exercise or recreation (gymnasiums, health spas, bowling alleys, golf courses, etc.) (United States Department of Justice [DOJ], 1991). A facility cannot be considered a public accommodation, and is not governed by the ADA, if it does not fit into one of these twelve categories, as they are exhaustive (DOJ, 1991).

Further defining the areas the public is normally permitted, included in the ADA are examples of exactly where the service dog team does or does not have accessibility rights. Within public entities, service dogs are allowed to accompany their handler through communal food preparation areas, such as self-service salad bars, but accommodations do not have to be made for areas such as restaurant kitchens. Service dog access to a public entity can be denied only if the dog's presence constitutes a fundamental alteration of the nature of the business. An example of this is in dormitories specifically reserved for students allergic to dog dander.

For sanitary concerns, access may be denied to areas such as hospital operating rooms, or burn units, because they are not typically open for the public. A service dog may not be asked to leave unless, (a) if it is out of control and its handler does not gain control, (b) it is not housebroken, or (c) it behaves in a way that poses a direct threat to the health or safety of others (DOJ, 2011a). 
"Gatekeepers" are the members of the working public whose position requires them to uphold and enforce these accessibility laws (Elliott \& Hogle, 2013). Gatekeepers are legally allowed to ask two questions to determine service dog legitimacy: (1) is the animal required because of a disability, and (2) what work or tasks has the dog has been trained to perform (DOJ, 2011a). The gatekeeper is not allowed to ask about the disability, request documentation, or ask the dog to perform a task. It is the responsibility of both the public entity and the service dog team to be aware of these questions.

\section{Non-public entity accommodations.}

Non-public accommodations, such as housing, and air travel, are not governed by the ADA. The legislation regarding service dog teams in those locations falls under either the Fair Housing Act [FHA], or the Air Carrier Access Act [ACAA]. The ADA neither affects nor limits the Air Carrier Access Act, or the Fair Housing Act (DOJ, 2011a).

The Fair Housing Act, protects people from discrimination in housing-related activities and "applies to virtually all types of housing, both public and privately owned."

Under the Fair Housing Act, housing providers are obligated to permit, as a reasonable accommodation, the use of animals that work, provide assistance, or perform tasks that benefit persons with a disabilities, or provide emotional support to alleviate a symptom of effect of a disability. (DOJ, 2015, p. 7)

The FHA does not restrict accessibility based on species, and by this definition, accepts emotional support animals, as well as service animals for a disabled person.

The Air Carrier Access Act "protects the rights of people with disabilities in air travel" (DOJ, 2015, p. 7). Under the ACAA, accessibility allowances are extended to 
both service animals, and emotional support animals. The ACAA description of acceptable animals is very similar to the FHA, however the traveler does not have to have a disability. The United Stated Department of Transportation is currently considering amending its Air Carrier Access Act [ACAA], after receiving complaints from the transportation industry, and individuals with disabilities saying "the current ACAA regulation could be improved to ensure nondiscriminatory access for individuals with disabilities, while simultaneously preventing instances of fraud and ensuring consistency with other Federal regulations" (United States Department of Transportation, 2018a, p. 1). These concerns regarding air travel have been the topic of so many news articles, that Schoenfeld-Tacher et al. (2017) questioned if the media coverage has over-represented the issue of misrepresentation. At the completion of this research study, the DOT had not released a response to their recognition of the industry and public's complaints.

With this information, it is important to point out the differences in the terminology used in the ADA, the FHA, and the ACAA. In both the Air Carrier Access Act [ACAA], and the Fair Housing Act [FHA], accessibility is extended beyond dogs, to include other species of animals who provide a work or task related to a disability, and to animals who provide emotional support (DOJ, 2015). Due to the species inclusive definitions of the ACAA and FHA, the word "dog" is commonly exchanged for "animal." Therefore, both emotional support dogs and therapy dogs are commonly called an emotional support animal, or therapy animals respectively. Assistance animal is an umbrella term encompassing service animals, emotional support animals, and therapy animals. The differences between emotional support animals, and therapy animals will now be briefly explained. As previously stated, the ADA accessibility provisions exclude 
"dogs whose sole function is to provide comfort or emotional support" (DOJ, 2011a, p.

1), so these definitions do not apply to dogs afforded accessibility rights to public entities.

\section{Emotional support dogs and therapy dogs.}

Animals who provide emotional support can be both emotional support animals, and therapy animals, however the two do very different work. An emotional support animal [ESA] "is a companion animal that provides therapeutic benefit to an individual with a mental illness or disability.... an ESA helps an individual simply by being present during social interactions or situations" (Campbell, 2016, p. 74). A therapy animal provides therapeutic support to a variety of people and, "participate[s] in structured, therapeutic interventions with licensed professionals over a restricted amount of time" (Bremhorst et al., 2018, p. 129). An example of this animal-assisted therapy is when a dog "visits individuals in a nursing home or hospital" (Parenti et al., 2013, p. 746).

Various research studies focus on the benefits of emotional support dogs and therapy dogs (Bremhorst et al., 2018; Hernandez-Silk, 2018; Kogan et al., 2016; Von Bergen, 2015). Some argue that emotional support animals should be recognized under the ADA (Bourland, 2009; Hernandez-Silk, 2018). For the purpose of this research study, the focus will remain on service dogs, as defined by ADA, and public entities. Nevertheless, it is important to be aware of the differences between the three main types of assistance dogs, particularly in navigating the various labels used in legislation.

\section{Population, Registration, and Certification}

Currently an official, national registry of service dogs, in the United States, does not exist. Therefore, determining the total population of service dogs is impossible. 
Research has provided speculations, and educated estimations on the number of service dogs and assistance dogs.

As explained, the label assistance dog, includes more than service dogs. Informal surveys suggest there are more than 16,000 individuals in the United States with assistance dogs (Beck, 2006; Sachs-Ericsson et al., 2002; Wilson, 1998). One study, on the demographics of assistance dogs, found that more than 4,000 assistance dogs were placed in the United States in 2013 and 2014 (Walther et al., 2017).

According to Sachs-Ericsson et al. (2002), two of the largest assistance dog training agencies in the United States are Canine Companions for Independence [CCI], and Paws with a Cause [PAWS]. CCI was founded by Dr. Bergin, the one who coined the label 'service dog,' (Blattner, 2015). CCI and PAWS collectively train approximately 200 dogs a year, and have more than 48 regional programs for training assistance dogs (Sachs-Ericsson et al., 2002).

Yamamoto, Lopez, and Hart (2015) found 2,599 service dogs were registered in California from 1999 through 2012. This number was available since California has a voluntary-based registration program, which provided residents with an ID tag for their assistance dogs. It should be noted, that of the 2,599 dogs voluntarily registered, 37 were not service dogs, rather they were therapy dogs, dogs released from assistance programs or companion dogs [pets], additionally the number of 2,599 is lacks accuracy because the researchers could not obtain an exhaustive list (Yamamoto et al., 2015).

California's registration program was voluntary, however some states legally require residents to register their dog as a service animal, such as North Carolina (Wisch, 2016). Doing so is in direct violation of the ADA, which states, "mandatory registration 
of service animals is not permissible" (DOJ, 2015, p. 1). In addition to collecting data on the demographics of service dogs, an additional purpose of a service dog registration, is confirmation of legitimacy. Certifications and resulting documentation are also manners in which people confirm legitimacy.

In regards to certification and documentation, The ADA also states, "covered entities may not require documentation, such as proof that the animal has been certified, trained, or licensed as a service animal, as a condition for entry" (DOJ, 2011a, p. 1). There are "individuals and organizations that sell service animal certification or registration documents online" (DOJ, 2015, p. 1), but "these documents do not convey any rights under the ADA and the Department of Justice does not recognize them as proof that the dog is a service animal" (DOJ, 2015, p. 1). This statement, made directly on the Department of Justice website, represents one area of confusion, and concern, regarding service dogs. The concern is that service dog handlers are getting mixed messages of required registration, and/or certification. Organizations, and even some states, like Maine, are saying certification is required, but the United States federal government does not recognize those documents as proof of legitimacy. In Maine, the law requires service dog handlers to have written evidence of certification in order to obtain a license and tag identifying the dog as a service dog (Wisch, 2016). This statelevel requirement conflicts with the federal-level statement on certifications proving legitimacy.

\section{Federal-to-state and state-to-state discrepancies.}

Under the DOJ, states may create laws for increased access, but they are not allowed to create, or enforce, laws that are more restrictive than the ADA (1990). 
Nonetheless, more than half of the states in the United States "have laws on the books that narrow the federal definition," or further restrict the laws regarding service dogs (Elliott \& Hogle, 2013, p. 7).

One example where the state's law is more restrictive than the Federal was found in Pennsylvania's definition of a disability. According to the ADA (1990), an individual with a disability is defined "as a person who has a physical or mental impairment that substantially limits one or more major life activities" (Sec. 12101). Pennsylvania's definition of a disability is far more restrictive than the federal definition, resulting in a narrowed list of who qualifies for a service dog (Elliott \& Hogle, 2013). Pennsylvania's definition of a disabled person excludes "residents who do not receive SSI, individuals who do not qualify for a special registration plate, or placard, and individuals who have not sought certain federal and state services" (Elliott \& Hogle, 2013, p. 6).

Another area of a discrepancy between federal and state law is service dog training. One of the most commonly asked questions on the ADA website is if "the ADA require[s] service animals to be professionally trained" (DOJ, 2015, p. 1). The answer is no, "people with disabilities have the right to train the dog themselves and are not required to use a professional service dog training program" (DOJ, 2015). Service dogs can also be trained by organizations. However, Arizona's law defines a service animal as "an animal that has completed a formal training program" (Wisch, 2016, p. 1), therefore excluding any dogs trained without the assistance of a professional training program.

Recognizing these discrepancies, Wisch (2016) created a table comparing assistance animal laws by state. Topics found in Wisch's (2016) table were (a) definitions of assistance animals; (b) laws protecting the rights of the disabled team; (c) 
laws against criminal interference, theft and assault of assistance animals; (d) laws and punishment for fraudulent misrepresentation (e) laws protecting specifically disabled persons, such as blind pedestrians, and (f) laws regarding licensing or uniforms. Wisch's work, titled, "Table of State Assistance Animal Laws," compared state laws for assistance animals and service dogs. Wisch used "assistance animal" as an umbrella term, however she explained the table "compares state assistance/service dog laws" (Wisch, 2016, p. 1).

Wisch's work is one of the strongest representations of the discrepancies, confusion, and conflicting laws regarding service dogs in the United States. Legislation confusion regarding service dogs is not confined to the United States. Bremhorst et al. (2018) reviewed assistance dog legislation in the European Union, and Australia, and concluded "we lack comprehensive national laws in many countries," and "even if laws covering assistance dogs exist, implementing these laws into practice is far less straightforward" (p. 129). Bremhorst et al. (2018) suggested "clarification of rights covering qualified assistance dogs when they are accompanying their owners would be helpful" (p. 129). Campbell (2016) also discussed the need for clarification and improvements in legislation related to assistance animals.

An example Wisch (2016) identified as a state-to-state legislation discrepancies was regarding orange service dog uniforms. As shown in the table below, Connecticut required an "orange-colored leash and collar"; Mississippi, and Tennessee, required a "blaze orange leash," Oklahoma required an "orange identifying collar," and Virginia required a "blaze orange leash," specifically "for the deaf or hearing impaired." Of these 
states, four defined the disabilities, for which a service dog could assist, in a more restrictive manner than the ADA (see Table 1).

Possibly one of the most detailed state-to-state differences was the terminology used in defining the parameters of the laws. Examples of the different labels used were: "assistance dog"; "assistive animal”; “dog guide"; "guide dog”; "hearing assistance dog”; "medical alert or respond dog"; "service animal"; "signal dog"; "support animal"; and "professional therapy dog." The "inconsistent vocabulary and confusion" regarding assistance animals has caused a lot of confusion, and inspired researchers like Parenti et al. (2013) to make suggestions for a revised taxonomy.

\section{Taxonomy}

The exact reason the label of "service dog" is used in the American's with Disabilities Act is unknown, however, it is possible that since Dr. Bergin coined the term, and participated in the creation of the ADA, her terminology was used. Nonetheless, in a 1999 letter to The Attorney General's Office, Dr. Bergin requested the language of the ADA be changed from "service animal" to "assistance animal" (United Stated Department of Justice [DOJ], 1999, para. 1). Dr. Bergin's reason for the request is unknown, and was denied on account that any "change of terminology would likely engender confusion among businesses and State and local governments" (DOJ, 1999, para. 5). 
Table 1

United States Individual State Expectations for Service Dogs to Wear Orange

\begin{tabular}{|c|c|c|c|c|}
\hline State & $\begin{array}{l}\text { Definition/ } \\
\text { Disability }\end{array}$ & Disability & Color & Notes \\
\hline Connecticut & $\begin{array}{l}\text { "guide dog" or } \\
\text { "assistance dog" } \\
\text { for the blind, deaf } \\
\text { or mobility } \\
\text { impaired }\end{array}$ & $\begin{array}{l}\text { Blind, deaf, } \\
\text { mentally or } \\
\text { physically } \\
\text { disabled }\end{array}$ & $\begin{array}{l}\text { Orange- } \\
\text { colored } \\
\text { leash and } \\
\text { collar }\end{array}$ & \\
\hline Mississippi & $\begin{array}{l}\text { Totally or } \\
\text { partially blind or } \\
\text { deaf }\end{array}$ & $\begin{array}{l}\text { Totally/ } \\
\text { partially blind } \\
\text { or deaf }\end{array}$ & $\begin{array}{l}\text { Blaze } \\
\text { orange leash }\end{array}$ & $\begin{array}{l}\text { Also includes } \\
\text { provision for } \\
\text { other animal } \\
\text { specifically } \\
\text { trained as a } \\
\text { guide, leader, } \\
\text { listener, or for } \\
\text { any other } \\
\text { assistance }\end{array}$ \\
\hline Oklahoma & $\begin{array}{l}\text { "Service dog" or } \\
\text { "signal dog" for } \\
\text { the deaf or hard- } \\
\text { of-hearing }\end{array}$ & $\begin{array}{l}\text { Deaf/hard of } \\
\text { hearing }\end{array}$ & $\begin{array}{l}\text { Orange } \\
\text { identifying } \\
\text { collar }\end{array}$ & $\begin{array}{l}\text { Includes a } \\
\text { licensing law } \\
\text { against } \\
\text { required } \\
\text { registration or } \\
\text { licensing }\end{array}$ \\
\hline Tennessee & No mention & & $\begin{array}{l}\text { Blaze } \\
\text { orange leash }\end{array}$ & \\
\hline Virginia & $\begin{array}{l}\text { "Guide or leader } \\
\text { dog" }\end{array}$ & & $\begin{array}{l}\text { Blaze } \\
\text { orange leash } \\
\text { for the deaf } \\
\text { or hearing- } \\
\text { impaired }\end{array}$ & $\begin{array}{l}\text { Class } 4 \\
\text { misdemeanor } \\
\text { for } \\
\text { fraudulently } \\
\text { representation } \\
\text { through a } \\
\text { harness, collar, } \\
\text { vest, sign, or } \\
\text { identification } \\
\text { of a service } \\
\text { dog or hearing } \\
\text { dog }\end{array}$ \\
\hline
\end{tabular}

(Wisch, 2016) 
Parenti et al. (2013) said one contributing factor in the "uncoordinated expansion of labels used to distinguish these animals" was "the use of animals in various assistive, therapeutic, and emotional support roles" (p. 745). Parenti et al. (2013) also said that since public assistance dogs provide a service, some mistakenly call these dogs service dogs. Public assistance dogs include: police dogs, search-and-rescue dogs, drugdetection, and bomb-detection dogs (Parenti et al., 2013). As evidenced in the state-tostate discrepancies, many have created their own definitions of what constitutes a service dog (Campbell, 2016; Wisch, 2016; Zetwick, 2016).

Another common mistake in taxonomy is to categorize therapy, or emotional support dogs, as service dogs. Some researchers provide evidence supporting emotional support animals doing work related to a disability, and therefore argue service and emotional support should be given same accessibility rights (Bourland, 2009; Von Bergen, 2015). According to the ADA, emotional support dogs do not fit the ADA requirement of performing work, or tasks related to a disability, therefore they are not afforded the title of service dog and the accompanying accessibility rights (DOJ, 2011a; Rothberg \& Collins, 2015). Huss' (2010) statement that "central in many disputes in this area is the problem of disparate definitions of service animals under various laws" (p. 1165) summarized the issue over confusion on labels.

An example where the seemingly open-for-interpretation taxonomy resulted in social confusion, was found in a story from 2013, in Oregon, when a legitimate service dog team was denied access to a local market (Gunderson, 2014). Despite there being a sign posted "service dogs welcome," the team was denied access by the business owner because they thought the dog was not a service animal (no reason was given). The 
disabled person filed a civil rights complaint with the Oregon Bureau of Labor and Industries, and the market was found to be in discrimination of a disability (Gunderson, 2014). This cases to illustrated, "how a well-known law has proved to be open for interpretation both by animal and business owners alike" (Gunderson, 2014, p. 1).

In addition to varying definitions, uniform expectations, and vocabulary, Wisch (2016) also investigated legislation on misrepresentation of assistance animals.

Consistent with the other topics, laws against, and penalties for misrepresentation of an assistance animal, differed state-to-state.

\section{Misrepresentation}

One example of state-to-state discrepancy on misrepresentation was found between New Jersey and Utah. New Jersey defined misrepresentation as "any person who fits a dog with a harness of the type commonly used by blind persons to represent that such dog is a guide $\operatorname{dog}[$,] when not trained as a guide dog." New Jersey's fine for misrepresentation was "not less than $\$ 100$ and not more than $\$ 500$ " (Wisch, 2016, p. 1). Utah had "a much broader view of misrepresentation" (Schoenfeld-Tacher et al., 2017, p. 642). Utah's law said a person is guilty of misrepresentation if "the person knowingly and intentionally misrepresents a material fact to a health care provider for the purpose of obtaining documentation from the health care provider necessary to designate an animal as a service animal" (Wisch, 2016, p. 1). In Utah, the punishment for misrepresenting your need of a service animal to a doctor was a class B misdemeanor.

In Michigan, misrepresentation was considered a misdemeanor, punishable by imprisonment up to 90 days or up to a $\$ 500$ fine. California had the strongest punishment for misrepresentation of a service animal with $\$ 1,000$ fine, and up to six 
months in jail (Food and Agriculture Code, 2004). Massachusetts did not have a law on misrepresentation, but in September 2017, advocates for service dogs in Boston were lobbying for a bill that would impose a $\$ 500$ fine and/or community service as punishment for misrepresentation (Leduc, 2017).

As of 2017, 19 states in the United States had laws against service dog misrepresentation (Ollove, 2017). That number grew to 24 in 2019 (Michigan State University, n.d.). West Virginia was one of the recent additions to the number of states with the laws against the use of misrepresented service dogs (Article 15. White Cane Law). In March 2018, an adaptation to West Virginia's White Cane Law was made to include a penalty for "fraudulent representation" of a service animal. The addition to the White Cane Law stated,

Any person who falsely represents that an animal is a service animal in order to obtain any right or privilege...is guilty of a misdemeanor, and upon conviction, shall be fined not more than $\$ 200$ or confined in jail not more than 10 days, or both fined and confined. (Article 15. White Cane Law, 2018, para. 2).

The punishment for a second violation was a fine of $\$ 1,000$ and 30 days in jail.

Misrepresentation as studied in empirical research.

Given the varying uniform expectations (Wisch, 2016); the "great variation in the breadth and penalties associated with these laws" (Schoenfeld-Tacher et al., 2017, p. 641); the "uncoordinated expansion of labels used to distinguish these animals" (Parenti et al., 2013, p. 745); as well as the lack of knowledge on the part of the gatekeepers and business owners (Elliott \& Hogle, 2013), the plausibility of incidental misrepresentation is viable (Schoenfeld-Tacher et al., 2017). Schoenfeld-Tacher et al. (2017) provided one 
possible reason for the increase in misrepresentation. "As assistance animals become more prevalent in society, there appears to be a parallel increase in the frequency of allegations of misrepresentation or fraudulent representation of animals as assistance animals" (p. 642). Unfortunately, the topic of misrepresentation is underrepresented in objective research.

Elliott and Hogle's (2013) publication presented the issue of service dog misrepresentation as a political issue, making the argument that "the ADA expects too much of citizen gatekeepers," and "few gatekeepers are experts on service dogs, the variety of disabilities that service dogs mitigate, and how the dogs should perform their work" (p. 3). According to their work, two possible contributing factors in misrepresentation are lack of knowledge on the gatekeeper's and business owner's part, as well as fear of a lawsuit. They said, “...the average restaurant owner or hotelier just isn't versed in this and they are concerned they will be the subject of an ADA lawsuit" (Elliott \& Hogle, 2013, p. 3). Elliott and Hogle (2013) suggested a service dog ID and the need for a certification process as possible solutions.

Campbell's (2016) work presented a case for change in legislation, particularly in Kentucky, which would adopt legislation to criminalize "fake" service and emotional support animals. Campbell's argument was made through an analysis of legislation and overview of news articles. Campbell stated, “...there are numerous news articles and media clips about the increasing abuse of service and assistance animals" (Campbell, 2016, p. 83).

In addition to legal changes, Campbell (2016) suggested improvements in the process of acquiring documents of identification for service dog handlers, and a universal 
identification system. In regards to misrepresentation, at the time of Campbell's (2016) publication, "none of Kentucky's neighboring states [had] passed this type of legislation" (p. 88). Campbell (2016) suggested Kentucky's legislature pass a law regarding misrepresentation inclusive of "all types of assistance animals...the statute should use the term 'assistance animal' and include service animals, emotional support animals, and therapy animals within the definition" (p. 90). Campbell explained increased awareness of the "current issue of service animal and ESA fraud" would help "discourage individuals from continuing to bend the loose federal and state laws" (p. 92) which, she argued, resulted in misrepresentation.

Empirical research does not conclusively prove that misrepresentation is an issue, and no research was found specifically focused on why service dog misrepresentation could be happening. However, as these articles represent, some research does exist on the overall issue of misrepresentation, and educated speculations into the reasoning. It is interesting to recognize, of the research found on misrepresentation, the publication dates are from within the past ten years, suggesting it is a relatively new development.

Unfortunately, limited academic research on service dog misrepresentation meant the majority of the remaining existing literature was not peer-reviewed, and was in the form of opinion-based articles and news stories. Before looking into the media sources, keep in mind, Schoenfeld-Tacher et al. (2017)'s results showed relatively low rates of assistance dog misrepresentation, and that the "media may be over-representing the views of a small, but vocal minority" (p. 11) regarding perceived misrepresentation. 


\section{Misrepresentation as presented in the news.}

In a video posted to the American Veterinarian webpage, Oliver Knesl, "director of major accounts for veterinary professional services in the US Companion Animal Division for Zoetis" confirmed, "in terms of fraudulent emotional support animals, they certainly are more visible" (American Veterinarian, 2017, 0:03). He said one reason that misrepresentation might be happening is that "as pets become more and more parts of our lives, and are seen as parts of the family, we are increasingly wanting to take our pets with us wherever we go" (American Veterinarian, 2017, 0:24). He explained, "it relates to people wanting public access for their pets" (American Veterinarian, 2017, 0:42), and though he recognized that some misrepresentation might happen to avoid fees or flight restrictions, the general purpose was to take a dog places it was not normally permitted.

Statistics from The Humane Society of the United States, and the American Pet Products Association (2018), supported Knesl's statements. As of 2018, 84.6 million United States households had a pet, and of those, 60.2 million had at least one dog, a number up from 43.3 million in 2012 (American Sheltering, 2018). In 2012, 66.7\% of the 43.3 million considered their dogs to be family members (American Sheltering, 2018). In $2017,37 \%$ of pet owners took their animals with them when they traveled, a number up $19 \%$ in 2007 . They also found that Generation Y pet owners were more likely to take their dog with them on errands than to leave the dog at home (American Pet Products Association [APPA], 2018).

In the month after Minnesota became the twenty-first state to pass misrepresentation of a service animal legislation, NBC's Edelman (2018) wrote an article titled, "Collared: New Laws Crack Down on Fake Service Dogs," and subtitled "Nearly 
Two Dozen States have Tightened the Leash Recently on Pet-Owners Illegitimately Passing off Fido as a Service Animal" (Edelman, 2018). Edelman's (2018) article included quotes from the public expressing their concerns and frustrations over this issue from a business' point of view. A volunteer at a Vermont performance venue said their venue allowed people to enter with service animals, however they had experienced "dogs bark through the whole show, sit in the middle of the aisle," and once "hump the legs of a stranger," but because they "have little grounds on which to challenge a patron who claims the animal as support" the problems continue (Edelman, 2018, para. 7). The National Disability Rights Network executive director, Curt Decker, explained why he believed business owners were scared to press the issue.

Are business owners and restaurants really going to go after people who claim their dog is a service or support animal? If it has a vest on it the owner says it's helping them? They won't. They don't want to get sued. (Edelman, 2018, para. 17)

In the same article, a sponsor of the Arizona bill for misrepresentation of service animals, Arizona state Senator John Kavanagh, was quoted saying, “I couldn't go into a store or an airport or even an office without seeing some disorderly four-legged creature dragging its owner around, wearing a vest that said 'service animal"” (Edelman, 2018, para. 4). Also in that article, the national director of research and therapy programs at American Human, Amy McCullough, said the issue of misrepresented service animals was "compounded by the confusing terminology," and "people prey upon that with the purpose of gaming the system" (Edelman, 2018, para. 19). 
In another article titled, "State News: Misrepresenting Service Animals may Soon be Illegal in Massachusetts," Massachusetts Representative Kimberly Ferguson, a sponsor of the Massachusetts bill, stated, "our goal is to prevent abuse of the system, because animals that aren't legitimate service dogs can give true service dogs a bad reputation, and that does a terrible disservice" (Lengyel, 2017, para. 3). The author added, "anyone can easily create the illusion that their dog is a service animal - service dog vests, capes and 'official certificates' are all available for purchase online" (Lengyel, 2017, para. 5). The author also provided a reason they believed misrepresentation was happening.

People use fake service animals usually to gain privileges that come with such ownership, such as the right to take a dog into an airplane passenger cabin without a fee or inside restaurants or stores that may not allow animals. (Lengyel, 2017, para. 4).

These news article examples did not necessary represent the norm, however, they did provide insight into some of the public's perspectives. Since research argues that news can influence public opinion (Zucker, 1978), and more research needs done to understand misrepresentation, they were reviewed.

\section{Service Dog Representation in Physical and Digital Communities}

In addition to news articles, incorporation of service dog related items, in physical and digital communities were observed. Observations were made of university training programs, retailers, entertainment television, and digital communications. The following observations were my personal observations. In the future these observations should be systematically researched. 
On university campuses, organizations like 4 Paws for Ability (n.d.) have introduced the service dog training experience to college curriculums. Through these programs, students who might not have previously had opportunities to interact with, or learn about service dogs, were able to foster, train and socialize service dogs in-training. 4 Paws for Ability's website said they trained an average of more than 100 puppies, across fourteen university campuses in Ohio, Kentucky and Indiana (4 Paws for Ability University Program, (n.d.). Similar university training programs were found in Pennsylvania (Susquehanna Service Dogs, n.d.) and West Virginia (Humanimal Bond, n.d.).

Service dogs were also seen represented in television entertainment. Netflix, a web-based media services provider, created a series titled, Dogs, a six-episode docuseries on the human-animal bond between people and their dogs. The first episode told the story of an eleven year old girl, who because of her traumatic seizures, was getting a service dog (Shah, 2018).

Service dogs will also soon be represented in the digital world of emoji (see Figure 1). Through a collaboration with the American Council of the Blind, the Cerebral Palsy Foundation, and the National Association of the Deaf, Apple developed "disabilityspecific emoji” (Heasley, 2019, para. 7). These emoji, set to be available in late 2019, include a service dog, a hearing aid, prosthetics, people using manual wheelchairs, and more. It should be noted that the designs selected for both the service dog and the guide dog, which is a type of service dog, provide a visual representation of the dog's breed, as well as the use of a specific vest and/or harness. These observations support the idea that the use of specific images can impact people's perceptions of service dogs. 


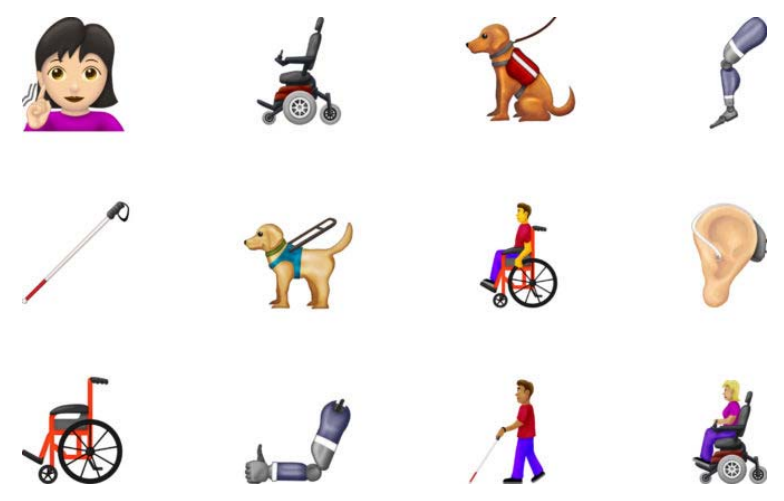

Figure 1: Emoji. This figure illustrates the disability related digital icons to be released in 2019. (Heasley, 2019)

Online resources, such as Disability Scoop, were found where people could "subscribe" to receive email updates on the topic of service dogs. Additionally, numerous groups, and forums, were found on social media platforms that focused on various aspects of service dogs. During the course of this inquiry, which spanned from 2014 to 2019 , I also observed an increase in the number of grocery stores, and retailers, with signs posted of their dog policy. Some of these signs included additional information on the topic of misrepresentation (see Figure 2).

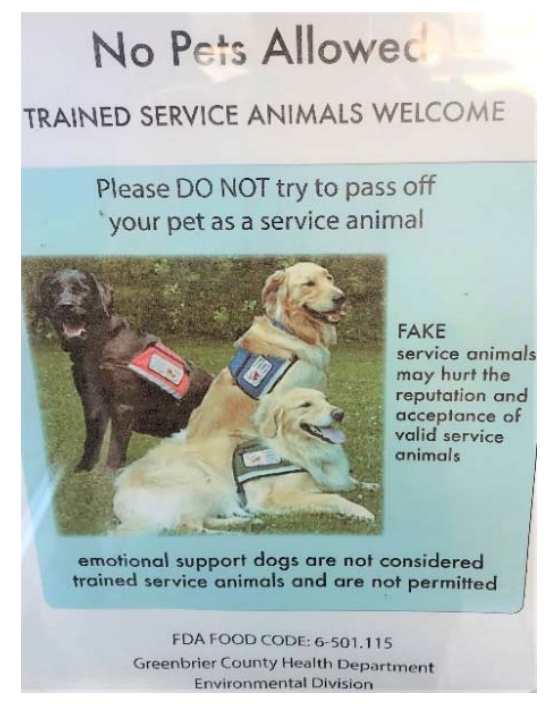

Figure 2: Café sign. This figure illustrates signage the researcher found on a café door in 2018. 
These examples, in conjunction with the increasing number of service dogs in society (Walther et al., 2017), supported the notion that service dogs are becoming more visible in our communities. As this change happens, it is increasingly important to understand the public's perceptions of service dogs. Huss' (2010) developed a collection of legal case examples to illustrate the "significant discrimination faced by persons with apparent disabilities accompanied by 'traditional' service animals” (p. 1189). Huss' (2010) work identified discrimination, lack of education/training of employees, nonapparent disabilities, perceptions of the role service animals, and individual dog training related to a specific disability, as concerns in the cases. Huss' (2010) collection of examples "illustrate the need for further clarification and education regarding the scope and coverage of the ADA" (Huss, 2010, p. 1193).

A large number of opinion-based news articles, blog posts, and websites were observed that portrayed the issue of misrepresentation, however, empirical research on the topic was minimal with just three studies found to be particularly insightful. One additional study was found that looked at human perceptions of emotional support animals, however, as it focused solely on perceptions of emotional support animals, it did not provide data related to service dogs (Kogan et al., 2016).

The first intuitive study was an on-going study conducted by the non-profit organization, The Foundation for Service Dog Support (2015). The survey titled, Public Access Challenge Report Form, was available online, and as participants voluntarily completed the form, results were sent to the organization. In this way, data was continuously collected and analyzed (C. Betancourt, personal communication, March 22, 2018). The target population for this study was "all service dog teams...regardless of 
geographic region," and inclusive of both program and privately trained teams (The Foundation for Service Dog Support, 2015, para. 1). The survey's goal was to "gain reliable and reproducible statistics that will provide clarification on the extent and nature of these challenges....the information gained will be used to drive evidence-based recommendations for public education and policy" (The Foundation for Service Dog Support, 2018, 2015, para. 1).

Data was provided through email communication with the Executive Director of the organization. As of March 2018, the research showed 70\% of the respondents consider their disability to be invisible (C. Betancourt, personal communication, March $22,2018)$. When asked "what type of access challenge did you experience," $47 \%$ of the teams were asked to leave without justification, and $32 \%$ were denied access all together. In $11 \%$ of the cases a manager corrected the mistake or remedied the situation. In $60 \%$ of cases the manager did not correct the problem, and $13 \%$ of the time the manager did not even speak to the service dog handler.

In $81 \%$ of these cases, the dog was wearing something to identify it as a service $\operatorname{dog}$ (C. Betancourt, personal communication, March 22, 2018). Participants were asked to identify the nature of business in which the access challenge occurred. They were given the following options: (a) retail - part of a regional or national chain; (b) retail local small business; (c) restaurant - part of a regional or national chain; (d) restaurant locally owned; indoor entertainment venue/tourist attraction; (e) outdoor entertainment venue/tourist attraction; (f) medical/healthcare setting; hotel/motel; (g) public office building (other than their workplace); (h) their workplace; (i) public transportation; (j) gas station; (k) church or community center; (1) K-12 school; (m) college or university; 
(n) public housing; or (o) dormitory (The Foundation for Service Dog Support, n.d.). Seventy percent of the respondents reported issues between 8 A.M. and 4 P.M, with restaurants and retail stores reported as the biggest problem areas. Even though this research study did not provide data related to the public's perceptions, it did provide interesting insight and validation of accessibility issues as experienced by service dog teams.

In the second insightful study, Schoenfeld-Tacher and Kogan (2017) researched perceptions and experiences pertaining to emotional support animals and service animals in professional veterinary programs. They looked at the prevalence of student requests for emotional support animals, and associate deans' perceptions of the issue and challenges. They found, in the past two years, $32.1 \%$ of professional veterinary programs had received requests from students for an ESA. Thirty-two percent of participants reported being aware of a college policy for service animals. Additionally, "participants were asked to indicate their level of understanding on legal regulations for ESAs and service animals" on a five-point scale. While " $50 \%$ reported minimal understanding [ 1 or 2] for ESAs....21.4\% reported minimal understanding for service animals" (p. 170). Furthermore, Schoenfeld-Tacher and Kogan (2017) found that 71\% of their participants expressed interest in learning more about ESAs and psychiatric service animals.

In the third study, Schoenfeld-Tacher et al. (2017) conducted a study on the "perceptions of US adults who [did] not own any type of assistance animal" (p. 641). Through an anonymous, online survey, with 505 individuals, they found widespread misconceptions regarding the definitions, laws, and rights of these three types of dogs. Their findings showed that $21 \%$ of the public were not comfortable describing the 
differences between service dogs and emotional support dogs (Schoenfeld-Tacher et al., 2017). Attributed for these misconceptions were the aforementioned inconsistencies in terminology, lack of standardization requirements and overlapping legal regulations. "Considering the range of operational and legal definitions of assistance animals, considerable variation is expected in the public's understanding and perceptions of laws regarding service animals" (Schoenfeld-Tacher et al., 2017, p. 641).

Schoenfeld-Tacher et al.'s (2017) results showed that most participants did not perceive assistance dog misrepresentation as an issue. Based on this finding, SchoenfeldTacher et al. (2017) presented the idea:

Assuming that the results of this survey are representative of true public opinion,

it appears that the media may be over-representing the views of a small, but vocal, minority when it comes to allegations of assistance dog fraud. This is not surprising, given recent research and the old adage that "bad news sells."

(Schoenfeld-Tacher et al., 2017, p. 642)

These three studies established the foundation of academic research on social group's perceptions of service dogs, emotional support dogs, and therapy dogs.

\section{Summary}

Service dogs are afforded access to any public space according to the ADA (DOJ, 2011a), and the working public are gatekeepers responsible for allowing or denying a service dog team access (Elliott \& Hogle, 2013). Different and conflicting laws have resulted in confusion between federal-to-state, and state-to-state laws. Furthermore, numerous news articles paint a picture of social frustrations ensuing from pet dogs being misrepresented as service dogs (Elliott \& Hogle, 2013; Huss, 2010; Stateline, 2017). The 
Public Access Challenge Report Form (C. Betancourt, personal communication, March $22,2018)$ provided data on accessibility issues as perceived by service dog teams, and Schoenfeld-Tacher et al.'s (2017) work provided data on the public's perceptions of service dogs, emotional support dogs, and therapy dogs. Schoenfeld-Tacher et al. (2017) results showed misunderstandings of the public regarding assistance animals, and lack of knowledge on the existing legislation. Additionally, Schoenfeld-Tacher et al. (2017) population did not perceive misrepresentation as an issue, and the researchers posed the question is misrepresentation of service dogs in news a case of, "bad news sells" created by the media.

These identified concerns directly impact the service dog teams, the working public, and our society as a whole. Laws have been created, changed, and continue to pass, but to move forward as a unified society respecting the work of service dogs; and to create informed legislation protecting the rights of service animal teams, and facilitating their entrance into public spaces, we need to understand the public's perceptions of the phenomena. This research study was designed to understand the working public's experiences of service dogs and how those experiences shaped their perceptions.

Different from Schoenfeld-Tacher et al. (2017), this study focused solely on the public's perceptions of service dogs, and did not exclude participants who had an assistance animal. Additionally, unlike any of the existing literature, this research study focused on the perceptions of the working public in our communities. The goal of this research was to contribute to the existing and growing literature on the public's perceptions of service dogs. Undoubtedly, more research is needed on this topic. The 
next chapter will establish the methodological framework that was used to inform this research study. 


\section{CHAPTER III}

\section{Methods/Procedures}

\section{Purpose of the Study}

The purpose of this study was to understand, through in-depth, unstructured interviews, the working public's experiences with, and perceptions of, service dogs in public places. The term gatekeeper was used to describe those within the working public whose position gave them responsibility of allowing or denying service dog team access. It is important to understand and develop a complete picture of the phenomena, from the gatekeeper's perception, to make informed decisions regarding service dog accessibility training, regulations and legislation that benefit both the public entities and service dog teams.

For the purpose of this research study, I chose to refer to the selected participants as "co-researchers." Kvale and Seidman provided a rationale for this statement, "...'coresearchers'... work with the researcher, not to summon up and state a prior experience like playing a recording, but to jointly explore the participant's experience and co-create a meaningful description" (Kvale and Seidman, as cited in Donalek, 2004, p. 516).

\section{Objectives of the Study}

The objectives of the study are reflected in the following research questions, which were used to guide the study.

1. What are the experiences of the working public with service dogs and service dog teams in public places?

2. How does the working public perceive service dogs? 
3. What are the working public's understandings of accessibility regulations as they relate to service dogs and public places?

4. What, if any, are the issues the working public identify in and around this topic?

5. Based on the data obtained, what are the important issues and areas that need further research?

\section{Methodology and Conceptual Framework - Phenomenology}

To gain the desired understanding, Moustakas (1994) instructions for conducting a phenomenological inquiry, as well as suggestions from Copen (1992) and Hycner (1985), were followed. A phenomenological framework was appropriate for this study because phenomenological designs are often used to "study areas where little is known or to explore sensitive content" (Donalek, 2004, p. 516). Additionally, phenomenological researchers seek to understand how "complex meanings are built out of simple units of direct experience" (Merriam and Associates, as cited in Ary et al., 2014, p. 502). In this research study, I interviewed gatekeepers to understand their personal experiences with the phenomena, and how those experiences shaped their perceptions of service dogs.

The following sections include a discussion of the history and purpose of phenomenology; an explanation of Moustakas' (1994) core processes of the phenomenological model, with the addition of initial engagement (Copen, 1992), and how these were incorporated in this study; constraints on population; a description of researcher's subjectivity; recruitment of co-researchers; and detailed descriptions of the data collection and analysis process. Finally, the concerns of credibility, transferability, dependability, and confirmability are addressed at the end of the chapter. 


\section{Phenomenology history and purpose.}

Rooted in philosophy, phenomenology can be traced back to early philosophers like Kant, Hegel, Brentano, and Descartes (Groenewald, 2004; Moustakas, 1994). Two of these men, Brentano and Descartes, strongly influenced German philosopher, Edmund Husserl. Husserl's work on phenomenology earned him the titles, "father of phenomenology," (Ary et al., 2014, p. 503) and "fountainhead of phenomenology in the twentieth century" (Groenewald, 2004, p. 43).

Husserl's work started after World War I, when European capitalist ideologies were wrecked and philosophy wavered between positivism and subjectivism. It was during this tumultuous time, and discontent with "a science that failed to take into account the experiencing person and the connections between human consciousness and the objects that exist in the material world," (Moustakas, 1994, p. 43) that Husserl "sought to develop a new philosophical method which would lend absolute certainty to a disintegrating civilization" (Eagleton, 2011, p. 47). Husserl "argued that people can be certain about how things appear in, or present themselves to, their consciousness," and that "anything outside immediate experience must be ignored" (Groenewald, 2004, p. 43). He reasoned, "realities are thus treated as pure 'phenomena' and the only absolute data from where to begin" (Groenewald, 2004, p. 43), and "all objects of knowledge must conform to experience" (Moustakas, 1994, p. 44). Within these views, the external world was a creation of personal consciousness and the goal of phenomenology became a "return to the concrete, to solid ground, as suggested by its famous slogan, 'Back to the things themselves"” (Eagleton, 2011, p. 48). 
The term 'phenomena' came from the Greek 'phaenesthai,' to flare up, to show itself, to appear, and 'phaino' meaning to bring to light, to place in brightness, to show itself in itself, the totality of what lies before us in the light of day (Heidegger, 1977; Moustakas, 1994). Phenomena is at the center of phenomenology, as it is what appears in consciousness, and what provides "the building blocks of human science and the basis for all knowledge" (Moustakas, 1994, p. 24). Husserl's Transcendental Phenomenology, the science of pure phenomena, "emphasizes subjectivity and discovery of the essences of experience and provides a systematic and disciplined methodology for derivation of knowledge" (Brentano, as cited in Moustakas, 1994, p. 45). Brentano explained the terminology behind the title 'Transcendental Phenomenology' as such, Husserl's approach is called "phenomenology" because it utilizes only the data available to consciousness - the appearance of objects. It is considered "transcendental" because is adheres to what can be discovered through reflection on subjective acts and their objective correlates. It is a "science" because it affords knowledge that has effectively disposed of all the elements that could render its grasp "contingent." (as cited in Moustakas, 1994, p. 45)

Moustakas (1994) added, "It is logical in its assertion that the only thing we know for certain is that which appears before us in consciousness, and that very fact is a guarantee of its objectivity" (p. 23). Husserl's work strongly influenced many, included American psychologist, Clark Moustakas, who later created a phenomenological research method, and a clear methodological framework for conducting phenomenological research studies (Moustakas, 1994). Hycner (1985), also developed guidelines for 
phenomenological analysis around the same time as Moustakas, and while his

terminology differs from Moustakas, their description of phenomenological analysis are similar.

\section{Phenomenology core processes.}

Moustakas (1994) identified four core processes "that facilitate the derivation of knowledge" in a phenomenological study (p. 33), and eight steps for data analysis. Copen (1992) identified a fifth core process that was included in this research study. These five core processes apply to multiple steps of the data collection, and analysis process. Therefore, the core processes will be presented first. I will explain how each of the core processes were addressed in this study. The eight steps of data analysis will be presented after the description of the data collection procedures.

Moustakas' (1994) core processes are epoche, transcendental-phenomenological reduction, imaginative variation, and synthesis. Epoche happens throughout the research process. Transcendental-phenomenological reduction primarily happens during first part of data analysis. Imaginative variation, and synthesis, primarily happen in the second part of data analysis.

Copen (1992) emphasized the importance of initial engagement as a core process of a phenomenological study. Moustakas (1994) described initial engagement in his Phenomenological Research Methods book, but did not label it as an exact process. Copen referenced the early works of Moustakas, from 1988 and 1990, including lecture notes. Groenewald (2004) presumed that one possible reason for the discrepancy could be that Moustakas identified initial engagement as a core process in his earlier works of phenomenological research, which inspired Copen to do so as well. Initial engagement 
was observed along with Moustakas' core process in this research study. I will now describe each of the core processes, including initial engagement, along with an explanation of how the core process was addressed. Since these core processes cover more than one data collection/analysis step, exact data collection and analysis procedures are presented later in this chapter.

\section{Initial engagement.}

As described by Copen (1992), initial engagement is an introspective process, done at the start of research, to identify an appropriate area of inquiry. It "involves a period of self-inquiry that facilitates discovery of a topic that represents a significant theme in the primary researcher's professional and personal development” (p. 21). Additionally, it "involves dialogue with one's Self regarding the subject in question" ( $p$. 21). At the start of any research study, one must identify their topic, and for

phenomenologists, this topic needs to be personal. As Moustakas (1994) explained, "in a phenomenological investigation the researcher has a personal interest in whatever she or he seeks to know; the researcher is intimately connected with the phenomenon" (p. 58). For me, initial engagement was a process that happened throughout my years in graduate school. A detailed description of my initial engagement, and internal inquiry is included below in my subjectivity statement.

\section{Epoche.}

As previously described, epoche is commonly known as the first core process of phenomenology (Moustakas, 1994; Patton, 2002). For this study, it was the second, following initial engagement. Epoche, a Greek word meaning to stay away from or abstain, is a way to, "free a researcher from prejudices and presumptions to be open for 
'whatever or whoever appears in our consciousness' and to approach it [the phenomena] with an openness to see "just what is there and allowing what is there to linger" (Moustakas, 1994, pp. 86-87). "Epoche is an ongoing analytical process rather than a single fixed event" (Patton, 2002, p. 485). This core process "occurs many times throughout the research project [and] involves a conscious decision to maintain an attitude of openness for whatever presents itself' (Copen, 1992, p. 22).

At many points throughout this process I entered into the intentional attitude of openness in epoche (Copen, 1992; Patton, 2002). In each moment of epoche, I consciously acknowledged my preconceptions and then cleared my mind of those ideas. In this way, epoche was both a preparation "for deriving new knowledge," and an experience as I looked at things "as if for the first time" (Moustakas, 1994, p. 85). For me, it was a challenge to, "create new ideas, new feelings, new awarenesses and understandings" (Moustakas, 1994, p. 86). However, each time I made the conscious decision to have a mindset of openness, readiness, hope and intention to see "this person, or situation, or issues with new and receptive eyes" (Moustakas, 1994, p. 89), I increased my "competency in achieving a presuppositionless state and being open to receive whatever appear[ed] in consciousness as such" (p. 90). I found epoche to be a particularly valuable exercise because of the personal nature of this research.

One aspect of the epoche process is reflective-mediation, which I found especially useful. In reflective-mediation, I allowed "the preconceptions and prejudgments enter consciousness and leave freely, being just as receptive to them as I am to the unbiased looking and seeing” (Moustakas, 1994, p. 89). In this way, epoche resembles Eastern yoga and meditational practices where one focuses on the breath. During this focus, any 
thoughts that come into consciousness were neither met with negativity, nor were they allowed to disrupt the meditation, rather they were recognized, then moved aside through the intentional refocusing on the breath. This is similar to Copen's (1992) correlation to sho-shin, meaning, "beginning mind," the way of looking at things in the Japanese philosophy of Aikido.

One's receptivity to knowledge while practicing sho-shin or epoche is not colored by one's past associations and assumptions. In the process of epoche, a narrow, predetermined consciousness is transcended. One arrives at knowledge freshly through the Self via pure intuition. (p. 22) Throughout this reflective-meditative practice, I followed Moustakas (1994) example, and as I experienced prejudgments or preconceptions, I labeled them and wrote them out on paper. (Moustakas, 1994, p. 89). I would review the list until "its hold on my consciousness [was] released, until I [felt] an internal readiness" (p. 89) for whatever presented itself. No matter how many items I had on the list, I was encouraged by Moustakas' (1994) words:

Although the Epoche is rarely perfectly achieved, the energy, attention, and work involved in reflection and self-dialogue, the intention that underlies the process, and the attitude and frame of reference, significantly reduce the influence of preconceived thoughts, judgements, and biases. (p. 90)

\section{Transcendental-phenomenological reduction.}

The second core process of Moustakas (1994) phenomenology, and the third of this study, is Transcendental-Phenomenological Reduction. There are three components of this core process: (a) bracketing; (b) horizonalization and; (c) delimiting. 
Transcendental-Phenomenological reduction happens primarily during steps one through five of data analysis, however components of this process are repeated throughout all of the data analysis. "The phenomenological reduction is a conscious, effortful, opening of ourselves to the phenomenon as a phenomenon... to see it as a phenomenon in its own right, with its own meaning and structure"(Keen, as cited in Hycner, 1985, p. 280). The task of this core process is "describing in textural language just what one sees, not only in terms of the external objective but also the internal act of consciousness, the experience as such, and the rhythm and relationship between phenomenon and self" (Moustakas, 1994, p. 81).

\section{Bracketing.}

Bracketing compliments epoche (Daniels, 2005; Groenewald, 2004). In bracketing, the phenomena is placed within 'brackets' for inspection, and everything else is placed outside of those brackets (Moustakas, 1994). This can also be described as the process in which, "the researcher 'brackets out' the world and presuppositions to identify the data in pure form, uncontaminated by extraneous intrusions" (Patton, 2002, p. 485).

Moustakas (1994) said bracketing was important, "so that the entire research process is rooted solely on the topic and question" (p. 97). "This is an essential step in following the phenomenological reduction necessary to elicit the units of general meaning" (Hycner, 1985, p. 280). Denzin provided an explanation of how bracketing and epoche work together,

In bracketing, the researcher holds the phenomenon up for serious inspection. It is taken out of the world where it occurs. It is taken apart and dissected. Its elements and essential structures are uncovered, defined and analyzed. It is 
treated as a text or a document; that is, as an instance of the phenomenon that is being studied. It is not interpreted in terms of the standard meanings given to it by the existing literature. Those preconceptions, which were isolated in the deconstruction phase [epoche], are suspended and put aside during bracketing. In bracketing, the subject matter is confronted, as much as possible, on its own terms. (as cited in Patton, 2002, p. 485)

Denzin, whose work was published prior to Moustakas, explained bracketing as a five-step process:

1. Locate within the personal experience, or self-story, key phrases and statements that speak directly to the phenomenon in question.

2. Interpret the meanings of these phrases, as an informed reader.

3. Obtain the subject's interpretations of these phrases, if possible.

4. Inspect these meanings for what they reveal about the essential, recurring features of the phenomenon being studied.

5. Offer a tentative statement, or definition, of the phenomenon in terms of the essential recurring features identified in step four. (as cited in Patton, 2002, pp. 486-487)

What Denzin (1989), described as bracketing correlates to Moustakas' (1994) data analysis steps. This is because, as previously stated, bracketing must be done during all stages of data collection and analysis to "avoid subjective judgements" (Groenewald, 2004, p. 50).

Bracketing was practiced during each of the eight steps of data analysis. Given my personal experiences with the phenomena, it was extremely important to 'bracket out' 
my own experiences, and reduce my focus to the phenomenon as described by the coresearchers. As a practical check of my bracketing success, I followed Hycner's (1985) suggestion of dialoguing with my committee about my presuppositions. "Such dialogue may very well bring out presuppositions that the researcher was not consciously aware of' (p. 281). A detailed description of how bracketing influenced my research is included below in my subjectivity statement.

\section{Horizonalization of data.}

Horizonalization of data, is a process through which statements germane to an experience are brought to light. During horizonalization, data are treated "with equal value" (Patton, 2002, p. 486). In treating meaningful statements equally, the data relevant to a phenomena are "lifted into the open" (Copen, 1992, p. 32). Within this research study, horizonalization was done through a written collection and listing of every statement germane to each of the co-researcher's experience. Those statements were taken from the interview transcripts.

\section{Delimiting.}

Delimiting is the removal of "data that are irrelevant, repetitive, or overlapping" (Moustakas, 1994, p. 97). During delimiting, the researcher "decides which statements are meaningful and necessary" (Copen, 1992, p. 24). The statements remaining after delimiting are a more refined collection of "only the horizons (textural meanings and invariant constituents of the phenomenon)" (Moustakas, 1994, p. 97). Delimiting refines the researcher's process in "join[ing] the remaining qualities of the experience, the invariant constituents, into encompassing themes" (Copen, 1992, p. 24). Delimiting was practiced at various points during data analysis. 


\section{Imaginative variation.}

The third core process of Moustakas (1994) phenomenology, and the fourth of this study, is imaginative variation. Imaginative variation "involves a reflective-intuitive, and analytic component of the investigation" (Copen, 1992, p. 24), as well as, “imagination" (Moustakas, 1994, p. 97). The goal of imaginative variation is to "derive structures that underlie the experience" (Copen, 1992, p. 24) and happens primarily during steps six through eight of data analysis. This process requires the researcher to analyze identified themes and, using imagination, seek all possible meanings, variations, and commonalities among the themes, to develop "enhanced or expanded versions of the invariant themes" (Moustakas, 1994, p. 486). Imaginative variation finds the structural meanings of the data. "The structures are brought into the researcher's awareness through imaginative variation, reflection and analysis" (Copen, 1992, p. 65).

Moustakas (1994) added that identifying the structural descriptions, alone, is not enough. "One has to find those structural descriptions that are common for all the participants. Only if one can narrow things down to common structural descriptions is it possible to talk about a phenomenon" (Douglas, 2011, p. 87). "Structural themes include broad universal themes that underlie all human experience, such as the relationship to the Self to oneself and to time, space, and others, whether something occurs by chance, intentionally, or causally" (Copen, 1992, p. 65). In finding common structural themes within and across experiences, the researcher is able to "see the same object from different views" (Patton, 2002, p. 486).

Moustakas (1994) listed four steps for identifying the invariant themes and arriving at the structural descriptions of an experience: 
1. Systematic varying of the possible structural meanings that underlie the textural meanings;

2. Recognizing the underlying themes or context that account for the emergence of the phenomenon;

3. Considering the universal structures that precipitate feelings and thoughts with reference to the phenomenon, such as the structure of time, $(\ldots)$;

4. Searching for exemplifications that vividly illustrate the invariant structural themes and facilitate the development of structural descriptions of the phenomenon (p. 99).

I practiced imaginative variation during multiple stages of data analysis, specifically during steps six, seven, and eight. During this process it was important to maintain the open attitude of epoche, while using my imagination, to see the underlying structures and themes.

\section{Synthesis.}

The final core process is synthesis, "an integration of the composite textural and composite structural descriptions" done for the purpose of "providing a synthesis of the meanings and essence of the experience" (Moustakas, 1994, p. 144). The synthesis of the textural and structural descriptions creates a comprehensive description of the "essences of the experience of the phenomenon as a whole" (Moustakas, 1994, p. 100).

I practiced synthesizing textural and structural descriptions for each individual coresearcher, and also for the co-researchers as a group. Evidence of this synthesizing is primarily represented in chapter five. Before explaining the eight steps of data analysis (Moustakas, 1994) that were followed in this study, I have included a statement 
explaining my subjectivity on the topic, followed by a presentation of information specific to data collection, including population, selection of participants, constraints, sampling, and recruitment procedures followed.

\section{Subjectivity Statement}

Animals have always been a huge part of my life, particularly dogs. When I was ten, my family had three birds, numerous fish, and a hamster, but my sisters and I wanted a dog. We recorded ourselves repeatedly saying, "You will let the girls have a dog," and gave the recording to our parents to play as they slept. Although I do not think it can be credited to our hypnosis attempts, a few months later, Ginger, a new puppy came into our home, and my life changed. My passion for dogs developed quickly. Even as a child, I enjoyed caring for, and training Ginger. I was always learning new things and found it easy to connect with other people because of our dog. When it was time to move out on my own, I quickly adopted my own dog, Gabbie, who thirteen years later is still sitting next to me as I work. I believe dogs can teach us a lot about life, living in the moment, instincts, protection, trust, and love, among other things. All of this is to say, I understand the increased interest in having a pet dog; I also understand wanting to take your dog with you everywhere. Before I learned about service dogs, I did not see the potential harm in taking a pet dog places where only service animals were allowed. It was through the journey of this project that my own mind has opened, and I have developed new understandings, and increased respect for service dogs. Unfortunately, it was also through this process that I developed a bias that clouded my own perceptions.

Professionally, my background has been in design, specifically fashion design.

As a designer, I enjoy looking at the world and figuring out how design can improve our 
lives. Before graduate school, I did not understand how I could blend my two passions of design and dogs into an academic career. It was during my graduate coursework that I learned about the design thinking mentality, and realized that through asking, "how can we make it better" (Beacham \& Shambaugh, 2010, p. 2), I could utilize my background to solve a design problem in the human/canine world.

Before graduate school, I had no prior experience with service dogs. However my university, West Virginia University, had a service dog training program. So, I chose to immerse myself into the world of service dogs, and adopted the "us-with-them" (Brown \& Katz, 2011, p. 382) mentality of design thinking. I enrolled in service dog training courses, and learned first-hand about training, and what it was like to be part of a service dog team. I also learned about the disabilities rights movement and developed an interest in the related legislation. Prior to this time, I knew these topics existed, however, I had not yet studied them. The classes I took provided an opportunity for me to openly converse with people who had service dogs, and explore potential research questions.

It was through these interactions, as well as public outings with my service dog in-training, that I started to see the challenges service dog teams faced in public spaces. Some of the challenges I observed were people touching the dog; misunderstood uniform or ID requirements; and questioning whether the dog was a legitimate service dog. I found this last challenge to be particularly common when the disability was invisible. In a private conversation, a woman, who suffered from PTSD, shared with me that on more than one occasion, she had been asked, "What's wrong with you? You don't look like you need a service dog." She described the experience as maddening and embarrassing. 
People also shared with me their frustrations regarding misrepresentation of a service dog, or as I heard many people call it, fraud. As explained in the literature review, research is lacking on misrepresentation of service dogs, therefore I found myself reading a lot of news articles and community forums. I knew all these sources were opinion based, but as I saw individual states develop laws against misrepresentation of a service animal, I began to believe misrepresentation was a proven problem. I developed a sense of pride for the people with service dogs, and in turn, a defensive mechanism towards misrepresentation.

Through dialoguing with my committee and peers, and reflective meditation, I realized how my own bias of misrepresentation was clouding my research focus. From what I observed, in general, service dog handlers knew their own rights, were following the law, and had strong expectations on how the public should, or should not, interact with them and their dog, but those expectations were not being met. I had identified that I wanted to learn about the public's side of this conversation, however it was not until I talked with my committee, and peers, that I saw how the potential issue of misrepresentation had become my driving force. I do believe misrepresentation needs researched, however it was not the focus of this study. Thankfully, through these conversations and reflective-meditation, I was able to bracket out my presuppositions, and open my mind to fully learning about the experience from the working public's perspective (Hycner, 1985). This was one of the most impactful epoche moments, for me, through this phenomenological research process.

Another component of my subjectivity comes from my extensive professional experience in places of public accommodation, including retail, hospitality, 
entertainment, office buildings, and education. I have personally experienced being at work, when a patron came in with a dog wearing a vest that said it was a service dog. Based on the dog's behavior, I did not believe it to be a legitimate service dog, however when I asked my manager about it, he said not to do anything because we could be sued. This experience was before I started graduate school and I did not know the legal questions I could ask. I do not believe my experience represents a single event. Subsequently, I have a personal interest in clarifying, and simplifying the process of service dog accessibility for both the service dog team, and gatekeepers.

In addition to this person interest, I specifically chose to focus on accessibility because it was the main challenge I identified that the Federal Government has legislation regarding. I believe that understanding the public's perspective on service dogs is similar to understanding a person's perspective to using a certain type of door (Norman, 2013). Without understanding how someone perceives a door as a door, and developing an understanding for why they use the door as they do, how can one design a successful door? Just the same, I believe we need to understand how people feel about service dogs in public, why they act the way they do around service dogs, and their interpretations of the legislation, before we can create any solutions on public interactions, legislation, regulations, uniforms or certifications. Additionally, from conversations with my committee, the literature review, and personal experience, I went into the data collection phase with the expectation of finding the lack of education and training at the heart of many, if not all, of the issues identified. 


\section{Population}

The target population for this study was the American public who work in places of public accommodation in Lexington, or Louisville, Kentucky, and whose job responsibilities require them to be gatekeepers of their facility. The constraint of location was set based on population numbers. Kentucky's three most populated cities were Louisville (621,349), Lexington (321,959), and Bowling Green (67,067). Since Louisville and Lexington both had more than double the population of Bowling Green city, the constraint of location was set to gatekeepers located in either Louisville or Lexington.

The state of Kentucky borders Illinois, Indiana, Missouri, Ohio, Tennessee, Virginia, and West Virginia. As discussed in the literature review, the use of terminology in legal nomenclature is one area of state-to-state discrepancy. The laws governing service dogs vary greatly in each of these states, as does the vocabulary. Comparing the states' laws was a challenge because of the variations in terminology used in the laws. Referencing Wisch's (2016) work, I created the table below to illustrate the different labels used in these eight states' laws on assistance/service dogs (see Table 2). 
Table 2

Comparison of Terminology Used in Service Dog Legislation in Eight Neighboring States

\begin{tabular}{|c|c|c|c|c|c|c|c|c|}
\hline & IL & IN & KY & MO & $\mathrm{OH}$ & $\mathrm{TN}$ & VA & WV \\
\hline \multirow[t]{9}{*}{$\begin{array}{l}\text { Terminology } \\
\text { Used }\end{array}$} & $\begin{array}{l}\text { Assistance } \\
\text { animal }\end{array}$ & $\begin{array}{l}\text { Assistance } \\
\text { animal }\end{array}$ & $\begin{array}{l}\text { Accelerant } \\
\text { detection dog }\end{array}$ & Guide dog & $\begin{array}{l}\text { Assistance } \\
\text { dog }\end{array}$ & $\begin{array}{l}\text { Companion } \\
\text { animal }\end{array}$ & Dog guide & Guide dog \\
\hline & Guide dog & $\begin{array}{l}\text { Autism } \\
\text { service } \\
\text { animal }\end{array}$ & $\begin{array}{l}\text { Assistance } \\
\text { dog }\end{array}$ & $\begin{array}{l}\text { Hearing } \\
\text { assistance dog }\end{array}$ & Guide dog & Dog guide & Guide dog & $\begin{array}{l}\text { Service } \\
\text { animal }\end{array}$ \\
\hline & $\begin{array}{l}\text { Hearing ear } \\
\text { dog }\end{array}$ & Guide animal & $\begin{array}{l}\text { Bomb } \\
\text { detection dog }\end{array}$ & Hearing dog & Hearing dog & Guide dog & $\begin{array}{l}\text { Hearing } \\
\text { dog }\end{array}$ & $\begin{array}{l}\text { Support } \\
\text { dog }\end{array}$ \\
\hline & $\begin{array}{l}\text { Seizure-alert } \\
\text { dog }\end{array}$ & Guide dog & Cadaver dog & $\begin{array}{l}\text { Medical alert } \\
\text { or respond dog }\end{array}$ & Service dog & Service animal & $\begin{array}{l}\text { Leader } \\
\text { dog }\end{array}$ & \\
\hline & $\begin{array}{l}\text { Seizure- } \\
\text { response dog }\end{array}$ & $\begin{array}{l}\text { Hearing } \\
\text { animal }\end{array}$ & $\begin{array}{l}\text { Narcotic } \\
\text { detection dog }\end{array}$ & Mobility dog & & & $\begin{array}{l}\text { Service } \\
\text { dog }\end{array}$ & \\
\hline & $\begin{array}{l}\text { Service } \\
\text { animal }\end{array}$ & $\begin{array}{l}\text { Mobility } \\
\text { animal }\end{array}$ & Patrol dog & $\begin{array}{l}\text { Professional } \\
\text { therapy dog }\end{array}$ & & & $\begin{array}{l}\text { Service } \\
\text { dog }\end{array}$ & \\
\hline & Signal dog & $\begin{array}{l}\text { Psychiatric } \\
\text { service } \\
\text { animal }\end{array}$ & $\begin{array}{l}\text { Search and } \\
\text { rescue dog }\end{array}$ & $\begin{array}{l}\text { Search and } \\
\text { rescue dog }\end{array}$ & & & $\begin{array}{l}\text { Three-unit } \\
\text { service } \\
\text { dog team }\end{array}$ & \\
\hline & Support dog & $\begin{array}{l}\text { Seizure alert } \\
\text { animal }\end{array}$ & $\begin{array}{l}\text { Service } \\
\text { animal }\end{array}$ & Service dog & & & & \\
\hline & & $\begin{array}{l}\text { Service } \\
\text { animal }\end{array}$ & Tracking dog & $\begin{array}{l}\text { Service dog } \\
\text { team }\end{array}$ & & & & \\
\hline
\end{tabular}

(Wisch, 2016) 
Another area in which these eight states differed was their legislation on the misrepresentation of a service animal. In the last two years, Virginia, Missouri, and West Virginia have created state laws protecting service animals from misrepresentation (Henderson, 2018; Wisch, 2016). Virginia's law was enacted in 2016 (Wisch, 2016), and Missouri and West Virginia's went into effect in 2018 (Henderson, 2018; Rhoads 2018). Also in 2018, Indiana passed a law giving landlords the right to ask for medical documentation validating the need for an emotional support animal if the person's disability was not obvious. (Loughlin, 2018).

In 2018, House Bill 326 was passed in Kentucky against the misrepresentation of an assistance animal when done specifically for the purpose of obtaining housing accommodations (An Act Relating to Assistance Animals, 2018). The penalty for “misrepresentation of an assistance animal [was] a violation with a fine of up to one thousand dollars" (An Act Relating to Assistance Animals, 2018, p. 3). In March, 2019, House Bill 411 was passed to amend Kentucky’s House Bill 326. The amendments included a more defined definition of misrepresentation, in regards to housing accommodations, and additional penalties (An Act Relating to Assistance Animals, 2019). The additional penalty states,

A lessor may evict a lessee and the lessor is entitled to a damage fee, not to exceed one thousand dollars, from a lessee if the lessee provides fraudulent documentation indicating a disability requiring the use of an assistance animal. (An Act Relating to Assistance Animals, 2019, p. 4)

At the start of this study, the remaining three states that share a border with Kentucky did not have laws against service animal misrepresentation. This did not necessarily mean 
misrepresentation was a null issue, as service dog misrepresentation was a topic in multiple local news stories from these states.

Here are some examples of the opinions expressed through news outlets. It is important to note, while the following statements lack substantial data backing the claims, I believe they provide insight into social conversations in the demographic region of the target population.

An article titled, "Websites Sell Unneeded Service Animal Certifications," published on a Tennessee local news webpage, presented the issue of unregulated service animal certifications resulting in misrepresented service animals. The article explained the value of a service animal "for people with disabilities, the right to bring a trained service animal out in public is key to living an independent life" (Smith, 2018, para. 2). Quoted in the article, a local legally blind resident said "when I put my hand on his harness it's like an extension of my arm" (Smith, 2018, para. 3) and credited her service dog for her new found "freedom" (Smith, 2018, para. 5). The author said, "There are dozens of websites, where for a fee, they will send you a vest to show your animal is a certified service, emotional support or therapy animal." They explained the concern as, "For some it's a way to try and bend the law to bring their favorite animal with them in public places" (Smith, 2018, para. 12). In the article, chairman of a service dog training organization in Tennessee, commented on certification process:

It's [a] major issue for us because we see it all. We really do. You can Google 'service dog access' and you will come up with multiple organizations that for $\$ 69.96$ we will send you a service dog certification. Well, there is no such thing. (Smith, 2018, para. 11). 
In response, the University of Tennessee College of Veterinary Medicine's, Dr. Ng, was quoted saying "because of the onslaught of the recent problems that we've had, we are discussing with the authorities about how to safely govern these sorts of regulations" (Smith, 2018, para. 13). Dr. Ng continued,

"We are so lucky in this society to have this term of emotional support animal and that we really should designate that for the people who need them and the animals that are well behaved in public settings. So when people are taking advantage of the system that's really hard, it's disappointing. (Smith, 2018, para. 15)

In Ohio, a local news webpage published an article titled, "Lack of Federal Regulations Leads to Spike in Fake Service Dogs" (Kosar, 2018). In that article, lead trainer for service dog training organization, Service Dogs 4 Veterans, John Holowenko, expressed his frustration of misrepresentation. The author summarized the complaint as, "because of a lack of oversight from the federal agency, there has been a spike in fake service dogs" (Kosar, 2018, para. 5). The lack of an official "registry or certification process that distinguishes a service dog from a pet" (Kosar, 2018, para. 7) was identified as part of the issue. John Holowenko said, “....anybody can throw a vest on a service animal and say 'oh it is my service dog"' (Kosar, 2018, para. 6). The article also said, "the ADA guidelines are too vague and leave room for interpretation and the lack of regulation has allowed people to profit off the system" (Kosar, 2018, para. 9). The news channel reported finding "several websites claiming owners can register their service dogs and selling service dog certificates, both things not recognized by the government" (Kosar, 2018, para. 9). 
An article was published in the Chicago Tribute titled, "Emotional Support Animals - from Dogs to Peacocks, Real or Fake - Present Challenges for Businesses". In this article, dog trainer, Jennifer Hack, said, "I get many inappropriate calls, including people suddenly wanting their dogs to 'become a service dog' because they are moving to a 'no dogs allowed' building or want the dog to fly for free," she has also "been offered money for fake paperwork" (Bomkamp, 2018, para. 8). This particular article also made it sound like emotional support animals had the same accessibility rights to public businesses, which according to the ADA, they do not.

Published on a Lexington, Kentucky local news webpage, an article was posted titled, "Fake Service Dogs: 'One of the Most Hideous Things I've Ever Seen.'” In that article, Karen Shirk, founder of the Ohio based service dog training program, 4 Paws for Ability, described "people using dog vests on dogs that aren't trained to be service dogs" as "one of the most hideous things I've ever seen" (Combs, 2018, para. 2). She said it "is disrespectful to everyone, and dangerous for real service dogs," and the issue "is disrespectful to the business owner who has to, by-law, let service dogs in, and they should be well-behaved, well-trained dogs" (Combs, 2018, para. 2). Also in that article, a Kentucky resident whose young son had a service dog, expressed his frustration, "I can't say why somebody else feels that you could just get a vest and put in on a dog. That's not what makes it a service dog" (Combs, 2018, para. 6). The article's writer continued to describe the resident's opinion, "fake service dogs aren't just a disrespect to those that actually need service dogs, it can also harm the genuine service dogs." They elaborated, "If a 'fake' service dogs tries to attack a real service dog, it can cause post traumatic disorder in the service dog and force them into retirement" (Combs, 2018, para. 13). The 
resident said, "this is not a matter of 'are we not hurting anybody', this is a matter of there are many ways they are hurting people" (Combs, 2018, para. 14).

A local news website from Louisville, KY published an article titled, "Robley Rex VA Hospital will Train Staff to Identify Fake Service Animals". The article said the VA hospital reported issues with "dogs being portrayed as service animals...but not all of them are true service dogs" (Glick, 2018, para. 1). Interim Medical Director, Kurt Thielen, attributed "a lot of that...to people simply buying service dog vests on the internet" (Glick, 2018, para. 2). A veteran at the hospital said he had seen "dogs growl at people, among other issues, which isn't representative of how a true service animal behaves" (Glick, 2018, para. 3). He added misrepresented service dogs "makes people uncomfortable... [and] it's best that they're not in there" (Glick, 2018, para. 9). In response to the reported issues, the hospital "is working on getting staff trained to notice the difference," (Glick, 2018, para. 4) and teaching staff the two questions they can legally ask. The interviewed veteran also said, "education is key when it comes to true service animals...the people that just throw a vest on a dog and call it a service dog make it very difficult for legitimate service dogs" (Glick, 2018, para. 12 - 13).

Again, I recognize these news articles do not present verifiable evidence, however, news articles like these can play a part in creating public perceptions of service dogs and were therefore considered. A future research study could be done focusing solely on the media's portrayal of service dogs. Additional information on criteria and the selection process are provided in the following sections: selection of participants, workplace, inclusion criteria, sampling, and recruitment 


\section{Selection of Participants}

For the purpose of this research study, I chose to refer to the selected participants as "co-researchers." Kvale and Seidman provided a rationale for this statement, "... 'coresearchers'...work with the researcher, not to summon up and state a prior experience like playing a recording, but to jointly explore the participant's experience and co-create a meaningful description" (Kvale and Seidman, as cited in Donalek, 2004, p. 516). Since this study sought to understand the working public's experiences with service dogs, it was necessary to recruit co-researchers who had experienced the phenomena "because they have been through the experience being investigated and can share their thoughts and feelings about it" (Ary et al., 2014, p. 503). Participants also had to be willing to share their experiences (Donalek, 2004).

\section{Gatekeeper workplace constraints.}

According to the ADA (DOJ, 1991), a place of public accommodation is a facility whose operations affect commerce and fall into at least one of twelve categories, as listed in previously in the literature review. Based on the results from The Foundation for Service Dog Support's Public Access Challenge Report (C. Betancourt, personal communication, March 22, 2018), many service dog handlers experienced accessibility issues in restaurants and retail stores, however as this research study sought the experiences of gatekeepers, and not of service dog handlers, no constraints on type of public accommodation were set.

I considered excluding gatekeepers who worked at "dog friendly" locations based on my belief that if a business advertises as pet friendly then the motivation for patrons to misrepresent a pet dog as a service dog would be lower. Additionally, there are members 
of the working public whose responsibilities do not require them to act as gatekeepers, however, in the end, this constraint was not set because all public entities and employees must adhere to the ADA accessibility laws, dog-friendly included. Additionally, opening the workplace constraints up to all public entities in Lexington and Louisville allowed for the possibility of a more diverse population.

\section{Inclusionary criteria.}

Co-researchers were selected based on the following criteria:

(a) Having experienced first-hand the phenomena a service dog entering their public place of business while they were working;

(b) Having worked, or currently work for a public accommodation in either Lexington, KY or Louisville, KY;

(c) Their willingness to share their experience(s) (Donalek, 2004).

\section{Sampling}

I utilized both purposive, and snowball sampling for this research study. Purposive sampling was appropriate as co-researchers needed to "have had experiences relating to the phenomenon to be researched" (Kruger, as cited in Groenewald, 2004, p. 45) and I desired equal representation from both Lexington and Louisville, KY. Purposive sampling is “...the most important kind of non-probability sampling” (Welman and Kruger, as cited in Groenewald, 2004, p. 45). Interviewing only people who had experiences with the phenomena in these two cities allowed me to investigate how their experiences shaped their understandings and perceptions of service dogs and how those perceptions related to their communities. As Krauss explained, "human-beings have a 
natural inclination to understand and make meaning out of their lives and experiences" (Krauss, 2005, p. 762).

Snowball sampling made sense for this research study as the co-researchers were "not centrally located but scattered in different sites" (Ary et al., 2014, p. 458). Starting with a local animal rescue organization, I asked for contact information for adults working in Lexington or Louisville, whom had personally experienced service dogs coming in their public place of business. When I received a potential participant's contact information, I called them and using the phone script (see Appendix B), I explained the purpose of the study, confirmed they had experienced the phenomena and asked if they would share those experiences with me. After confirming a participant's interview, I utilized snowball sampling to find additional participants. During each conversation, I asked for suggestions of additional participants, and their contact information. Requests for suggestions were made during both the initial phone call and after the interview.

Snowball sampling was utilized until data saturation and a sufficient number of co-researchers were interviewed. Boyd "regards two to 10 participants or research subjects sufficient to reach saturation" (as cited in Groenewald, 2004, p. 46). Creswell (1998) suggests five to 25 for a phenomenological study, and Morse (1994) suggested at least six. I started recruitment with the goal of finding eight co-researchers, with equal representation from Lexington and Louisville. The total number of co-researchers for this research study was 11, of which seven worked in Lexington and four in Louisville. 


\section{Recruitment Procedures}

I followed the same recruitment process for each participant. During the initial conversation, whether in-person or on the phone, I asked if the person had first-hand experiences with the phenomena. I did not provide any definition of service dogs to the participants. If the potential participant stated they did have first-hand experience with service dogs in their place of business, an interview was requested. If they did not, but knew a colleague or friend who did, that person's contact information was requested. If during these conversations they stated they neither had, nor knew anyone that had personal experiences with service dogs in their business I thanked for their time and went back to ask previous participants for more suggestions.

During recruitment, I explained that I wanted to understand their experiences and knowledge as they are an important part of Kentucky's working public. I emphasized the value I placed in their individual participation, and my desire for understanding their personal experiences. Some asked if they needed to prepare for our interview, and I answered they only needed to start thinking about their experiences and remembering as much as possible.

In each initial conversation, I clarified with the potential participant that the requested interview was for the purpose of a dissertation, and confidentiality was guaranteed. From personal professional experiences, I understood that talking about anything that happens in the place of business is often against company policy. Therefore, if this concern was brought up, confidentiality was reemphasized. Nevertheless, and unfortunately, numerous potential participants were not willing to be interviewed because of confidentiality concerns. 


\section{Research Procedures}

\section{Instructions to co-researchers.}

Co-researchers were invited to participate in this research study in which they would be interviewed on their experiences with service dogs. They were told the interview would last approximately one hour and follow-up could be necessary. The coresearchers were asked to refrain from doing any special research prior to their interview, but rather to think about all of their experiences with service dogs, particularly in their workplace.

\section{Interview site selection.}

Once a participant agreed to participate in the study, an interview time and place was determined. A location was suggested as the place of business where the participant experienced the phenomenon, under the assumption that seeing the space helped create a holistic understanding of their experience. However, if that was not possible, other options were explored, including local libraries or cafes. Locations selected were quiet spaces where the audio-recorder could pick up the interview completely, and somewhere the interview would not be interrupted. Additionally, convenience to the co-researcher was valued.

\section{Data collection (interview process).}

An interview for the purpose of data capturing "is literally an inter view, an interchange of views between two persons conversing about a theme of mutual interest" during which the researcher seeks to "understand the world from the subjects' point of view, to unfold meaning of people's experiences" (Kvale, as cited in Groenewald, 2004, p. 47). Interviews are the generally agreed upon appropriate data collection technique in 
phenomenological studies (Ary et al., 2014). Patton (2002) explained, “one must undertake in-depth interviews with people who have directly experienced the phenomenon of interest that is, they have "lived experience" as opposed to second hand experience" (p. 104). According to Bailey, the "informal interview is a conscious attempt by the researcher to find out more information about the setter of the person" (as cited in Groenewald, 2004, p. 47).

Following the design of Groenewald (2004), unstructured in-depth interviews were conducted. Unstructured interviews are commonly used when the researcher “assumes the stance of a receptive, nonjudgmental listener or learner" (Boyd, 2001, p. 566). Boyd (2001) explained that researchers often choose unstructured interviews because they have little information on the topic, however since epoche requires a setting aside of all presuppositions, the researcher in a phenomenological places themselves in a very similar position of having little information on the topic.

The data collection [interview process] started after receiving approval from the West Virginia University’s Office of Integrity and Research Compliance [IRB] (see Appendix D). This research study was granted an exemption because of the interview procedures used, confidentiality of co-researchers was guaranteed, and they were not placed at risk through their participation in this research study. Data-collection interviews continued until data saturation and an appropriate number of interviews was reached.

Regardless of location, my preparation and set up for each interview looked the same. Prior to the interview I confirmed the meeting location through either email or text message, whichever the participant indicated they preferred. The day of the interview, I 
arrived at the location at least 15 minutes before the pre-established time, to make sure I arrived before the participant and we had two seats and a table at which to sit. While I waited for the participant, I participated in bracketing, that is made sure I set aside any preconceived ideas of what I could find in the interview. I also reviewed my interview questions, any notes I had on the participant, and set up my recorders. I recorded each interview with two recorders, in case one malfunctioned. I took notes during each interview directly on my list of interview questions. When the participant arrived, I introduced myself and presented them with the cover letter for my research study. I also thanked them for their participation before beginning with questions.

Each interview followed the same format for consistency, however variation was expected in the duration of the interview and the number and type of probing questions asked (Groenewald, 2004). I followed Miles and Huberman's (1994) suggestions for 'memoing' throughout the data collection process. "Memoing captures the thoughts of the analyst on the fly" (Miles \& Huberman, 1994, p. 75). Memoing during an interview represented the researcher's field notes, "what the researcher hears, sees, experiences, and thinks in the course of collecting and reflecting on the process" (Groenewald, 2004, p. 48). Notes made during memoing were used with the transcripts for correlation with the data.

Each interview began with introductions, presentation of the IRB approval, and reaffirmation of confidentiality. A pilot interview was done prior to data collection to clarify and refine research questions (Ary et al., 2014). Before asking any scheduled questions, I requested that the co-researchers answer as openly and honestly as possible. 
I reassured them there were no right or wrong answers, but that I wanted to hear about their experiences.

To start each interview, I asked the co-researcher to share their overall experiences with animals in their life. Following their answer, and subsequent conversation, I brought the focus in to dogs and then to service dogs. I considered "the participant's experiences, feelings, beliefs and convictions about the theme in question" when developing the interview questions (Welman and Kruger, as cited in Groenewald, 2004, p. 47). The list of interview questions is included in Appendix C.

Co-researchers were "given space to tell their stories at their own pace" (Boyd, 2001, p. 566). Probing questions were asked, as needed, to develop a holistic understanding of the co-researcher's experience. Questions regarding demographics were asked at the end of each interview. This was done at the end of the interview for two reasons: (1) so the interview had the flow of a natural conversation to begin, and (2) to give the researcher time for memoing, immediate post-interview reflections, and quick review of the field notes to identify any topic areas that needed clarification or expansion. In some cases, demographic information had already been shared naturally in the answers to interview questions. While participants were not selected based on demographic parameters beyond location, the demographic questions were asked to give the researcher "a better idea of accompanying (demographic) data and factors that might have an influence on the interpretation and analysis of the collected data" (Douglas, 2011, pp. 9192). Demographic data collected included: gender, ethnicity, age, marital status, education level, and employment status. Each interview was audio-recorded, with 
permission of the co-researchers. Following data collection, I transcribed each interview, noting moments of pause, and other nonverbal cues.

For confidentiality and protection of co-researchers, all digital notes, memos, recordings and transcripts were kept in a file on my password protected, personal computer. All physical notes and memos were kept in a locked file cabinet at my locked personal residence. All documents and related interview data will be kept for the minimum requirement of three years and then deleted.

\section{Follow-up.}

Preferred contact method and information for each co-researcher was confirmed at the end of each interview and potential follow-up discussed. Follow-ups were conducted as a "validity check" during the analysis"” (Hycner, 1985, p. 292), or when needed. Follow ups were done either through email, text, on the phone, or in person, depending on the purpose of the follow-up.

\section{Pseudonyms.}

For privacy, each co-researcher was given a letter code and a pseudonym. I, the primary researcher, was the only one who knew which code and pseudonym belonged to which participant. The co-researcher letter codes were CRA, CRB, CRC...CRF, where CR stood for co-researcher and the following letter represented the order in which the interview was conducted in relation to the others. For example, the first co-researcher interviewed was given the code CRA, the second CRB, and the third CRC. Codes were used during data collection before pseudonyms were selected. The co-researcher's real names were not written on any notes or memos. All notes and memos were organized according to the letter code. 
After all 11 interviews were complete, pseudonyms were selected so that the first letter of the pseudonym name matched that of the letter code. For example, CRA is Adam, CRB is Becky, and CRC is Cathy. Subsequently, the first letter of the pseudonym name matched the order in which the co-researcher was interviewed. For example, Becky was interviewed after Adam but before Cathy, and Kevin was the last person interviewed. In addition to selecting the first letter of the name based on interview order, I followed Allen and Wiles (2016) and Loviglio's (2012) suggestions for selecting pseudonyms and used the Baby Name Wizard (n.d.), an interactive graphic representation of baby name popularity and trends over time, to pick names popular for someone around the co-researcher's age and gender. This additional step was taken to avoid any unintentional correlations between the selected pseudonym and co-researcher.

My co-researchers were: Adam, Becky, Cathy, Donna, Emily, Faith, Gloria, Haley, Isabelle, Janet, and Kevin. With the exception of Isabelle and Janet, I interviewed each of the co-researchers separately. I would have interviewed Isabelle and Janet separately, however unexpectedly, Janet brought Isabelle with her to our scheduled interview, because as she said, Isabelle "would have more to add" to the research. I did not want to upset my co-researchers so I embraced the change and the interview with Isabelle and Janet was done with the three of us.

\section{Data Analysis}

A special focus was placed on organizing, analyzing and synthesizing the data according to Moustakas' (1994) modifications of van Kaam's methods of data analysis and Hycner's (1985) guidelines for phenomenologically analyzing interview data. In following these processes, I was able to "complete an analysis of data in an organized and 
disciplined manner" (1992, p. 25). Moustakas (1994) created eight steps for data analysis. Transcription was not one of the eight steps, however as I transcribed each of the interviews, I included it in the data analysis processes. Next I will present the steps followed in data analysis.

\section{Transcription.}

According to Hycner (1985), transcription is "an obvious but important step in phenomenologically analyzing interview data" (p. 280). Each transcription included "the literal statements" and "significant non-verbal and para-linguistic communications" (p. 280). Each interview, with its set of field notes, was assigned a code name [CRA, CRB, CRC...CRF] prior to transcription for confidentiality. The layout of the transcription followed Hycner's (1985) suggestion of leaving a large margin to the right of the transcription as a space for noting observations and what the researcher believed were the units of general meaning. This space was also used for memoing during the analysis process (Miles \& Huberman, 1994). "Researchers are easily absorbed in the datacollection process and may fail to reflect on what is happening" (Groenewald, 2004, p. 48). However, memoing helped "the researcher maintain a balance between descriptive notes and reflective notes, such as hunches, impressions, feelings and so on" (Groenewald, 2004, p. 48).

I decided to transcribe each of the interviews myself for multiple reasons. The first reason was feasibility. The majority of the co-researchers preferred to be interviewed in a café. Subsequently, some of the recordings had too much ambient noise to be transcribed by a transcription service. Additionally, some of my co-researchers had strong southern accents and understanding the recording required not only listening to the 
interview multiple times, but also using my researcher notes to determine the exact words used. Another reason I decided to transcribe the interviews myself was to spend valuable time in the data. Listening to the interviews repeatedly, allowed me to become very close to, and familiar with the data, as well as provided additional opportunities to note nonverbal cues such as moments of pause and voice inflections. After all of the interviews were transcribed, I followed Moustakas' (1994) eight steps of data analysis for a phenomenological inquiry. Each of these steps required a reengagement with epoche.

\section{Step 1: Listing and preliminary grouping/horizonalization.}

Step one was the first step taken in discovering the individual textural description of the co-researcher experience (Moustakas, 1994). Using the transcription, a list of statements relative to the co-researcher's experience was created. Statements were identified and included in the list without analysis or evaluation (Copen, 1992; Moustakas, 1994). All key phrases and statements that [spoke] directly to the phenomenon in question" (Denzin, as cited in Patton, 2002, pp. 486-487) were highlighted and set apart into a list. Step one specifically required a conscious effort of bracketing to see the data "in pure form" (Patton, 2002, p. 485).

This step is also known as horizonalizing or horizonalization (Moustakas, 1994), because as these statements are brought to light they are "lifted into the open" and become the horizons of the experience (Copen, 1992, p. 32). "During this step the researcher obtained an accurate description and understanding" (Copen, 1992, p. 24) of the co-researcher's experiences as expressed in their own words. Horizonalization of the data is a component of transcendental-phenomenological reduction. 


\section{Step 2: Reduction and elimination.}

The second step taken in data analysis was the reduction and refinement of the horizons identified in step one. Step two was a practice of the core process of delimiting. During this step, every expression in the created list was tested for two requirements:

a) Does it contain a moment of the experience that is basic, necessary and sufficient to understanding it (Moustakas, 1994, p. 121)?

b) Is it possible to abstract or label it? If so, it is a horizon of the experience (Moustakas, 1994, p. 121).

When both of these conditions were met, the horizons of the experience became "invariant constituents [ICs] of the experience" (Moustakas, 1994, p. 121). Expressions that did not meet these requirements were eliminated, as were "overlapping, repetitive, and vague expressions" unless they could be "presented in more exact descriptive terms."

\section{Step 3: Clustering and tentative thematizing of invariant constituents (ICs).}

During this step, the invariant constituents [ICs] identified in step two were clustered into themes and labeled to establish "the core themes of the experience" (Moustakas, 1994, p. 121). As Hycner's (1985) instructed, this step required a renewed effort of bracketing to "determine if any of the units of relevant meaning naturally cluster together" (p. 287). "Such an essence emerges through rigorously examining each individual unit of relevant meaning and trying to elicit what is the essence of that unit of meaning given the context" (p. 287). 


\section{Step 4: Final identification of the invariant constituents and themes by application (validation).}

During this step, the invariant constituents and their accompanying themes were checked against each complete transcription to determine

a) Are they expressed explicitly in the complete transcription?

b) Are they compatible if not explicitly expressed?

"If they are not explicit or compatible, they are not relevant to the co-researcher's experience and should be deleted" (Moustakas, 1994, p. 121). The elimination of irrelevant ICs and themes was again a practice of the core process of delimiting.

Hycner's (1985) suggestions guided the exact processes of this stage in the analysis. This step was done first for each of the individual co-researcher's lists of ICs, and then for the group as a whole. After identifying the themes in each separate interview, I looked for commonalities across all, or most of the interviews. The common themes were clustered together "indicating a general theme that emerged in most or all of the interviews" (Hycner, 1985, p. 26). Care was taken to not "obscure significant variations within that theme manifested in the individual interviews" as "the variations may indicate the significance of the theme" (Hycner, 1985, p. 26). Also noted were the themes "unique to a single interview or a minority of the interviews. These individual variations are important counterpoints to the general theme" (Hycner, 1985, p. 26). Some of the ICs appeared in multiple clusters because it appeared they were essential to a number of different themes.

Hycner (1985) warned there was more "room for 'artistic' judgement' here" than in any of the previous steps and the "major danger in this procedure is of course that 
since more of the researcher's judgement comes into play here that the researcher's presuppositions might interfere" (p. 10). Therefore, as a check on this, I followed Hycner's (1985) suggestion and had an "outside impartial panel...repeat the process to see if they come up with the same clusters" (p. 10). Groenewald (2004) called this checking of the ICs and themes a "validity check" (p. 20).

\section{Step 5: Individual textural descriptions.}

During this step, an individual textural, comprehensive explication and description of each co-researcher's experience was created by "using the relevant, validated invariant constituents and themes" (Moustakas, 1994, p. 121). The ICs and core themes identified in the previous steps were the "building blocks of a textural portrait" (Copen, 1992, p. 57). The textural description is the "what of the experience," the "feel or shape of the experience, just 'what' appears in consciousness" (Copen, 1992, p. 65). In chapter four I present, in narrative form, the individual textural descriptions of each of the eleven co-researchers.

\section{Step 6: Individual structural descriptions.}

During this step, "an individual structural description of the experience was created for each co-researcher" (Moustakas, 1994, p. 121). The "structural description is the dynamic that enables the researcher to understand 'how' something comes about" (Copen, 1992, p. 65). The structures are what "underlie the experience" (Copen, 1992, p. 24). Through analysis of the individual textural descriptions and the core process of imaginative variation, the "imbedded aspects of the experience were explored and developed in terms of primary structures, such as Self in relation to time and space, relationships with others, and connections to work" (Copen, 1992, p. 26). "Structural 
themes include broad universal themes that underlie all human experience, such as the relationship to the Self to oneself and to time, space, and others, whether something occurs by chance, intentionally, or causally" (Copen, 1992, p. 65).

I referenced Moustakas (1994) four steps for arriving at the structural descriptions of an experience:

1. Systematic varying of the possible structural meanings that underlie the textural meanings;

2. Recognizing the underlying themes or context that account for the emergence of the phenomenon;

3. Considering the universal structures that precipitate feelings and thoughts with reference to the phenomenon, such as the structure of time, (...);

4. Searching for exemplifications that vividly illustrate the invariant structural themes and facilitate the development of structural descriptions of the phenomenon (p. 99).

\section{Step 7: Textural/structural synthesis.}

During this step, "a textural-structural description of the meanings and essences of the experience was created for each research participant" (Moustakas, 1994, p. 121). This description was created through a synthesis of the essential constituents, meanings and themes (Copen, 1992). Synthesis is a core process of phenomenology done for the purpose of "providing a synthesis of the meanings and essence of the experience" (Moustakas, 1994, p. 144). 
This step provided an opportunity for "an excellent experiential 'validity-check" (Hycner, 1985, p. 292). The researcher returned to the co-researchers with the written summary and themes to check on two main issues:

a) Whether the research participant agrees that the essence of the first interview has been accurately and fully "captured." If not, obviously some corrections will need to be made.

b) If the participant is in essential agreement with the summary and themes and $s / h e$ would like to add further information to that already gathered (Hycner, 1985, p. 292), a follow-up interview was considered.

\section{Step 8: Integrated textural/structural description.}

The last step in data analysis was the creation of a "comprehensive description representing the group" (Copen, 1992, p. 27) through analysis of the textural and structural descriptions for all of the co-researchers. "Such a composite summary describes the "world" in general, as experienced by the participants" (Hycner, 1985, p. 294) and accurately captures the essence of the phenomenon. Moustakas (1994) added that identifying the structural descriptions, alone, are not enough; "one has to find those structural descriptions that are common for all the participants. Only if one can narrow things down to common structural descriptions is it possible to talk about a phenomenon" (Douglas, 2011, p. 87). Chapter five includes the integrated textural/structural description of the co-researchers. This entire process of data analysis required the researcher to make judgement calls with the data, however as the analysis was rigorously completed, presuppositions were bracketed and epoche kept the researcher open to the 
data, "it would seem that the danger of inappropriate subjective judgements creeping in would be minimal" (Hycner, 1985, p. 284).

\section{Credibility, Transferability, Dependability, and Confirmability}

The mechanisms to assess rigor in qualitative research include credibility, transferability, dependability, and confirmability (Ary et al., 2014). The following sections discuss how each of these concerns of rigor were addressed in this research study.

"Credibility in qualitative research concerns the truthfulness of the inquiry's findings" (Ary et al., 2014, p. 531). Credibility was established in three main ways (a) member checks; (b) low-inference descriptors; and (c) epoche and bracketing. Coresearchers were asked to review and critique the researcher's interpretation of the data collected. Doing these member checks confirmed "the degree to which the participant's viewpoints, thoughts, feelings, intentions, and experiences [were] accurately understood... and portrayed" (Johnson \& Christensen, as cited in Ary et al., 2014, p. 533). The use of "low-inference descriptors such as verbatim or direct quotations" (Ary et al., 2014, p. 533) used in describing the data helped establish credibility. Additionally, the processes of epoche and bracketing utilized in this study are both strategies of reflexivity, done to "use self-reflection to recognize one's own biases and actively seek them out" (Ary et al., 2014, p. 534). Reflexivity eliminates the invalidity producing researcher bias.

"Transferability is the degree to which the findings of a qualitative study can be applied or generalized to other contexts or to other groups" (Ary et al., 2014, p. 534). "Accurate, detailed, and complete descriptions of the context and participants" were included to "assist the reader in determining transferability" (Ary et al., 2014, p. 535). 
Hycner (1985) addressed the issue of transferability and generalizability within a phenomenological study saying "in the process of even investigating the experience of one unique individual we can learn much about the phenomenology of human being in general" and that "the results in a strict sense may not be generalizable, [but] they can be phenomenologically informative about human being in general" (p. 295). The thick, rich, detailed descriptions of the co-researcher's experiences enhanced transferability so the results "can then be related to and integrated with those of other phenomenologists studying the same experience or phenomenon" (Eichelberger, as cited in Patton, 2002, pp. 106-107). Additionally, I included a subjectivity statement for the readers to understand my own biases. This helped limit reactivity which limits transferability (Ary et al., 2014).

Dependability in a qualitative research study is concerned with trustworthiness, "the extent to which variation can be tracked or explained" (Ary et al., 2014, p. 536). An audit trail, triangulation of the data and a dependability check were used to enhance dependability. "One of the best ways to establish dependability is to use an audit trail" (Ary et al., 2014, p. 536). Detailed documentation was kept, including all field notes, raw data, observations, what was done, when, how and why, and all other information to "attest to the dependability of procedures employed" (Ary et al., 2014, p. 537). Triangulation of the data collection included the in-depth interviews, audio-recordings, field notes and follow-ups. Additionally, I followed Hycner's (1985) suggestion for a dependability check and had an external, outside, unbiased trained researcher check the invariant constituents and themes and verify the findings. Doing so "is a helpful check in further establishing the rigor of the study" (p. 286). 
Confirmability deals with neutrality, "the extent to which the research is free of bias in its procedures and its interpretation of results." (Ary et al., 2014, p. 537). As with dependability, "the audit trail is the main strategy for demonstrating confirmability" (Ary et al., 2014, p. 538). Additionally, the previously mentioned processes of epoche, bracketing, and reflexivity, along with the triangulation of data collection, and peer review all enhance confirmability.

Rigor was emphasized in all aspects of the study. The researcher worked as Eichelberger described a phenomenological researcher: "rigorous in their analysis of the experience, so that the basic elements of the experience that are common to members of a specific society, or all human beings, can be identified" (as cited in Patton, 2002, pp. 106107).

\section{Potential Limitations of the Study}

Hycner (1985) identified potential limitations relevant in phenomenological research. The following could have been limitations for this study.

1. Interviews were audibly recorded but not visually. Video recording would have allowed for further analysis of body language and nonverbal cues in the responses.

2. Co-researchers were asked to verbally describe their experience with the phenomenon and therefore restricted to their own vocabulary. Given the opportunity to incorporate additional means of expression the intended meanings of experiences may have been augmented.

3. Confabulation and psychological defensiveness could both have limited the interview data. As Hycner (1985) described "confabulation is meant that a 
participant fills in gaps in memory according to his/her later subjective viewpoint, or in a manner that s/he believes would please the interviewer" (p. 296). Psychological defensiveness could present itself if the participants felt uncomfortable about the previous experience(s) of the phenomenon and therefore chose to act defensively or alter their verbal description of the event.

4. Since I conducted the interviews and I am the main researcher for this study, the co-researchers could have adjusted their responses to what they thought I wanted to hear. Utilizing a trained interviewer could have eliminated this possible reaction.

5. Given the vast amount of data generated from just one interview, the number of co-researchers in this study was limited. A study done with a larger set of participants, with more diversity, or in a different demographic location, could result in a greater understanding of the phenomena or different results.

6. This study focused on participants willing to talk about their experiences of the phenomena. Potentially if data was included from interviewees not comfortable with sharing their experiences, whether because of embarrassment, fear of backlash on their business/job, or other reasons, the results could have been more comprehensive.

7. Replicability was a limitation due to the differences in another interviewer to myself, interviewees, environment, zeitgeist and phenomenon. "Given the fundamental nature of existential phenomenological research at this stage of development, it is understandable that there have been few studies undertaken to 
replicate the results of previous studies" (Hycner, 1985). Nonetheless, all procedures and processes have been included for potential replication.

\section{Use of Findings}

This study was designed to understand the experiences of the working public when a service dog is in their place of business. One benefit of developing deep understandings of the experiences from the public's perspective is so that as a society we can work to create legislation and cultural change that not only protects the rights of the disabled, but also those of the public. Additionally, insights into how the public feels and thinks about service dogs in public places can aid in the development of informed training programs for service dog organizations and service dog teams.

In the next chapters, I will present the findings of my study, resulting from a careful review and analysis of the transcripts, the individual textural and structural descriptions and the synthesis of essences and meanings inherent in the experience. 


\section{CHAPTER IV}

\section{Findings}

\section{Introduction}

This chapter presents the findings obtained through collected data on the individual experiences and the perceptions of a group of 11 co-researchers. I sought to better understand how those working in places of public accommodations defined, described, and understood, and perceived service dogs, particularly related to their roles and responsibilities as gatekeepers and members of the working public. Their interviews aided me as I approached the following research questions:

1. What are the experiences of the working public with service dogs and service dog teams in public places?

2. How does the working public perceive service dogs?

3. What are the working public's understandings of accessibility regulations as they relate to service dogs and public places?

4. What, if any, are the issues the working public identify in and around this topic?

5. Based on the data obtained, what are the important issues and areas that need further research?

\section{Description of Participants}

All of the co-researchers in this investigation worked for a public entity, in either Lexington, Kentucky or Louisville, KY, and reported having experienced service dogs coming into their public place of business. All of the co-researchers expressed interest and willingness to participant in this research study. The group of eleven co-researchers 
was comprised of two males, and nine females. Their ages ranged from 21 to over 60 . While it was not part of the inclusion criteria, none of the participants had a service dog at the time of the interview. One co-researcher had an emotional support dog that was formally a service dog. Another had a therapy dog in training. Of the 11, seven had pet dogs at the time of the interview, four did not. All of the co-researchers reported having a pet dog at one point in their life. Additionally, all of the co-researchers' responsibilities required them to act as gatekeepers in their establishments, however, only two were in positions to create policies on dogs being allowed on the premises (see Table 3). I will first present a short introduction of each co-researcher. Following the introductions, is a presentation of the data in the form of detailed textural, narrative descriptions of each individual interview. 
Table 3

Background of Co-Researchers

\begin{tabular}{|c|c|c|c|c|}
\hline $\begin{array}{l}\text { Co- } \\
\text { Researcher }\end{array}$ & Age & Occupation & $\begin{array}{l}\text { Pet Dog at Time } \\
\text { of Interview? }\end{array}$ & $\begin{array}{l}\text { Responsible } \\
\text { for Policy on } \\
\text { Dogs }\end{array}$ \\
\hline Adam & $30-39$ & Mental health counselor & $\begin{array}{l}\text { Yes - therapy } \\
\text { dog in training }\end{array}$ & No \\
\hline Becky & $50-59$ & $\begin{array}{l}\text { Retired from education } \\
\text { administration }\end{array}$ & Yes & No \\
\hline Cathy & $60+$ & Retired school teacher & Yes & No \\
\hline Donna & $30-39$ & $\begin{array}{l}\text { Assistant store manager } \\
\text { in retail }\end{array}$ & No & No \\
\hline Emily & $30-39$ & Clinical music therapist & No & No \\
\hline Faith & $40-49$ & $\begin{array}{l}\text { Sales associate in } \\
\text { grocery store }\end{array}$ & No & No \\
\hline Gloria & $40-49$ & Boutique owner/manager & Yes & Yes \\
\hline Haley & $30-39$ & Landlord & Yes & No \\
\hline Isabelle & $20-29$ & $\begin{array}{l}\text { Student, adoptions } \\
\text { specialist in animal } \\
\text { shelter }\end{array}$ & $\begin{array}{l}\text { Yes - emotional } \\
\text { support dog, } \\
\text { formerly service } \\
\text { dog }\end{array}$ & No \\
\hline Janet & $40-49$ & $\begin{array}{l}\text { Adoptions specialist in } \\
\text { animal shelter }\end{array}$ & Yes & No \\
\hline Kevin & $60+$ & $\begin{array}{l}\text { Restaurant } \\
\text { owner/manager }\end{array}$ & No & Yes \\
\hline
\end{tabular}

\section{Adam.}

Adam, a white / Caucasian male in his thirties, is married and has at least one child. Adam has a master's degree and works as a counselor in an office building. Previously Adam worked as a chef in a restaurant kitchen. He works $40+$ hours per 
week. Adam has experience with patients bringing service dogs into the counseling office and with patrons bringing them in the restaurant.

Adam does not have a service dog, but has friends or family that do. He does not have an emotional support dog, nor does he have friends or family with an emotional support dog. Adam does have a pet dog he is currently training to be a therapy dog. Adam also has friends or family with a therapy dog.

\section{Becky.}

Becky, a white / Caucasian female in her fifties, is married and has at least one child. Becky has an Associate's degree and is retired from her previous career in education administration. Becky currently works 1-39 hours per week for a floral delivery company, and as a volunteer with a local animal shelter. Becky had at least one pet dog at the time of the interview. Becky has neither a service dog, emotional support dog, nor therapy dog, and none of her friends or family do either. Becky has experienced service dogs coming into her workplace both when she was working in a school and while working a community food festival.

\section{Cathy.}

Cathy, an Asian American female in her sixties, is married and has at least one child. Cathy is a retired school teacher. Before retirement she also worked part-time "selling educator liability insurance" making "presentations on college campuses and conventions, in schools, and to school administrations." Cathy currently volunteers for many local organizations, including the library and animal shelter. Cathy had two pet dogs at the time of the interview. Cathy does not have a service dog but has friends or family that do. Cathy has neither an emotional support dog, nor a therapy dog, and her 
friends or family do not either. Cathy experienced service dogs in her workplace both as a teacher, and while working a community food festival. Cathy is the only co-researcher who arrived at the interview with a typed-out history of her experience with service dogs. She did so at her own will.

\section{Donna.}

Donna, a white / Caucasian female in her thirties, has never been married and has at least one child. Donna has extensive professional experience with a number of large retailers and for ten years, "traveled with a luxury makeup company." Donna also has previous experience volunteering in safe house for women who escaped sex trafficking or sexual exploitation. Currently Donna works 40+ hours per work as an Assistant Store Manager for a retail store located in a shopping mall. Donna has experience with service dogs in both the safe house and retail store. Donna did not have a pet dog at the time of the interview. Donna does not have a service dog, nor do any of her friends or family. She does not have an emotional support dog, but has friends or family that do. Neither she, nor her friends nor family have a therapy dog.

\section{Emily.}

Emily, a white / Caucasian female in her thirties, has never been married and does not have any children. Emily has a master's degree and works as a clinical music therapist in a hospital. She works $40+$ hours per week. Emily also has experience teaching in a university setting. Emily did not have a pet dog at the time of the interview. Emily does not have a service dog, emotional support dog, or therapy dog. Emily's friends or family do not have a service dog, emotional support dog, or therapy dog. 
Emily has experience with service dogs, emotional support dogs, and therapy dogs in the hospital and while teaching in the university.

\section{Faith.}

Faith, a white / Caucasian female in her forties, is divorced and has at least one child. Faith completed some college but does not have a degree. Faith works $40+$ hours per week, as a sales associate in a grocery store, where she proudly "can work anywhere in the store," with the exception of the meat and seafood department, because of her allergies to seafood. Faith has experienced a number of dogs coming into her workplace, including service dogs, emotional support dogs, therapy dogs, and companion dogs (pets). Faith did not have a pet dog at the time of the interview. Faith does not have a service dog but has friends or family that do. Faith does not have an emotional support dog but has friends or family that do. Neither Faith, nor her friends or family have a therapy dog.

\section{Gloria.}

Gloria, a white / Caucasian female in her forties, is married and has at least one child. Gloria has her master's degree and currently owns and manages a fashion boutique. Formerly, Gloria worked as a physical therapist. Gloria had one pet dog at the time of the interview. Gloria does not have a service dog but has friends or family that do. Gloria volunteers with a service dog organization that places service dogs with veterans and first responders. Neither Gloria, nor her friends or family have an emotional support dog. Gloria does not have a therapy dog, but her friends or family do. In addition to her volunteer work, Gloria has experience with service dogs, emotional support dogs, and companion dogs in her boutique 


\section{Haley.}

Haley, a white / Caucasian female in her thirties, is separated and does not have children. She has her bachelor's degree and has worked as a "landlord and managed lowincome housing" for ten years. Haley has experience with service dogs, emotional support dogs, and companion animals being brought into the apartments she manages. Haley had a pet dog at the time of the interview. Neither Haley, nor her friends of family have a service dog. Haley indicated she did not know if her dog was an emotional support dog because the dog does provide her support emotionally. Haley's friends or family do not have an emotional support dog. Neither Haley, nor her friends or family have a therapy dog.

Haley's housing facility is governed by the Fair Housing Act. Under which, both service animals and emotional support animals are afforded accessibility rights. Therefore, as a gatekeeper, Haley does not have to distinguish between the two types of assistance animals. Her experience, however, added value to this research study as she not only provided insight into her knowledge, but also the perceptions of her residents regarding different assistance animals.

\section{Isabelle.}

Isabelle, a white / Caucasian female in her twenties, has never been married and does not have children. Isabelle is currently pursuing her bachelor's degree and working in both retail, and for a nonprofit animal shelter. Isabelle has an emotional support dog, which was formerly trained to be her service dog. Isabelle does not have a therapy dog. Isabelle does not have friends or family with a service dog, an emotional support dog, or a therapy dog. Isabelle came to the interview with Janet. Isabelle and Janet work 
together and assist in adoptions at an animal shelter. Isabelle said employees of the shelter are looked to as, "beacons of knowledge about all things related to dogs." Isabelle and Janet provided insight into the knowledge of employees in an animal shelter, and also into the public's perceptions when adopting a service dog, emotional support dog, therapy dog, or companion animal.

\section{Janet.}

Janet, a female in her forties, lives with her domestic partner and their many pets. When asked, Janet did not indicate her race/ethnicity, nor did she discuss if she has children. Janet has completed some college, but does not have a degree. She works 40+ hours for a nonprofit animal shelter. Janet has worked for a nonprofit animal rescue/shelter for seven years. Janet had at least one dog at the time of the interview. Janet does not have a service dog, but has friends or family that do. Janet does not have an emotional support dog, but has friends or family that do. Neither Janet, nor her friends or family have a therapy dog. Janet brought Isabelle with her to the interview. Janet and Isabelle work together, and Janet felt Isabelle had more personal information to share on the topic than she did. Janet and Isabelle provided insight into the knowledge of employees in an animal shelter and also into the public's perceptions when adopting a service dog, emotional support dog, therapy dog, or companion animal. Janet said they are responsible for helping the public know the differences.

\section{Kevin.}

Kevin, an Italian-American male in his sixties, is married and has at least one child. Kevin has his bachelor's degree and, with his wife, owns and runs a restaurant. Kevin works $40+$ hours per week in the restaurant. Kevin did not have a pet dog at the 
time of the interview, however he described his daughter's dog as "part of the family." Neither Kevin, nor his friends, nor family have a service dog, an emotional support dog, or therapy dog. Kevin's restaurant allows pets on the outdoor patio, and he has experienced service dogs, emotional support dogs, and therapy dogs inside the restaurant. As a business owner, Kevin was very curious to learn about service dog accessibility laws.

\section{Results in the Form of Textural Descriptions}

\section{Adam.}

Adam was the first person I interviewed. I had not met Adam prior to our interview, however we had talked on the phone when I asked for his participation in my research study. During that phone call I confirmed he met the qualifications, and he shared with me that he was in the process of training his pet dog to become a therapy dog. I also knew that he worked as a counselor in Lexington, but I did not know more than that prior to our meeting.

My interview with Adam took place the evening of October 15, 2018, at a coffee shop convenient to Adam's office. In selecting the interview location, I suggested either the library or coffee shop nearest Adam's work, and he selected the coffee shop. I arrived early to set up and make sure we had a spot with two chairs, and as far away from the ambient noise as possible. I got a coffee and sent Adam a text message explaining where I was sitting in the coffee shop. When he arrived he also got a coffee. Once we were both sitting and comfortable, I started the interview by asking him to describe his overall experience with animals in his life. 
Adam shared that he grew up in eastern Kentucky, on an "80 acre place." $\mathrm{He}$ clarified that it was not a farm because they "did not have farm animals." They did, however, have a lot of pets, which included ducks, pigs, and "particularly cats and dogs." As Adam described the diversity in his level of comfort with animals, he shared that his "first word was duck," he occasionally road horses, and that he has an "affinity for pigs," saying, "they are smarter than people give them credit for." He summarized animals "have always been super important in my life."

When I asked about his experience with dogs in particular, Adam said, "my dog was literally my best friend in high school." He "had a lot of challenges growing up... was bullied a lot at school and came from kind of an abusive home environment." Adam received this particular dog, his "first serious, serious dog," after his mom left. As he described, giving him his dog, Pal, "was like the only nice thing she ever did to [him]." He "did not have a whole lot of support anywhere," but his dog became his closest companion.

Dog training came naturally to Adam and he "started training Pal", an "Australian shepherd," when Adam was a child. His "dad was not really happy about it," and "did not really want the dog," but Adam's response to his dad exemplified the dog's value to him. He remembered thinking, "do not get rid of my dog. I will do whatever to keep this dog." So, Adam "kept [his] end of the bargain" and without any proper training, he successfully trained Pal. Adam credited his success with Pal to the dog, saying, "I think we always idealized our pets from our childhood, but he [Pal] was really very intelligent... I have never seen a dog as smart as him...he was truly an exceptional dog.” 
The impact Pal had on Adam's life was evident as he paused, chuckled, and with a smile said, "I have not thought about this stuff in a while."

Adam continued to share his other experiences with dogs throughout his life. He recalled another dog "probably a border collie," who "showed up at the house" and "hung out with [him]" during a time in which he had "boomeranged back to [his] dad's house in [his] twenties." "After kind of unsuccessful business ventures and some struggles with alcoholism," that dog "was there for [him]" and then "after I [Adam] left, he [the dog] left too."

Recognizing Adam's usage of terminology commonly used in dog training, such as "verbal commands" and "positive reinforcement," I asked Adam if there were other dogs he trained besides Pal. His response brought our conversation to his current dog, Allie. He said, "the only other dog that I have trained that I could say I had success with, because I had enough time, would be my current dog, Allie." Allie is "also an Australian shepherd." He "decided to go back to the original breed that [he] grew up with."

At the time of our interview Allie was two years old, and a family pet for Adam, his wife, and their children. Additionally, Adam was "training her currently to be a therapy dog," which Adam shared is "a different kind of training, especially strange because she is such a high energy breed." Adam said that because of an Australian shepherd's energy level, they are not the popular choice for therapy dogs, rather it is usually "a golden retriever or a poodle, a standard poodle." He explained, "They can be any breed, but it's more typical of mild mannered dogs." Nonetheless, he purposefully sought out an Australian shepherd because he, "want[ed] a dog that is going to be able to keep up with [him] physically." 
Allie's therapy dog training "involves a lot of discomfort for her and by discomfort $[$ he] mean[s] she is going to sit still... which actually makes her very tired because as excited as she is, it does take work and effort on her part to sit still in a singular location when [he] tells her to." He described Allie as "kind of a tough case" and "one of the hardest headed dogs [he had] ever seen in [his] entire life....smart but stubborn," but "once [he] got her trained, [he can] take her around town without a leash." He clarified, "not like around where there's leash laws, but out where there aren't any."

Just as Adam described Pal, he also described Allie "to be of exceptional quality" and "[he] think[s] she can handle" the therapy dog training. He laughed and proudly shared with me how he impressed his co-workers who had "seen [his] dog in the beginning" and then witnessed the transformation of "seven or eight months later she was listening." Adam shared that he worked with a trainer to get Allie her "Doggie Good Citizen" which "means that the basic behavioral functions of the dog are met... they are able to follow basic commands without a whole lot of coaxing. They listen. They listen well, and... are not prone to jumping up, making a mess...."

After Adam said he took Allie "into [his] counseling office... a couple of times... and there was somebody's service dog in there," I asked Adam if he was aware of the differences between service dogs, emotional support dogs and therapy dogs. Adam enthusiastically interrupted my question with his reply, "Very much so!” I asked Adam to share with me his information on those dogs. He replied, "So the idea is that service dogs perform a function related to somebody's disability and disability in particular, and it can be a wide range of things." He then provided me with examples of people he personally knew who had service dogs. 
I had a next door neighbor who was hard of hearing, actually he was deaf, he could hear...just barely a little bit, but he had the dog in case something happened or he needed to be aware of something, or if there was a noise, because he couldn't hear anything, the dog would pull him and wake him up and serve that function.

He continued, My mom actually was blind also, my whole life, so I knew that she had a service dog a long time ago when she went to [a school for the blind]....So she had a service dog for blindness that would just kind of guide while she was moving and it would sit down when she would stop moving, and it wouldn't let her go into a direction that was bad for her to go in.

With a hopeful sound in his voice he added, "pretty interesting stuff... a lot of different functions for that. I know there are a lot of different applications but those are the two most common that I know of."

Adam then provided his opinion on and understanding of emotional support dogs. Emotional support animals, they really, in my opinion, they are as valuable as service animals because if you take a look at what a disability is, you know, behavioral health or mental disability is just as debilitating to a lot of people. He continued to share his knowledge of accessibility rights. "Emotional support animals don't have the same leeway to go a lot of places that a service dog can.” He clarified, "you can't be refused service at a restaurant for having a service dog, but an emotional support animal you can because it's not a protected class in a lot of areas." He continued, 
"now there are cities that I understand are changing their modality of that, but for the most part, not so much."

He then went back to expand on service dogs. "Now I think that actually you can have a service dog though for a mental health disability." He provided an example of an organization he knows where "veterans that have posttraumatic stress disorder...actually get service dogs for that and it's a distinction above the emotional support animal." $\mathrm{He}$ continued,

I know those dogs are trained to apply therapeutic pressure. I think is the majority of what their function is...I don't know exactly how you get it too meet that level of need but I know that there is, for some folks, a way to do that.

He continued on to describe therapy dogs.

Therapy dogs, which is what I hope Allie to be, is rather than having a primary function for one specific mental health disorder, for one specific purpose [or] use for somebody's disability, her job is basically to be there to help people relieve stress by therapeutic touch of the animal and to basically help alleviate people's anxiety.

Adam made the distinction between therapy dogs and service dogs or emotional support dogs, "it's kind of like meet the person, and then disengage from the person and move to the next person instead of, hey stick with this person for the next several years."

As far as therapy dog use "they are utilized in a lot of different settings... I know they use them in nursing homes and hospitals," Adam said. He shared that he had personal experience seeing a "therapy dog come around" a medical facility while his father was doing "physical rehab after a stroke." Adam's specific therapy dog goal for 
Allie "is to have her hang out in the counseling office with [him] and help [him] treat clients." Looking to the future, he said, "one day I hope to use her in instances of children that have autism and stuff like that because there's been a lot of research in that direction that says that type of therapeutic touch can be very valuable."

Regarding a therapy dog's behavior, Adam said, "you want a very well trained dog in case something unexpected happens and the dog will be able to listen... you don't want a big fluffy dog that's jumping around on everybody because that's not the deal." When I said Adam made a "very clear distinction between the emotional support and therapy dogs," he happily agreed and replied, "they are both mental health companions but there is a big difference between what they are trained to do."

Since Adam had previously stated, "you can't be refused service at a restaurant for having a service dog," I asked Adam to expand on his knowledge of accessibility rights for emotional support and therapy dogs. He said, "well, to be honest with you, you could probably get away with it in a lot of places because people are so uneducated about it." He added, "But it's actually illegal for you to pass your therapy or emotional support animal off as a, uh..." paused to think, showing care in his word choice, then said “service animal." He continued, "but yeah, there are a lot of places you can't go." At this point Adam shared what he identified as a potential issue. "You can't go into a restaurant...which is kind of rough when the dog has been at work all day at the office and you can't go grab a quick bite and take your dog in." I confirmed that he was talking about a situation such as having Allie with him at work. He said, "Absolutely. Which is kind of a problem if you think about it, because you can't leave them in the car, but you can't take them in, so what are you supposed to do? Drive through only." He provided 
evidence to further support his opinion, "she is trained to not be a behavioral disturbance, as a service animal would be [trained]. She's got her Doggy Good Citizen. I mean it doesn't make a whole lot of sense to me in some ways." Adam explained why he thinks those particular accessibility rules are in place.

I think the reasons some of those things are in place are so it won't be abused, but you know, people that have emotional support and therapy animals are probably not going to be abusing it because you have to, you know. I could see the therapy dog though being the most abused because it's not like a prescription you get from a physician.

At this point I asked Adam to expand on his last statement regarding the physician's role in obtaining an emotional support animal. I asked him "so in your experience, have the physicians given approval for the emotional support ones over therapy since it's for a person?" He replied, "Yeah," and explained "since it's for a person, I know you need a diagnosis that meets the criteria to have an emotional support or a service animal...granted, and I think you have the option, it depends on money." Adam then addressed the financial aspects of obtaining one of those dogs.

I don't know about the insurance thing. I haven't really crossed that so I'm not sure, but I do know that one option is to have a dog that you already have and have it trained to be... to fulfill those functions.

He continued, "but for a lot of people I think they're prescribed a dog and they are taken from some of these project groups that train emotional support and service animals." I confirmed that one of the groups he was talking about was the one for the veterans with posttraumatic stress disorder that he had mentioned previously. He said, "Yeah" and his 
voice got excited as he provided another example. "Well actually there's one program too that I heard about where the prison inmates were actually helping to train emotional support animals that were later being given to people with mental health disabilities... it was a pretty neat story."

I asked Adam how he learned of these groups. "Mostly in the news" he said. He added, "which is kind of surprising...but yeah, I heard it on a local news station I feel like a couple of times of the same thing." Adam added that he thought he also saw articles in a national newspaper or an online national newspaper, "but as far as academic journals [he had not] come across anything, but [he had not] looked either." He observed, "so there's plenty of research out there." He shared that he had has "paid particularly good attention" to a medical magazine that "has a lot of exposés on therapy and emotional support animals," one that "is a pretty good resource for stuff like that."

I asked Adam to explain how he determines the difference between a service dog, an emotional support dog and therapy dog when he sees a dog entering a facility. He responded,

Well, you kind of have to go on what the person says, you know. You're not allowed to ask about somebody's disability...the only think that you can do, that I'm aware of, is ask what the dog is trained to do... and in hearing that pretty much determine. But if they say it's a service dog, you have to kind of go with that.

Adam paused, and then laughed and said, “so, I mean, I don't know." Even though I knew this from our pre-interview conversation when I confirmed Adam had experience with the phenomena, I asked Adam if anyone with a service dog 
had been in his office while he was working. He replied, "Oh yeah! Yes, many times." Regarding how Adam recognized the dog as a service dog, he said,

I usually don't question it in my life of work...a lot of times they are wearing the vest, that says 'service dog' on it, or they've got like a device on, that special collar or something like that. I've learned to sort of just not question it. You can look at the dog and tell its mannerisms and see that is a very well behaved dog. Adam shared that "when [he] was a chef... a long time ago," there was "only one time" when a dog "was allowed into the restaurant that [he] was like there is absolutely no way that's a service dog because it's not well trained enough." He said the dog "was getting up and trying to get people's food, and it was making a disturbance." These behaviors made him think, "no way, there's just no way, [he] didn't believe it. [He was] sorry to say, [he] didn't believe it." In that particular situation, Adam said, "they asked [the person with the $\operatorname{dog}$ ] to leave... because the dog was a disruption...it defecated on the floor." He said, "You can't have that...there are limits to what is acceptable behavior, obviously for a dog like that, they can't be ill behaved. Like no bite-y dogs...like you can't do that." I asked Adam to provide more behavioral examples to recognize a service dog. He replied, I mean, traditionally they've been very mild mannered. Usually they don't want to be pet if they are on the job, you can tell that. Like if you get too close they just give you this apprehensive look like, hey man, I'm at work. And they are taking a lot of cues from their owner, a lot more cues than a regular dog would who is just scoping things out, looking back and forth. They are very focused on what their function is. 
I asked if Adam felt he can tell when a service dog is working and he replied, "I like to think I can.”

I asked Adam to expand on the things he had seen the dogs wearing, like the vest and collar he had mentioned. "I don't think there's a uniform thing," he replied. "Sometimes you can tell who they were trained by, by what kind of vest they are wearing, like where they got their training, because it's kind of standardized when they have some sort of relationship with [a particular organization]." He provided the example of "a typical orange vest that [he had] seen numerous times that says 'service dog,", then added,

But you can order a thing that says 'service dog' off of [an online animal product retailer]. You could just order it and put it on your dog and say that it's a service dog and people still can't really be questioning you. But the behavior of your dog is going to tell the story, and it's really a very unethical thing in my opinion. I asked Adam to share more about why he saw that as unethical. "Well," he started; he sighed and started again, "obviously I've got counselor ethics, so I'm bound by like this pretty strict code of conduct and behavior, but more so than that, I mean you take somebody that's got" he stopped himself, then started again.

For me it goes back to my mom. We may have had our differences, but she did struggle with being blind...so to imagine, you know the service dog to me is just the same as the white cane. Like why would you go out and pretend...to have a dysfunction or an issue treatable by the $\operatorname{dog} . .$. and pretend that you need that? 
He added,

And then to have your dog give bad behavior, it makes all service dogs look bad, because you're labeling that dog that way and then people are going to be skeptical when somebody comes in that really needs their dog with them. Regarding news articles sharing his point of view, Adam said he tries to avoid reading them.

I get angry when I see headlines like that, so I don't go into depth reading that stuff. I pretty much see the headline and go, why would you pass a dog off as a seeing eye dog? Like what is wrong with you? It frustrates me to no end that somebody would do that.

I asked Adam if he thought misrepresentation of service dogs in the news was a true representation or a case of "bad news sells." He replied, pensively "I wonder." Then he described a "feel good story" of "an Army veteran who was prescribed a service dog," but was denied access to a home improvement retailer, then, in response, a direct competitor "hired him and the dog." He described the story as, "incredible" adding "I think that you will find what you're looking for and I think the more we look for positive stories about how these animals can affect people's lives, the more that's going to be focused on." He brought it back around to the issue of misrepresentation "You can set something up to be this untouchable thing, doesn't mean people won't mess with it, but boy! How rough do you look if you're caught doing something like that when everybody has a respect for these animals."

Acknowledging Adam's knowledge, I inquired about how he received his information, and if he had any training. He replied, "I wouldn't say so, no. You have to 
kind of hunt for the stuff yourself." He mentioned a national purebred dog registry as "a really good resource," and said he "got a lot of information" from a nonprofit therapy dog organization and a companion animal organization. He said they "were a good source for a lot of that literature and then of course the dog trainer [he] worked with for the first couple of weeks [with Allie]...gave [him] a bunch of resources." Adam then thought back to his professional educational training and with a little bit of surprise in his voice, he shared,

You know honestly we didn’t even talk about it in my degree program, not the whole time. It never came up one time in either degree program - sociology for my bachelor's, clinical mental health counseling for my master's. So in seven years I never heard a word about it.

The next topic I asked Adam to talk about was if he perceived an increased presence of canines in our society. Adam replied, "I would think so, in a way, but if you think about it, we have been breeding dogs and trying to get dogs to fulfill certain purposes for us for generations and generations...for probably thousands and thousands of years." He continued, "As far as them being a certified part of society, like monitored in some way, I think that's probably pretty new, or at least that being taken seriously is pretty new." He added, "But I think man's best friend is a pretty accurate description. It's been that way for a long time."

At the time of our interview, Adam said no one "that [he is] close with" had a service dog. I asked him to think about some hypothetical situations regarding service dogs. In the first hypothetical situation, I asked if he had "Allie and there was a dog dressed as a service dog" but that dog was not "showing the behaviors that [he] believe[s] 
are in line with a service dog," what would he do? Adam replied, "I would remove my dog first, because I do not want to take the chance that the dog is going to aggress or do something strange because my dog is not made to handle that." Adam shared a bit more with me about Allie's training and how in a potentially stressful situation, such as another dog "breaking leash," that "most of the time [he] get[s] her to sit, lay down, [and] even if the dog is clawing at her face she'll still remain laying there," but he "would probably remove her as quickly as possible." He said, "I don't want it to be traumatic for her because that hurts her ability to do her job." In that hypothetical situation, Adam said he "would like to think [he] would do more but the reality is [he] probably wouldn't." $\mathrm{He}$ attributed the risk of verbally confronting someone with the potential result being a video posted to a popular video streaming website, showing the interaction and putting the blame on him, even if the other "dog was not trained very well." I asked Adam about his familiarity with other potential risks in verbal interactions such as that, particularly for businesses. In a raised voice, without pause, he exclaimed, "Oh yeah! You can get sued!"

Based on our conversation up until this point, I then asked Adam for suggestions on "how can we make this situation better... what can be done to help the community embrace service dogs, emotional support dogs, and therapy dogs, at the right times and in the right situations?" He confidently replied, "I've got a great response!" He continued, I mean we've got certification processes for the dogs already through the [national purebred registry he formerly referenced], and a couple of other organizations that are nationally accredited. I think they should dole out some kind of icon or patch, or some sort of a uniform vest, and those that know this dog was trained for this 
purpose, we are not going to buy it on [internet website] or make one ourselves.

It needs to be some sort of verifiable marking they could wear to let you know.

I asked if Adam had a "preference on whether it was something on the dogs or the handler carries." He said, "I don’t think it should be something the handler carries because that is too big of a time, too personal to get into that in-depth of a conversation." He said needing to have a conversation "would be more stigmatizing." He continued, "of course some people might argue it might be more stigmatizing to have a dog walking around with that particular thing on." He added, "but...at the end of the day, we have to find a consensus that is going to work for everybody and also protect the people that need the dog in the first place." He added, "I think for their protection issuing out some kind of... article...some kind of patch that would go on the vest, or some kind of [national purebred registry he formerly referenced] certified or accredited or whatever.” Regarding misrepresentation and duplication, he said, "You'd still have people bootlegging but I think that would make it more difficult."

I asked Adam if he thought there needs to be some type of regulation to remove the ones available online. He replied, "Yeah, I don't think you should just be able to put a service dog vest on your dog and buy that for fifteen bucks." I asked if he thought it was "reasonable for that to be a government mandated movement." He said, "Yep. Yeah I do." He continued, "Here's the deal," he paused thoughtfully. "I mean this in the nicest possible way, but you've got the Stolen Valor Act, for soldiers. You've got people that dress up...like soldiers to get financial reward or to bum money or to benefit in some way." To stop that behavior he explained, "they passed the Stolen Valor Act." He clarified he was not putting "service dogs necessarily on the same line as troops, but 
honestly the military does utilize dogs, and how would you feel if you've got a combat dog...that is losing what it is supposed to be." He provided a personal comparison. If I were to dress up in a lab coat... and to pretend, not necessarily say I'm a doctor but give the illusion that I'm a doctor, that's a very, very terrible thing to do, and it's also illegal to give people that impression. So why would we not have the same thing for dogs that are medically mandated for folks?

Going back to his suggestion of the patch, he said, "I think that would be enough, but I like the idea too... of removing those other things and regulating them out on the market." To make a pet a service dog he repeated, "You shouldn't be able to just put a vest on your dog, it shouldn't be that easy." At this point I asked Adam about his understanding of the various state-to-state laws. As I was asking the question he started to smile in recognition. He shared his thoughts with me. "You know it's the same as me being an alcohol and drug counselor, but I can't go state-to-state and practice." Making the comparison he said, "I have to get independently licensed through each state, and I feel like the therapy dog, emotional support dog, like there's a lot of that. Is this disorder recognized for an emotional support dog in this state?" As he explained the differences state to state he said, "You've got cities that will allow an emotional support into say a [coffee shop], or something like that, and then you've got the city right next door that's like...you're not even allowed to have a dog." He laughed and added, "So I mean there needs to be some sort of uniform consensus."

Adam then shared his knowledge of and opinion on federal guidelines. "We do have federal guidelines. It's just that the states often want to be more restrictive than the federal guidelines." He offered the suggestion, "if you do a federal mandate, and maybe I 
sound like a big government guy, but if you do a federal mandate, it should be enough to satisfy the states' recommendations.... g guess not leave it open-ended for any weirdness." I said I had heard researchers call the ADA "very open-ended" in my review of literature. He said,

Well sure, it's like everyone thinks they are an attorney. Go on [social media platform] there are people arguing right now about probably this, and everything else, and you know, the Americans with Disabilities Act, it comes down to interpretation, and people interpret what they want to interpret from most everything they see, with their own skewed bias, and if you get a good enough attorney they can argue it for you. So we need to make it pretty cut and dry, like I said, remove any potential for abuse.

For suggested punishment he said, "you put a vest on your dog," he clapped his hands, "you pay a fine." He clarified, you "shouldn't be thrown into prison... but you should be punished for that, to pretend like you need these concessions to be made for you."

I asked if Adam felt the laws "should be the same for therapy and emotional support dogs as it is for service dogs." He replied, “No, I don't," and added, "as much as I love therapy dogs, and as much as I love my dog, I do not think she deserves to be able to go in everywhere I would take a service dog." He added the "difference would be is if it is for work." By work he said, "if I'm taking her to a conference or something like that." In that case, "I get why they don't let her into a restaurant, because she's not supposed to be there...I get that." He added, "but the protections and stuff, like if you injure my dog, if you do something aggressive to my dog, I think you should be punished for that." He said, 
If you do damage to a service dog that's a pretty serious crime in a lot of areas, and I think it should be the same, because she's got a right to go to work and do what she does the same way as anybody else.

Adam then said that since Ally is "not even a full therapy dog yet," that "trying[ing] to take the exam," meaning therapy dog exam, "would be very belligerent of [him]." He said that he did not "even want to misrepresent right now" by taking her out as a therapy dog. "She needs to get a little big older...we're working on it...it's a long process." Adam continued to explain his opinion on service dogs and emotional support dogs. "I think emotional support and service dogs are the same thing though, and people just haven't realized the importance of mental health yet." He explained, "I see how hard it is for people to struggle and have every bit of a degree of emotional pain that somebody has physical pain." He said, "from what we know about the brain, pain is pain. The same areas light up whether it's emotional or physical so that kind of adds credit to those being very valid disorders that need treatment." He finished, "if a dog helps you with that, then we should let you have the dog wherever you're at."

To clarify, I asked Adam if I correctly understood that he believes service dogs and emotional support dogs should be grouped together. He replied, "Yes," and added, “it's just different. For me it's all about utility." When considering taking his therapy dog somewhere he said, "For me it's like... what reason did I have for my dog to be right there with me." He resolved, "It would be nice if I could take her into a restaurant. It would be super cool, but like does she have reason to be in there? No, not really." He then countered "but like into a nursing home or a hospital...yeah, I should be able to do that without anybody giving me the runaround for it." 
I asked Adam if he thought a patch for therapy dogs would be as ideal as for service and emotional support dogs. He said, "Yeah," and added, "I think the [national purebred registry]...they've got different lengths of time for therapy dogs, like the more hours they have, the more seniority they get." He added he thinks, "they send a little certificate," but that "it would be nice if they sent...like a stripe... a patch or some sort of badge... anything that she could wear that would denote, 'hey this is how long she's got in doing this." Regarding Allie, he said he "hopefully I can get her certified and we can start working on that [getting a uniform].”

Adam and I discussed the challenges that people with "mutts," or non-purebred dogs, face in the certification process, and then moved on to the community aspect of our interview. I asked Adam his suggestions on training the community if "some sort of standardization," like "a patch," was created. Adam responded, "I think you would want the most glowing examples" of service dogs and emotional support dogs "with the most seniority." Then with those dogs and "a little bit of material, like handouts or something, ... do a door-to-door campaign.... a good faith visit.” He suggested going to "business owners and stuff like that" to "give them some education. The benefit, Adam said, "would help you find out two things really quick." The first would be "how effective the policy is going to be" and the second, it would "let you know where the people are that are going to give you the most trouble." Adam said that in figuring those two things out "maybe there could be something done when that discovery came to light....like, what do we do about that." Originally when Adam shared these ideas with me, he used the words "therapy dogs." When I asked for clarification, he said he meant 
service dogs and emotional support dogs but he was "probably saying therapy dogs because it's on [his] brain."

He continued to explain a different idea for therapy dogs because he does "see them as very separate." For them, he suggested "have a seminar, because most counseling agencies need continuing education credits offered for any mental health clinician" and teach them "about what this stuff is." He added, "especially therapy dogs." What their "value" is, "what are their uses," and "is this something you could do." He said, “because I don't know a whole lot of therapists that utilize them either, strangely." He shared that he "did have one professor that...had a therapy dog" but "we just never discussed it." He found out his professor had "one, maybe two" therapy dogs "because [he] was talking about" training Allie.

Adam went on to share with me why he started training Allie as a puppy. He said, "it's like learning a new language or anything; the younger we start, the better we are going to be." I acknowledged the challenges that come with training a puppy and he responded, "it's harder on me" than it is on Allie. Adam proudly talked about the improvements Allie has made in her training and how "surreal" some of those training moments have felt. He said, "When we get done I'll show you a picture of her" and smiled.

Our interview was wrapping up, but I took a moment to look over my interview schedule. I decided to inquire about a few more questions. I asked Adam what "feelings or thoughts" he has had when he has been at work and "someone comes in with a dog" that he believed "is a working dog of some kind." I clarified not a therapy dog. He replied, “depends on where I am.” He explained, 
If they come in the counseling office it's easier for me to talk about that because I know they are going to be a client. There's going to be a story behind why the dog is there. I get to know.

If the dog is "out and about in public," however, "it's none of my business at all." $\mathrm{He}$ said, "You go, dog. I want to know as little as possible and I want to take it at face value."

Regarding the emotional response, he said, "it always warms my heart to see an animal giving a contribution out of the love that animals have for us." He added, "not to sound like a hippie or something, but that's how I feel about it." I asked if that response relates back to his childhood, to which he replied, "Heck yeah, man. Absolutely." He started to say "the exposure when you're young..." stopped himself and started again. I was raised around animals. Even though I haven't had the most solid life, or the easiest life, and I'm not the greatest person there ever was...but always I've had a soft spot for animals. Always....animals always...they just put me on a different wavelength.

I asked Adam if he had any "verbal interactions" with people regarding dogs in public places. He recalled working at the restaurant he talked about earlier. The restaurant was in "a heavy shopping area" and his boss had made the comment, "I wish people would quit bringing their dogs in." Talking about a different dog than the previous story, Adam said he "defended the dog" and told his boss "listen dude, chill, it's not a bit deal. That dog is fine. ...I don't know if it's a legitimate dog or not, but that dog is well behaved, what's the problem?" He added, "When we have a problem dog we'll 
know." He said, "a couple months later we had the problem dog" and he made the comment, "Well we know now. See the difference?"

I asked if Adam had any training about service dogs in the restaurant. He answered, "No, I've never known there to be any, even in the counseling office I've worked in there's no training about it. It's just something you learn if you want to.” Considering the responsibility of knowing about the federal law, Adam said, "You're responsible for learning about something that you may not even care about." I mentioned some people might not know it even exists and he responded "god forbid somebody doesn't know it exists." Based on that comment, I asked Adam if he had noticed stores and other locations posting signs of their pet policy. He said he had "seen [the signs] a few places," and shared with me about a new local restaurant he heard about that is completely dog friendly. I asked if he had taken Allie there; he had not and explained, "I think people that don't have an education about it expect dogs to just stay with other dogs," as in get along with other dogs, "but," he added, "it's actually not a good idea if you've got a dog you're trying to train out a lot of those instinctive behaviors and things like that." Adam explained "They will pick up a lot of bad behaviors if you take them to the dog park, because they are around all of these other dogs that don't have that specialized training." Adam said he "had a couple of events that happened in the dog park that really turned [him] off to the whole thing." He also said that he will not take Allie out "until [he] feel[s] very confident that no matter what happens she will be able to handler herself in a very cordial manner." Going back to the discussion of dog-friendly events he said Allie is "pretty good, but...you just don't know what other people are training their dogs for, or if they are even training their dogs." 
I reviewed my interview questions one more time and upon confirming I had asked all of the questions, I thanked Adam and asked if he had any questions for me. He did not but requested to see a copy of the finalized research once it was done. I confirmed his email address and ended the interview. Immediately after, I made my postinterview notes and turned off the audio recorders.

\section{Becky.}

Becky was the second person I interviewed. Becky and I had previously volunteered together at the local animal shelter, so we did know each other a little bit prior to our interview. I set up Becky's interview day and time through a phone call and text messages. During our initial conversation, I confirmed Becky met the qualifications, and that she was willing to participate in the study. I did not know about her experiences prior to our meeting.

My interview with Becky took place the morning of October 16, 2018, in a private meeting room at a local library. In selecting the interview location, I suggested either the library or a coffee shop convenient for Becky. Becky and Cathy know each other and requested to be interviewed on the same day, so they could have lunch together afterwards. Their interview times were separate but followed one another. Cathy volunteers with the library and made a suggestion on the location. Therefore, the location was selected based on Cathy's suggestion, and convenience for both. I reserved a private room and arrived early to and make sure we had access to the room and to set up. Once set up, I sent Becky a text message explaining where the meeting room was located in the library. After she arrived and we were both sitting and comfortable, I started the interview by asking her to describe her overall experience with animals in her life. 
Becky started and explained most of her experiences with animals were not until she became "an adult". She explained, "as a child [they] had a dog, but it wasn't a dog that lasted very long....We would have them, and then they would go. Short stints" she said. The reason she gave was her "dad." He "didn't have much patience. If they barked too much he would "take it back." She pondered, "maybe it [made] me want one even more, because they didn't last long ... maybe it was that. I thought it was cruel to not give them a chance. I'm always for the underdog I've noticed." She said she "wanted to be a vet until [she] found out" some of the required medical procedures, but she "always loved animals and wanted them to be part of [her] life.” Therefore, when Becky became an "adult" and she could "choose her own," she said she has had "dogs that [she] has just loved; cats that [she] loved." She also "love[s] reptiles, and ended up marrying someone that loves them even more." "So we have a lot of animals in our home" she said.

Becky shared that while she was working she "never had enough time to do much more" with animals other than her own "pets." However, when she and her family moved to Kentucky, she was retired, and learned about the volunteer opportunities with the local animal shelter. She enthusiastically remembered thinking, "this is what I want to do!" Becky said the volunteer opportunity has helped her "find things around town that [she] wouldn't have known about normally." One of her contributions at the time of our interview was "foster[ing] kitties." She said, "I wish I could do more, but I know when my plate is full."

Through the volunteer opportunities, and "attending the different events," Becky said, 'I've been exposed more to people with service dogs, and that's how I can help 
you." I asked Becky if she had any experience or knowledge of service dogs before volunteering. Becky explained her personal connections with a guide dog trainer.

Becky's hometown friend, is a "puppy raiser" for a guide dog organization. Becky has "known her... [for] 10 years," and throughout that time, "she has had a puppy that she's been raising." Becky explained her friend keeps the puppies only while training them and then they are placed with someone who needs them, at which point she gets a new puppy to train. Becky said she thinks the dogs trained through that particular organization "are more for visual service." She added, "it's been interesting...go[ing] out somewhere with her...I would want to cross the street and she'd say 'no, you must go this way and cross the sidewalk,' and there's certain things you have to do. So I learned." Becky stated, "I have a lot of respect for people who do that... who can incorporate this into their life."

Becky continued explaining what she learned through her friend. "You can't just go to the store. You have to think about bringing your dog." She said the experience "really made me imagine what it would be like to really have to depend on a service dog." Becky said, "I mean now they have emotional support animals, and I'm sure that's really something for people who need it. I can't imagine."

Becky shared a story she had heard "on the news the other day," of a "lady...who has an emotional support squirrel and they wouldn't let the squirrel in the airplane, because the squirrel is a rodent." Becky said the airline "just [allowed] dogs, animals, pigs, but not rodents." She chuckled, then thoughtfully said, "I mean it's funny. You don't think of that. I mean, where do you stop? I don't know." She added, "I know I 
love my dog. My dog is my emotional support. I love her.” Becky smiled and happily laughed.

I asked Becky to share with me her understanding of the differences between service dogs, emotional support dogs, and therapy dogs. Becky replied, "umm I probably don't know the difference properly." She continued, "It's been explained to me before that emotional support, I guess there's different guidelines for what you can do with them, where you can go with them, when you can pet them or not." I asked what had been explained to her with each one, clarifying that I wanted to understand what information had "been passed on." Becky said, "Like an emotional support, now it seems like you can bring them in any store, you know as long as there's concrete and there's no food served." She shared that in a large national chain retailer she had seen "manager discussions...if the dog was in a cart or not." She said, "I can understand that. You've got to think of sanitary, where other people are putting stuff." She added, "but an emotional support, it doesn't seem to have any guidelines that I'm aware of."

Becky said she had "worked events before where you can bring in your support animal, and that's the fine line. What is the difference in how you prove that if there's not actually something to look at?" She said, "I don't know what the guidelines are for that."

Continuing with her explanation, Becky said, “Therapy dogs, I know you're not supposed to pet them if they're wearing a jacket...they have 'more rules' so to say." I asked about service dogs. Becky replied, "Oh gosh, what's the difference between a service dog? I think it's pretty much the same thing as a therapy dog, as far as wearing a jacket and not petting them and letting them go from their raiser first." 
Noting Becky's confusion, I referenced back to her experience seeing the manager discussions and asked her to expand on that story. From what Becky saw "the dog was on the ground and [the manager] said the dog had to be up off the ground." She said the manager and customer "were having a discussion about what kind of dog it was and whether it was allowed to be in the store." She said with a laugh, "that's all I know, I walked away."

I asked Becky if she had heard any other similar conversations elsewhere. She said her friend who trains "the guide dogs, is constantly having discussions of whether she is allowed to come in or not with her dog." She recalled a recent story her friend had shared that she experienced while out with a guide dog in-training. "It was [at] a home show. They did let her in, but [her friend] felt like they were giving her the stink eye the whole time."

I asked Becky if she had any similar personal experiences, and she began telling me about her experience as a gatekeeper at a community food and music festival. For the event, Becky was part of a group of volunteers offering "doggy daycare" for the festival goers. She said the "event...it's in a big field, and from what I understand, there are other events held there that any dog is welcome." She explained,

And at this event, I don't know if they were trying to keep down the poop, as well as what dog can come in....but if your dog wasn't a therapy dog, or a guide dog rather, then you could leave them in doggy daycare with us.

Becky said, "I saw people slipping dogs into their purses, and then they would challenge us on whether it was a service dog or a therapy dog." The volunteers "couldn't be in that position of proving if their dog could sit and stay or different things like that, so 
the dogs were pretty much let in.... people want their dogs with them and we couldn't challenge them" she said. Becky added, "there needs to be a set of guidelines, or some kind of certification...like a license of some sort, so people can show if they can be let in or not." Becky explained, "because it puts the volunteers like us, it put us in a bad situation, because I'm not going to tell somebody no your dog's not allowed here. People get angry."

I asked Becky what the volunteers had been told as far as what dogs were allowed in the event. She paused, then said, "I want to say a therapy dog or a guide dog. Not a therapy, a guide dog, because therapy comes almost, I'm thinking that's more like a support dog, a therapy dog.” Becky said,

They were talking about guide dogs that had to be let in, like at a store, what is the word they use, umm, not a seeing eye dog, but they have some other phrase they use now.... A PC [politically correct] word they use.

I asked if they called them service dogs. She said, "No."

Becky explained more about the dog daycare process from the event she worked. She said when an attendee came up, we would ask them... basically ask if your dog is a guide dog, and it might have been, and that was pretty much it....there was a form they would sign, and they would sign off if they brought the dog into the festival, and if not they could leave it.

Becky said they "would've loved to take donations" but the dog daycare was free for attendees.

Becky said she learned when determining if a dog should go into the festival, 
apparently there's little things that are obvious, like a guide dog would sit, it wouldn't go nosing under, we had a table set up with a table cloth and display, and a guide dog would know better than to sniff under the table. I didn't realize that actually. There's little things like that that you can tell, and otherwise, apparently it's more of an emotional support type animal, which is wonderful but it's not what they wanted in the festival.

Becky said, "if [the attendees] challenged us with that, we just said sign the form and have a good day." Becky shared that a volunteer coordinator was with them the whole time and approved the decision. She explained the coordinator, plus other volunteers "know a lot about that stuff."

I asked Becky "Were there any cases where someone came in and said this is just my pet, and then changed their mind when they knew they couldn't take their pet through?" She enthusiastically answered "Yes!" Laughed then said, "That's a good question. Yeah, there was people that when they realized the situation they said 'well I'm signing that, that what my dog is."'

When I asked if the dogs at the festival were wearing anything, Becky answered "You know, I don't know if I saw any jackets that day now that you say that." She sounded surprised. As far as the dog breeds at the event, she said they "were across the board." They "had from Labs to shiatzus" she said, and approximately $25-30$ dogs "throughout the day."

Becky "did that festival last year" but did "not remember having those kind of problems last year." She said in the previous year "there were people that were surprised" they could not take their pet in," but "if they didn't want to put the dog in the 
kennel, they left." However, at the most recent festival they "didn't see that as much....It was more of an issue." Becky did not remember the paperwork being part of the process in the previous year, and thought "there [were] more dogs this year." She added, "I feel like somehow word got out that you could bring your dog in if you just do it." I asked Becky about the feelings and thoughts she experienced when she saw a dog approaching their table. She said,

That was the first time I was in the situation where I had to possibly refuse a person because they couldn't bring their dog in, and it made me feel really awkward not having a steadfast quote, policy or something to go back on.

Becky stated,

I don't want to be put in that situation again without some firmer laws. People get angry. Even the people last year, like I said, [the people] that couldn't get in, they got a little angry, but I don't know this year was different, people were more angry.

Becky said the attendees "fully expected their dog to be part of their day and I ruined their day. Or they went on in anyway."

Becky said, "all the volunteers" and their coordinator "felt the same way." Based on their experiences, she said, "to be honest with you, we may not do it again....we are wondering if we should even bother....it wasn't worth it....Our place is not needed. The doggy daycare didn't seem to be...needed for the few."

Becky talked about a change she had observed. She shared, "I am seeing more dogs out than I used to. Whether they're any kind of therapy dog I have no idea." She thought out loud "Where was I the other day, I saw a dog walking in the store and I was 
surprised." Becky said it "might have been" at a home improvement store, "and maybe they're okay there and I just never paid attention."

I asked Becky her opinions on dogs being integrated more into society. She shared that she thinks her current city is "very dog friendly," which "[she] love[s]. She said,

I travel quite a bit, and I've noticed other countries that I thought were a lot more dog friendly, and maybe we are starting to do that, and the service dog thing is just, how we have to have so many rules about everything.

Becky said, "I really noticed that when I went to Paris, there were just dogs everywhere and it didn't matter if it was a fancy department store or what, they were there." I asked if the dogs in Paris appeared to be assistance dogs of some sort, and Becky said, "not at all." She said, "they were little groomed up poodles, which you'd expect, all kinds of dogs, it didn't matter, and there was never any kind of service jacket or anything like that. It was just something that was part of the culture."

I asked Becky to tell me more about what she would find helpful, as a gatekeeper, to make decisions on which dogs could enter or not. She said, "if they had something... whether it was an ID card, or something they could show people, on what level of training their dog is" that would tell "whether they're allowed to be in an event or not." She added, "if it's an emotional support that's fine, and I imagine there's different places that dogs are allowed." She stopped herself and recalled "another place" she was surprised to see a dog. She recalled being in a bookstore bistro and seeing "these people, they were like greyhounds, they were huge thin dogs, kind of like that, and there were 2 of them." Becky described the situation as "they say at a small booth at the restaurant, 
and their dogs just tucked on in underneath, and you would have never known they were there." She laughed and said, "I was surprised, but I was like okay if they're good then what the heck!" The dogs were not wearing any vest or identification. Becky shared a more about her puppy raiser friend, and how she has seen her friend train the dogs to "tuck under the table as part of their guidelines for training."

In reference to Becky's suggestion of the ID tag, I asked if she preferred it to be on the dog or something the handler carries. Becky answered "I didn't think of that to be honest with you. Just having a little dog tag that said what it is, you know like we have rabies tags that would be perfect." She explained, "that way nobody is embarrassed." She said, "because I know if there's food served somewhere that makes a difference if the dog can come in, and that's understandable, but if it's indeed your guide dog that you need, then that would be wonderful." She added, "Jackets are nice as well, but that would be something that would suffice."

I asked Becky to expand on how a tag would help avoid embarrassment. She said, "I go back to that festival that I worked. Sometimes people would challenge me, and I don't like awkward situations, so if they started to do that I'd be like, 'hey if that's what you...I back off." She explained, "Whether it's a store or an event, or whatever," the tag "is more for them, [the gatekeepers]." Becky added, "I mean, if people want to bring their dogs with them anyway, they are going to do it. So, you know that's all you can do." Becky suggested to also "make the public more aware", then added, "but going back to that, I guess if it's a guide dog you're not supposed to pet it, they still need their jacket." 
I asked Becky where she learned not to pet guide dogs. She said she learned it from her friend and "maybe [saw] it on TV when then do the Canine for the Vet program....I think that's part of their training, that you're not supposed to pet them while they are going through training." Becky summarized, "I've just somehow learned that."

I asked how Becky learned about service dogs, emotional support dogs, and therapy dogs. She said, "Really just life experiences....and a little bit of reading and what you see on TV." Becky confirmed she had not received any formal training on the topic.

When I inquired what additional suggestions Becky had to improve the whole situation, she paused, then said, "Wow, I hadn't thought about that, because it's like you don't want the government to take control, but there needs to be some kind of guidelines, or we'll all just do anything we want with our dogs." "Which," Becky said with a laugh, “to me doesn't sound bad." She continued, "Oh wow, I'll have to think about that. I really can't give you an answer on that right now."

Becky stated, "Every now and then you come across a situation" then stopped herself and shared a recent learning experience. Becky explained that one of her friends "had some people come and stay" and one of the visitors was "afraid of dogs." In describing her reaction to finding out the person was afraid of dogs, Becky gasped and asked "What?" Becky learned about the fear because the friend asked Becky to watch her dog during their stay. Becky said, "I guess there's people like that out there....I can't imagine that feeling but it's out there."

I asked if the topic of fear of dogs had come up during Becky's volunteering experiences. She said, "nobody has talked about that," but "as a life experience, I have 
come across people who are afraid of dogs, and I would keep my dog away, understanding that and respecting that." She continued, "You know what just came across my head is like you used to be able to get peanuts on an airplane, and now, because of all of the peanut allergies you have to be careful." She added "so now you're going to have..." but interrupted herself and said, "in my son's school system, there was somebody who needed a guide dog in a classroom, and there was another child who was allergic to dogs." She explained she "worked in a [school] office where they were talking about it" and knew "they had to make accommodations somehow...move one of the people to a different environment." She said, "in a controlled environment you can do that....but, what's going to happen next?" She stated, "It was interesting."

In addition to the emotional support squirrel she already mentioned, I asked Becky if she had seen or read other similar stories in the news. She said, "There was a peacock a lady wanted to bring on board." I confirmed she meant an airplane. Laughing, Becky said, "So, it's hard. To me that's ridiculous, but to this woman that peacock is everything." Becky recounted "Back in the day, I mean we are talking about over 35 years ago, I had to fly a dog with me, [and] she had to go underneath with the luggage." She pointed out "so we have gotten further, now they can tuck under your seat."

I asked Becky, hypothetically, if she took part in creating legislation regarding service dogs, emotional support dogs, and therapy dogs, what would be her thoughts. She expressed "I think you have to be considerate of the other passengers, like in an airplane for example, there's a fine line on respecting your privacy or your space, without going into someone else's space." She started to explain, 
If [a passenger is] willing financially [to] do what they have to do to bring this pet on board, cause right now they have regulations on size, and that's having to be met, and if you have to have something, maybe not necessarily...

Becky stopped herself and said, "now I'm thinking about the rodent, because he was small but..." She took a long pause and expressed "Golly, this is rough. I hate making guidelines, but there has to be something, that's why we have traffic signals, you know?" She stated, "I think what they have in place right now is good." Then added, "I hate to say no rodents. Maybe that can be addressed in some way. I didn't even realize that until it came up, but having a size regulation just makes sense for an event like that."

Becky thought out loud "whether we have outdoor patios when there's food, there has to be guidelines on safety and health." She paused and said,

I think what they have going right now is sufficient. As far as people taking a dog into a festival because they're an emotional support and not a guide dog, I feel like we've gotten past that now. If you're having an event outside, maybe you need to have a playground area, or a dog walking area or something.

She stated firmly, "but people are bringing their pets with them. I think we need to embrace that."

I asked Becky if I understood correctly that she was saying for any event, if there's an outdoor area then people are allowed to bring your animals. She confirmed "Yeah!" Then added, "Within reason, and what that reason is, I don't know." She laughed and said, "Because then comes the peacocks and the squirrels. You know, I don't know!" 
I asked Becky about her familiarity with what she called "what they have in place now." She shared, "To be honest with you, it hadn't ever been an issue for me until I worked that festival, and then I had to understand what was right and what was wrong, and that day was confusing for us." She started saying "normally if I see a dog in public..." Then stopped herself and added, "It's funny because I keep referring to dogs, but I don't care". Becky continued, “but that's when I guess you have to open the line, because people are going to use more than dogs for support. So at some point, there's got to be an issue for people's safety."

I asked for clarification on Becky's statement "but I don't care" to see if she meant she did not mind people taking other species of animals in public. She answered, "Yeah, as long as they people are considerate." She explained, "There's a leash law, and the leash law should be for any pet, not just for dogs.” Becky elaborated, “...honestly I don't think a cat should be allowed to roam, because dogs aren't allowed to roam. I think everything has to be on a leash or in your home, or in your yard." She added people should "clean up after" their animals, and repeated "if everybody would be considerate" then countered "but that doesn't happen." I mentioned to Becky the topic of people being inconsiderate towards someone with a service dog and asked her suggestion for navigating the situation. She replied, "Yeah, I know, you can't get people to just have common sense and, consideration, but that's why we have laws and guidelines."

I asked, if there were new laws put into place regarding service dogs, how Becky would want the information disseminated to her. She answered "I guess I would want to know about it like any law or legislation, and that would be my responsibility to know about it." She continued, "I know there are some states that are better with animal 
control than other states, and I have found out that moving to the state of Kentucky, that we are about on the bottom." She added, "I need to be more aware."

I asked Becky how she had finds information on the topic. She said the rescue shelter volunteer coordinator "has been a wealth of information" and she "hear[s] about things from her." She added, "I want to know more, so it's up to me now, to go to her, go to the [local animal rescue], and see if they have a little coalition going on, just reading about it myself, and being aware."

Based on Becky's comment that "some states are better with animal control," I asked if she noticed other differences between states. She said she did and "you forget that some things are state to state, you think why isn't this national, but it isn't." Becky shared her understanding of Kentucky's legislation on hoarding animals, and said the people guilty "maybe get a slap on the wrist." She added, "There needs to be more fines or something." The state in which she formerly lived, Becky said, "they had their cases, but after [the hoarders] were shut down, it didn't happen again.”

I asked about Becky's awareness of service dog uniform laws and if she knew the laws could change state to state. Shocked, she exclaimed, "Oh really?" She said,

That's stupid. I mean you should be able to go anywhere in the United States and see if a dog is working. You know, maybe he's in training or whatever by their jacket color, maybe by different regions or different companies, organizations. She stated, "That's a shame. It should be across the board."

Becky explained that having "something to designate by just visually looking at [the dog]" would help parents. She said she had "seen parents interacting...with their children, like asking before they can pet [the dog], and if they see the jacket, they'll teach 
them not to touch. That would be a good lesson." Becky placed value on the possibility and said, "because we are teaching the next generation."

Becky talked about service dogs becoming more popular. She said, "sometimes I'll watch the Today Show, and they have the dog...they are raising a guide dog, and they bring him on the show a few times. It's getting to be a more popular notion of having this." Becky added, "and unfortunately [with] the wars," and "the vets coming home, [they] sometimes [have] more and more emotional things." She stated, "I think that's what's bringing this out into the limelight so to say." She explained, "You hear more about it I think than you used to, especially like I said the support dogs, I feel like you never heard that as much until, however many years it's been since the vets with the PTSD." Becky said she personally "never heard of PTSD so much until this past war, unfortunately, with the heroes coming home with brain injuries and physical as well. It seems as it's all come out around this time."

After talking about the increase in service dog popularity, Becky said, It's sad to say, because I hate to dis anybody, but you see people sometimes will jump on a bandwagon just because they can get away with it....like I said, at that festival, it's obvious it was a comfort dog, it's wasn't a dog that can offer support. She speculated "but what are you going to do?" Becky said that for gatekeepers "you have to say either open it up to dogs, or don't, because when you start letting a guide dog in, that's when you get the conflict."

Becky shared with me that she has "a son that is disabled, so [she] know[s] about that community a little bit." Her son "goes to an adult daycare, and there's somebody who has a guide dog at home," but "he doesn't have him in the center." Becky expressed 
a desire to "find out if they are even allowed." She said she knows dogs are "allowed in [the daycare] at points" because they "have had dog days just for fun," but "if somebody there needed one," she "wonder[ed] what they would do." Becky shared that she “thought about getting [her son] a guide dog...but he doesn't really need one to help him." She decided to "let them go to someone who needs them."

Through taking her son to different outdoor community activities, Becky said she had seen "volunteers who have guide dogs in training." She said the volunteers "a lot of times" are "university students and they're doing this for their service organization." Becky also shared that before moving to Kentucky, she "used to work with a foundation that raised money.... and one of [their] programs that received the money...they were puppy raisers." She explained the puppy raisers were in a "juvenile delinquent program and it made such a difference in their lives to help raise these puppies." She said, "they'd even come to school because they knew they had a reason, it was kind of like the prisoner kind of thing, when they help raise these dogs." She said, "they would go to the ceremony to watch the dogs given to their new owners for life," and "it was emotional...it's a nice program."

Becky and I talked more about her natural "affinity for animals." Becky said, "I don't know why I love them so much. [They are] the best creatures ever." She joked "I mean the dogs, cats are okay," and laughed. As we talked, I reviewed my interview questions one more time and upon confirming I had asked all of the questions, I thanked Becky for her time and participation. I asked if she had any questions for me, and she did not, so I confirmed her contact information, thanked her again, turned off the audio 
recorders, and ended the interview. Immediately after the interview, I made my postinterview notes.

\section{Cathy.}

I interviewed Cathy right after interviewing Becky, the morning of October 16, 2018. Cathy was the third person I interviewed. Cathy and I had previously volunteered together through the local animal shelter, so we did know each other a little bit prior to the interview. I set up Cathy's interview day and time through a phone call and text messages. During our initial conversation, I confirmed Cathy met the qualifications, and that she was willing to participate in the study. I knew Cathy had numerous experiences with the phenomena but I did not know the details of her experiences prior to our meeting.

My interview with Cathy took place in a private meeting room at a local library. In selecting the interview location, I suggested either the library or a coffee shop convenient for Cathy. Cathy and Becky know each other, and requested to be interviewed on the same day so afterwards they could go to lunch. Their interview times were separate but followed one another. Cathy volunteers with the library and made a suggestion on the location. Therefore, the location was selected based on Cathy's suggestion. In the interim between Becky and Cathy's interviews, I took time to memo and put away my notes from Becky's interview. Prior to the interviews, I had reserved a private room. I arrived early to make sure we had access to the room and set up. Once set up, I sent Cathy a text message explaining where the meeting room was located in the library. After she arrived and we were both sitting and comfortable, I started the interview by asking her to describe her overall experience with animals in her life. 
Cathy shared that she "had an animal in [her] life, [her] whole life" and she "had to have one...all the time." Those animals "included horses, cats, turtles and dogs." When I asked if she had a preference on "what kind of animal [she] had to have," she answered, without hesitation "dogs." She added that with dogs "Each and every time it's like that's your one true dog...you think this is a once in a lifetime dog and then it happens again."

I asked about Cathy's current dogs and she proudly shared that she has "adopted two," the most recent of which has been especially challenging for her to train. Cathy said, "getting one as a puppy that you raised, and molded" is much easier than adopting one who is no longer a puppy. Nonetheless, Cathy described training both dogs as "a good challenge...they teach you so much." With a smile, she emphasized, "It was hard, but what you learn from them to pass on in the future is really good."

Cathy's most recently adopted dog is a "Golden [Retriever]." Cathy said the breed is important to "understanding...he is different, he's needy, and more dependent." While training him, she said she "started implementing special ed. techniques" including "approximation of a behavior and intermittent reinforcement." When training a dog, Cathy said, "intermittently reinforce[ing]" behaviors helps make sure the commands are "sustained overtime, in different environments, and with different people so then you can say the dog really knows it." With a smile she added, "not that mine are greatly trained." We chatted a bit more about her dogs specifically and their training. Cathy was very happy to talk about her dog and smiled proudly while sharing their accomplishments. She described one of their successes as "he's a little showoff." 
I asked Cathy if she was familiar with service dogs, emotional support dogs, and therapy dogs. Without hesitation she said, "Uh huh, yeah." I asked her describe her understanding of the differences between those dogs, including her experiences with them. Cathy said, "The differences, as far as I understand," she hesitated, paused, then continued, "can, uh, go anywhere. Therapy dogs, no. ESA, I'm not so sure, I think they can't go everywhere."

She went on to share a personal experience from the 2008 and 2009 school year, when she was teaching high school. During that time she had "a student with cerebral palsy that had a partially trained service dog." I asked Cathy if the school provided her with training prior to the dog coming to her classroom; she said, "No, nothing." The dog "just showed up," she said with a smile. The family of the student, however, "shared information about the dog, and what to do.”

Cathy said the student "tried [to bring the dog to school] a few times," but "unfortunately... it just didn't work." She said the reason was "because [they] didn't have an administrator that would insist that the kids not touch the dog during the day and mess with it." I asked Cathy what happened when the other kids touched the dog and she said, "then the dog was all agitated and was confused." In a sad voice, Cathy said, "so [the student] never could bring it to [high] school.” I asked her how she, as the teacher, responded, and Cathy answered "I just did like you're supposed to do in public...you let [the student] do her thing and [the dog] was at her side, it was really cool."

When asked how she knew to react in that way, she said, "I guess by that age I had already [learned] to respect the dog and let it have its space." She shared that occasionally the student would tell the dog to "stay" with her, and she would "hold" the 
dog if the student "would go to the restroom, but" the experience "was mostly just winging it." Cathy summarized with a smile, "just experiencing life I guess."

Cathy also had an experience trying to help someone in her community procure a service dog. She said a "gentleman in [her] neighborhood" had lost both of his legs, and the community was raising funds and trying to help him get a service dog. She "was in charge of finding a trainer, at a discounted rate, to help him pick out a dog at the [local animal shelter], and get trained to a certain level." Cathy said she found and visited a "service dog training program," and "talked extensively with [the trainer]," who "was willing to train his dog at a very discounted rate."

Cathy described the training facility as "amazing," and the trainer "knew her stuff...she had a real passion for it....She was going to help him get all of his paperwork done... she was really enthusiastic to give this guy a chance... it wasn't just business.” In a sad voice, Cathy concluded "[they] were in touch...for a long time...but his medical bills took the [fundraising] account." So even though the man did not get a service dog via their efforts, she added, "it was an interesting learning experience, and he knew we all tried."

During our interview, Cathy showed me a typed description of her experiences she had prepared prior to our interview, "to collect [her] thoughts." Therefore, she read what she had prepared, and I asked questions accordingly. Following the experience with the "school year with the service dog," Cathy's next experience happened "a few years later as a retired teacher" when she "held part time employment selling educator liability insurance," and "made presentations on college campuses and conventions, in schools, and to school administrations." She said, "In this roll, and in general public, it was clear 
to [her] that service dogs had become a typical encounter." She said it "was approximately 2012 when there was a sudden abundance of 'service dogs' visible, especially among students at the [local university]."

Cathy continued, "Along with this was a surge in "therapy dogs" on campus." She said, "Upon investigation, I discovered that there was no valid reason for this huge increase in the population of either animal." She found that "While [the local university] had implemented a training program...for service dogs, it did not account for a nearly $400 \%$ increase of these animals on campus." She clarified "That's my estimation." I asked Cathy if there was anything to which she attributed the increase. She said, "No, there were more...they were just more visible." She emphasized the number was "far more than this little program has...I think the program has like 20 students."

She continued reading "I also discovered that the internet now made it easy to buy a service dog harness, and businesses were prevented from requiring verification about it." At this point she "then learned about the misuse of the therapy dog vests and that privilege." Cathy said, with emphasis, "Therapy dog labels were exploding to allow students to have pets in housing and take them to class, though the latter is not an approved access for a therapy dog." She said, "Adults and students were using this privilege to enter businesses such as grocery stores and restaurants with their so called therapy dog."

She shared that after "blatantly ask[ing]" them, " a number of students told [her] they simply had their doctor write the medical excuse, and they proudly stated that no they did not have genuine need for a therapy dog." In a shocked voice she said "They would tell me, they just did. They would have their doctor write a note." Cathy shared 
that "As a volunteer at the [local animal shelter], the staff has stated to [her] several times these past three years that they recognize this abuse of privilege."

Also in the education environment, Cathy shared, "A good friend of [theirs], who...just retired from the math department" at the local university, "is highly allergic to dogs," and he "had a graduate student that kept bringing in her so-called therapy dog to his office." Cathy described the situation as "he was being forced to have this dog in there with him" and "in the end, after she graduated, he found out that she didn't, that was just her own thing....she was emotionally fragile, he thought, but she didn't have any legal basis to have that dog." "He was subjected to this," Cathy said.

Her friend's negative experience is what Cathy attributed as the reason "why [she] actually called the disability office at [the university] twice about the explosion of dogs." She said when she called they responded "Where?" To which she said, "Well, look around," and made a suggestion they create a "link on their student ID something that says you have all the paperwork and it's a true service dog out there, not a therapy dog...that's all you have to do, put it on their ID card."

She said she explained to them,

You all are having a lot of these therapy, and it's an insult to the person that has to have a service dog or therapy dog, and other people shouldn't have to be around it, they just shouldn't. They may have health issues but that professor needs to know that dog should be in that class, and who should have one and who shouldn't.

Cathy lightly pounded on the desk while describing her phone conversation. 
I asked how they responded, and she answered "They said 'well, we don't see it as a problem." To which she answered, in a high-pitched, sarcastic tone "okay." She said, "So I just do my own little thing. You have to let it go, but," then trailed off. I acknowledged Cathy's suggestion of something linked with the student IDs on campus, then asked what suggestions she had for social improvements. Cathy answered and explained how the ID idea would work outside of the university setting. She explained, "If I have a service dog, then my ID could have something on it, a little chip that says it's truly a service dog." The benefit, she explained, would be "so in a restaurant they would never embarrass the person or anything." I asked if she meant the people who have the dog. She answered "Yeah, if they're asked to show proof, you could just have a standard little thing on your driver's license, or whatever, and that's a routine practice to ask."

Cathy added, "but when you have a little Pomeranian in the top of a grocery cart basket, probably not a service dog." She said, "those businesses should be able to ask those people about that." She immediately clarified,

Not that it bothers me to be around the dog, not at all. It's just, I find it terribly demeaning to the people who have to have one, because they would like to just have a dog. They would like to just have a pet. I'm sure.

I asked Cathy if her suggestion would be something visible, on the dog, or more private. She answered "Well, I do think we need to standardize," she spoke slowly and with emphasis, "have one standardized service dog vest, and it comes through one, and I guess it has to be government, even though I don't like big government, but it would have to be, that. That has to be controlled." Confidently she continued, "You shouldn't be able to buy them, because I mean this this is really bad." 
Cathy recalled "one time at [a chain grocery store]" when she "asked the manager" about another shopper who had "a Pomeranian in her basket." Cathy said the manager "went over to talk to [the shopper]" and then thanked Cathy. She added, "other times, the manager said 'I can't say anything." To which she said she replied, "Yeah, you can because that's clearly not a service dog. I mean you could just nicely say 'please next time, leave your dog in the car."”

She summarized, "there should be something standard and discrete or respectful." She paused and thought, "even if it was something on the dog's tag, or you could get any vest, but then it has something there, like an insert, that anybody can see, and it can have a chip in it so it's official." Cathy stopped herself and asked, "Well you've seen with the airlines, what was it the guy with the peacock?" She added that she had heard on the local radio

...about a month ago, one of the vets at [a local veterinarian office] was on and he was saying that the American Veterinary Association is trying to establish clear, distinct guidelines and regulations for what qualifies for a service dog and have identification requirements.

Cathy suggested contacting the veterinary for more information. She said "He might be a good resource too because it's just gotten so crazy."

Cathy shared that "In [her] role as a book buddy" at her "public library," she has “observed service dogs on rare occasion," and "sadly [she has] witnessed visitors bringing a clearly non-service dog into the facility far more often than a true service dog." She explained an incident that "just happened the other day" when a visitor "was in [the library] working at the computer, and [the visitor] had a service dog thing on her 
dog," but she was yelling at the dog "Down! Down! I need you to go down!" In a disapproving voice, Cathy said she thought, "You're not a service dog." I confirmed it was the dog's behavior that made her say so; she said, "Yeah, it was clear...very clear."

Cathy also shared another experience she had as a "local animal shelter volunteer" at a community food festival. Her job during that event was to offer dog daycare to attendees who brought their pet dogs to the event. While offering dog daycare, their "little team took a little antidotal tally about how many people claimed their dog was a service dog in order to bring them into the food venue." She said, "it was about $80 \%$, and there were like six of [them] that agreed each time 'that's one, that's not one." Cathy said the animal shelter employees that were there with the volunteers "could tell [the difference] instantly."

I asked Cathy if the organizers had given her any training, or preparation, prior to the event. She said they did not, that she went in "just with knowledge" she already had. She said, "because I know you're not really allowed to ask anything." She added, "the staff for the doggy day care, we did have a right, if they said it was a therapy dog, to say no, but nobody was willing to do that." I asked "why not?" She answered "I think they just did not want the resistance. It was just let them go, that's on their conscious, not ours." I asked about the gatekeeping procedure. She said the people attending the event had to "just verbally say their dog was a service or therapy dog, that's all they had to do." I inquired about how Cathy identified legitimate service dogs from misrepresented ones. She stated, "Well, you can tell obviously by their training... and when somebody comes in and says their three month old golden retriever is a service dog, there's a clue, because I've already learned enough to know that's not going to happen." 
I confirmed she meant from their age. She added, "and then of course by their behavior." Cathy provided an example from the food event she had worked of "one couple" who "had both been in the military" and had " 2 beautiful dogs." In a serious tone, Cathy said, "The owners went up to the table, and those dogs just sat instantly. They were composed the whole time, very calm, very poised." She added, "and of course the reaction of all of us is we're not going to touch them because they're true service dogs."

"The other ones," Cathy said in a lighthearted voice, "they're having people pet them, [and say] 'yeah this is my little therapy Chihuahua." Cathy said when that happened, she and the other volunteers thought "your therapy dog doesn't need to go in there and eat with you." She added the whole experience "was kind of interesting" and even though that was "the second year" of them offering dog daycare, it might be the last. She explained,

I don't think [the animal shelter] is going to go there next year, because it was a waste of time, because the vast majority of people just took their dogs in anyway, they just lied. It was just not even worth it.

Cathy said one of the animal shelter employees also described it as "a total waste of everybody's time" and said, "It's nice to get the [donation] money...but we are not going to sweat that we are actually helping anybody keep their dog here because they're all just, people will just say that these days." Cathy provided an example that "[she] even had a parent tell [her] that they had their college-age child's doctor write them a note so they could have their dog living with them.” 
Based on that example, I asked Cathy if she has said anything when people tell her they are misrepresenting their dog as a service animal. As far as the parents, she said, "I would never, no." As for the students, she said,

Most of the time I would just say 'Well what do you think about that? How's that sound coming out of your mouth? You know I'm not going to judge you, it's done, it's over with, but just think about it in the future.

In those instances, she said, "I do my little bit of preaching about people that have a genuine need for the dog." I asked her about the students' reaction to her words. She said,

I think a lot of young kids, they listen and they're learning.... The first step was that they had a little more empathy. They never really thought about it from that other person's perspective, [that] maybe it could be a little bit an insult. Cathy and I then talked about the different views of misrepresentation. She brought up the point "we're really different than Europe, big time different." When I asked her explain, she shared observations from her trip to various European countries "a couple of years ago." She described the situation with dogs in public spaces in Europe as "The people that owned the dogs were with the dogs, but their dogs were not being visited by all these other people....it was just accepted." She made the comparison that "here it's such a novelty that people run up and pet the dog and kids do, but it's so routine there." She added, "there's this boundary of respect that it's their dog, that's their family...Just like you wouldn't go pick up their kid, you're not going to go pick up their dog." She added, "it's not anything negative, it's just this is my little family and the dogs are in that... they convey their dogs are their family." She described the overall 
observation as "neat" and explained that in Europe "You're responsible for your dog, and if they bite somebody, you're responsible for it and nobody argues about it. You're responsible for that dog's actions, but they're allowed to go anywhere."

She expressed her feelings on the situation as "It would be wonderful if it was like that in the United States of America [but] I don't think we can ever have that." She explained, "We're too congested, we have too vast of landscape....the diversity is so great." Whereas "Europe" she said has "pretty much homogenous populations," which Cathy said facilitates that "those things can be taught and it's small." She repeated, You know in an ideal world it would be nice here, but I don't think we can ever have that. America is just so different, it's so vast that it's so diverse, like New York City is so congested. We have crazies out there, there's a whole crazy population.

I asked Cathy if she thought it had been like that forever in Europe. She answered "I don't know, that's a good question because it just seems so every day... it has to have been a long time." I inquired if Cathy had an opinion on the influx of dogs in American culture in public places. She said she wondered "What do we do with this now" and made some suggestions to navigate the social change.

Cathy suggested accepting pet dogs in some public places. She said, "I think you could allow it....you could have that flexibility in certain situations," then countered "but then, American people aren't going to follow the rules, they're just not, they're going to abuse them." She provided an example of another area she identified the need for change. Cathy said, "dog parks have become dangerous for our animals, and filthy because a lot of people don't do their part." Therefore, "a long time ago" she "wrote a 
proposal up" for the "Urban County Council" and suggested "when you get your dog's annual shots, you will get a card, and then when you go to the dog park, you scan the card, it unlocks it, [and] you go in." The card in turn "shows that your dog has been vaccinated, and it gives you access...it also causes you to have a little more respect for that right to have that."

Cathy shared that the food event, at which she volunteered "for three years," was at a different location previously and "people brought their dogs no problem," but "when they were forced to do doggy daycare, that's when this whole service and therapy dog came." She shared her thought that since, in the event, "none of the dogs had any issues, so why can't you just let them [in] and then everybody knows that you are responsible for anything they do....even if somebody causes your dog to go crazy, it's still your job.”

I asked Cathy what she would do if she was in some hypothetical situations. The first situation was if there were dogs present and the person she was with had an allergy. She said she would ask the person with the dog "Could you give him some space please? He's highly allergic, he loves dogs, but he needs some space." Cathy equated that to "when people are anxious." With a gasp she said, "Like my book buddy, she's so scared of dogs." She explained, "that is very common in the south, in African American culture....they are totally frightened of dogs." Cathy said she found out about the fear when she offered to take a dog "to the home to visit... and the vast majority of the residents did not want a dog there, and they happened to have a lot of African Americans." Cathy continued to explain, 
It's probably where they grew up, they lived in congested areas, dogs were loose, probably chased them, and in their culture, they're very often taught to be afraid of a dog and assume the dog's there to harm them. That's still present these days. About the realization, she said, “[it] took me back a little bit, because I don't think of it anymore, that it's still there."

I then asked Cathy if, hypothetically, she was with someone who was scared of dogs, and they saw someone with a service dog, what she would say. Cathy said she would say "That's fine you're uncomfortable with that. Let's move a little bit away....let's let them go in front of us, and watch...just so you can feel okay that they're there but you don't have to get too close."

I asked Cathy what she thought was the best way to communicate and connect with the general public about service dogs. She first said, "You know, there's so much media out there." Then offered the idea "even in the library, if they had community events that teach training...teach it." Another idea she had was to have "many groups of people with service dogs come out and maybe have a little march for them." During the march, the people with service dogs could explain "we want you to know what this is, and please don't abuse us though because this is how it makes us feel." She thought "Maybe they need to stand up and educate us, you know, seniors, in schools, kids, all over." She stated, "it's going to have to be human to human."

I asked Cathy what she thought is the best way to communicate with gatekeepers regarding expectations for service dogs and accessibility. She answered that at the event they "should have known a little more about why [they] were asked." She said, 
...basically we were told you can't do anything to reinforce, you just ask and if they bring it up then you just have to assume they are [service dogs]. So I don't know, you know, that's the part that has to change.

Cathy said that "if you know they have to have something on them to verify, that is all uniform across the county, and across states, then you have the basis to say, to help the person understand that is the gatekeeper." She continued, "that's all they're really going to have to do....some uniform monitoring system, like a registry." She added, "You're going to have to teach about red flags like the dog's behavior, you can educate them (the gatekeepers) about that on the spot, but that's going to set the stage right there to have that."

I inquired as to Cathy's awareness of an existing registry. She stated that she "think[s] there are some," but her knowledge was "not as much on that stuff." She said that she knows through her donations "to the guide dogs thing" that "they are pretty rigorous about their ID, and the expectations for the client, and when the dog goes into retirement and all that stuff."

Since Cathy had previously mentioned the peacock, I asked her if she felt the news was a true representation of what has been happening culturally, or if she thought it was a symptom of "bad news sells." Cathy answered succinctly, "I don't think it is bad news sells, but I think it's a symptom of the 'me first society,' it's whatever I want to do and it doesn't matter." She compared it to "running through a red light because I want to get to the next light and if I kill you oh well." I asked Cathy if the "me first society" was a trend she had seen in her professional experience. She said, "Oh, it's a huge trend. It's sad." In conclusion, she added, "Now-a-days I consciously try to do is look at who's 
doing good and who is doing good things, and who is having kindness in humanity and joy." Cathy said, "because it does seem like there's a lot on the other side."

I reviewed my interview questions one more time and upon confirming I had asked all of the questions, I thanked Cathy for her participation and time. I asked if she had any questions for me. She did not, so I confirmed her contact information, thanked her again, and ended the interview. Immediately after, I made my post-interview notes and turned off the audio recorders.

\section{Donna.}

Donna was the fourth person I interviewed. I had met Donna briefly prior to our interview, and after confirming she met the qualifications, she agreed to participate as a co-researcher at our first meeting. All I knew about Donna prior to our interview was that she had experience with the phenomena and expressed happiness to help in any way she could.

My interview with Donna took place the on November 8, 2018, at a coffee shop convenient for Donna. In selecting the interview location, I suggested either the library or coffee shop most convenient for Donna; she selected the coffee shop. I arrived early to set up and make sure we had a spot with two chairs, and as far away from the ambient noise as possible. The coffee shop was in an industrial building and at times, unexpectedly got very loud. When I arrived, I got a coffee and sent Donna a text message explaining where I was sitting in the coffee shop. When she arrived she also got a coffee. Once we were both sitting and comfortable, I started the interview by asking her to describe her overall experience with animals in her life. 
Donna shared she "had a dog growing up, a small dog" and she "had him from the time [she] was 2 until [she] was a senior in high school. She said, "when he passed away I became bitter towards dogs.... the whole experience for me was very traumatic and heart wrenching, so after that I've not had a dog since." Donna shared that she "had a cat" but "recently" had to put the cat down, and it "was like déjà vu all over again." She resolved, with a laugh, "I'm probably going to move on to like goldfish now."

Donna then shared that she had "worked for [a local nonprofit] which...rehabilitates those who have been sexually exploited [and] one of the residents there had a dog, because she's legally blind." I asked her to tell me more about her experience with that dog in particular. She replied,

I don't remember what type of dog he was. I think he was a lab, he almost looked like a golden retriever. I don't know what he was, but the first time I met the dog, they instructed me, you know we are not going to be lovey dovey, which I'm not that way with animals anyway, because I'm not really a dog person anymore. I asked if she said that because of her "experience with [her] childhood dog." She answered, "Yeah, I do like them, I just choose to, it's too much emotion for me to pull back up." She continued, "so being a guest in this safe house they didn't want to disturb the dog and what its main focus was." Donna said, "I can't remember if she had seizures too, but he was mostly there like as her seeing eye dog, and I'm sure emotional support too because she was legally blind."

Donna continued to explain she was "not sure how long [the woman] had the dog prior to entering into [the] program." She thought it was, "a year or two" and the "dog went everywhere with her throughout the home." In the home, there were "five or six 
other girls that lived in the house" and "everybody kind of had to follow what was right for her and the dog so he didn't lose focus on why he was there." I asked Donna who gave her the "information of the proper way to act." She answered "it was a combination of all of the girls that were there" and "the program director of that particular safe house... probably may have mentioned something" but she couldn't "remember exactly." She said she was "bypassed through the onboarding process" and did not receive any official training regarding the dog. She learned through experience.

She explained that the "first experience" she "had in the home," she "went in as a volunteer to do like spa things for the girls, teach them the appropriate way to do makeup and things," and later became a "mentor." Regarding her response to seeing the dog for the first time, she said,

...it's not natural for me to bend down like most people who are big animal lovers to pet a dog and do things like that. I don't react that way to animals. I might put my hand down and pat its little head, but that's about the extent of what happens. Donna said she that dog was the only service dog she had seen outside of ones she had seen at work, and she never had any negative experiences with that dog.

I asked Donna to share more about her other experiences with service dogs. At the time of our interview, Donna worked for a mission-based retail company in the shopping mall and she shared they "see service dogs all the time, not just that come in the store, but also that walk in the mall with their pet owner." She paused, thought, and then continued, "I feel like we see a combination of service dogs, emotional support dogs, and then ones that are actually there for trauma, experience, anxiety, seizures, and things like that, seeing eye dogs for the blind." She said, "they do come into the store and most 
people are really nice when they come in." She added, "the girls that work with me they are all animal lovers" and "I feel like everybody already knows that when there's a dog...you just know not to, I feel like we all know...we aren't going to reach down and lovey dovey, get the dog all excited." Her store is located in a "glass cove... in the middle of the mall" so they "get crossing from both ends," from that vantage point, she said they "see at least two to three service dogs a day at the mall."

Since Donna mentioned the emotional support dogs, I asked if she was "familiar with service dogs, emotional support dogs and therapy dogs, and the differences in the types of those dogs." She answered "probably not as well versed as I should be." I inquired why she said so, and she replied, "I think I have a vague understanding of each of them, maybe." I asked for her to share with me her understanding.

Donna paused, "umm," her voice wavering, ...so I feel like that emotional support dogs, maybe what I know is that they are going to be there more for, like the first thing that comes to mind when I hear about emotional support dogs is the elderly. Dogs that are just there to be a structure of support for somebody, maybe who has like suffered a traumatic experience or loneliness or whatever that may be.

She continued, Therapy dogs, would be I guess, I don't know if [she named a colleague's name] dog is a therapy dog or if she's an emotional support dog, I can't remember which one, but I want to say he was training her to be a therapy dog.

Sounding unsure she said, "she's probably the one that I've mostly, if that's true, as a therapy dog, which has only been a few instances." 
I asked Donna what instances she had interacted with that therapy dog. She answered her colleague "does group therapy" and the dog "didn't do anything at [their] groups because he was just training her to be around other people." She added,

I know that he was wanting to take her into, I can't remember if, I don't think it was nursing homes, I think it was rehab facilities or something like that...and use her kind of as therapy to help people recover.

She continued, "Now the service dog, now I'm confused." Validating her stated confusion, I said, “That's okay.” She said, “uh, I don't know” and stopped silent. I reassured her it was "important" for me "to know if people have confusion or if it's very clear." Donna said, "I feel like I should have done more research before"; I reminded her I "did not want [her] to do research." That "I want[ed] to know, just as a member of the working public... [her] understanding of these things as they are now.” Donna said, "Okay" and I redirected my questions.

I asked how she got the information she had shared on the different types of dogs. Donna answered "the basis of information that I know probably came from my psychology degree. I'm sure at one point we...probably touched based on all three of these." She continued, "I know at one point we have to have talked about it, and then whatever I've learned from having volunteered at [the local nonprofit clinic].” Donna still sounded embarrassed and nervous, so I reassured her again the goal of my research.

I asked her, from the dogs she had seen in the mall, "how do you identify that it is a certain type of dog, like a service dog, emotional support, therapy or just a pet." I also asked if she made the distinctions at all. Donna answered "Well, okay, pets they don't have the vest on." She continued, "some of them have a red vest on, and I think I've 
seen, I don't know if this is correct or not but I'm wanting to say yellow vests." Donna said, "I can't remember what the other color is, but there are two colors that we see often, and then we see pets." I asked if, in addition to the vest, there are any items, or "any other ways" she has identified a dog as "something other than a pet." Donna replied, "No, just the vest."

Regarding the size of the service dogs she had seen she said, "I feel like the majority of them, I don't know because I don't know a whole lot about dogs, maybe midsize dogs." Donna added that in "a little over a year" she had seen "maybe five...small dogs... whichever type of service dog they are with the vest on...walking around." The "rest of the small" dogs she had seen "are pets on leashes that walk around with their owners."

I asked if pets are allowed in the mall and she answered, "No, [but] they come in," and the mall manager had not communicated with her about the dogs. She was not aware of any mall signage regarding the pet policy but said, "I think that's something I'm going to look for."

Donna shared that on "in the past three months...there have been dogs in our area that have gone to the bathroom." The incidents happened "in [their] concourse...right in the center where [they] are." She said she "didn't see the dogs" from two of the accidents so she didn't know if they were pets or service dogs. She learned about one accident because she "could see it," and the other from "a customer in the mall." I asked if mall employees or managers talked to her about the incidents and she replied, "No." I asked Donna if the owners cleaned up after their dogs. She said, "Usually" but "this last one did not, they just left it." 
The one incident where she did see the dog, she said, "was some type of service dog because it had a vest on." I confirmed the vest was how she knew it was a service dog, and she replied, "Yeah, it had a red vest on." I asked if she could remember anything on the vest, such as signage. She added, "it had something...maybe 'service animal'...something was written on it." In the instance of that dog, the owner "was very apologetic about what happened." She said, "I'm sure they were embarrassed," and she and her coworkers were "all very professional."

Donna then shared an experience, from the week prior to our interview, of "a lady in the mall that was training a service dog." Donna said the lady was "training...right out in front of our store" and she observed them "for like ten minutes." She described the sight. "They would walk, and she would stop, and the dog would sit, and she would walk around the dog, and kind of stomp around a little bit, and move around while the dog just sat there the whole time." Donna said the lady. "was doing her own thing" then "she'd walk back over to the dog." She said, "I don't know if she clicked or did something" but "then they started moving, and they would walk about five or six feet and they would stop, and she would do it all over again." Donna said, "they walked up through the mall, and ...came back and...went through the same motions again." She added, "there was a man that was with her...but he stayed behind... and he would follow them. They would stop, he would stop." She observed "then she would do her thing with the dog and he would stand back...then at one point he did surpass them." Donna stated, "I'm sure that was some sort of test for the dog."

I asked Donna how she understood "it was a service dog in training." She replied, "it had a vest on... one of those red vests or whatever they use." She added, "you could 
tell that the dog seemed like it was very seasoned because the whole thing came very natural." She speculated,

Maybe it was towards the end of the training or something because the dog did really well. I mean at one point they walked over to the couches and sat down for a short period and he just sat there, didn't move, didn't bark, didn't reach up to be pet, nothing.

Donna said she "should have gotten it on video and sent it to [me]." I thanked her for remembering the story in such detail.

I inquired about the thoughts Donna has when she sees these dogs. She answered she "wonder[s] what their role is with the human being they are with, the person they are with." Excitedly, she said seeing the dog "strikes curiosity," and she "want[s] to know... why do they have this dog." I asked if she had "ever had any conversations with these people about that." She said she had not "because [she is] not sure how [she] would broach the subject" or "the appropriate way to bring it up."

I asked Donna if she had "any emotions beyond those thoughts." She answered "I think I'm indifferent." Which, she said, "hinders [her] from interacting with them." I asked her how so and she responded "because I don't feel the need to walk up to them and pet them, and ask them questions about the dog because I'm just indifferent about the animal being there to begin with." Donna said, “It doesn't bother me that they are there and it doesn't upset me, but I'm not excited about it either." She summarized 'I'm indifferent."

Donna shared with me that her company works with "greyhound refugee programs" to "raise money" and get the "retired racing dogs" adopted. "Twice a month," 
she shared, "their foster parent comes in with the dog" and "they set up in the corner of the store....and stay for about four hours." Donna said she did not recall any other dogs coming in the store while the greyhounds have been there, but that those "dogs are so well behaved" she did not think it "would even phase them." Donna added, "if I were to get a dog, I think I would get a greyhound, except for all of the shedding. I can't stand all of the hair."

I asked if Donna and her co-workers had "any training" regarding service dogs when they were hired. She repeated three times "No," neither from the mall nor her employer. She stated she "didn't receive any paperwork through the mall" but she speculated her company "probably... received something regarding the space and policies and procedures...for being in their mall, what their expectations were for their store." Donna and I discussed the chain of command in her company and she explained she did not know of her superiors receiving any training on service dogs either.

Donna and I talked about misrepresentation of service dogs. She said she was not aware of any stories locally or in the news, "but" she added, "I also don't watch the news." I asked if Donna had seen anything on social media." She shared the "one thing" she could recall from social media was "the stories of our people in the military who have dogs when they are oversees and serving in another county." She expanded, "I guess they work together as a military dog," and also shared that she was aware of "canines that work with the police department."

I asked Donna if she would like to receive more information "about these dogs" and "what suggestions" she had about the best ways to disseminate information. Donna answered, "it's important for anybody that is in the service industry...to have a basic 
understanding of the disposition that you're supposed to have when a dog like that enters your store, or enters whatever it is that you do." The reason she said is "so that you are [able] to present the appropriate disposition, out of respect not only for the dog, but for the owner of the dog, the person that actually needs that dog."

"As far as getting that information across" Donna continued, "I don't think if the stores put something like in a manual that the employee would ever read it." She said, "most people go through those things and just sign it." She countered "one of the strongest platforms that people can learn things on is social media." Donna said, "social media...it literally...runs our country...everybody is in their phone, everybody is down and active in this new level of communication."

I asked if there "is a certain engine or provider" within social media that she thinks is best. She answered "videos...people are more apt to watch something, or look at something that's a photograph, than a long written out post." Donna recalled "what I've seen on social media, with the canines and the dogs with the military...they've all been videos... unless it's one of those active writings that prompt where each screen is different...written on the screen as it goes."

I asked who Donna thought should put such informational videos online. She said, "it would depend on the level of contact that you are going to have with these service dogs" and provided an example of herself. She said, "we see them very often, we don't have a whole lot of contact with them, but they are there and it could happen." She explained, if her company were to "put something out about service dogs, if they made a blog or made a new page in the employee handbook...our employees would respond well to it because they are a mission based company." She added, "I feel like that's what 
service dogs are, they are here for a mission to help someone else out" and since her company "is very animal friendly" and "are supporting saving the endangered...for [them] it would be better reciprocated if it came from them than the mall, or just someone raising awareness into the store or giving a flyer out." Donna clarified information coming from another source "would still be received well" but would not "have the impact that it would if it came from [her company]." She shared that her company "put[s] something out, it's something they believe wholeheartedly and so they put a lot of effort into what they are supporting and what they are putting out there."

Prior to her current job, Donna gained a lot of experience, spanning over ten years, working with a variety of national retail chains. Based on those experiences, she said that for other, non-mission-based companies, "their focus isn't the same...they are not mission driven." Those companies "are big corporate department stores that support a lot of different brands and a lot of different charities" and "don't focus on one organization." Therefore, Donna said any service dog education would not have an impact coming from them. She shared that while she was working for those companies, she was "sure they passed by" but that she did "remember having contact with service dogs... any type of interaction at all." Nonetheless, she stated it was just as important for people working in those locations to have the same information on service dogs. The issue she identified was "just how to get it to them."

Considering it from the service dog handler's point of view, Donna identified potential concerns with the public not knowing how to interact with a service dog. She said, 
I mean if you are going to bring your service dog into a public facility, like the mall, and you're going to go to various stores, you're obviously going to have contact with a lot of different people, and they are going to encounter a lot of different personalities.

She said, some of those personalities will be people like her, who she described as "indifferent...not going to reach down and pet the dog and goo-goo-and-gah-gah over it because that's just not who [she is]." Others will be "people like my boss that love, love, love, dogs, and they want to touch the dog, and know the dog's name, and pet it, and hug it, and ask all these questions." Donna said, "it's important...especially if the service dog is new to being in that role, that the public do, that they have basic understanding of the behavior that you are supposed have towards a service dog." The reason being "so the dog doesn't lose focus as to why it's there or doesn't become sidetracked." Donna added, “I don't know how all that works because I'm not really well versed but I don't see how exciting a dog would be" she paused and continued, "a good thing." She provided the example "what if the owner all of the sudden has a seizure right there and [the] dog is all excited, is it going to be able to regain focus." Donna concluded "I don't know how their brain works, I don't know how all of that intertwines, but I just don't see that as being a positive thing."

I reviewed my interview questions one more time and upon confirming I had asked all of the questions, I thanked Donna and asked if she had any questions for me. She did not, so I confirmed her contact information, thanked her again for her participation, and ended the interview. Immediately after, I made my post-interview notes and turned off the audio recorders. 


\section{Emily.}

Emily was the fifth person I interviewed. I had not met Emily prior to our interview, however we had talked on the phone when I asked for her participation in my research study. During that phone call, I confirmed she met the qualifications, and picked the day and time for our interview. I did not know anything more about Emily prior to our meeting.

My interview with Emily took place the on November 15, 2018, in the same coffee shop where I had interviewed Donna. In selecting the interview location, I suggested either the library or a coffee convenient for Emily; she selected the coffee shop. I arrived early to set up and make sure we had a spot with two chairs, as far away from the ambient noise as possible, and in a different location from where I had interviewed Donna, because of the previously recognized noise. I got a coffee and sent Emily a text message explaining where I was sitting in the coffee shop. When she arrived she also got a drink. Once we were both sitting and comfortable, I started the interview by asking her to describe her overall experience with animals in her life.

Emily said her "first pet was a goldfish" when she was "six-ish." She said she also "had a golden retriever through high school." Then she paused and said, "My family wasn't big pet people...I've haven't had a pet since then really. Travel too much. Do too many outdoor activities, we'd have to figure out what to do with them." I asked Emily to expand. She said, "I guess my parents just never decided to invest a lot in having a pet. We had a dog in high school that was it."

I asked Emily if she had any meaningful person interactions with dogs since their pet. She said, "Sure... a couple of my friends' dogs I like." Then she paused again and 
said, "I don't know if I'm a huge animal person. I like the ones that are important to my friends." Emily continued,

I would have a dog if I had someone to help me take care of it, number one, and could figure out what to do on the weekends when I want to go outdoors. That's really the big thing to having a dog for me.

I asked Emily if she was familiar with service dogs, emotional support dogs, and therapy dogs. She answered "To a certain extent, yeah." I asked her to describe her experiences with those dogs. She replied, with a laugh "People like to put them in the same sentence as music therapy." I asked Emily to "tell me more about that."

Laughing, Emily shared,

Well, we have them at the hospital at [the local university], you know I worked at [the university] Health Care for five years, and the program of service dogs, or not service dogs, therapy dogs, grew while I was there.

She added, "they had more [dogs] and expanded the floors that they were allowed to visit, pediatrics and cardiac, and those are the 2 main ones I know they go to, I think they've expanded it from there." I confirmed Emily was talking about the hospital having therapy dogs. She confirmed "Therapy dogs, yeah." I asked Emily if anyone at the hospital shared information with her as to why they were expanding the floors the dogs could visit. She said, "No, but I didn't ask.... just saw them more frequently, or more of them."

I inquired about Emily's knowledge of the differences between service dogs, emotional support dogs, and therapy dogs. She said, with a laugh, she "recently had to read a policy of [the university where she currently works] because [her] student told 
[her] she was going to bring her emotional support dog to class." This event happened "at the beginning of this past semester." She paused then continued, "I don't know the ins and the outs, but I know therapy dogs require some sort of certification or training, and you can expect certain things if they have done that, as far as behaviors." She added, "and I know emotional support dogs is not the same level of that sort of requirement." I asked if she meant emotional support dogs to therapy dogs. She answered "Yeah, or at least I think that is correct."

Emily expanded on the situation with her student and the emotional support dog. “So I was like, she can't just decide, number one, she can't just tell me she's going to bring her dog to class and number two I feel like there might be a policy about this." Emily paused then said, "So, generally you're not allowed to have them in facilities and even in campus housing unless it's gone through the Center for Disabilities and they approved it for emotional support." She said the student had "emailed [her] before school started" and she "just told [the student] what the policy was."

I asked Emily if she had done any other research on the topic prior to this instance. Emily said, "I think I was previously told by another professor that that was not okay to do." I inquired as to the outcome of Emily's email. She said with a laugh, "She brought the dog to class one day...she said she didn't get my email when I had given her the policy, so I had to call her into my office and then she didn't bring it again." Emily said, "It wasn't even a big huge discussion, I just told her what the policy was and she said that it was getting trained to be a therapy dog, and I was like 'okay', but I haven't seen her since." 
Emily shared, "Class is only 50 minutes, and if she's going to be a therapist, I feel like it's a great opportunity to figure out how to move through 50 minutes of something." Emily said, "I told her I'd be happy to help her come up with some strategies on so that we can adhere to the university's policies." Her voice sped up and she appeared more enthusiastic as she said, "But was really interesting though, is I don't think you're allowed to ask to see the paperwork if the dog has been trained." She continued, "So if she told me it was a therapy dog, versus and emotional support dog, I don't think I was allowed to ask her to show, to prove it."

I asked if Emily knew of "any other colleagues or anyone else who had similar experiences. She said she knew of just "the previous colleague, where I worked, who is not there anymore." That colleague "just had to talk with the students about that's not something they could do, bring them into the facilities if they're not specifically a therapy dog, or through the Center for Disabilities." I inquired if any of Emily's directors or bosses had addressed the topic with her, and she said, "No, [she] went through the hierarchy and asked what the policies were, and then they found the university-wide ones." She added her superiors "said they would maybe put one out for the [university department] which is where I teach, but I haven't seen anything since. I think the blanket one probably worked out." Emily confirmed the knowledge was not part of onboarding and she had experienced this with only the one student "so far."

I asked if Emily had seen a lot of dogs on campus. She answered "Not at [her current university] but at [her former university] there were lots." She reasoned "I believe they train them in some fashion, like the students could take the dogs that were in training and help train them. So there were lots at [the former university]." I asked if 
Emily remembered what kind of dogs they were training. She guessed "golden retriever," but as far as the type of training, she said, "I don't know. I probably assumed they were in therapy dog training or service. Probably service dog is my guess.”

I asked if anyone explained the training program to Emily. She said, "I wasn't explicitly told, and I did not ask. I went one day in the room, they have one day when the have them all in the room and you can play with them. Like a staff wellness." I probed and asked Emily "With your knowledge, did you know anything about these types of dogs before you had this one situation where you had to read about the policies?" She answered,

Oh sure, yeah, I mean they were all around at [her former university], the ones they were training, I'm assuming service dogs. They had the therapy ones in the hospital, that were volunteer, and then just being in a helping profession people often have therapy dogs.

Emily added, "one of my clients, a kid with autism, [and] his parents worked on getting him, I don't know what the label of the dog that they were working on for him was." She paused then stopped. I asked about the dog's purpose. Emily thought for a while then said, "I believe it was to help him socialize with a living thing, because one of the hallmarks of autism is not being able to socialize very well, so he didn't really engage with peers too much." She continued, "So I think one of the goals was to help him be engaged with an animal, and have a companion, maybe that was what it was, a companion." Emily said, "they had him for a little while, or one of the students would bring one in they were working with during our speech and music therapy co-training sessions." 
I asked Emily to share with me some of the conversations she had with the child's parents about the dog. She said they talked about "just that they were working on getting him one and how that might facilitate some of the goals." I inquired about Emily's emotions and thoughts on the situation. She shared, "my thoughts were sure sounds great, I think he can use all of the socialization he can get. I would be willing to see if an animal can help facilitate that." Ultimately, Emily said she did "not think the dog was able to come regularly enough to really document a solid change." She also did "not know that [the boy] ever really got to take [the dog] home.... It was usually a student bringing the dog that they were working with into our sessions." Emily said the student was "probably part of the training program that trains the animals."

Based on our conversation so far, I asked Emily again, if she "had to define the differences, or if there are differences between a service dog, emotional support dog, and therapy dog" if she would do that for me. She replied, "Sure, I'll give you to the best of my knowledge," and started, "So a service dog, I believe, is supposed to facilitate some function that someone is lacking." She provided examples "like a seeing-eye dog, they are the eyes for that person to help them navigate the world, or epilepsy they can sense a seizure coming on and help protect them." She stated, "So there's some sort of specific function, way that they are functioning in that person's life."

Emily paused, cleared her throat then continued. "Then a therapy dog, I believe, has enough training to be well behaved and you can anticipate how it would behave in a more elevated situation, like in a hospital." She offered the example "or...like with a kid with disabilities who might not act the same as a regular person, might do something different, the dog's not, it's not going to freak out." She added, "they have enough 
training to be able to go connect with someone who might have some sort of special need, be it medical or isolation or," she paused then said, "I'm not sure what other settings they go into." Emily explained, "My experience is mostly with medical. I'm sure they make home visits, or something like that in different capacities, Hospice, or they can do any sorts of things." Emily said, "[people] volunteer, is my understanding, I don't know that anybody gets paid to bring their therapy dog anywhere, to the best of my knowledge."

Emily continued, "And then of course, to have a service dog, you would have to have some sort of," she paused then said, "I don't know if you can just outright pay for it yourself, but I think you can get it through insurance capacities because it would be serving that medical need for you." She continued,

And then I don't think emotional support dogs have any sort of level of requirements. I'm not sure what it takes to get the certificate to say that, I don't know that it's a complicated process, but I don't know. I've never looked into it. I asked if I understood Emily was thinking an emotional support dog was for one person and she confirmed "Yeah, yeah....Anxiety or whatever they feel that might want extra support with."

I asked Emily about her understandings with these dogs and accessibility. She said, "I don't really know other than the policy at the university I teach at now." With a laugh she added, "I know airplanes have had some trouble with what to do with them." I asked her to share with me more about her knowledge on that topic. She said, "Oh I just know that one big article about the peacock and someone trying to bring their emotional support peacock onto the airplane." Then she added, with a laugh "But apparently 
miniature horses are okay?" She shared, "that was actually in our policy, our university policy!” She continued, “I don't know how horses squeeze by. I guess it's their capacity to learn and be trained. But umm, hedgehogs?" She concluded "that's all I know, just from the news stories."

Emily and I talked about social interactions with dogs and she shared she had "never heard any negative impacts of having any sort of interaction with any levels of these dogs." I asked Emily, when she sees a dog out, how she identifies whether it is a service dog, emotional support dog, therapy dog, or pet. She answered "Well the vest is often a sign that it at least serves some purpose. Although I don't know what the official logo is versus someone just slapping a vest on their dog."

I asked Emily to expand on what she had seen and expects to see dogs wearing. She answered "I guess the ones I'm most familiar with, are the ones used with the students training them on campus, so they were red." She added, "That's all I know really." When I said I was aware of the dogs on campus but had not seen them, she continued,

I don't think our therapy dogs at the hospital had any sort of special thing that they wore that I can recall. We just knew who their owners were and who they were. It was the same 2 or 3 people and dogs.

She said there were "three specific pairs of people and dogs that [she could] think of." I asked Emily if she identified any particular colors as best for marking the dogs. She said she had "not thought about it" and "red, since that's what [she had] seen." I asked if there were any colors she thought did not make sense for marking the dogs. She laughed and replied, "No." 
I asked if there were ever new dogs that went into the hospital that she thought were not part of the therapy dogs. Emily recalled "there were new dogs, but I never didn't think they weren't part of the program.... The fact that they were carrying a dog made it obvious, that they were allowed to bring a dog in the hospital." She added, "some people would sneak [dogs] in sometimes, or [the hospital] would make exceptions for people who really missed their animal on occasion, especially when they were in hospice." I asked if it was "pretty clear when they were being snuck in." Emily answered "Oh for sure, yeah....they would just sneak them in."

I asked Emily what thoughts and emotions she has had around the dogs. Happily she responded "I mean I love dogs...happy to be around them as long as they aren't licking me, [or] getting my clothes wet." Emily laughed and added, "I tend to like golden retrievers better since we had one, or I just happen to like those."

She continued,

One of the lenses that I see dogs through is related to that people combine them with music therapy sometimes, which makes a disconnect between [a] clinical therapist, who has say a master's degree in a field, and a volunteer animal.

Emily shared, "often when I am engaging or talking about service dogs or therapy dogs, it's in a context that someone has said it related to my job." She paused then said, "So, one of my biased first thought is 'let me know when the dog gets a master's degree." She laughed and continued, "then you can put us in the same sentence." Emily concluded "But if I was ever a hospital administrator, or something, I would absolutely support a program of that sort of nature. So I don't have super strong emotions about animals either way." 
Based on what she shared, I asked Emily if people had equated her work to that of the dog. She answered "Yeah!" Emily explained, "I don't think they do it necessarily on purpose. It's usually in enthusiasm for things that patients are able to receive....like the therapeutic benefits." She said it's often thought of as, "Oh great, we get music, we get dogs, we should do them together." As far as who suggests combining the dogs and music therapy, Emily said, "sometimes it's the people who are the dog owners.

Sometimes it's just staff who are excited about things that are happening at the hospital." I asked Emily if the hospital staff had talked about the logistics of allowing a dog into a therapy session. She said the dogs "are not usually allowed in unless that has been address through the appropriate channels" and clarified "I'm really just talking about hospitals."

I inquired about Emily's experiences with her co-workers and their excitement "about the idea of co-therapy with the dog and the therapist." With a laugh she shared, "Right, like a dog will come in and interrupt my session and they will just walk in." She said, "it has happened that I'll be in the middle of running a music therapy with someone, and it's the time that the dogs are on the unit, so they want to make a visit." Emily said, "if the owner isn't aware enough, or the nurse or whatever, to consider what might already be happening in the room, they might just come in and start playing with the dog." She added, "Which is great. I'm all for the dogs, if they could just wait until I'm finished with my session that would be cool."

I asked Emily if there had been any verbal interactions with the dog handler in those instances. She said, "Not unless the dog owner, or the nurse, or someone who is a gatekeeper of some sort, can look at me and communicate with me about what's 
happening." I acknowledged what Emily had shared, and inquired about how she is "still very open to the idea." Emily said, "Oh sure, no one is doing that purposefully or maliciously, just a lack of awareness or opportunities to understand my profession." She said, "Outwardly" her music therapy session "looks a lot like having fun playing music, which" she said, "is understandable, versus if the doctor is in there talking to them, doing a procedure, you might think 'oh maybe now is not the time." Emily shared that she is "kind of forward" and is willing to "stop people if [she] feel[s] like" it is needed for the patient. The example she gave was "if someone just said 'I want to kill myself' and then the dog just walks in."

I acknowledged Emily's use of the term "gatekeeper" and asked her to explain her understanding of the term. She shared the meaning within the "field of music therapy" and how it is used to "screen someone who will become a music therapist and become part of the field in the future." She said she also understands it in "regards to the literal door in the hospital, who gets to walk into it and who has authority to decide that maybe you should or shouldn't walk into it."

I asked Emily, as a gatekeeper, what information she would need to make a decision on a dog team entering her therapy sessions. She answered "I might just assume, depending on where I work, that it has been Okayed at the facility that they've all decided that infection control is appropriate, and we are now offering this to the people that we work with." She continued, "The next step I would want to know [is] that the patient is open to the idea or interested." She paused and said the patient "could see [the dog] and then decide if they want them to come in or not." 
Emily added, "It's interesting to think about, I've never thought about it this before." She said, "nurses do that for me sometimes, and I'm like 'no let me go in, I'll talk to them and let them decide." She thought out loud, "So maybe I should let the dog come in, just as long as I know that they don't have any special risk factors for infection." She added, "I don't think that the unit staff would let them on if they [have risk factors], or they would flag a person. I don't think I would have to do that.” Emily said another "thing to consider" would be "if the kid had autism or something, and they are known to freak out with a dog, or just things that could be elevated."

I asked if there was anything Emily expected the dog team to have on them to show her to help her make a decision as a gatekeeper. She answered that "as a frontline clinical music therapist, no, because [she] would assume that would have happened." However, in a different position, Emily said she if I "was a manager of the facility [she] would want to see paperwork of training." I asked Emily what her knowledge was of the training requirements and she answered "Zero." She said she did "not know where people go to do that," and did "not know what it takes," but she "know[s] you can" and that people "are doing it."

I asked Emily, how she would respond if she was in a hypothetical situation with someone who is scared of dogs in general, but there is a working dog nearby. Emily said she would "probably avoid it first, no reason to be there," but "if they had to be in the same space," she said she would "go talk to the person with the dog and see if there's any way to create distance or what can be done." I asked how she would handle the situation if the issue was an allergy instead of a fear. Emily answered in regards to the hospital 
setting that she would "probably close the door until the dog was gone...they don't usually stay very long." She added,

Well in a hospital they [the nurses and staff] are going to know how big of an issue it is going to be for that kid, and they are going to decide it's just not okay for the dog to come on the unit that day if it is that big of an issue.

Emily shared that it would not be her responsibility to know, but if hospital staff had not done those things prior, [she] "would probably just close the door or not let the dog come in the room, or have the nurses be a little more aware that if they do interact with the dog, they need to wash their hands."

Recognizing Emily's job did not require her to be a gatekeeper for service dogs, emotional support, or therapy dogs, I asked her how she thought we could make the situation easier to navigate for other gatekeepers. She answered "you're probably on the right track with some sort of universal emblem of some sort." She explained, "just like a credential for a person that we know to expect a certain thing from that credentialed professional." She provided the examples of “A doctor's ID, whether an ID or badge, probably in the form of a vest or something, a tag, or their owner has one." I asked if the ID should be concealed and she said, "something very obvious would be helpful and easy." She confirmed that as long as the identification was visible on the dog, verbal interaction between gatekeeper and handler is not necessary.

Emily added, "then again, I think that I feel like any healthcare, or any situation where there's a vulnerable population of some sort, whoever is the decision maker in that place is going to vet it first." She said if "a worker, [or] anyone under that decision maker sees this dog they can likely assume it's been approved and know that it's been 
checked out for it to be okay." I confirmed she was saying "the higher-ups would have hopefully done that vetting." She countered with a laugh "Hopefully, knowing that it's legitimate, not a knockoff vest or something."

I reviewed my interview questions one more time and upon confirming I had asked all of the questions, I thanked Emily and asked if she had any questions for me. Emily asked "How on track was I with understanding these different levels?" So, I shared with her the definitions for the ADA and we talked about the differences. She also wanted to know about where to find out more information. As she described "it's not something someone says one day 'let me go research what exactly this involves.'”

As we talked about the roles of therapy dogs, Emily said, "Everyone is always like 'oh I'm going to get my dog to be trained to be a therapy dog." She said, "I wonder if that's a misconception." During our post-interview conversation, Emily also said misrepresenting a dog as an emotional support dog or therapy dog "doesn't sound very hard."

Additionally, she inquired as to my personal thoughts on her decision "to not let her [student] bring [the dog] to class." So we talked about that and she shared the "[student] said other professors kind of allowed it." Emily suggested "All these students that have depression, maybe they should get a dog and go through the office and get it approved."

After chatting a bit more and answering Emily's questions of curiosity, I confirmed her contact information, thanked her again for her time, and ended the interview. I turned off the audio recorders. Emily left the coffee shop and I made my post-interview notes. 


\section{Faith.}

Faith was the sixth person I interviewed. I had not met Faith prior to our interview, and we set up our interview through text message. Faith said she primarily communicates through text message during the day. During our initial conversation, I confirmed Faith met the qualifications, and that she was willing to participate in the study. I knew Faith worked in a grocery store, but I did not know more than that prior to our meeting.

My interview with Faith took place the on December 13, 2018, in a private meeting room at a local library convenient to Faith's work. In selecting the interview location, I suggested either a library or a coffee shop nearest Faith's work, and she selected the library. I arrived early to make sure we had access to the room and to set up. Once I was in the room, I sent Faith a text message explaining where the room was located in the library. She arrived exactly at our arranged meeting time. Once we were both sitting and comfortable, I started the interview by asking her to describe her overall experience with animals in her life.

Faith said, "In my family, my mom has had dogs, we've had gerbils, [and] we've had hamsters. We love all animals." Faith said, "the only thing [she does not] like is cats... because [she is] allergic to them." She added, "dogs have been my, probably, I guess my 'go to."” She and her sister "used to have a Pitbull, which," she said, "everybody said that they were dangerous," then countered "they're not, it's just how they're raised." She and her kids also "used to have a little dog... a Chiweenie, it is half Dachshund and half Chihuahua." Faith said they "loved it, but when they got so busy with school and activities, [they] just couldn't take care of [the dog] way that he needed 
to be taken care of." She shared with me the process she and her kids went through to rehome their dog with a family friend.

Faith continued, "I've always loved animals, and with being at [her current grocery store employer] for almost 13 years, I love the rescue dogs that they have that come in throughout the whole [store], all the times I've ever been there." Faith described "one lady that [came] to mind" from when she "worked in the pharmacy." Faith said the woman "has seizures really bad" and "needs the dog." She said, "don't ask me how, but it's amazing how they can, a dog will know if she's getting ready to have seizures or not, and none of us will know that, but the dog does." She added, "I think that it's awesome how they are trained to know that."

Faith described "another friend of [hers] that...has Type 2 Diabetes [and]... also [has] a dog." She said that "when his blood sugar gets too low, the dog just goes hysterical, and it's because he's trying to tell everybody," she snapped her fingers and said, "Hey, he's getting ready, he needs insulin and he needs something!" Faith added, "I thought that was awesome. I didn't realize that they could actually train it to do that, and I was amazed."

I asked Faith to tell me more about the dogs she had seen while she was at work and her experiences with them in the store. Faith explained, "a lot of people are wanting to touch the dogs." She said she tells them "You can't touch them, not unless the owner tells you that you can touch the dog, and that dog has to have that command." Faith shared that the woman she described from her time in the pharmacy, still comes into the store with her dog. Faith said she has known the dog "since she's been a puppy," and "when the dog sees [her] she gets so excited." Therefore, the woman allows Faith to pet 
the dog. She said, "the woman will tell her to sit, and then she's like, 'Okay', and [the dog] goes straight to me." The woman has said, "I don't care if Faith pets her, but Faith knows I have to let her know it is okay for her to pet."

Faith shared that "kids especially, they love dogs" and she has observed them wanting to pet the dogs. In those situations, Faith said she tells the children, I know you want to touch the dog, but can't touch it....It's a service dog. It's trained to be with that person for a reason, whether it has seizures or whatever it may be, that that's why that dog is there, and that dog is going to protect that person and be like, 'Look! Hey, come on! I know something’s going on!' Faith described witnessing a service dog at work. She said, I've actually seen the one dog, the woman I'm talking about, I have seen [her] dogs literally pull, when she was getting ready to have a seizure, the dog literally pulled her over to a chair because he knew she was going to go down. She said when it happened people asked her "why weren't you nervous about this?" To which she replied, "because I know that he has his instincts, and that's what he's trained to be, to do."

Faith then shared that one of her family members is a police officer who had experience training a "drug dog [to work] with him." She said, "they start [training] as a very small puppy, and then they just keep training, and it gets more intense and more intense until they're completely trained." In talking about "watching him with his dog," she expressed "It's amazing how they can do that!"

I asked Faith how she learned her information about service dogs. She said, "Well, I got curious when I've seen the dogs come in [the store]." The dogs "normally 
have a little vest on it, and it'll say certain different things." She said, "I know that there are veterans, and they have [the dogs].” She explained she has numerous family members in the Armed Forces, so she recognized the military insignia on the dogs. She said that "with having [her family] and just seeing the customers" she thought "I got to learn some more about this." Faith said she "Googled it...read about it, and got more familiar."

Faith shared with me her thirteen year history with her current employer. I asked if her employer had provided any training on the dogs that she had seen in the store. She said she learned everything "completely on [her] own," and the topic had not come up with her managers at all.

I asked Faith how she differentiated the service dogs from the pets. She answered "I just kind of see their actions. People say I have a good feeling about people's actions...how they are as a person." She described an instance of "one guy" who "was carrying the dog, but [the dog] didn't have harness on it, or anything saying service dog or anything like that." She said the dog "got tired, and it didn't want to do anything, so [the customer] ended up" asking her "Can I go get a buggy and put my jacket down so that my dog can sit in here and go shopping?" She told him "Yeah, that's no problem" and the customer told Faith "I have to have her, she's for my... I have really bad anxiety.... I get really anxious, really easy."

Faith said, "Apparently when he would get anxious the dog knew, and he would just pet that dog." The man told Faith "this dog has really helped me," and the man's wife said, "this dog is amazing, it goes wherever we go, wherever he goes, that dog is 
there." Faith replied to them "That's great, I really didn't know about somebody having anxiety that bad having to have a dog either."

In response to Faith's “curiosity", the customer acknowledged "[the store has had] a $\log$ of dogs [come in]" and he did "not care to talk to [Faith] about it". He told Faith "a lot of times they don't want us to put a vest on [the dog]....A lot of times the dogs don't like it." However, he showed Faith "he had a bracelet that had it on there, and had the dog's name." "The dog [also had] a collar and on the collar, it [said] 'service dog for anxiety for this patient." The customer said to Faith "dogs are more of a person's friend than anything because they can do the love."

Faith related that customer to her "uncle" who "has old timers". Faith said he "got a $\operatorname{dog} . .$. and he loves that dog that dog is like his child." She talked about the family dynamic between her family and her uncle. She said the customer's dog and her uncle's dog inspired her to "look up more about anxiety," about which she commented "I never even knew a dog could have that instinct!"

I inquired about what exactly Faith searched for when she did her research. She said she types "service dogs for anxiety" or "dogs for people who have anxiety or have depression." She shared a personal story of a "friend of [hers]" who "had really bad depression." Faith talked about how she interacted with the friend, and said the friend "just got a dog." Faith also talked about "being a single mom" and how that has influenced her relationships with her sister, parents and extended family.

Faith shared personal stories about her ex-husband and his family, her children, and a recent breakup she went through. She said, "When we were going through that whole transition, they (her children) wanted a dog," but "at that time [they] lived with 
[her] parents, [and her] parents didn't want another dog." Faith compromised and told her kids they could get a fish, but as far as a dog, she said, "maybe we will have one later...right now, we're just too busy." Faith said,

I don't want it to be locked up in a cage for all day while I'm at work, and then when the kids get a home to be for a few minutes, let him out, and then back in a cage. I don't want that.

I asked Faith to think about her experiences while at work, and asked her to explain more about how she recognized service dogs from pets. She reiterated "look at body language with people, it's kind of like you can figure it out." She continued, "Because I mean most people that have that need, dogs for whatever reason, they have different body language with the dog."

Faith added, "and then we do have people that come in that are not service dogs, and they literally have purses and their dogs are being in there in you're going 'hmm."' Faith made a wondering face. Faith continued,

I know some of these people that I'm talking about with the dogs, they have lost their significant other. Well, that dog, it is like, their happiness. They have a reason for being, they have a reason for living...Because of that dog.

She referred back to her uncle and said,

I have found out in my research, and with my uncle...that with having [his dog], he's living longer, and it's because as he knows he has to help take care of [his dog], he knows he has a reason to get up and go walk, take [the dog] out for a walk. 
Faith shared that her uncle is "in a nursing facility... and everybody knows that when they see [the dog], here comes [her uncle], and if they don't [see her uncle], they go looking." Faith recounted a recent event when her uncle had fallen in his room. She said the dog "knew something wasn't right," so he "went out [to the nurse]" and the nurse "knew something was wrong because [the dog] was just going in circles... and as soon as he saw that she looked at him, he would start moving." Faith explained that eventually the dog led the nurse back to her injured uncle. She said the nurse "found him because of the dog." Faith said, “I thought that was wild, because I don't think [the dog] was ever known to do that....but because he has been with [uncle's name] for so long....he just knew something was wrong."

After Faith shared more about her uncle, I asked her about her employer's dog policy. She said, "They're not supposed to come in." She explained, "As far I know, there is no sign, but I've never known of anybody to be thrown out that has a dog for any reason." Faith shared, "there's this woman, she carried[d] around this little Chihuahua all the time, it was a miniature Chihuahua, and she'd bring it thing in every day. She would have him all wrapped up in her jacket." Faith said, "and as far as I know of today, that dog had no service, no service, it's just her dog. It's just her pet, and that dog goes wherever she goes."

I inquired if when Faith saw a dog entering her store, if she felt the need to determine whether it was a service dog or just a pet. She answered "most times I do.... most of the people that come in now, I know them because I was right at the front door." Faith explained that her job responsibilities had changed and she was no longer at the front door, rather she is "doing four jobs in one every day." Therefore, she does "not see 
them very much." Nevertheless, Faith said, "most people that's been at [the store] for so long, they know whether [they are] service dogs or they're just dogs that these people need for some reason." She reiterated "I've never known of [the grocery store] to throw out anybody for having a service dog, or just a regular dog in there."

I asked Faith to describe what the dogs she understood were service dogs were wearing. She answered, "most of them have like a, it's some kind of like vest, and normally it has some kind of thing on it, like the Red Cross thing on it like a little package little thing." She continued, "and as far as I know, most dogs, that's what they're supposed to have on. From what I've done research over, if you Google it, most dogs," Faith emphasized the words 'most dogs', "have something like that to detect that they are a service dog for some reason, whatever it may be, but then there are some dogs, they don't like those, and they do have a collar that are on those." Faith said the vest is "normally like a grey or black."

I asked Faith if she had experienced any negative interactions with people who brought their dogs in the store. She recounted "Only thing is, is a lot of kids, and a lot of people, if they're dog lovers and they love dogs, they want to pet them." She added, "I know that, and a lot of people don't understand that you can't pet them."

I asked Faith to describe some of the encounters where she had witnessed people wanting to pet the dog. She said, "most [handlers]" say "Okay, hang on just a moment," and 'they talk to their parents... and be like 'he's a service dog or she's a service dog, I have to give [the dog] the command [before] they can pet."

Faith described "one woman" who "is so sick and she has a dog," but "doesn't let anybody touch her dog." Faith said, "I think I'm the one person she let touch it." She 
recounted that the woman frequents the grocery store because she likes the coffee shop inside, and when she visits, she brings her dog. Faith said when kids want to touch the dog, the woman tells them, "No, I don't want you to touch her." Faith asked the woman, "Why don't you like people touching the dog?" She found out the woman "feels that everybody has germs" and "that it's best that nobody touches her dog, so that when she does pet the dog later, when she gets home...that those germs [do not transfer] because her immune system is not very good." The woman told Faith "I know people probably think that I'm a B...I'm just so sick all the time." The woman allows Faith to pet the dog because she "always hand sanitize[s] [her] hands."

Faith shared about her current job's meaning in her life, and the connections she has made through her years with the grocery store. Faith said her job "gives [her] that community." She said,

I see people that I know, and I see people that I trust, and they know me on a personal level... people tell me all the time, you're always smiling, you're always helping somebody....yeah, even though what's going on in my life, I can make somebody smile.

I asked Faith approximately how many dogs she sees throughout one day in the store. She answered, "about six" and that number is pretty consistent each day. Time of day did not matter either; "it's kind of all day," she said. Faith explained she sees a lot of the same people and dogs "because a lot of the people...they live real close and...there's a bunch of people that come in every day."

I asked Faith if the differences between service dogs, emotional support dogs, and therapy dogs had come up in her research. She answered 'No, I've not really seen 
anybody with therapy or anything like that, except for that one guy with anxiety...and the depression with my friend, but other than that, I really haven't."

When I asked if her employer had any rules on allowing the dogs in shopping carts, or if they had to be on leashes, Faith said, 'I've never known anybody from management to go up and say, 'okay, you have to take that dog out' or 'you need to do this'. I never seen that." She continued, "I've seen a lot, and we have so many associate managers that walk around all day and like I said, I've never seen either nothing."

I asked Faith that if her employer was to adapt their policy to allow only service dogs, and not pets, entry, as a gatekeeper, what information would she need and how could they make the situation easier for her. She said,

If [the grocery store] told me that only service dogs could come in, I would say that they would have to make [a sign]... as soon as you first come in the door and it couldn't be just like a little piece of paper like this.

Faith held up an eight and half by eleven piece of paper. She said the sign would have "to let people know that if it's not a service dog that it cannot come in here, and if it does come in here that you are going to be asked to leave." She added that if her store no longer allowed pets, and just allowed service dogs, it would "probably...turn a lot of people away from [the store] completely."

Faith said, "it will probably break my heart because there's a lot, there's a lot of people that come in with dogs." She explained,

I know people who have lost loved ones, and get a dog just because they're lonely, just to have that companion, and dogs do that. Dogs have that, I don't 
know what it is, but it's in their nature that they can nurture that person and they want that and all dogs want that.

Faith clarified "unless you have got a dog that you want just to be aggressive, but that's how you've had it, but that's totally different."

Faith continued, "Most people have dogs because they want a companion, or they're missing that." Faith said, "I've got four years left of high school, when my kids go to [college], I [am] probably going to get a dog. That's no joke because I'm going to miss my kids." Faith elaborated on her children and their future college and career plans.

I asked how Faith would want her employer to disseminate information to her if a policy changed. She answered "They would have to tell me, they'd have to give me really good points about why." She emphasized the word 'really'. She said, "I'd really want to know why, because I don't see having a Chihuahua, or whatever dog in there if it is, if it makes that person feel better or less lonely." Faith added, "yeah, I don't want it to pee on the floor but okay, it's concrete, it'll wipe right up, if it is poop, it'll wipe right up. It'll clean." I asked Faith if she had any such incidents with dogs in the store. She answered, "None." She also did not recall any interactions with customers who were unhappy about dogs being in the store.

I asked Faith if she had seen any news stories regarding service dogs, emotional support dogs, or therapy dogs. The only story she said she had seen was one of a dog who was injured, "ended up breaking one of its back legs", and money was raised to get the dog "a wheel chair thing, like a roller...dog actually, would fit its bottom on." Faith recalled that a local couple adopted the dog for their daughter who had "Type 2 Leukemia." As she recalled the story, Faith said, "the way that [the girl and the dog] 
interacted with each other when they first saw each other, it was like God literally did that for a reason." The only other story she recounted from the media was of a television program where the host finds homes for rescue dogs and renovates the shelter.

I asked Faith, if a customer asked her why a dog was in the grocery store, how she would handle the situation. She answered,

I would tell that customer 'Well, it's a service dog, there's a reason why that dog has to be there, whether it might be, I don't know, what the reason is, but it could be anxiety...depression...diabetes, it could be any [reason], and if you really want it to know more about it then you can ask the person yourself.'

Faith added that she would offer to facilitate the conversation by asking the handler, "Ma'am, I just have a question for you. This lady over here has asked me a question about your dog. So would you mind talking to her?" She said, "I would just be as helpful as I could."

In the event the dog was not a service dog, Faith said she would tell the asking customer "They're probably lonely. They just want a companion." She added, "most people don't want to be alone."

Faith and I talked about misrepresentation of service dogs. She had "not yet" seen any she believed to be misrepresented, but she was familiar with the idea. She said, "I've thought about...if somebody was actually doing that, and I think that's wrong, but I mean, if it's not a service dog, then it's a dog." She explained, "How I see it, what's it going to harm somebody for having a dog in a grocery store... what's the harm of it?" She continued, "I don't see any harm in it." Faith shared that she has worked in all areas 
of the store, except the meat and seafood department, because she is "highly allergic to seafood," and the café because "[she] will not work there."

I asked Faith how she would handle a situation of a customer who is allergic to dogs being in the store at the same time as a service dog. She said she understood the concern, but questioned, "how much are you going to pass a dog in the store if you have an allergy, and...Unless they didn't give that dog a bath, you're not really going to smell that dog." She added that when customers bring their dog in the store, she is "sure the dog is clean." Regardless, Faith said she would suggest "just try to avoid it," and provided an example of how she avoids cats. She also questioned, "Why do they want to go around the person that has a dog?" The store "is huge," she said. "You can either go on one side and that person can go, and if you need to go down that alley, wait until that person leaves."

I asked Faith about her opinion on sanitary concerns that come with dogs being in the grocery store. She said, "they do try to keep it sanitary, and they're always cleaning." She added, "most people I know, that if they go over to the salad bar and make their salads, normally don't have their dog." In the event "it is a service dog... they'll have the dog stay and they'll go make their salads." Faith said if "somebody was worried about that," she would say,

Look, they have to have this $[\mathrm{dog}]$ for a reason. You have to have air to breathe, they have to have that dog to live. That dog helps them. What's it to you that that dog just stand right there while they make a salad? They're not touching anything else.

She added, "That's just my opinion." 
As I reviewed my interview schedule, I asked Faith if she had any questions for me. She inquired as to the purpose of the research study. I explained my status as a graduate student and how this research topic fit my area of interest. Through this conversation, the topic of standardization arose. Faith said she had "seen the vest and stuff," and emphasized "there's no standardization. There's nothing that's going to be like 'Oh yeah, you know that's a service dog.' There's just nothing really."

In regards to purchasing a service dog vest online, Faith said, I don't think that's right. I think that if it is a true service dog, then there should be some kind of way of making sure that it's a service dog before you get that vest to saying that it is a service dog.

She explained the "vest has to be different," and suggested "the markings are different symbols...for people who have service dogs." She also suggested "that's [the] only vest that they can get," and that people "could only get these vests, at like a veterinarian place, or like a pet store that you know that you have to pass something to make sure that they are [service dogs]."

Faith added, "With people...not knowing, and seeing just the service dog for the first time," they might wonder "is that a service dog or is that just a regular dog?" She said the different vests would help because "then you know that that is a service dog, because it has that vest on, or it has that marking, or it has that, so you know that is a service dog. So you won't have to guess."

Faith said for "people who are bringing in regular dogs..." she immediately clarified "like I said, I don't think anything's wrong with it," but the vest would be an “indication, and people would know that's just a regular dog, it's not a service dog". She 
continued, "then you would definitely know....she may be lonely or he's maybe lonely, he might just want that companion." Faith said in those cases, "She really doesn't need that dog, but in a kind of way she does... because it's like her little companion so she won't be lonely, but it's not a service dog. That's why they have the dog with them." Faith added,

If there was a designation it would be a lot better, because a lot of people then wouldn't be like, 'Oh can I pet your dog?' Because it [the vest] would let them know, it's a service dog. There's a reason why that dog has that vest on.

In the event standardization was to happen, I asked Faith what she thought was the best way to communicate the change to the public. She answered, "newspaper...internet, definitely put something on [the] internet because so many people nowadays they look at the internet, even the paper on internet." She added, "Everybody's going to go to the grocery store, it's somewhere they're always going to go.... Most people put something up at a grocery store." She explained that "people don't look" at some of the signs the store puts up, and the sign "would have to be something bright...something to catch your eye" and make people realize "Oh, we need to read that."

Faith also suggested restaurants. "If you know people who own restaurants, that you can put something up in there, then that would let them know." She said, "I know there's people who go in the restaurant that have dogs....they have to have it, they cannot be without that dog, and that dog has to go in." She said other restaurant guests "probably look at it" questioning "why they got a dog?" If they had that vest on," she continued, "and they had that little manual, they could be like 'well look, these are the 
reasons why' and they could actually have symbols that tell that is a service dog, [and] this is what that dog does." Faith said,

[the manual would] let everybody know in the society, in today's world, that they would realize that that's why that dog is there, it's for that person, and it would give them an indication of what that person might have because it would distinguish all of the signs or whatever. That's what that person has. That's why that dog is in there.

I asked Faith her thoughts on the service dog vest divulging a person's disability. She said, "I can see their point in that too....but the more people [who know] about that with you, they're probably going to be nicer to you." She added, "today in society, you see all kinds of people.... I think it would be better for people to know than not to know." Faith said provided an example of what she would say. "Look I know you have this disability, and I know you don't want people to know, but if they don't know, if something happened, then you can't get the help you need." She continued, "but, if people know about it, and know exactly what you've got, then if something happens to you, somebody can call $911 \ldots$ and it can save somebody's life!"

As Faith and I finished our interview, I reviewed my interview questions one more time and upon confirming I had asked all of the questions, I thanked Faith for her time and participation. She expressed excitement and interest in my professional goals and asked questions about my future plans. Faith did not have any more questions pertaining to the research topic, so after we chatted a bit more, I confirmed her contact information, thanked her again, turned off the audio recorders, and ended the interview. Once in my car, I made my post-interview notes. 


\section{Gloria.}

Gloria was the seventh person I interviewed. I had not met Gloria prior to our interview, however we had talked on the phone when I asked for her participation in my research study. During that phone call I confirmed she met the qualifications, and she shared with me that she had experience with service dogs in her boutique, and as a volunteer with a local service dog training organization. I did not know more than that prior to our meeting.

My interview with Gloria took place on December 17, 2018, in a backroom of her boutique. Gloria volunteered her boutique as the location for our interview, and the backroom as it provided privacy for our conversation. The backroom was a quiet stock room with a table and two chairs. I had not been to Gloria's boutique prior to our meeting, so I arrived early to make sure I had plenty of travel time. I prepared my notes in my car and then went in. The boutique was busy so I let a sales associate know I was there to meet Gloria, and looked around the store while I waited.

Once Gloria was finished helping customers, she and I started the interview. During our phone call, Gloria had told me that she would not be able to take forty-five minutes to an hour for the interview; she was just too busy; however she would try to give me thirty minutes. Respecting her time constraints, I skipped the preliminary questions about her overall experience with animals in her life, and started by asking her about her relationship with dogs in her life.

Gloria shared that she "had a dog growing up," and has "always loved dogs," but as an adult she "never thought [she would] have one for a pet because it's a lot of work." Her kids, however, "begged for one" and when the opportunity presented itself to "keep 
[a] dog from being euthanized," they "rescued" their current pet dog. "That was the kids' Christmas gift from Santa," she said. They adopted their dog "five years ago."

While telling me about their "Christmas gift," Gloria shared that her "daughter is a huge dog fan," and while "running for office," with a local service organization in 2017, her daughter "had to choose an organization" for which to "raise awareness" and "raise funds." Her daughter chose a local nonprofit, service dog training organization. Gloria explained that the organization "takes rescue dogs and train[s] them" to "give the dogs to our country's veterans and war heroes who need a service dog." Later she explained this included "first responders, police, firemen, [and] EMS." Gloria shared that the dogs are trained at a formal training center and "in the prison system," therefore the training "costs a lot less."

She continued to tell me about how her daughter "raised a ton of money" and they "did it again this year." One of the service dogs "was named after her [daughter] and given to a veteran," and in the second year they "raised enough [money] for two dogs." Gloria added that "one of [her] best friend's dad has PTSD" and "if he makes it through the application process, he will get a dog." She summarized, "So yeah, it is pretty cool. It is really cool."

I asked if that was Gloria's "first experience with service dogs." She answered, "Yes, the first experience I should say to truly understand." She explained that "through helping the organization [she] was around them more, and different people have different ways of working with their dog." However she "had been around them before." In particular she "had one come in [the boutique] when [they] first opened." Gloria said she “just knew you shouldn't pet it and that kind of thing," but after volunteering with the 
service dog organization she has "become more comfortable with it." Her comfort included being "more open to talking to the people who have the dog about their dog...on planes or whatever, because usually that dog is their buddy so they are usually very passionate about it and want to talk about their dog."

I asked how Gloria learned she was "not supposed to touch" the dog. She answered "I don't even know how I started learning about it because I didn't grow up with service dogs, I didn't really know that much about them." She laughed and shared that "before [she] did this [the boutique]" she "was a "physical therapist" and "in the hospitals they would teach us about them." She confirmed the information came from higher-ups. She said she would also "see them in the malls or whatever," and "just knew that you're really not supposed to touch them because they're working." Gloria added, "but you know you're always friendly to them," and "sometimes you'll just say "what a beautiful dog." She said she "never touched them until now, with the organization" and since she "know[s] the veterans" they will tell her "oh you can pet him."

I asked Gloria how she would describe her knowledge of service dogs. She answered, "I would say I know more than the average person because of us being so involved with [the service dog training organization]." She continued, "I have nothing but wonderful things to say about service dogs." She slowed down and added, "if they are truly a service dog," with emphasis on "truly." Gloria said, "Now there's a lot of people, and this is something I'm very frustrated about...they'll say 'oh this is my, my service dog', but they're not really, they haven't gone through the training." She explained, "a lot of people just have a dog and say 'oh well I need the dog to get through my day" but the dog "hasn't gone through the necessary training and they want to take 
them on the planes." Gloria added, "I get that, but that means everyone should be able to do that." She said she "understand[s] they're really trying to work through... with the laws a better system so that in order to truly let a dog come through, they need to show proper identification, because there's a lot of fakes."

I acknowledged Gloria's mention of misrepresentation of service dogs and asked if she had "experienced it first-hand." Gloria answered "Yes, I mean when you see a dog who's a small dog, and they're barking." She stopped herself and said, "you know there was someone who actually came through my store... she had like a little harness and I think I saw a badge on. I've seen dogs come through here, they don't ask." Gloria stated that "people feel like they can take their dogs everywhere but they don't take into account that maybe someone's allergic." She would "rather" they ask "do you care" before bringing the dog in. She added, "never do you have to ask me if it's a service dog and you have a badge on." She brought it back around to the "one particular dog....there was no way it was a true service dog because it was barking...in the store." Gloria said the customer with the barking dog "ended up having to pick an order up and then she left after a few minutes" and that was the only negative experience she had with dogs in her store. She stated, "So I can see where it's getting a little out of control, people just assume they can slap a harness on and call it a service dog."

I asked if Gloria had "seen an increase from when [she] opened...regarding the number of dogs." She answered, “Oh! Oh yeah!" She clarified "probably not just since [she] opened the store 6 years ago, but definitely." She stated,

I love how people are taking their dogs everywhere, don't get me wrong, but I don't want someone to go out and wrongly call their dog a service dog if they 
haven't been through the training and a true certification. You can tell the difference.

I asked Gloria to explain how she could tell the difference between a service dog and any other dog. Without pause, Gloria answered, "They are supposed to have an actual photo ID." She said, "all the dogs," meaning the dogs who have been trained through the organization with whom she volunteers, "have been fully certified and have been trained and have the proper documentation." She said they do "not just [have] 'service dog' embroidered onto their harness" but "they're supposed to have an actual ID, just like you and me, and they are supposed to carry that around with them."

I inquired if the ID was an organizational or national expectation. Gloria said it "is just [from] talking to the veterans" and added, "so [she] wouldn't know." She shared, "from talking to one of the guys that [they have] become very good friends with," who "is very adamant about carrying proper documentation" is "how [she] kind of knew...he showed [her] the ID." I asked if the ID "helps him keep his dog with him without pushback" and Gloria answered "Yes, yes."

I asked if Gloria's boutique had a dog policy. They did not and Gloria had not thought about having one. She said, "If a dog makes someone comfortable," stopped, then said, "I don't think anyone would bring a dog in here that would harm someone else, that would...have an accident on the floor, whatever, I think most people have a good grip." She added, "and we're very friendly here so we want everyone to be comfortable." Based on that statement, and recognizing she had previously "mentioned the vest," I started to ask Gloria how she "personally distinguish[s]...whether it's a pet," and before I could say "service dog," she replied, "Well, you've got service dogs and you 
have therapy, they're different." She continued, "you can have an emotional dog" and added, “a lot of that, eh, I don't like to judge but I think a lot of people just assume they need one, or [they] need to take [their] dog because they don't want to leave their dog at home."

Gloria provided an example of a "girl who is like [her] sister" who "takes her dog to [an upscale department store]." She added, "he's a goldendoodle," and the girl does so "because she doesn't want to leave him at home." Gloria added, "and she's a very educated woman that works at [the local university]. She's pretty and the dog's cute, so I think she just gets by with it."

She brought it back to the question "But how can I distinguish, well, usually a true dog, like for the Post Traumatic Stress, and ones that are taking care of older veterans, they're larger dogs." The reason being "they need to be able to support the weight of their hero and so they're bigger." Gloria continued, "I guess I'm bigger with those dogs than I am emotional therapy dogs. Emotional therapy dogs tend to be smaller and just a lap dog, and to you know for someone's comfort." She said, "I've never asked if it's a therapy dog," then provided an example. "There's one person who came in, and had a little, it was a yappy dog, and it had a little thing that said 'service dog' on there," she said, and she "didn't ask them but [she] was quite shocked." Gloria said, "After knowing so much about the larger dogs helping the veterans," she thought to herself, "I don't see what that dog is going to do for that person." Gloria has "never confronted anyone about it" but added, "I don't think I would because it doesn't bug me since we don't have a policy." 
I asked Gloria to continue to describe her understanding of the difference between service dogs, emotional support dogs, therapy dogs, and pets. She started by referencing the organization with which she volunteers, and said, “I don't know a ton since I'm just a volunteer." Then continued by providing some examples "you've got people who just need a support dog... you could have PTSD, but not have Parkinson's, or not have any reason for a dog to learn a 'brace' command." In that case, "if [the person is] feeling unstable [the dog] could still be a large dog, and not have every bit of knowledge about [the brace command]." In the case of a support dog, the dog, she said,

[The dog] is just there to keep that person in check...when they are starting to get nervous or whatever, those dogs should know simple things, and they can detect heart rate issues, or stress, and even just as simple [as] if someone's crying they know what to do.

Gloria stated,

So I know there's a difference between therapy and service. I don't, in terms of the emotional, I don't. I haven't had a lot of experience around that, and I know some people just they feel very close to their dog, and they might have nervousness or whatever so they probably need them for comfort.

Gloria added, "I'm being honest that I don't have all of that knowledge." She shared that in the service dog training organization she volunteers for "most of the time they're going for a true service dog that can help with the brace commands and stuff, because they know as these people age, [the dogs] might as well know it, in case they get weak." I asked Gloria to make an estimate on the number of dogs that have come into her store. She answered "eight in the past year" and they were not any similarities in breed 
or size. Gloria said there were "only two that [she] would say were truly service dogs." She recognized them as service dogs because they were wearing "a true vest" and were "larger dogs, usually a lab or a German." I asked Gloria if the "vest had anything written on it or a symbol." She answered "Yeah like 'service dog do not pet' that sort of thing." I asked Gloria if she had had any "verbal dialogue" with the people who brought dogs in her boutique. She said there was "with one of them." Gloria said that particular day they "we had some boxes" around the store, so she had said, "Oh your dog is beautiful...let me know if I can help you get around." The customers said, "Oh no we're fine" and she replied, "something like... I'm glad that you brought your dog in." I inquired about Gloria's "thoughts or emotions" she has had when she first sees a dog entering her store. Regarding "any dog," she said, "the ones that we see a lot are usually just the smaller ones, the ones that are just on a leash." She added,

I'm shocked they don't say 'are we allowed to bring our pet in here' and if it's a small dog, I would say 'if you could hold the dog that would be great, because I can't be responsible if that dog gets lose, or bites a customer or a small child.' Gloria added she has "never felt nervous" or "been upset" over it, but that the experience has been "more of a 'wow, they brought their dog in without asking"" event. Gloria speculated one reason "people just think [the boutique] is pet friendly" could be because they "have posted a few...funny pictures" on social media of dogs in the store.

I asked Gloria about her experiences with dogs in other stores, and if there were any that made her wonder "what is that dog doing here." She answered "Oh yeah, usually the small ones," and added, "it's usually older people who feel like they need to have their little companion with them." To clarify, I asked if Gloria "is it the size or is it 
the behavior of the dog, or a combination of the two, that makes you think that's definitely not a service dog." She said it is both.

Gloria and I talked about her "as a business owner" and if there "are any improvements" she would like to see "regarding service dogs, accessibility laws, and the rules for a public business." She said, "It's tough because for me, it doesn't affect me that much, we are just a small little business."

Gloria shared her opinion on dogs in public spaces and allergies. "I don't think it is right for any dog, if it's not a hypoallergenic dog, should you be allowed to put others at risk." She equated the situation to "kind of like [her] kid bringing a peanut butter jelly sandwich into a classroom where there's kids with peanut allergies" and added, "that has definitely become something I didn't have growing up, and didn't know anything about growing up, and now it seems to be more common." Likewise, Gloria said, "you'll see in some businesses dogs are not allowed...pets are not allowed." She stated, "I don't think there's any reason to put anything that service dogs are allowed...service dogs should always be allowed."

Gloria said, "I think there should be more education about service dogs" and shared that "[her] daughter's school has one." To clarify, I asked "They have a service dog?" Gloria answered, "it's more of uh, therapy, see I always get them confused, but you know for like emotional support. If you have testing anxiety." She said her "daughter loves visiting [the dog]" and that "during finals [she] know[s]" the dog "is there and everyone comes in and pets it." Gloria said she "think[s] it helps with everyone's jitters." 
Gloria continued, "dogs are becoming more common, whether it be service, therapy, whatever...more people are learning about them, so it's not a surprise for people to see a dog walking." She shared the "biggest thing [she is] very passionate about is dogs not being labeled service or therapy when it hasn't been through the training and had the proper identification." Gloria added, "We've got so many veterans from Vietnam that why would you argue when they fought for our country."

I asked Gloria her thoughts on the "best way to disseminate information to the public so they can learn." She answered, "I think social media is your number one way to do it." She did "not know what organization" but suggested "usually the ones that are training [service dogs]...they would have something out there...to share it." Another idea she shared was for "people that actually have dogs" explaining "how to determine whether this is truly a service dog or not and getting that information out."

Thinking, Gloria said, “other than that I don't know, because it's not like you're going to put a billboard up....I really, really don't know...but I think social media is a really excellent place to start." She talked about the service dog training organizations again as "they're going on the news and they're doing all of this stuff, and they probably won't get charged for that type of information, to put out there" which she noted "helps educate people as well." The goal of education, she said, "it's not just...know between these," rather she felt "it's learning what [service dogs] do and maybe how you could apply to get a service dog, or how you could get more information for people who truly need it." In that way, if the service dog training organizations shared that information, Gloria said, "they could do like a 2 punch thing." 
I asked Gloria how her daughter found the training organization for which she chose to raise awareness and funds. Gloria shared that her "husband is a veteran," so her daughter "want[ed] to do something with veterans," but also "really want[ed] to do something with dogs." She said they "started thinking about service dogs" and "looked up organizations in the Kentuckiana area." Through her "online" search, she "looked through four or five" and "called about four." She said her "gut was with" the organization they chose "when [she] saw their photos and talked to a woman...one of the leads of the organization." Gloria said "They're just amazing people," and added that "after [she] talked to [the woman]" she "could tell that [the woman] was very impressed that a 13 year old was wanting to do this." At that point, she and her daughter "were like 'okay we've looked through these four or five, let's go with [the organization they chose]." Gloria said because of their experiences, "we have lifelong service with them." I thanked Gloria for her husband's and her family's service.

We chatted a bit more about the service dog training organization with which she and her daughter volunteer. Gloria explained the organization has been around for about six years and "they just had their second annual event that [she and her family] helped with.” Gloria described the event as “pretty amazing for people who don't know a lot about dogs." She said she "brought a lot of [her] friends to this event, and for them to be able to interact with the veterans, and the service dogs, they are helping get the word out too."

In addition to Gloria's suggestion of the organizations presenting information on the news, I asked Gloria's how she would prefer to be notified if laws regarding business owners and accessibility changed. She replied, "I'm so laid back about it...any way at 
all" and mentioned the "chamber of commerce...or email...or through Facebook" as options, adding "send the information and have a phone number to call if I need anything."

I asked about Gloria's "understanding of the uniforms that are required or not required." She answered "I don't know so much about the uniform, most of the ones that I have seen are just a wider, sturdier vest, with their documentation on it." She added, "usually if they are truly documented, they will have that little badge hanging from them that shows their ID." She explained the ID is "clipped" on "kind of how you can clip on a leash, there's a little clip and your ID hangs from that."

Regarding Gloria's opinion of the most effective uniform, she said she does "not care." She mentioned the size and comfort of the animal as considerations. "I really want the pet to be comfortable, and you know if it's a large dog, they don't mind those type of larger vests." Based on what a friend told her, the larger vests "can be a burden" on the dog, but "they know they are working with it on...if they're properly trained, they know that when that is on them, it is time to go to work." She added, "I really don't mind as long as it's the typical harness that you see that has 'service dog,", and "if [handlers] want the "do not pet." She continued and mentioned the dogs should "have some sort of proper identification just like we would have an ID."

I asked Gloria if she thought the ID, versus a vest, would deter people from misrepresenting their dog. She said,

Well they can always make a fake ID, I mean they can always make it, but having something special that is made by wherever they get the certification, and that across the nation everyone has that same thing, it's got the hologram or whatever, 
if someone needed to, TSA, they know that is a proper documentation, that it's not a fake.

She said, "if there's people who are really going to go out and fake something then going to malls or doing whatever, no big deal," but that and ID "should be just as important as us traveling." Gloria added that she "didn't think that anyone at [department stores] would sit there and look at [the ID]," but that it would help "if they are traveling" because "TSA knows how to deal with that kind of thing." Gloria concluded "if it's enforced, hopefully that will lessen the amount of people that are, you know, because it's not like they can just go get that harness. They're probably expensive to have that proper identification," and "it takes a lot of time."

I asked Gloria there was "anything extra regarding service dogs and public knowledge" and "disseminating the information," or anything else that she would like to share. She replied, "I think you know where people truly get impact, not just hearing from the organizations, but from the people themselves that have dogs and why they are so necessary, because that's where my friends learned." Gloria recounted the value in "just hearing the stories that people were suicidal and this dog came into their life, and immediately they had a purpose to get up in the morning, go let it out, feed him...." She said, "I hope that type of information goes out so people can treat service dogs with respect, and treat the people that have the dogs with respect as well." Gloria stated that in sharing stories, "information gets out to the public so that they're a little bit less turning their nose up at them." I asked if by "them" she meant the person with the dog." Gloria answered "Yeah, because some people just might not assume the right thing, just saying 
'oh that person's got a service dog." She added, "I think that there's a lot of education that's lacking to the public because it's still somewhat a new thing."

I asked Gloria what she would say "if someone is misrepresenting their dog as a service dog, and the conversation did come up." Gloria said she "wouldn't want to judge because maybe they don't have the money, because it can cost up to $\$ 100,000$ for some of these service dogs." She continued, that "if they are faking," she "would ask "now why are you doing that when you should have a properly trained dog, and there's a huge difference of what it could do for you?" Gloria proposed the idea to "maybe twist it and...lead them to the proper organization that they can get [help]." With a laugh, she said that "other than that" she "probably wouldn't get too much involved." Gloria speculated "there's got to be a reason that people are doing this....most of the time...they just want to bring their pets everywhere." She added that "doesn't bug [her]," but that "it's more of the travel thing and...bringing their dog on the plane." Gloria said, "if it's a true dog that's trained, there's not going to be barking and yapping" but that she does not want "a dog yapping" on the plane.

I inquired if Gloria's "friends and veterans take any personal offense to people misrepresenting service dogs." She enthusiastically answered "Oh yeah" and explained, "I think it's because they know what kind of training their dog went through." She said the service dogs create a common bond between the veterans and "they can talk to each other...there's just a common bond and they have such respect for the dog."

She said the response should be to "just say thank you for your service," but that misrepresenting a service dog is "kind of like someone saying that they were in the military and they weren't." She shared that she had "seen the... training camp...and it's 
intense...it's a big deal," and they "give a lot of respect to the dogs that have gone through that training." Gloria added she "does not talk to them too much, but they just feel that [the ID] is a necessary need." She explained that the veterans "want their dog to be recognized as a positive part of the community instead of it being looked down [on]," but when "someone else had a bad experience with a dog who truly wasn't going through training" that negative experience could harm the service dog's positive impression in the community.

Gloria shared with me a personal story of her "best friend's...dad" who "was in the Vietnam War" and "has really bad PTSD." After "they spent thousands of dollars on bills going to therapy," they realized a service dog could be "the last card." She said, "the hardest part" was getting him to consider a service dog because "that's a pride thing, [he didn't] want to tell everyone that [he] had a problem." However, through the service dog training organization with which Gloria volunteers, he became "so intrigued by the dogs... and the other veterans... and [he] learned how these dogs are truly life changing," that he recently started "look[ing] into getting a service dog" and "picked up the application" to get a service dog. Gloria said that for the veterans, "getting there is the hardest part, recognizing these dogs can save your life," and that "talking to others who have one" allows the veterans to "feel a commonality that 'hey we've got something going on and I'm okay." She added the dogs "help [them] not only live longer but live a good quality of life."

For her, she "absolutely love[s] to see service dogs" and has used it as an opportunity to teach her kids that when they "see the service dog, or someone with a [veteran] hat on, [they] always say "thank you for your service." Gloria added she 
"hope[s] that's another good thing that comes with the service dogs being a little more common is that we show respect to our veterans."

As we finished up our interview, I reviewed my interview questions one more time and upon confirming I had asked all of the questions, I thanked Gloria for her time and participation. Excitedly she said, "I can't wait to her how this goes, you'll have to send me a message," and invited me to follow the service dog organization we talked about on social media. She did not have any questions, so I confirmed her email address, thanked her again, turned off the audio recorders, and ended the interview. Once in my car, I made my post-interview notes.

\section{Haley.}

Haley was the eighth person I interviewed. I had not met Haley prior to our interview. During our conversation after the interview, we realized that we are from the same hometown. In setting up the interview, Haley and I communicated through email. During our preliminary conversations, when I confirmed she met the qualifications, she shared with me that she worked in low-income housing. I did not know more than that prior to our meeting.

I interviewed Haley the same day I interviewed Gloria, December 17, 2018. Haley suggested her office for a meeting location and the time was set for just after she finished work and the leasing office closed. I had not been to Haley's leasing office before our meeting, so I arrived early to make sure I had travel time. When I went in, Haley and her co-worker were in the main room. Haley was on the phone with a resident, so her co-worker shared with me information about the housing development, and introduced me to Haley's Yorkshire terrier, Lily, who often goes to work with Haley. 
When Haley finished her phone call, she directed me to a private meeting room with tables and chairs. I set up my recorders, prepared to take notes, and waited for Haley to close the leasing office. Once we were both sitting and comfortable, I started the interview by asking her to describe her overall experience with animals in her life.

Lily stayed in the room with us during our interview and Haley started "Well, as I look at one roll on the ground besides us, I've always had Yorkies." She said she "grew up with Yorkshire terriers, and when [she] went out on [her] own, [she had] wanted one for a long time" and though it "took [her] a while to convince [her] husband, [she] finally got one." Haley added, "So I'm used to having a pet at home." Proudly, she shared that Lily "just turned six, [that] weekend" and she has had Lily "since she was a puppy."

I asked Haley if she was familiar with service dogs, emotional support dogs, and therapy dogs. She answered she was and I asked her to describe her "understating of the differences between them." Haley replied,

So I am a landlord, and I managed low-income housing, and emotional support animals are quite the drama in our industry. The ease with which people can become 'disabled', really is the qualification for someone to have a support animal.

She continued, "doctors will just write notes like crazy; they're easy to obtain, [and] as management, we're not allowed to question the notes that they have. You just can't ask questions, you just have to accept it." She added,

You can't charge any fees for assistance or service animals, and so, making a distinction there, service animals that are providing a specific function versus an 
assistant animal that's more therapeutic, in nature. So, no deposit no pet rent of any kind.

Haley continued,

A law was actually just passed recently in Kentucky, and I know there are a couple of states that have done things like this, that do permit landlords to verify the letters that are given to them by a resident or an applicant's physician.

With the passing of the law, Haley said they "are allowed now," with emphasis on "now", "to require, I think there were five factors on the letter." Haley explained the factors as, We have to know why the physician is qualified to act on your behalf, like how are they treating you? We have to have them say that you are actually disabled according to the Fair Housing Act. There are like five different verification steps."

She added, "So that's kind of nice." She said since the law passing, she "had a couple of people say 'I'm going to get an emotional support animal,'” and she was able to respond, “Okay, that's great. Let me just send you a list of the qualifications that you'll need a physician to provide in the letter." At which point Haley said, "it quickly goes away, you know what I mean?"

She continued and shared some more of her opinions on the assistance animals. She said, "So I do think animals are therapeutic just in general, and I do think that people probably need them on various levels. So I think in the industry, we just..." Haley paused, then said, "We get a lot of people who are trying to avoid a fee or a deposit, but then I also have residents here who have them completely legitimately, and I can see the benefit they make in their life." She stated, "so I don't want to sound negative about it, 
because I do think there's a true benefit, [it] is just hard to sort of sort out legit and illegitimate.” Haley said,

And at the end of the day, really, it's not my job to discern that. If your physician has provided you with the appropriate documentation then I just put it in my file and move on. It's not like I need to make a value judgement.

Haley returned to the original question "But anyway, so yes, pets are purely for pleasure, therapy or emotional support animals, assist people who are disabled according to the Fair Housing Act, and then service animals provide a specific function for people with certain needs."

I asked Haley how the new law has affected her feelings when a tenant brings up an emotional support animal. She answered, after a long pause,

Again, I think landlords are touchy about this, because we see people abuse it to try to avoid fees. And so, my guess is a lot of people, whenever people say an emotional support animal, is that you instantly feel like you're just trying to get taken advantage of.

She shared, "[she has] felt that" and is "not proud of feeling that way." Haley said she does "not think that's a fair response." In those moments, Haley said, "I try to temper that personally... when I feel that to say, 'don't think that; don't let that be your first reaction. Everybody's needs are different. You don't know this person, you don't know their situation, [and] you're not their physician." She shared that she tries to "go through all of that in [her] head," but the law "has been helpful to be able to say to people, 'I'm absolutely willing to accommodate your need. Here's what I need in order to do that. So you can just provide that to me and it'll be fine." Haley shared, "I think it's helpful to 
maybe push back a little bit, but also remain willing and able to help people who truly have a need and who are able to provide documentation on it."

I inquired as to her housing complex's pet policy. Haley said they "accept one small to medium-sized dog, per apartment, less than 50 pounds at maturity." They "do not accept [pet] cats". She said the buildings "were built in 1938" and they "are on the historic register". She explained, their "wood floors are original," and since "cat urine is apparently really acidic and will strip wood really quickly" they do not allow pet cats in the apartments. Haley added, "actually we have a guy here who did have an emotional support cat and his floors are ruined....when he moves it's going to be bad."

Since Haley had mentioned people trying to avoid fees, I asked about their pet deposit policy. She explained, “the deposit is $\$ 300 "$ and "it is not a refundable deposit, so whereas the apartment deposit, when you move out you're eligible to receive some or all of that back, the pet deposit you will not." She added, "The deposit does not cover damages, so if your dog eats the carpet, when you move out, that would be billed separately as opposed to like the $\$ 300$ going toward it." Haley said, “there’s [also] a pet fee, or a pet rent of $\$ 25$ a month.”

I asked if she had noticed any situations where she thought someone was misrepresenting a dog as an emotional support animal because of its size or breed. She answered, "That's a good question. I feel like it's typically more to avoid the fee, but it does certainly help that." She explained, "Whereas we can restrict a pet, we cannot rescue a support animal, in any way, so we can't say no cats, we can't say no pit bulls.” Haley added, "You can have an emotional support horse. You can have an emotional 
support rooster.....it doesn't have to be service, just emotional support." She said that is a federal law for emotional support animals in housing.

I inquired as to how Haley learned about the rules and regulations. She spent time "trying to think of what training [they have] received." She shared that she is "involved with the (local) apartment association.” Haley explained, “There's a Kentucky association, and then major cities, will have their own," and "they provide a lot of training and education." She shared that "the director of the (local) apartment association did a lot of the work to pass the...bill [that] changed [their] ability to verify" emotional support animals, and "he has done educational sessions for people in this business, in the area, and has brought people in." Haley said, "He worked in legislature and stuff, so that's been really helpful to have somebody who knows what they're talking about'. The alternative, she shared, "is kind of like, through the grape vine," and information that make her think, "Wait, what?"

Haley and I talked about her role and responsibility in learning about the laws. She shared that the CEO of [their] management company is on the board for the (local) apartment association, "so he's really supportive of [her] being involved in that, but [she is] the only person in my company who is." As far as her co-workers, Haley said, they all "use a training program, which is an online kind of training schedule" and she "think $[\mathrm{s}]$...they just recently added a training on support animals." She added, "because again, really the waters even at the federal level have been a little bit murky. So I think they just officially added that to our schedule." Haley stated, "I don't know if people have taken it or not, but I would hope that if they don't have the right answer, [they] know where to get it, but I just don’t know for sure." 
As for how many residents have gone in with a service dog, Haley said they "only have two on [their] property" of "251 apartments." The emotional support dogs, she said they had "probably less than ten" on the property at the time of our interview. She shared that the residents "typically" have the dog "when they are applying."

In the event a resident adopts a dog while living on the property, Haley said she "and [her] leasing agent are always shocked by people getting a dog and not calling [them first]." She shared a story of a "gentleman a couple of years ago who had gotten a little baby pit bull, for his family.” Haley said,

Unfortunately we do restrict that breed, which I do personally think is ridiculous, but I get it...liability, I do get it. I think it's unfortunate that breed has been kid of treated, and generalized the way it has been, but I still have to uphold that. So I had to say, 'I'm so sorry. You can't keep the puppy' and his children [were] devastated, and it was just like, why wouldn't you make sure it was okay before? Haley explained, "I love that the [adoption agencies] do call [first]" to check their animal policy, and to avoid situations like that.

We talked a bit more about the property and she shared that they "often see people in the playgrounds with their dog off-leash, so that the dog can run and be fenced in, but," she added, "it's not really what that's for." Since they "have a community garden in the very back corner that is really probably bigger than [they] need," she said they "have had talks about converting possibly half of that to a little dog area." Haley said, "I hope that that will happen in the future, but right now, there's nothing specific."

We also talked about owner responsibilities for their dogs while on the property. With a laugh, Haley explained to me "a pet waste DNA program [they have] in place." 
She said,

So every dog, service or support, has their mouth swapped with a Q-tip type thing when they move in, and we send it off to a lab that collects DNA....then if we find pet waste that someone has chosen not to pick up, we can have it DNA tested. Haley laughed and talked about the value of the program as it "pretty much solves your problem, because the first person to get fined...word spreads....it's been really helpful." She added that "it's also helpful... because that way we do get to meet the animals and things like that when they bring them in." She summarized, "I love it. It's a great program."

I asked Haley if I understood correctly that no one had brought their dog in to prove it was a legitimate service dog. She confirmed "No." Then said, And you know you can go online and pay money to have your support animal registered. Which is completely fake, and not necessary....we always hear stories about that. People are like, 'Oh I spent $\$ 75$, my dog has a vest, they mailed it to me,' and I'm like...that's not really how this works.

I requested Haley tell me more about the things people have told her. She continued, 'there are places who, I mean it's a business where they take people's money and tell them that their dog is certified, but they're in California, and they're not a physician," she explained before they were allowed to "verify the authenticity of the letter," residents were “ providing a letter, but it's not from somebody that's actually treating them." She said,

So, in the past, there was nothing we could do about that, whereas now, one of the things that we can look at, is who is your physician and what kind of care do they 
provide, and if they're not in Kentucky, how are they really...

She stopped, laughed, and continued, "really treating your health?"

I asked if Haley had ever called the doctors to confirm the authenticity. She answered "No." She said she has "never felt the need to call." Haley explained, "really, the people that have provided the appropriate documentation, there hasn't been a question....It's all been legitimate." I asked her if she felt that "just having that in place, where people have to fill that out, is enough of a barrier to weed out a significant number of impersonators?" Haley answered "I do, yeah, for sure."

Haley shared that the service dogs and emotional support dogs on her property are not required to wear a specific marker. I inquired if Haley was familiarity with assistance animals and accessibility laws for public entities under the ADA. She said she was not familiar with them. I explained public entities "have to allow service dogs" entry, but there are no federally mandated uniforms. I asked Haley to imagine she was in the same sort of position, but working at a retail store, and in that role, what type of uniform did she think would be the most effective to communication to her that the dog is a legitimate working dog. She paused to think and answered "probably a vest...something easy to see." I asked if she identified any particular color for the vest and she answered "yellow just popped into my mind, just because it's bright. I'm thinking about caution tape, and reflective gear and things that catch your eye. I feel like I've seen dogs in red," she said sounding unsure.

Haley paused for a while then said, "It would be nice that there was some uniformity." She added, "I don't how to do that though. It's not like there's an agency that is out there to do this. It is people's individual positions, so I don't know how that 
would be regulated." She said with a laugh, "It sounds like a financial opportunity for some company who wants to maybe be at the forefront of their vest." Then concluded "but yeah, I think a vest word probably easiest."

I asked if Haley thought her suggestion would help in the housing department. She answered "I don't know...I don't think it would... because with support animals, they don't have to provide a service." She took a long pause, thought, then continued. "The laws about even addressing people who have a disability, like we can require that the physicians say that they are disabled, according to the Fair Housing Act, but we can't ask how they're disabled." Haley added, "I think that potentially, if the disability, if it's obvious, you definitely can't ask. If it's not obvious, I think maybe there's a little more wiggle room, but I still think it's not wise to press that with people." She stated, "I don't know how that works in grocery stores, or retailers where support animals are excluded." She said, "because I know that the laws are different for housing that they are, even for hotels or stores, so I don't know how that works." She wondered "Do they just come up and say, is that a service dog? I would presume."

I asked Haley her opinions on the best ways to disseminate information to people regarding new legislation, such as the one we discussed, particularly for the people the law affects. She answered "Well, fair housing is a big ubiquitous term that you hear in this type of work." She continued, "Fair housing laws are really important, and people should be trained at least annually on fair housing and how to make sure that we are providing equal opportunities for everyone." She said, "So it seems to me like a fair housing issue that should be covered under that training and hopefully everybody should be doing every year to avoid lawsuits." Haley shared that "there's no overarching 
regulation" and "no one is coming to check if you've done your training, but they do have in the industry testers that go out, call properties or visit properties [and] try to see if people know what they're doing."

I asked Haley her opinions on the best ways to disseminate information to the general public regarding new legislation. She paused for a while, thinking, then said, "honestly, probably just signage at businesses is, I guess." She added, "I mean a Facebook ad at this point...we're all on Facebook" and laughed. She continued, "but no, I think businesses typically have signs that say, 'service animals only'.....So maybe signage like that. I don't know how else."

Haley paused again to think, then said, "I don't know if you do advertisements, TV ads or Facebook ads." She added, "I was joking [about the Facebook ads] but in all seriousness, a lot of people do get there a news, sadly, from that medium." She said with a laugh. "So yeah, I don't know if that would be helpful. I don't really know how else though."

I asked Haley if she had observed a change in the number of pet owners during her ten years as a landlord. She shared that her current property "did not become petfriendly, until 2014." Therefore, she said, "it's hard to completely gauge....but I do recall phone calls that would end quickly once people realized that we didn't accept pets." Not allowing pets was "a deal breaker right off the bat" for a lot of tenants. "As it should be" she added. Making a personal connection, Haley said, "if I was moving, it's the first question I would ask. 'Do you accept a small dog, because if you don't, bye'. [Lily] is not an option for me." 
I asked if Haley had noticed an increase in the amount of dogs she has seen in public. She answered "I tend to notice dogs just because I love them" but she did not notice an increase. I asked if Haley had seen any dogs "tagged as a service dog" that make her wonder on its legitimacy. She answered "the dogs I usually see that have a vest or something like that, I've never thought, 'oh, I wonder if that's such a-.'” She stated, "Which is interesting, that I ask that question on the phone, but then in-person I don't." Haley concluded "So...no, I haven’t questioned that in person."

I asked Haley how she would determine if a dog was a service dog or an emotional support dog. She started out by saying "I don't think that I would ask on a personal level, for any reason." If she was required to know the difference, Haley wondered and struggled, "Oh gosh, how would I phrase that?"

While thinking, she shared a recent experience when she "went to a resident's apartment" and noticed "a really cute dog" that she "did not know he had." Haley said, she "just emailed him and said, “...by the way I met a really cute puppy. I didn’t know if he was yours, if so, congratulations. I do need to get you a little bit of information on our pet policy. So just let me know." She said, "he emailed back and said, 'Oh yeah, he's my new dog. Isn't he cute? I'll come to the office."” After recounting this experience, Haley suggested "maybe just questions that are vague enough to leave the impetus on the person to describe the animal" and "not saying is it a pet or is it a service animal." She said that when she tells people about the pet policy, they "tell [her] pretty quickly if it's not a pet." She added, "I try not to directly ask, I just kind of provide information that might incline the person to tell me more." 
I asked if Haley felt "any need to distinguish between a service and an emotional support animal." She answered "typically [with] service animals, the disability is more prevalent." She shared an example of a resident "who is blind... and has a service dog." She explained,

I don't need necessarily a letter from someone verifying that she's disabled because it's apparent to me. So that might be the only reason, because for assistance animals, we are asking for a letter, declaring a disability, whereas if it's obvious, I don't know that that's as necessary.

Haley added, "I don't think it would matter other than that."

I asked Haley if she was aware of any news coverage concerning service dogs, emotional support dogs, or therapy dogs. She said she was not. I then shared with Haley some background on the different accessibility allowances for the ADA and air travel. Haley commented, "I feel like I've heard something that a peacock....Did they refuse service to someone who had a peacock, or did the peacock not get on the plane?" I answered that I did not know, and asked if Haley had experienced any issues with people claiming animals other than dogs and cats as emotional support animals. She answered "I've never, I have been fortunate in that regard."

I asked Haley if this topic had come up during discussions within her community of landlords. She answered "Yeah, it's always a lively conversation, with different experiences and stories." She observed "from other landlords, a lot of annoyance and people who are quick to assume that they're being lied to." She said, "I just think the general perception is that people are trying to avoid paying fees for their animals...the primary thing I hear is they're trying to get away with skirting the rules on that." She 
added, "I try my best to not assume the worst, and I feel like a lot of people are just a little bit jaded about it."

Haley then described a recent personal interaction with another landlord. "So my husband and I are divorcing, and we were looking for an apartment....we wanted to have equal care of our Yorkie," she said. "The guy that we were talking about renting from, I know in a very limited professional setting." Haley explained, "He's an older gentleman, he has 12 units, it's not his primary role, so he has a business and he happens to have these 12 units."

She continued, "I called and explained my situation, and he was very kind and wanted to help. I said 'you know, we do have a Yorkie. I just want to make sure that's okay." At which point "he was very quick to say. 'Absolutely not, there is absolutely no way. I do not allow pets at all." Haley said she asked the man "Okay well, I just want to be clear, if the situation were that she was not a pet, but she was a support animal would that change your decision?" He answered "Absolutely not. There's no way."

Haley said she responded "Okay, well, just from a professional standpoint, I just want to encourage you that that's actually illegal." She said the man "was so upset with [her] and so defensive, and just shut the conversation down." She said she explained to the man, "I just want you to know, of course, we would abide by whatever rules you have, but just from one business person to another, I would just be really careful." Haley said the man "was just very adamant that he was not required." Which made her think "someday someone's going to bring a lawsuit." She stated, "it's just sad when people are so reticent to hear, that they might want to look into learning more." 
Haley shared that "when people call" her and ask "Do you charge for support animals?" She is "very quick to say, no," and she tells them "no one can charge you, so if you're calling somewhere and they're telling you that there is a fee, you need to be aware that there's not...and that's across the board, so there's no one that's exempt from that." Haley said she has "encountered a lot of people who are like 'really, that's not what I was told." 'She concluded "So I don't know if people, like this gentleman, just aren't educated, or I don't know if there are people who are trying to see what they can get away with.”

Haley then shared some more stories from her colleagues' experiences. "The craziest story I think I've ever heard," she said, "a guy had three emotional support chickens," she added "and this is so crazy, I don't even think it is real, this has to be made up," then explained "apparently he was eating the chickens, and then going out and replenishing them so he would have three!" Haley said she still questions if that was a real story. She reiterated "I just feel like the general gist I get, the sense I get, is that people are just kind of over it, and just feel like people are just trying to take advantage of them." Haley confirmed the issue "is more financial than anything" and "it's everywhere."

I asked if Haley was aware of any legal issues surrounding the topic. She answered 'I don't think I've actually encountered someone who has had a lawsuit, which is kind of surprising. People like to threaten landlords a lot with attorneys." She added, “so far as people actually getting sued, I don't think I have. I'm curious, so I'm going to ask." 
I asked Haley, as a gatekeeper, if she would like to see any more changes made, in addition to the recently passed legislation. She paused, thought, then said, "I don't know, I mean honestly, these new provisions are extremely helpful, and I don't know that I would ask for much more." Haley added, "In my head, it would be helpful if there was some sort of restriction on animal type. I think it would be a little bit crazy to have an emotional support horse in a 709 square foot apartment." She added, "but thinking from a patient care perspective... how do you restrict that?" Haley speculated,

If someone really does have debilitating anxiety, and grew up with horses, and it's the one thing that helps them get out of bed in the morning, how do you slap a restriction on that, and say, sorry it's not legitimate?

She thought "I guess in one sense...you don't have to live at my property." Then she asked "but what's the answer? You live somewhere that doesn't have any regulations, that maybe isn't a great spot to be, or you own your own home which may not be financially viable?"

Haley stated, "if someone moved in with three chickens, I think it would be really difficult...just imagining...a roosters crowing, and then I'm getting noise complaints." She said, "So, that would be helpful in theory, but I also don't think it would be necessary just for people who do require an animal to function at their best." She concluded, "So I don't really know that I would ask for much more than what we have, honestly."

Haley and I talked a bit more about how the bill has helped her as a landlord. As I reviewed my interview schedule, I thanked her for her participation and we talked more about Lily and my research topic. During this time, Haley stated that misrepresentation of a service animal is included in the Kentucky housing bill. She said, "I want to say the 
fine is like $\$ 1000$ or something, if you misrepresent a service animal." Haley found a text she had sent to a tenant with the requirements from the housing bill, took a screenshot and texted the screenshot to my phone.

I thanked Haley for her participation, time, and staying late after work. She did not have any further questions for me, so I ended the interview and turned off the recorders. Once in my car, I made my post-interview notes.

\section{Isabelle and Janet.}

Isabelle and Janet were interviewed together, making them my ninth and tenth coresearchers, and ninth interview. The original interview was set up with Janet through text message. After confirming she met the qualifications to participate in my research study, we selected a day, time, and location. In selecting the interview location, I suggested either the library or coffee shop nearest Janet's work, and she selected the coffee shop. I arrived early to set up and make sure we had a spot with two chairs, and as far away from the ambient noise as possible. Previously, I had not met Janet or Isabelle. I knew Janet worked at an animal shelter in adoptions, but prior to our meeting I did not know more information about her. I have presented Isabelle and Janet's textural description together for two reasons (a) Isabelle shared more than Janet, and at times Janet responded simply agreeing with Isabelle's statements, and (b) the dynamic in their conversations back and forth provided valuable data.

Janet and I were scheduled to meet at the coffee shop after her shift ended, the evening of December 19, 2018. I got a coffee and sent Janet a text message explaining where I was sitting in the coffee shop. When she arrived, I learned about Isabelle and how Janet felt Isabelle could add more to the interview. Even though all of the other 
interviews conducted for this study were done one-on-one, I did not want to upset my coresearchers so I embraced the change and began the interview with Isabelle and Janet together. This interview followed their stream of consciousness, as evidenced in the Isabelle's first response. Therefore, using the interview schedule and my notes, I asked questions based on their responses. Occasionally information stated at one point in the interview related back to a previous conversation.

Since I had not done so previously, I confirmed Isabelle fit the qualifications, and started the recorders. Also, so Isabelle had all of the same information as all of the other participants, I also shared the goal of my research study. Isabelle's response naturally started the interview. She said, "I will go ahead and let you know I have an emotional support dog....an ESA." Isabelle shared that she and Janet "work with people on getting animals approved for them and into their homes through [the shelter]," and in doing so, she had "seen the struggle of getting them onto campus from both sides... as someone who has one and needs one, and someone who is trying to follow guidelines [and] make sure everyone is working inside the laws." I asked both Isabelle and Janet to share with me their understanding of service dogs, emotional support dogs, therapy dogs, and pets, including the differences between those dogs. I also asked them to share where they learned their information. Isabelle responded "So I've had an emotional support dog for about three years now, and I've suffered with severe anxiety attacks as well as depression." She said, "having an animal gives me a reason to get up, get out of bed, like do my normal things." Isabelle explained that "for about a year" she had her dog "certified as a service dog" because her "panic attacks had reached a point where [she] couldn't even get to class and go through [her] day to day." Getting her dog "certified" 
meant she "had to go through all of the hoops to get him certified" but then he could "be on campus with [her] in class."

Based on her experience of getting her dog "certified to be on campus," Isabelle said, "the biggest issue that I see is that Kentucky doesn't have tight enough laws to forbid people from faking service animals, from faking ESAs." She shared why she felt that way:

Having mine [the dog] who was trained to be in public spaces, and to be in public spaces without disrupting anything, it was really distracting to have him doing his job and them someone else a few seats down having their puppy, who they claim was a service dog...distracting my service animal from doing what he needed to do.

Isabelle added, "which in eight weeks, there's no way an eight week old puppy is a certified service dog." Isabelle continued on and shared that she is "also involved in a community of service dog handlers who've trained their own service animals." The benefit, she said in "people [being] able to train their own service animals" was that doing so had "a tremendous impact [on] their day-to-day lives" because "it cuts down on the cost of having to train a service animal, as well as get[ting] someone to certify your animal as emotional support," which, she added, she had "been through."

Isabelle returned to my question and said, "There's major differences between an emotional support animal and a service animal." She elaborated "so a service animal provides a specific service for a person and they are trained for a specific person, and they have to be able to perform those commands... at a moment's notice, and sometimes without being given a command." She explained, "Whereas [an] emotional support 
animal is just kind of a companion, keeps you company, helps alleviate symptoms of depression or anxiety." She added that for emotional support animals "it is not by law required to be allowed into any public spaces. So they can't go in the stores or anything like that, unless it's a pet friendly store." Isabelle continued, "The only thing the ADA protects emotional support animals for is housing." Housing complexes, Isabelle said, “can't charge you an extra fee, can’t deny you housing, anything like that. Whereas a service animal is allowed to go in public places with you even if it's not a pet friendly place." She added, "emotional support animals can technically be restricted by breed because they are not a service dog." She continued, "A lot of landlords aren't empowered, or aren't knowledgeable of what the actual guidelines are just because it's hard to enforce them." She said the situation "sets them up for a lot of lawsuits if they were to say someone wasn't allowed something they deemed essential for their livelihood."

“Therapy animals," Isabelle continued, "are trained to support other people's needs....they have a handler...it's like what you see at hospitals or nursing homes where animals are brought in to help others." Within her job responsibilities, Isabelle said, "I've seen a lot of people that don't know the clarification." They “don't know the difference... and there's even a third step below those two, which is just a companion animal." Which she said, "is just a pet. It's something you have [that] can be restricted by laws, by breed restrictions, stuff like that." Isabelle said, "We have a lot of people that come into our shelter looking for service dogs, and then myself or Janet help them, [and] educate them on what the different criteria for those are." At which point she said, "they 
usually realize they are not looking for a service animal. That they are looking for an emotional support animal."

At this point, Janet was still very quiet, so directed to both of them, I asked "have you had anyone come in who says they are looking for a service animal and understands what it means?" Isabelle answered "There has been a few but...less than one percent who wants a service dog and knows what a service dog is." She shared, "most recently" they "had a lady coming in looking for an animal that had an aptitude to be trained for her son who had autism." That customer, she said, "understood the training and guidelines" as well as "had a trainer set up to help her." Isabelle added that "because our organization...does not adopt out service animals," they have to "make sure that people know that we are not connected to any type of aptitude for training."

I asked both Isabelle and Janet what terminology the customers use when they come in looking for a service dog or emotional support dog. Janet spoke up "sometimes they say 'therapy' and they really mean 'emotional support'. They don't know the difference" she said. I asked Janet if when they realize the confusion, if they educate customers on the difference. She answered "yes, because they will say 'I have a doctor's note"" and "when they say that we definitely have to correct [and explain] 'oh, so you mean emotional support." To this point, Isabelle added, "even the ability for us to educate people varies." Isabelle said, "not everyone we work with is clear on what all the stipulations and guidelines are." Regarding her own knowledge, Isabelle said, "I know I wouldn't be as clear on them if I didn't personally have an ESA and didn't have to go through all of the paperwork." 
Isabelle then provided information regarding Kentucky legislation. "Recently Kentucky actually changed their laws. As of July, you can no longer certify your own animal as a service dog." She said that under the new law "where you could previously...certify your own dog," now "you have to have... a registered animal trainer that certifies your dog for you." Isabelle said the purpose of the law is "in an attempt to help reduce fake service dogs," but countered that "it's also creating a barrier for people with low income...now they have to pay the hundreds and thousands of dollars to work with a trainer."

I asked Isabelle how she knew about the certification and where one could find out about it. She replied, "If you Google 'Kentucky service animal law' you can see where the law has been changed, but" she added, "they've done a very poor job of outlining what exactly is needed." In that Isabelle said, "They just say a certified trainer must certify your dog, but they don't have a list of what certifications, what that would be." I brought up the ADA statement on certifications and Isabelle said she was aware of what it stated. She explained, "So federally there isn't a standardization, but each state can interpret that how they want to, and each state is free to enforce certifications at their level.”

At this point, I referred back to Isabelle's personal experiences of getting her dog certified. I asked if that is what she went through when she got the service dog certification. She answered, "Yeah" and explained for an ESA "you just have to have a doctor's note." Isabelle added, "Which is another thing Kentucky also changed." She explained, "it used to be that you could go online to those online psychiatrists, or something like that, pay your twenty dollars, and in like five minutes you had an ESA.” 
After the changes she said, "Now it has to be a medical provider that lists their medical license number, as well as one that you've seen for a specific amount of time to treat that specific case."

I asked Isabelle to elaborate on the steps she went through with the university. She answered "I had to meet with my personal advisor, through the disabilities resource center, and he set up accommodations for me." Accommodations included "professors would have to let [her] make up work if [she] were to have a panic attack in class, or stuff like that." Isabelle said she also "had to meet with the director of the center," who "went over the guidelines," including "all the behavior for [her] dog on campus [and] what accessibility needs [she] would have [by] having a dog on campus." Isabelle said she also "had to meet with him again" and take her dog "to make sure the dog actually performed like he was supposed to." After all of those steps were completed, she "got a service dog card specifically for [the university]." The purpose of the card, Isabelle said was "so if any of my professors were to question it, I would have a thing from the university saying [the dog] could be there."

Since Isabelle had previously commented about a puppy being misrepresented as a service dog, I asked her if she encountered other similar situations. She replied, It wasn't so bad when I first started taking my service dog on campus, and then it seems like the last year, to year and a half, it has really, for lack of a better term, exploded with fake service dogs.

Isabelle elaborated, "It has gotten a lot more problematic for the people who are truly needing service animals." She said, "People are bringing like their emotional support animals, who they can legally have in dorms, now they are bringing them to classes, and 
it's being disruptive for the rest of us." Janet asked Isabelle to confirm the local university no longer allows dogs on campus at all; Isabelle verified the statement and said, "[the university] won't allow us to adopt [out] dogs to their campus because we can't guarantee they are housebroken, which you have to do guarantee when you're filing ESA paperwork."

I asked Janet and Isabelle if they had seen a change in trends at the animal shelter with people adopting assistance animals. Janet ardently responded, "Yes. Yes, and I think they are abusing the system, meaning that for people who actually do need emotional support animals. If they keep abusing it, it's really bad for the people who really need them." She said she saw an increase in, "probably the last 3 years." I asked them to what they attributed the trend. Without pause, Janet answered "selfishness," and that "people have learned to manipulate the system." She said, "if they want a certain breed and their apartment says no, then all they have to do is go to a doctor." She clarified, "if they want ... what they call 'bully breeds'...then they will go to the doctor, and get a note," at which point "the landlord can't deny them." Before adopting out animals, the shelter employees "call all landlords to verify" their animal policy. Isabelle added, "People don't want to pay pet deposits"; Janet agreed. Isabelle shared that she thought "pet deposits [were] kind of crazy high" in the area. Isabelle shared, "you can usually tell who is wanting an emotional support animal based off the animals they are picking." She clarified, People bringing in ESA paperwork most often... they are the ones who are coming in and wanting a bully breed that they know their landlord isn't going to 
allow without the ESA paperwork... or [the] high energy, high drive, needs a ton of training and work [dogs] that, in most cases, would cause people more anxiety. Isabelle surmised, "bully breeds or working breeds are probably the most abused ESA breed." She said people "want the cute, fluffy, high energy dog that's going to be so much fun to play with, but," she added "we know how this is going to end up and we have experience with this and a lot of times people don't listen." She shared that sometimes adopted dogs are brought back because adopters “don't necessarily take our education....they get their blinders on. It's like their ESA notes blind them from seeing what's actually happening."

Later in the interview, Janet referenced back to this question and added, "you can tell if they really need the animal [as an ESA]" by "their body language." She said, "if they are willing to share information... will tell you their life story...you realize this person is legit." Isabelle agreed and added, "the ones who are really looking for an emotional support animal... are trying to hold it together." Janet said the ones who do "not actually need the animal....their attitude is snippy," and when she or her coworkers explain they need the ESA paperwork, "they will say 'well, they can't tell me no! I'm just going to call my mother and have my mother come in and adopt the animal."” Isabelle added, "they are entitled."

I asked Isabelle and Janet if their employer provided them any education regarding service dogs, emotional support dogs, or therapy dogs. They both answered, "No." Isabelle explained, "being a nonprofit...they are solely focused on getting animals into homes." I asked from where they both learned their information. Janet responded, 
"I just looked up stuff on the internet." The reason, she shared, was from personal motivation.

While sharing this story, Janet appeared more confident in what she brought to the interview, and elaborated on her answers. Janet "had a dog that was blind and deaf" so she "was on [online retailer's website] ....getting a harness for [her dog]." She shared she would put her dog "in a stroller to take with [her] to the mall, and wanted something to say she was deaf so kids wouldn't come up to her because she would be snappy." During her search for the harness, Janet was surprised to find "you can just buy patches that say 'service dog', or buy a harness that says 'service animal."” She thought "Why should you be allowed to buy this if your dog is not a service animal?" At which point, she shared, she "started paying attention."

At the time, Janet was working at an adoptions center in a pet retail store and observed, "People were just coming in the store....with the harness on their dog saying 'service animal."” She asked some of them, "Oh so did you do any training." To which they nonchalantly replied, "No, I just ordered it off of [online retailer] and now I can take him anywhere." Janet exclaimed, "I was shocked! ....People actually told me!" Janet said the realization prompted her to ask the dog trainers working in the pet retailer, if they "[knew] this was going on." They did, but were surprised she knew. She recalled the learning experience as a whole. "People were just coming in with patches sewed on their regular harnesses, and I was like, oh no, I have got to do some research on this!” In addition to the "fake vest," Janet recalled seeing the animals "not behaving right" and "vests that [said] 'emotional support' or 'therapy dog."” Janet laughed and continued, 
"I've seen it all at [retailer]....so I just researched it on my own." She summarized her thoughts during the realization as "this is crazy."

Janet shared, "probably a month later" she saw "a special on 20/20 on people flying with emotional support animals and carrying their doctor excuses with them." She recalled the story inspiring her to "start doing more research on that." In the story, "they were having micro pigs, snakes, chickens...bearded dragons and stuff like that...they were saying that they were going to crack down. You can't just get on a plane with a chicken....they were not in animal carriers.” During her research Janet said she was thinking "Why would you want a chicken to be an emotional support animal to fly with you on a plane?" In a questioning tone she pondered, "maybe at home, but a chicken just running around on a plane?" She then made a personal connection to the situation and explained how even though she "like[s] snakes," she would "not want to sit next" to one on a plane. Overall she remembered thinking, "this is crazy...getting on planes with snakes and pigs... that's crazy, that's wrong."

Based on Janet's story, I asked how Isabelle and Janet would navigate a similar situation if someone was sat next to a service dog, but was scared of the dog. Isabelle started "I have fairly strong opinions on that...it's one of those things I get on my soapbox about and sometimes say things that people don't agree with." She continued, If it's a legitimate service dog, it's trained to stay within so many feet of its owner. It's not going to bother you. It's not going to want attention from you. It's going to be solely focused on its job. 
Isabelle added,

You wouldn't deny someone with a different illness access to their medication....a blind person walking with a cane, you wouldn't tell them their cane was annoying you, or that their cane was offensive. Or you wouldn't tell someone with seizures 'oh sorry, you can’t have your epilepsy medication because I don't like the bottle it's in.

Isabelle stated, "You can't deny someone access to a public space because you're sensitive.”

Regarding airlines, Isabelle suggested "it would be fair...if you had a dog allergy or something like that, and you had a reasonable complaint to be moved to a different seat." As far as seeing "news articles," Isabelle said she had seen "people having outright fits when they see someone on a plane with a dog, who is a legitimate service animal," which made her think “you are being really selfish. You don't know what that specific person has gone through. Maybe the trauma they've been through in their life and needing that."

Establishing a personal connection, Isabelle shared that she, "went through two or three years of $t$ trying different medications for [her] anxiety." She said she "feel[s] like people don't take the time to put themselves in someone else's shoes when they are throwing their little temper tantrums on airplanes." Referencing back to "moving seats" Isabelle suggested "politely asking to change seats, but not throwing a huge temper tantrum." She also said she had "been on flights next to a service dog and that made the flight for [her]," then added, "but I'm also an animal lover." 
Isabelle talked about her personal experiences having a service dog in a "public space." She said, "you feel weird because everyone is looking at you. You don't walk into [a store] with an animal without people looking at you." In those moments she said, You are just trying to get what you need to get done and people are making a big deal out of the fact that you have a trained animal that's not bothering [anyone], it makes you feel self-conscious. It makes you feel bad about the illness that you can't do anything about, and it makes it hard for you to want to access public spaces.

Isabelle suggested "I think people who are throwing these temper tantrums need to take a step back and realize they don't have a service dog for funzies; they have a service dog to treat something that is a legitimate cause."

I asked Isabelle and Janet's opinions on snakes and exotics as service animals. Isabelle answered, "they have yet to show that snakes have any kind of... aptitude to be trained to perform specific tasks for a human." Isabelle continued, "as far as exotics as emotional support animals...I think the handlers need to think that they are choosing this treatment method and ... maybe think of a form of treatment that's not going to be imposing." She suggested, "maybe thinking about how they could be affecting the people around them by choosing that treatment." Janet answered,

I have a bearded dragon, and a turtle, and I've had guinea pigs and hamsters....I feel like those are animals they can make you happy; you're happy to own them, but I don't feel like they are for emotional support....I just don't see any type of exotic pets being emotional support animals. 
I asked how they would feel if a federal law was passed that only dogs were accepted as service and emotional support animals. Isabelle answered, "I feel like they should include cats as emotional support animals, maybe not up to service animals." She explained, "from working at the shelter, I can see where cats do have the ability to build the same connections with an owner that a dog does." She concluded,

So I feel like when it comes to emotional support, it's almost that connection that you have with your animal, and the ability for the animal to almost sense when you need something, I feel like cats have enough personality and ability to understand that cats should be included in for ESAs.

Janet agreed.

I asked if either of them were familiar "with the federal law for mini horses." Neither were familiar, and when I shared the provision in the ADA for mini horses, Janet was shocked because "they are mean suckers." Isabelle said, "the only issue [she] would have with that is their ability to be potty-trained." She explained that "it's not so much the size" and that she had "dealt with people having ridiculously sized animals on campus for emotional support" but that "no one should have to clean up after a mini horse on a plane."

At this time in the interview, I took a moment to review my interview schedule. For clarification, I asked Isabelle how she learned her knowledge. She answered "all of my stuff came from me having an emotional support animal that was then trained to become a service animal." Isabelle shared that she is "a college student from pretty much a middle class family." They "had the ability to afford the doctor end of things...but couldn't afford the multiple thousands of dollars it took to get a service animal." 
Therefore the motivation was "trying to navigate how [she] could meet [her] needs without spitting up thousands of dollars that our insurance wasn't going to cover." For training her dog, she "worked with a trainer ... that was willing to essentially charge [her] the same as everyone else but split up the sessions ...to get the most out of the training with the least amount of money."

Isabelle explained, Because it's hard, it's a grey area when it comes to anxiety, panic attacks and depression on whether or not there's truly a qualifier for a service animal, even though it is covered under the ADA, but it's technically a mental illness.

Her goal was "trying to do it cost effectively, how to do it without spending years on a waitlist." The process "took a lot of online research using government websites, state and local and federal." She said she "couldn't afford to hire a lawyer or do any of that" so she did it herself. She explained, it also required "a lot of arguing with people about how [she] was right, and having to find those laws and sub-laws and bylaws." She said, "I had to have that knowledge in order to have my service dog go places with me." Professionally, it "was hard to find employment without having that knowledge and [being able to] show them that the business itself is protected, since it was my service dog they weren't liable for it." Isabelle shared one previous employer "refused...to accommodate [her] needs" which resulted in her having to leave her position. I asked Isabelle her "impression of that research process." She answered "It mostly made me feel crazy.” She said,

I feel like if I was blind, or deaf or had seizures, people would be like 'oh yeah, you need your service dog, bring him along' but since I have almost like an 
invisible illness, people looked at me like 'are you really sick? Do you really need that?' And it took a lot of 'no really, here's my years of medical history.' Isabelle summarized, “I feel like I had to share parts of my story that I really shouldn't have had to share because my disability is invisible."

Isabelle continued and explained "Even with emotional support animals, that's something that is hard for them to navigate as far as how much emotional support do you need." She said, "Because no one can measure how much anxiety you have, or how much depression you have. There's not a litmus test for that. They can't prick your finger and tell you how depressed you are." In her opinion, "it makes it hard to tell the difference between the people who really need it and people who are working the system."

I asked Janet and Isabelle if they had seen dogs they believed were misrepresented, and if so, how they identified legitimate service dogs from ones they believed were misrepresented. Janet enthusiastically stated she had seen some misrepresented. "First of all," she said,

...if you have a five pound poodle and it has a service vest, but you're carrying it, you're carrying the poodle and it has a service vest on, or it's in your cart... how is that a service animal? What is it doing for you?

I asked if she meant the dog's size was a "red flag." Janet answered "Yes." At which point Isabelle countered, "I mean sometimes when it comes to size, it can be something like blood sugar problems where they just have to notify their handler that they are having that." In a strained voice, Isabelle continued, "so I can kind of see that, but most of the time." Janet interrupted, "when it's barking." Isabelle agreed, "Yeah, like barking, 
trying to get down to play, it usually comes down to behavior." In agreement, Janet replied, "That's not a service animal, because service animals know not to play, they know not to get attention, they are focused on a job they are supposed to be doing." For clarity, I asked if "behavior across the board" communicated to them the legitimacy of a service dog. They both confirmed it did.

Isabelle elaborated on the expected appearance and behavior of a service dog "Another thing too that clues me in, is that a service dog should never be harnessed into its vest." She said, "Its vest should almost be like decoration, or a flag saying 'I am working." She added "[and] they should have good leash skills. They shouldn't be pulling a handler. They shouldn't be trying to get into bins at a pet store." Isabelle explained, "Even in times of high distraction they should stay focused. They shouldn't have accidents in a public place." As far as people putting "every patch you can imagine" on the dog's vest, Isabelle believed it was "like they are saying 'if I put enough patches on this animal no one is going to ask me any questions."”

Our conversation naturally transitioned into the verbal interactions had with service dog handlers. Isabelle stated, "If somebody has a real service dog and you ask to pet the dog, they will tell you no, because the animal is working." She exaplained, however, "if it's not a real service animal they will be like 'Oh yeah! He loves attention, he loves cuddles."' I asked Isabelle and Janet their "understanding of verbal interactions you're allowed to have with someone who has a service dog." Isabelle explained, From what I know, from having one, you can only legally ask two questions. Is your dog a service animal and what tasks is it able, or what tasks does it perform? Other than that, they cannot ask for medical documentation. They can't ask for 
like a service dog ID card. They can't ask you to have the animal perform that tasks. It's just the two yes/no questions and after that they can't continue to ask questions.

I asked Janet her answer and she made a facial expression showing agreement with what Isabelle had said, but did not verbally reply. Later in the interview she shared that she thought you could ask for proof of the dog's certification or ID.

I inquired as to their opinions on why they had seen so many different uniforms being used. Isabelle said, "I think it's to stop someone from asking them.... If someone were to want their animal to be an unmarked service animal ... because the vest doesn't really mean anything." Isabelle stated the questions could be asked because uniform requirements are "not a state law...not sure if it's a federal law, but you don't have to mark your service animal as a service animal. They don't have to be vested, they don't have any service things marking them." Janet did not answer.

Directed to both co-researchers, I asked their opinion on a "visually identifiable uniform standardization for service animals." Janet said she prefers "the one that actually says 'don't touch me. I'm working."” To her, "that is a legit service animal." Janet provided the example that she had "noticed lately they have started using more dogs at the airport," and that the dog's vest says "I'm working. Do not touch me." For her, “see[ing] a service dog...makes [her] think of a police dog...it's working, it's got a job to do." She explained the uniform "is how people recognize authority," and "that's what people's reaction should be when they see a service dog. They actually are working; they are doing a job. It should be like the same thing." Janet added, "I don't know how that can happen." 
Isabelle agreed "it would need to be visible," and added "something brightly colored that you could tell when an animal walked into a business that it was working and that it wasn't someone's pet that they decided to take to the mall today." Isabelle suggested, "the dog should be vested with, like if it's a service dog, I think it should say "service dog." Going back to her comment on the amount of patches she had seen people use on their vests, Isabelle clarified "I don't think people need to go as far as all those patches that say 'please don't pet me. I'm a service dog.' Because" she continued, "with increased education, people would teach their kids not to touch service dogs." I asked both of them if there is "any particular color" they thought "most appropriate." They both answered red. For Isabelle, "the emotional connotations with something in red, it's very official"; she also added, "royal blue" as a suggestion. Janet said, "like fire truck red."

Later in the interview, I asked them how they would respond to those who do not want to put a uniform on their service dog since it could disclose a disability. "From personal experience" Isabelle said, “the second you walk into a business that isn't pet friendly, with your dog, it's out there that you have a disability." She said, "there's no hiding a 70 pound golden retriever....it's going to cause you less hassle to just mark your dog...when you walk into a non-pet friendly establishment." The hassle, she said, would be "you're asked why you're bringing your pet in" at which point she said the handler would "have to explain, oh it's a service dog, and... go through 'is it trained', and [so] on."

I asked if they their opinions on requiring service dog handlers to put a standardized uniform on their dog. Isabelle said, "It's going to be easier for people to 
navigate spaces by marking [their] dog." She added she doesn't "know very many people within the service dog community that object to putting a vest on their dog... a bandana, something that marks their dog as a service dog," and because "in society...everyone is taking their pets everywhere... unless you can mark that yours isn't just a pet, people are going to assume you're just bringing your pet in because you don't care about the company's policies." I asked Isabelle if she thought "it was reasonable to say if you are not willing to put the uniform on your dog, then you can't expect to be allowed entrance to public spaces?" She confirmed, and made the comparison of "you wouldn't be able to tell your doctor 'I'm only going to take half of my pill.'”

Adding to the topic, Isabelle said a visibly identifiable uniform "would also increase the ability for people to forge it." She said, "even if there was a standardized vest, someone out there is going to forge it." She acknowledged that "you can get a vest on [online store]," and that she did not think a standardized vest would "make a difference as far as fake service dogs go.”

I asked what they thought about something like a "driver's license" or an ID. Janet replied, "That would be nice." Isabelle replied, "It would be really nice” but countered, "they would have to really look into how they are requiring people to do that, what costs are going to be in it." In the event there were fees associated with obtaining a service dog ID, Isabelle expressed concern over "some pushback." She explained the reason was "anytime you take something that is free and then you put a cost to it, and not only are you putting a cost to it, you're putting a federally mandated cost to it... someone out there is going to offended." She said people would respond "Oh well this is just 
another way for the government to make money," and added, "they'd have to be really, really careful how it's done.” Isabelle said of requiring a standardized ID, It limits accessibility for low income, marginalized families who maybe don't have a way to get to the doctor's once a week to get that paperwork, or maybe don't have a car to get to the place that's doing it, or even if they don't have access to a regular working computer.

Isabelle stated, "standardizing things will slow down the fakes but also increase the cost of things for people who maybe can't afford it." She offered the solution of "have it be something required that your insurance would cover because then if there's insurance coverage it would be almost like picking up your prescription once a month." Isabelle later commented, "if we went the route of... a standardized government issued... uniforms, I think the person should have a standardized, almost like a driver's license."

Later in the interview, Isabelle commented on the financial aspect of having a dog, and that it "comes back to more education of what it costs to have a dog." She provided a personal comparison of how her emotional support animal has cost more than her antianxiety medicines. She emphasized "it is important to increase education, not just for service animals and emotional support animals, but across the board." Within their job responsibilities, they both agreed, "we don't have time to fully lay out what it's going to cost people."

I asked for Janet's opinion on fees for getting a service dog ID. She said, "I don't' know. I have to think about that one," and took an extended, silent pause. She then said, "Since we're talking about insurance, like health insurance, I think it should be, 
I guess picked up by your insurance. I could see that." Her reasoning was "because the people who go to the VA hospital, it's picked up by the VA, so it could be picked up by other insurances."

In regards to the community aspect of the phenomena, I asked Isabelle and Janet for suggestions for improvement, particularly referencing their personal experiences with shelter adoptions. Janet answered "I think it starts with the doctors. I can't walk into my doctor's office and say 'hey write me a note for an emotional support animal.'” Isabelle added that she "had to go through years before [her] doctor would write [her] a note." Janet reemphasized,

I think it starts with the doctors, I think why is it so easy to walk into a doctor's office and say 'I need a note for an emotional support animal'? I don't think it should be that easy. I mean, not if you've never seen the doctor before, you don't have a history with the doctor. I mean, have you been on any type of medication? It shouldn't be that easy to just make an appointment and tell the doctor you need a note.

To this point, Isabelle shared that she "was told by a doctor that at [the local university] both psychiatric and student health services no longer write notes for emotional support animals." The reason she "can only assume [was] because they've had an influx of students just looking for emotional support paperwork and not actual mental health help."

When asked if they perceived any other reasons, in addition to the previously said selfishness, for the apparent increase, Isabelle accredited it to the "cultural acceptance of mental health problems." She said, 
I think the increase in awareness of mental health issues, and communities as a whole being more accepting of it, has increased the amount of people who feel like they can actually help themselves by getting an emotional support animal and not feeling ashamed, or like a black sheep for getting one.

Janet added that she has "anxiety" and "[didn't] think she could survive without a dog or cat in the house."

I asked why they perceived a growth in misrepresented dogs, to which Isabelle responded, "because there's no system for checking whether or not it's truly needed." One main place where she identified the issue was in housing where "landlords aren't educated on what the policies are. They're just trying to keep themselves out of lawsuits, they just say 'yes, I'll accept your paperwork' out of fear of being sued." She offered the solution to "educate homeowners, educate landlords and property owners, and educate them on what their rights are as well as increase education on what it means to have an emotional support animal and what that entails."

As far as the adopters she had worked with, Isabelle credited misconceptions leading to misrepresentation. Isabelle said,

A lot of people come in and they think they are going to get this magical emotional support animal that is going to magically solve all of their problems, and that they are never going to feel sad again, or never feel anxious again, when that's not necessarily the case.

Isabelle added, "there's a lot that goes into being an animal owner" and for her "there have been times when [her] emotional support animals have not been very much emotional support because they are the ones causing the anxiety." Janet expanded on 
Isabelle's perceptions of the adopters and said, "They forget you got to still take it to the vet, you got to get the vaccinations. They don't think about that. They just think about it is going to love me, it's going to be there for me."

I acknowledged their references to education and asked their thoughts on "the best ways to educate people on service dogs, emotional support dogs, therapy animals, and etcetera." Isabelle answered first making a connection to their jobs. "I feel like animal shelters, in general do a much better job at going into the community and educating people." She said, "People see us as the beacon of animal knowledge...that we should know everything about animal care, animal welfare, emotional support animals, [and] service dogs." Based on that, Isabelle suggested "shelters can have programs where they go to...college student housing developments, or large housing developments...or invite all of them" to "a presentation," or, she added, "go to those communities and educate them on what their rights are."

Another option Isabelle proposed was for people "wanting [or] maybe thinking about getting an ESA." She suggested to "have like a coffee hour and educate them on what it takes to have an emotional support animal, the care aspect, and what their rights are as pet owners and emotional support animal owners." Janet responded that she agreed with Isabelle's suggestions but did not offer more. I asked Isabelle and Janet the best way to disseminate information to people. They both replied social media. Janet said, "everybody checks their social media."

I thanked both Isabelle and Janet for their time and collaboration in my research study. Janet laughed and said, "Isabelle has [been] more [helpful] than me." Isabelle inquired more about my thesis, which led to a discussion about people's connections with 
their animals. Janet and Isabelle both said they "would rather spend time with their animals than their loved ones." Isabelle added she "is as single as it comes" and “choose[s] not to go on dates...because [she] could sit at home with [her] dogs and...know it's going to be awesome versus a mediocre at best date." Janet added, "When your pets are around, you are happy." Isabelle commented, "That would actually be a really interesting study." We wrapped up our conversation, I collected Isabelle's contact information, and confirmed Janet's. I thanked them again for their participation and turned off the recorders. Once in my car, I wrote my post-interview notes.

\section{Kevin.}

Kevin was the eleventh person I interviewed, but tenth interview. I had not met Kevin prior to our interview, and our communication prior to the interview was all through email. Kevin was the only interview done after "the holidays." He expressed interest in participating, however was not able to schedule an interview until after the start of the year. Through our email correspondence, I confirmed he met the qualifications, his interest and willingness to participate, and set up the interview. Other than the fact that Kevin was a qualified participant, and that he owned a restaurant, I did not know more than that prior to our meeting.

My interview with Kevin took place the on January 22, 2019, at his restaurant. Kevin had suggested the restaurant as the location. The time of our interview was selected based on convenience for Kevin and, as he said, the restaurant "should be quiet enough at that time of day." I had not been to Kevin's restaurant before our meeting. I arrived early to review my notes and prepare in the car. I went into the restaurant a few minutes before our scheduled time. One of the restaurant servers suggested a quiet table, 
offered me coffee and I set up the recorders while I waited for Kevin. Once Kevin and I were both sitting and comfortable, we briefly talked about my research and his restaurant, which he calls a café, then I started the interview by asking him to describe his overall experience with animals in his life, specifically dogs.

Kevin shared, "as a child, [they] had two pet dogs" and "they were always important to [him]. He added he "came from an immigrant family" and his "parents were from Italy," but in his family they "weren't animal-centric." He said their "lives were more about the kids and the family, and the pets were sort of an extension of that, but not really vital to [their] upbringing." Kevin shared that "in [his] wife's family, it seems to be the opposite."

Kevin's wife "came from a farm family, more of an early American family, many generations in the U.S...her genealogy goes back" and "there was always a dog in the story...the dogs were a part of the family. They were a family member." Kevin attributed learning about dogs as family members to "his wife's family and that experience." "Consequently," he said they "have had two pet dogs."

Kevin explained how both of those dogs "died a tragic death," and that it "was a very difficult thing" for him to experience. He said he had "been around a lot of that over the years." He observed that "having a dog as part of the family, and losing it, and seeing what it does to the children and everything, it's been kind of a hard process, actually." $\mathrm{He}$ explained that trauma as the reason he and his wife do not have a dog.

Kevin shared that his daughter's family dog, and it "is part of our family." $\mathrm{He}$ described the dog as "the most loving, caring, therapeutic animal." He added, "Even though she's not a service dog, or has been trained as service dog, she's just very 
therapeutic to the whole family." He said they "love cuddling with her, and she's definitely a part of the family, and caring for her doesn't seem like a burden or anything like that." Kevin stated, "So, that's kind of like the whole story of my connection with dogs."

I asked Kevin to describe his comfort level around different breeds and sizes of dogs. He said, "I have a high comfort level with dogs. I love dogs." He immediately added, "I'm not a cat person. Don't talk to me about cats." He laughed and said he "like[s] all animals" and that he is "very comfortable with dogs and all breeds." Kevin shared he had "been chased and bitten by dogs" when he worked as a "newspaper boy," so he is "not about to get all cuddly with a Doberman, or some kind of watch dog, or junk yard dog." Nonetheless, "people's pets" he would "let them jump on [him] and snuggle." In that case he said, “I don't care if it's a Great Dane, or a mastiff, or a poodle, or a bichon. It doesn't matter." He added that he is "not intimidated by big German Shepherds." Kevin mentioned he had seen "a K9 officer in the airport" with "a big German shepherd" earlier that day. He said he "wanted to pet it, but it's a guard dog." He surmised the dog was "a luggage-sniffing K9 dog," which he said, "you're not supposed to [pet]" because "he's working, [and] you're not supposed to bother him."

I commented on Kevin's traumatic experiences as a child and still being comfortable around dogs of all breeds and size. He replied, "I've kind of sloughed it off. I kind of had my battle wound on my right thigh from that, but yeah, I didn't let it scar me for life or anything like that."

I asked Kevin to describe his knowledge of service dogs. He said his knowledge was "just as a casual observer and a business owner." He shared that in the restaurant 
"service dogs have been [their] guests over the years." Kevin said, "the ones [he is] most familiar with are for the blind," but they "have had others, for other types." He knew there had been other types "because [he] noticed the customer wasn't blind," but he did not "know what they were there for...but they were definitely service dogs."

In his experience, "the dogs are so well-behaved, more well-behaved than any other type of dog." The breeds were "usually like a big Lab or a German shepherd, something like that," and "usually they have some kind of jacket or vest or something" on." He described their behavior as "really soothing, and ...always in a calm demeanor." He said, "they usually just lay under the table or beside the table, and they're less trouble than most of our customers." Kevin chuckled at that comment and added, "It has not really been an issue." He added, "as far as service animals, it's been a favorable experience. We've never had any issues with any of it. It's been pretty benign."

He said they "have had to sometimes clarify to some other guests who are wondering why there's a dog" inside the restaurant. He said, "most people know about service dogs, but some people are ignorant, so you have to explain." I asked Kevin to expand. He said, "it has been maybe once or twice in the 20 years that we've had the restaurant" that he remembered "somebody saying, "why does that person have their dog in here?' Something stupid." Kevin said he answered them "Well, it's a service animal." He said the person asking, “They didn't understand it, they saw that person wasn't blind, [and] they said, 'that guy's not blind. Why does he have a dog?"' Kevin repeated, "People are just not aware and you have to explain." Kevin said that after he explains the situation, the questioning customer usually says “oh I didn't realize" and "become[s] 
compliant." He said, “they don't make a fuss about it, but just sort of an off-hand comment...something like that."

As far as a formal animal policy, they "don't really have anything published or written for [their] staff to follow." Rather, "it's just been something that became organic, just over time, became...presented itself." He said he had noticed "it became an issue about the dogs" because people were bringing their pet dogs with them out to eat. He said, "most of [his] staff is...socially aware that service animals are a thing," as are he and his family. I asked Kevin if he had "seen an increase in the amount of dogs that have been brought in." He answered, "No, not really...it's pretty much now and again. It's really not any frequency that I could even measure."

He shared the restaurant's pet policy is "when the weather is favorable" to “allow...people who want to bring their dogs...to sit out on the patio...as long as it's well behaved and doesn't bother anybody." He clarified that is the case if "it's not a service animal, but just their pet." He said, "we are welcoming to that," and added, "we haven't had any peacocks in here lately or anything like that, or really anything other than a dog."

Kevin shared that for his family and him what "might have been one of the early introductions...to what a service animal" happened about twenty years prior. At the time, his daughter was in a community youth organization for young girls, and "somebody in her troop had an older sister who was doing...a [service] project and she trained a service dog." He remembered they brought "the service dog to the café... and the older sister taught the younger girls about service animals and what they were." As he remembered, the older sister needed to "get the service animal trained in a public establishment," so, having the restaurant, he "coordinated with them." He said, the "older girl gave a talk," 
and the restaurant "served them lunch, finger sandwiches and stuff like that." Kevin added that, "subsequently, over the years" he and his family "either on vacation or out eating out" would occasionally see a service dog and they would "talk a little bit about it." He said "many times the conversation [would] make its way" back to that experience with the service dog presentation in the restaurant.

Kevin shared that he has "been involved in the restaurant business for a long time" and has "probably experienced a blind person with a dog before," but that presentation was one of his first experiences with service dogs for other disabilities. He said, "this dog wasn't being trained as a seeing eye dog, it was just a service animal." That was the only official training Kevin has had regarding service animals.

I asked Kevin to expand on his "haven't had any peacocks in here lately" comment. He said he did not remember "seeing any footage of it," but that he remembered "hear[ing]" about it "on the news." He said later when he "was watching a comedy bit...and [the comedian] talked about the peacock," he made the connection. Kevin said he "had mixed feelings" about it. He said,

I guess I'm suspect that some people may abuse the whole service animal privilege or whatever. People traveling on airplanes and want to bring a bird, a service bird or a service monkey or, you know, I'm curious as to if that's a real thing.

Kevin shared that "someone told [him]... you can go online and register a service animal, pay like $\$ 300$ and get a certificate, and that's valid." He said, "I don't know if that's true...but I'm curious to know the legitimacy of that, and if that's really a thing." Kevin commented that he wondered if "that is something that [the service animal 
industry is] vetting and kind of straightening out." He said, "because I guess it's an emerging thing."

I asked Kevin to share with me his understanding of the differences between service dogs, emotional support dogs and therapy dogs. He said, "I'd just be speculating, I don't really know." I asked him to speculate. He said, "My understanding would be that an emotional support animal would be one, if I'd require emotional support, I would have an emotional support animal." He added, "Whereas a therapy dog would seem like one that I would take them to a nursing home to visit maybe elderly people, so that they could have a therapeutic experience. That would be my guess."

I inquired if Kevin had experiences with either emotional support or therapy dogs in the restaurant. He recalled one instance from "a couple of months ago" when "a colleague, or friend, or associate" had "decided to train a therapy dog." He stopped himself and questied, "or was he an emotional support animal?" He continued, "I think it was a therapy $\operatorname{dog} . .$. they brought the dog in [the restaurant]" at which point the handler shared with him that the dog was in "training" to be a "therapy dog." He said the woman told him "I decided to do this, it's something I wanted to do and I'm going to do it." $\mathrm{He}$ shared that his thoughts afterwards were "Oh well, I thought she had an emotional support animal."

I inquired if the handler had asked about bringing the dog in before they arrived. Kevin said, "they didn't" but that "they may have called and spoke to one of [his] staff." While describing how his staff would have potentially responded, he said, "we allow therapy dogs, you're allowed emotional support animals," then he asked me "what's the 
umbrella term?" I replied, possibly "working dogs" but that I was not sure what he meant.

At that moment a customer needed Kevin and he stepped away for a moment. When he returned, he explained he has "a few supervisors, manager-level people" who can make the call on whether a dog is allowed in "because they know." I asked how he and his employees differentiated between the dogs. Kevin replied, "usually the emotional support animals have some kind of insignia...like a scarf or something that is clearly marked and labeled and you look at it and you just...we make the assumption that it's legitimate."

I inquired if in that situation there were any questions they would ask the handler. Kevin answered, “We don’t really. We are just compliant." He explained, If they come in, and they appear to be a legitimate service animal... we train our staff to be very smooth and welcoming, and make our guests feel welcome and appreciated, and not make them feel that they're any different. Just make the very smooth process... Try to make them show respect and dignity to that person so that their experience is favorable.

He said they do not react as if the animal causes a complication on where to sit the customer.

Kevin said, "But if they just come in, they just have a collar, or a bandanna, or something that's not official looking, then we'll [ask], 'is your dog emotional support animal?" He added, "We don't really allow dogs in the restaurant unless they're something that you... It's an emotional support animal." Kevin added later in the interview that their “experience has been that if they don't have anything like that, the 
guests will notify us." In most cases, he said the guest asks, "Is it okay? I have a dog, he's a service animal, is it okay if we bring him in?" To which they reply "Sure, no problem." He said the guests will often "make a reservation." If they do not make a reservation, however, and "maybe if they're two people, one person will come in and say, 'We have a service animal. Is it okay if we come in?'” Again, Kevin said his staff would respond "Sure, no problem. Bring them in." He summarized, "They come in and it's a non-event."

I asked if that was the same for a service dog, at which point Kevin replied with a laugh, "Service dog, that's the umbrella term that I was thinking." He asked me "Is that different? Is a service dog different from emotional support, or are they all...?” I explained that is "one of the things I am trying to figure out... what are the perceptions that people have." Satisfied, Kevin continued, "My perception is that service animal is an umbrella term, and that underneath that you have emotional support, therapy dog, seeing eye dog. You got all these categories." He added, "That's the way I would understand it, but I'm interested in learning the real nomenclature."

I asked Kevin if he had any thoughts or emotions when he saw a dog entering his restaurant. Pensively he replied, "That's a good question," then continued, Usually it's strictly business like, 'okay, we got a service animal, we gotta find a good spot' because you want to make them feel comfortable... make sure they have...lots of room around them. You don't want to stick them back in the corner, a little too tight.

He said, "Those are the first things that come to my mind." Beyond those, he said he might make a comment of "how well-behaved" the dog was, or "oh, isn't that a beautiful 
dog." He shared that he is "not too mushy like [his] wife is." He laughed, and said his wife would react by saying, "Oh, oh, he's so sweet! Oh, can I pet him?"

I asked Kevin about his "understanding of the laws as a business owner regarding service dogs." He clarified "Again, I haven't read any laws or anything," then answered, "my understanding is... if a customer has a service animal, it's discriminatory to not allow them in, sort of like an ADA guideline that public spaces need to allow people with service animals into their...otherwise it's discriminatory." He provided an example, "like you can't [say] 'get out of here with that wheelchair', type of thing." Kevin restated, "so again, I'm open to be educated if that's not the case, what our rights are, our obligations as associated with service animals."

Kevin shared that he is in a state and national restaurant organization, and has "a lot of friends that are in the restaurant business" and that the topic of service dogs is "not like a hot topic or anything." It has "never really been an issue," he said. Kevin said he “didn't talk once about any service animals" with his restaurant friends.

I asked Kevin, as a business owner, "are there any improvements [he] would like to see regarding service dogs and accessibility." He answered "continuity" and "consistency." Based on what Kevin had shared about uniforms being representative of a service animal, I asked "What do you think is the most effective uniform for a service dog?” Kevin answered,

So this may sound funny, but one of the things that sort of, is color and sort of shape and style like...the service vests, and the whatever, the collar, the bandana...scarf or whatever, kind of reminds me of Boy Scouts or Girl Scouts, when they have the color or little badge or some kind of insignia, usually is a 
pretty good indicator that it's legitimate. It kind of looks like a uniform, not just something plain.

I asked if Kevin perceived any value in any one type of uniform over the other." He answered that he did not but "uniformity would be helpful." He added, "Whatever you guys decide to go with it is fine with me." The important thing being "as long as they're all the same so we know what to look for... [that] would be helpful." Kevin suggested,

So even if it's a little jacket, or a little blanket that goes over their back, but I guess it has to be kind of secured somehow, but I think the bandanna or the little vest or something....as long as there was some sort of official uniformity, consistency.

Kevin provided the example of "the Red Cross...everybody knows you see a white flag with a red cross on it, you know that's the Red Cross." He added, regarding recognition of the color blue, "Police wear blue."

I asked if there was "any particular color" he already associated with service dog uniforms." Kevin replied, "this whole time we have been talking, I've been seeing yellow and red in my head...like there's a yellow vest with a red patch." He did not know why. "Maybe I've seen it," he said. He said the uniform needed to be something "on the dog...not the handler," the reason being "the dog is the service animal, not the handler."

He added, "if the handler had a lanyard with some kind of laminated ID card...that'd be great to correspond with the dog." He noted that if customers have to "go in their purse" to pull out an ID it would be troublesome. However, "if they truly 
need a service animal to have this special accommodation...if they had a lanyard... anything that makes it more fluid for the business operator is a good thing" $\mathrm{He}$ explained, as a gatekeeper, "so we see the lanyard, we see the vest, and like, 'sure, right this way, no problem."” He summarized, "I think you can't have too much.” He added, "If the word got out there, then, and somebody had a peacock, then they'd have to have a little yellow vest for it, and a lanyard." The vest and lanyard he said, "would probably be a positive thing to legitimize and make sure that people aren't abusing the system."

I inquired what Kevin thought would be the best way to get the word out about any change in regulation regarding service dogs. He answered, "have a website, and [social media] pages, and all that stuff, because that's how people get their information these days." He said, "that's the best way to get information out there, for both the service community and for the restaurant operators, and for the people that are in need of a service animal." He added that "email" is his preferred method of contact as a business owner. "The thing I like about emails," he said, “is I don’t delete my emails...I go back and I can look at it and find it again." To him, magazines result in "a lot of wasted paper, a lot of trees getting cut down" and he "never look[s] at" them.

Kevin mentioned the restaurant association he is a member of, sends out "informative emails." He added it would "be an excellent opportunity" for me, the researcher, "to connect with them." He offered to "send [me] the contact information of [their] local president, and her phone number, and email."

I reviewed my interview questions one more time, and upon confirming I had asked all of the questions, I thanked Kevin and asked if he had any questions for me. He asked for me to clarify which questions he is allowed to ask someone with a service dog, 
the stories he had been told about certifications, and what animals, in addition to dogs, are legally recognized as service animals. He also asked if the "whole peacock thing is bull." I answered his questions, and we talked a little bit more about how airline regulations differ from public facilities. Kevin inquired about my future career goals. We chatted a bit more, I confirmed his email address, thanked him again for his time, and ended the interview. Immediately after, I made my post-interview notes and turned off the audio recorders.

\section{Summary of Chapter 4}

This chapter presented the findings from eleven, in-depth, unstructured interviews with gatekeepers on their experiences with, and perceptions of, service dogs. The data was presented in the form of rich, textural descriptions of each individual co-researcher's interview. Data was analyzed to reveal the underlying structural descriptions. Textural and structural descriptions were synthesized within, and across the interviews, to bring to

light the results of this research study. The next chapter is a presentation of those results, as well as a discussion of implications, and recommendations for future research. 


\section{CHAPTER V}

\section{Results/Implications/Recommendations}

\section{Purpose of the Study}

The purpose of this study was to understand, through in-depth, unstructured interviews, the working public's experiences with, and perceptions of, service dogs in public places. The results of this study were analyzed to identify the primary aspects of the phenomenon from the gatekeeper's point of view. Additionally, the results of this study identified areas needing further research.

\section{Objectives of the Study}

The objectives of this study are reflected in the following research questions, which were used to guide the study.

1. What are the experiences of the working public with service dogs and service dog teams in public places?

2. How does the working public perceive service dogs?

3. What are the working public's understandings of accessibility regulations as they relate to service dogs and public places?

4. What, if any, are the issues the working public identify in and around this topic?

5. Based on the data obtained, what are the important issues and areas that need further research?

\section{Integrated Textural/Structural Description}

Throughout the data analysis process, the experiences of the co-researchers often became the gateway to understanding their perceptions. In chapter four, I presented the 
data through detailed, individual textural descriptions for each co-researcher. The textural descriptions were analyzed to identify the embedded, underling structures of the experience, which were then used to synthesize the textual and structural themes within and across the data. In this chapter, I will present results, interpretations, and conclusions made through the data analysis, implications of the findings, and recommendations for future research.

\section{Themes/Conclusions/Interpretations/Implications}

The conclusions, interpretations, and implications are presented in the following themes, each with subthemes: misunderstanding, confusion, and lack of knowledge; dogs in society; misrepresentation; desire for standardization; and education (see Figure 3). Each of these themes emerged from the analysis of co-researchers' interview data. These themes encompassed areas of importance or concern, as expressed by the co-researchers. Each broader theme includes subthemes as described in this chapter.

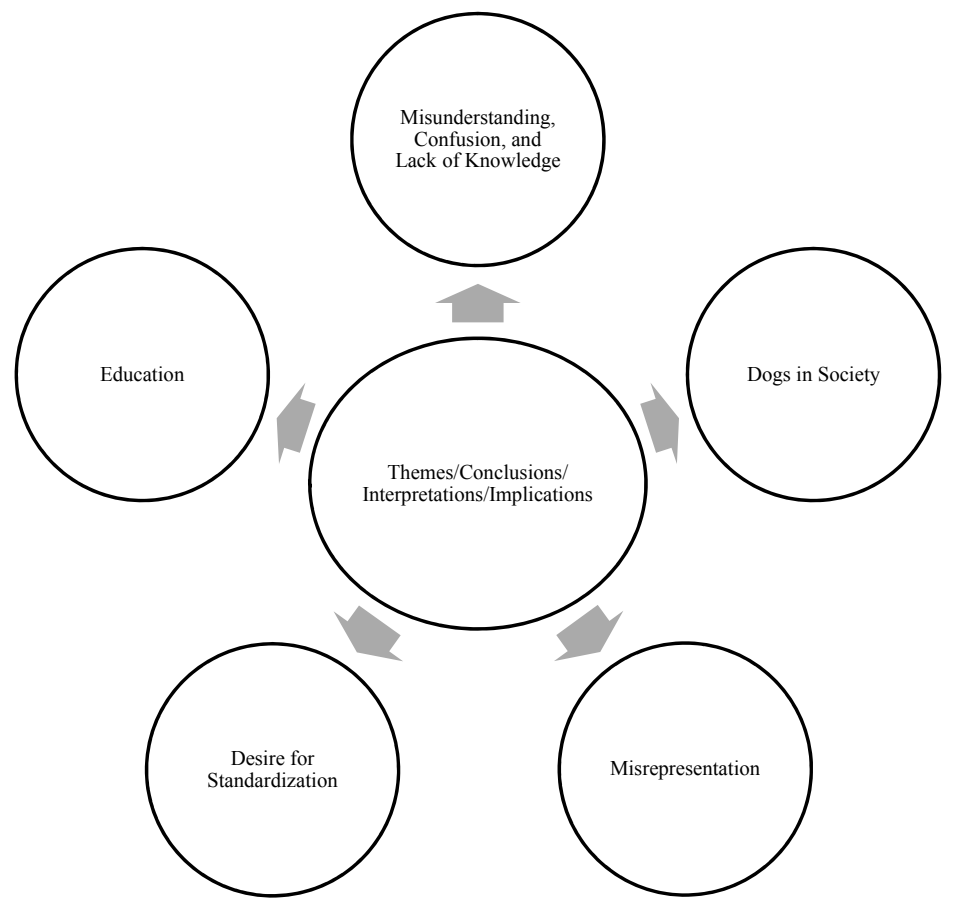

Figure 3: Main themes/conclusions/interpretations/implications of this research study. 


\section{Theme 1: Misunderstanding, Confusion, and Lack of Knowledge}

Three main categories of assistance dogs are (a) service dogs, (b) emotional support dogs, and (c) therapy dogs. When I started my data collection, I intended to focus on my co-researchers' experiences with, and perceptions of service dogs, because they are the only assistance dogs afforded public access rights, through the ADA. The Fair Housing Act, and the Department of Transportation laws extend accessibility allowances to emotional support dogs, but, since this research study focused on gatekeepers in public businesses, I chose to focus solely on their experiences with, and perceptions of, service dogs. While immersed in the interviewing process, however, I realized I needed to intentionally ask questions to understand my co-researchers' experiences with, and perceptions of, all 3 types of assistance dogs. I listened carefully to my co-researchers' perceptions and added probing questions to help clarify my understanding of their ideas.

From my literature review, I was aware of the possibility that co-researchers did not properly understand the differences between service dogs, emotional support dogs, and therapy dogs (Schoenfeld-Tacher et al., 2017). During recruitment, I confirmed potential participants had experiences with service dogs coming into their workplace, and asked if they would share those experiences with me. I did not provide any definition of service dogs. I explained that I wanted to understand their experiences and perceptions, as they are an important part of Kentucky's working public. Some co-researchers asked if they needed to prepare for our meeting, and I answered they only needed to start thinking about their experiences and remembering as much as possible. 
Prior to the interviews, none of the co-researchers showed signs of misunderstanding, confusion, or said they only had experiences with emotional support or therapy dogs. I did not want to potentially influence the memory of their experiences, or their perceptions, so I did not provide any additional information. I went into the interviews open to the possibility of hearing about the different types of assistance dogs, but with the goal of focusing on their experiences with, and perceptions of, service dogs.

I quickly learned, however, that focusing solely on service dogs was not feasible in this study. I thought I was going into the interviews with co-researchers who clearly and correctly knew what a service dog was, and how it differed from the other two assistance dogs, and could therefore share their experiences specific to service dogs. The realization of misunderstandings, confusion, and lack of knowledge, however, became apparent as early as the second interview. Therefore, I adjusted my probing questions to develop an understanding of each co-researcher's perceptions of the 3 assistance dogs. Through this adjustment, the co-researcher's misunderstandings, confusion, and lack of understanding regarding all things service dog, emotional support dog, and therapy dog, became apparent and provided valuable insight into the phenomenon. These results support Schoenfeld-Tacher et al.'s (2017), and Schoenfeld-Tacher and Kogan's (2017) findings of widespread misconceptions, and lack of understanding regarding assistance animals. Under the theme of misunderstanding, confusion, and lack of knowledge are the subthemes of: (a) terminology; (b) characteristics, (c) role/responsibility of the dog; (d) perceived need and social impact; (e) accessibility; (f) behavioral expectations; (g) uniform expectations; and (h) certification/registration expectations (see Figure 4). I will 
explain how each of these subthemes are part of the main theme and the implications.

Recommendations are included in each subtheme.

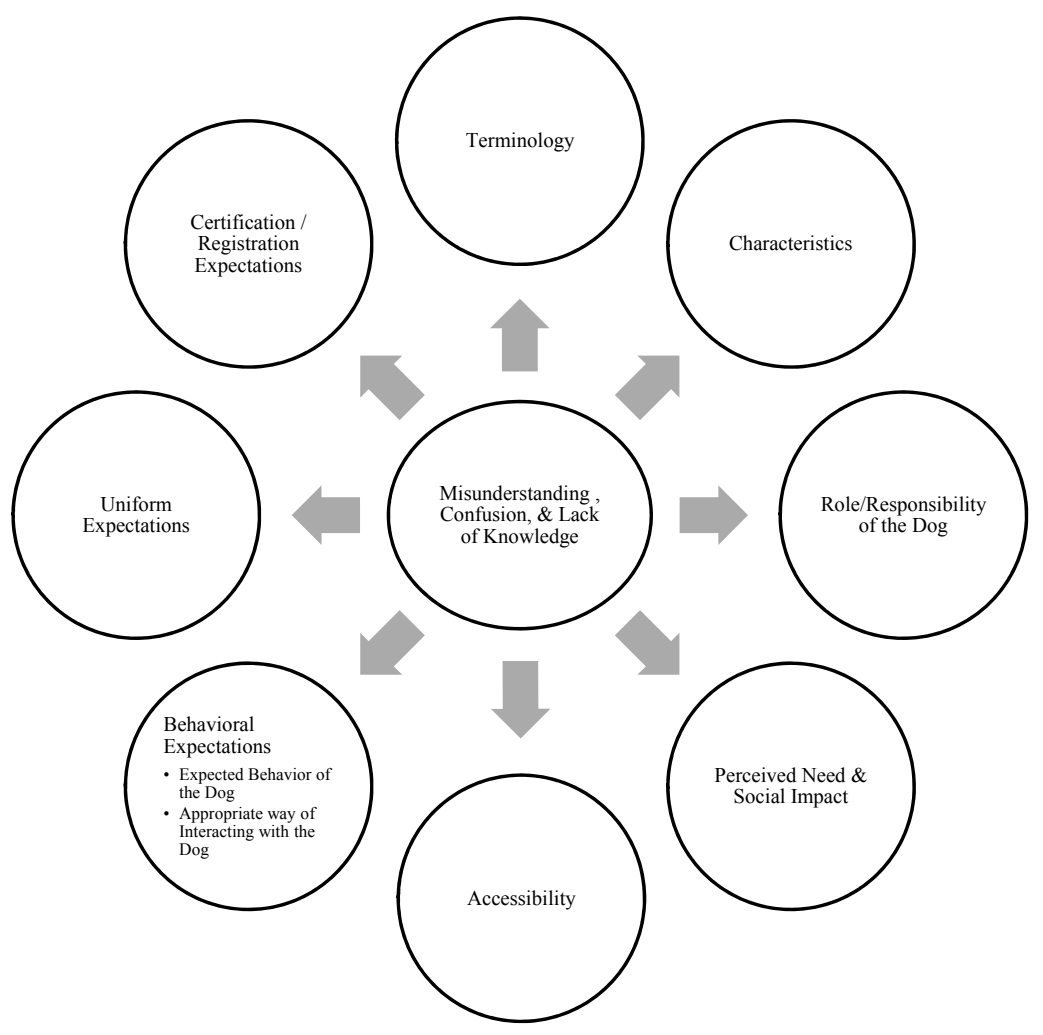

Figure 4: Main theme 1: Misunderstanding, confusion, and lack of knowledge, and related subthemes.

\section{1a. Terminology.}

Terminology was one of the most interesting aspects of the data analysis. Not only did it make it challenging to understand the co-researcher's perceptions directly related to either service dogs, emotional support dogs, or therapy dogs, but through their verbiage, quite a few of the co-researchers would contradict themselves throughout the interview, or use labels that appeared to limit the definition of a service dog. I interpreted these contradictions as either confusion, or lack of knowledge on regarding terminology. 
Becky's interview is one example of term usage limiting the definition of a service dog. During Becky's interview, she primarily used the term "guide dog", and not service dog. Since Becky started using "guide dog" right after she said she had "experience with service dogs," I inferred that she correctly understood guide dogs to be a type of service dog. I was not surprised to hear her primarily use "guide dog" since she had a longtime friend who raised guide dogs. From context, I inferred that Becky differentiated guide dogs and service dogs, from emotional support dogs, and therapy dogs.

It was never clearly stated, however, that Becky perceived service dogs as being able to assist with disabilities other than blindness, and if she did, then the term "guide dog" was not sufficient. Additionally, Becky's choice of terminology created confusion in the meaning of her statements. For example, Becky would say things like "I am seeing more dogs out than I used to. Whether they're any kind of therapy dog, I have no idea," and in talking about our society becoming "a lot more dog friendly," she said, "maybe we are starting to do that, and the service dog thing is just, how we have to have so many rules about everything." If Becky understood that service dogs, or guide dogs, were afforded accessibility rights, then why would she have seen an increase in therapy dogs? Furthermore, after saying "guide dogs had to be let in," Becky questioned "what is the word they use, not a seeing-eye dog, but they have some other phrase they use now?" I asked if she was thinking of "service dog," and she said was not. If Becky was using "guide dog" to describe her experiences to me, it made me wonder if she was also asking festival attendees if their dog was a guide dog, instead of asking if it was a service dog. Since service dogs can assist with disabilities beyond guiding the blind, using the label 
guide dog for all service dogs could result in confusion for both a gatekeeper and dog handler.

In Gloria’s interview, she said, 'I know there's a difference between therapy and service," but she did "not know in terms of emotional." Through her interview, it became apparent, that while she used correctly used the term "service dog," to describe a dog who provides assistance in the form of physically supporting someone who is unstable, she was unclear on what other tasks a service dog could provide. She also occasionally used the label "emotional therapy dogs" to describe emotional support dogs and therapy dogs. Gloria admitted her lack of knowledge when she said,

I guess I'm bigger with those dogs [service dogs] than I am emotional therapy dogs. Emotional therapy dogs tend to be smaller and just a lap dog and to you know for someone's comfort. I've never asked if it's a therapy dog. In the last sentence she dropped the "emotional," and described those dogs as just "therapy dogs."

Haley did not appear to be confused on terminology, however her use of "assistant animals" to describe "emotional support animals" represented a potential concern for interpretation of legislation. In Haley's work as a landlord, she said she had experience with both "service animals" and "emotional support animals." While describing her experiences, however, I noticed she used a variety of terms including support animal, assistance animal, service animal, and emotional support animal. First, Haley said, "emotional support animals are quite the drama in our industry." Then she said that being disabled "really is the qualification for someone to have a support animal." Afterwards, she said landlords are not allowed to, "charge any fees for 
assistance or service animals," and "service animals are providing a specific function versus an assistant animal that's more therapeutic in nature." From this description, I inferred that Haley used emotional support and assistance/assistant ubiquitously. After my interview with Haley, I looked up the housing law she had talked about and found out the law uses the term, "assistance animal.” The Kentucky bill states, "“Assistance Animal' means an animal that works, provides assistance, or performs tasks for the benefit of a person with a disability, or provides emotional support that alleviates one or more identified symptoms or effects of a person's disability" (An Act Relating to Assistance Animals, 2019). Therefore, it makes sense that Haley would use the same terminology. Nonetheless, the fact that the ADA does not use "assistance animal," and differentiates between service animals and emotional support animals, could result in a lot of confusion for someone with an emotional support dog when they are determining accessibility rights between public entities and housing. This conclusion supports the findings from Schoenfeld-Tacher and Kogan's (2017) that, in general, people lacked understanding of the differences between service and emotional support animals.

In Janet's interview, she described a social concern over the public not using the correct terminology. In describing some of the people who were looking to adopt dogs, Janet said,

Sometimes they say 'therapy' and they really mean 'emotional support'. They don't know the difference....Because they will say 'well I have a doctor's note' so when they say that we definitely have to correct, 'Oh so you mean emotional support.' 
Isabelle, who works with Janet, added to the complexity of the interaction when she added, "there's...just a companion animal, which is essentially just a pet." Based on their comments, if the public does not know the difference between the types of assistance dogs, unless the person from whom they are procuring the dog educates them, the proliferation of incorrect terminology usage will continue.

In Kevin's interview, a misunderstanding of the service dog label was discovered. While Kevin correctly described the differences in the type of work a service dog, emotional support dog, and therapy dog do, his understanding of the terminology was incorrect. Kevin said his, "perception is that service animal is an umbrella term, and that underneath that you have emotional support, therapy dog, seeing eye dog. You got all these categories." Given the other co-researcher's confusion, I do not believe Kevin is the only person who has this misconception of the 'service dog' label. The implication of this misunderstanding is that people could incorrectly think emotional support dogs, and therapy dogs are legally allowed in public entities with service dogs.

\section{Implications and recommendations.}

These are some of the examples of the misunderstandings, confusion, and lack of knowledge regarding terminology found in the data. This conclusion supports the need for a revised taxonomy Parenti et al. (2013) suggested. The implication of this subtheme is that as people create rules, regulations, and legislation regarding these dogs, the potential for contradicting verbiage, and confusing conversations continues. The concerns in the implications of this result support Huss' (2010) finding that "central in many disputes in this area is the problem of disparate definitions of service animals under various laws" (p. 1165). This makes me wonder how terminology suggestions, such as 
those made by Parenti et al. (2013) can be standardized both culturally and politically. A suggestion for future research is look into the preferred terminology from the assistant dog handler's perspective. Along with this, look into why certain labels are preferred over others. Having such knowledge can help organizations, and politicians, cohesively understand and intentionality use a standardized labeling system.

\section{1b. Characteristics.}

The characteristics the co-researchers used to identify service dog legitimacy represented an area of misunderstanding and lack of knowledge. The main characteristics I noticed were breed and size of the dog. As Cathy said, "a little Pomeranian in the top of a grocery basket, probably not a service dog." Gloria said that "after knowing so much about the larger dogs helping the veterans," when she saw a little dog in her store wearing "a little thing that said 'service dog'," she did not "see what that dog is going to do for that person." Janet also implied size was an indication as to legitimacy when she asked,

First of all, if you have a five pound poodle, and it has a service vest, but you're carrying it, you're carrying the poodle and it has a service vest on, or it's in your cart, how is that a service animal? What is it doing for you?

\section{Implications and recommendations.}

Unfortunately, the implications of this misunderstanding could result in discrimination against someone with a legitimate service dog. As Isabelle said, "sometimes when it comes to size, it can be something like blood sugar problems where they just have to notify their handler that they are having that." In which case, a large physical stature of the dog is not needed for them to be able to do their work. There are 
certain breeds that are more commonly seen as service dogs, due to breed characteristics, such as size, however, breed/size alone is not an appropriate determinate for establishing a service dog's legitimacy. As Elliott and Hogle (2013) presented, the 2010 revisions of the ADA recognized the value of service dogs for invisible, psychiatric disabilities. Awareness is needed to educate people on the various ways service dogs mitigate disabilities, which will also bring awareness to disabilities that are not necessarily visible, such as epilepsy, diabetes, chronic fatigue syndrome, and PTSD.

Recommendations on this subtheme are for service dog organizations and for service dog handlers. I recommend that those who are most familiar with the various ways in which service dogs assist someone with a disability, share their knowledge. Additionally, research can be done to collect a large amount of data by asking service dog handlers what main task/work their dog does related to their disability. Information from such research studies needs to be shared with the public to create awareness, and educate people on the legitimacy of different dog breeds/sizes as service dogs.

\section{1c. Role/responsibility of the dog.}

When asked to define the differences between the assistance dogs, some of the coresearchers were very comfortable, whereas others were very uncomfortable. The responses I got when I asked if the co-researchers were aware of the differences between the assistance dogs, ranged from Adam's enthusiastic "very much so", to Emily's "to a certain extent", to Cathy's "uh huh, yeah," without hesitation. Donna said, "I'm probably not as well versed as I should be. I think I have a vague understanding of each of them, maybe." Haley confidently said she knew the differences but acknowledged, "waters even at the federal level have been a little bit murky," and Kevin said, "I'd just be 
speculating. I don't really know.” This conclusion supports Schoenfeld-Tacher et al.'s (2017) findings that members of the public had different, and inconsistent understandings of assistance dogs. The results of this study provided more detailed insight into the development of those inconsistencies.

My interview with Becky provides a good example of this subtheme. During my interview with Becky, said she had, "been exposed to more people with service dogs," and provided examples of her experiences with a friend who raises seeing-eye dogs. Since seeing-eye dogs are a type of service dog, and she gave the example directly after that statement, I inferred that she understood seeing-eye dogs are a type of service dogs. Becky then said, "Now they have emotional support animals," and provided an example of "a lady on the news... who has an emotional support squirrel". When I asked Becky her "understanding of the difference between service dogs, emotional support dogs, or therapy dogs," she answered, "I probably don't know the difference properly." Becky explained that she had been told that for "emotional support" dogs "there's different guidelines for what you can do with them, where you go with them, when you can pet them or not." She added that for "emotional support, now it seems like you can bring them in any store... it doesn't seem to have any guidelines that I'm aware of." Becky then said she had "worked events before where you can bring your support animal." The events she was referring to, I later learned, were the food festivals in which she worked as a gatekeeper and provided dog daycare services.

Becky continued explaining her understanding of the different types of assistance dogs. “Therapy dogs, I know you're not supposed to pet them if they're wearing a jacket, they have more rules so to say." I asked, "Okay and service dogs?" To which she 
answered, "Oh gosh, what's the difference between a service dog? I think it's pretty much the same thing as a therapy dog". At this point, I understood that she differentiated emotional support dogs/support animals, from service dogs/guide dogs and therapy dogs, which she thought of as the same thing. I also understood that emotional support and support animals were allowed in the event she worked. However, later in the interview, when asked if she remembered exactly what her employer said as to what dogs were allowed in the event she worked, she answered, "I want to say a therapy dog or a guide dog," and "if [the attendee's] dog wasn't a therapy dog or a guide dog, then [they] could leave them in doggy daycare." Becky corrected herself "Not a therapy, a guide dog, because therapy comes almost, I'm thinking that's more like a support dog, a therapy dog." Then she said for the event she worked, "they were talking about guide dogs that had to be let in, like at a store." This contradicted her former statement that "support animals" were allowed in the event. At that point in the interview, it could be understood that Becky viewed "therapy dogs" similar to "emotional support" and "support animals," and that "guide dogs" had accessibility rights in public places, "like stores". It was unclear if she either misspoke when she said emotional support were allowed in stores, or if she was confused on the differences between the dogs. Becky's interview is representative of how misunderstanding in the differences between the types of assistance dogs can lead to confusion in other areas such as accessibility.

Donna and Haley's interviews provided additional examples representative of the misunderstanding, confusion and/or lack of knowledge on this sub theme. When describing therapy or emotional support animals, Haley said they "assist people who are 
disabled according to the Fair Housing Act." This is misunderstanding of a therapy animal, because they do not assist with disabilities.

Donna correctly described emotional support dogs as, "Dogs that are just there to be a structure of support for somebody, maybe who has like suffered a traumatic experience or loneliness." She also correctly understood therapy dogs could be used in "rehab facilities" or "nursing homes....as therapy to help people recover." When she tried differentiating service dogs, however, she, like Becky, expressed confusion when she said, "Now the service dog, now I'm confused." Donna's confusion caused her to question herself as a co-researcher and thought she "should have done more research before" the interview. In her particular case, she needed reassurance before she would continue to participate in the interview.

Overall, while Donna had correct basic understandings of emotional support and therapy dogs, her confidence with the topic influenced her ability to talk about the differences. At another point in the interview, Donna mentioned seeing "a combination of service dogs, emotional support dogs, and then ones that are actually there for trauma, experience, anxiety, seizures, and things like that, seeing eye dogs for the blind," and eventually she described service dogs as "here for a mission to help someone out." However, she never verbally expressed the connection between the two statements. Donna is a good example of how lack of knowledge can cause lack of confidence and in turn, result in a gatekeeper who questions their own ability to differentiate a service dog from an emotional support dog, or therapy dog.

Along with their comfort, or confidence in their knowledge, I realized that the coresearchers who were closest to the phenomenon had the most complete and accurate 
knowledge regarding service dogs, emotional support dogs, and therapy dogs. For example, both Adam and Isabelle correctly and clearly defined the differences between service dogs, emotional support dogs, and therapy dogs, both in their definitions and accessibility. Adam had a therapy dog in-training, and Isabelle had an emotional support dog, who was formerly registered as a service dog. This is important to note because it implies that a person's exposure to emotional support dogs and therapy dogs can positively impact their awareness of service dogs. Nevertheless, since those dogs have more restrictions than service dogs, according to the ADA, the converse is not necessarily true.

Gloria had extensive experience working with service dogs for veterans and first responders. She voiced strong opinions on identification usage, and protecting the service dogs from misrepresentation, however, her knowledge on emotional support dogs and therapy dogs was lacking. The inexperience with emotional support dogs and misunderstanding between the differences with therapy dogs, led her to express concern over the legitimacy of someone's need of those dogs. She said,

You can have an emotional dog and a lot of that, I don't like to judge, but I think a lot of people just assume they need one. Or I need to take my dog because they don't want to leave their dog at home.

Gloria's perception of emotional support dogs is in direct opposition to Adam's, who said, "emotional support and service dogs are the same thing though and people just haven't realized the importance of mental health yet." Adam used brain scans to support his theory when he said, 
The same areas [of the brain] light up whether it's emotional or physical so that kind of adds credit to those being very valid disorders that need treatment and if a dog helps you with that then we should let you have the dog wherever you're at. Another aspect of this subtheme is the lack of awareness that there are differences between the types of assistance dogs. Faith is a good example of this perception. Faith understood that service dogs are "trained to be with [a] person for a reason," and provided the example of a seizure alert dog. She understood the importance of a service dog and equated their importance to their handler as "you have to have air to breathe, they have to have that dog to live." Faith described emotional support dogs, as dogs for someone who "is lonely" or "lost their significant other." Faith said she did not have experience with therapy dogs, however, she did not see the need to differentiate between the different types of assistance dogs. This perception is concerning from the point of view of a gatekeeper in the event the store develops a policy that only accepts service dogs. The lack of understanding would require the company to invest heavily in educating their personnel on recognizing the differences.

\section{Implications and recommendations.}

The misunderstanding in the role and responsibility of the various assistance dogs supports the existing literature on the public's perceptions of assistance animals. Recommendations on this subtheme are for (a) service dog organizations/service dog handlers, and (b) for future research. To the service dog organizations and service dog handlers, I recommend that those who are most familiar with the various ways in which a service dog assists someone with a disability, share their knowledge. It is through 
increased education that people can learn about disabilities and the various was in which a dog can help mitigate those disabilities.

Additionally, since gatekeepers do not clearly know or understand the differences between the three types of assistance animals, I ask, how can they enforce the regulations? Based on this conclusion, another recommendation would be to establish an educational program to help gatekeepers and/or other public individuals understand their role and responsibilities regarding accessibility and assistance animals.

For future research, this conclusion also emphasizes the need for additional research on the public's perceptions of assistance dogs, how the perceptions were created, and what needs to change to provide clarity and education. Moreover, the results of this research study provide examples of the different perceptions of emotional support animals. Adam expressed opinions in support of Bourland (2009), and Hernandez-Silk's (2018) suggestions to include emotional support animals with service dogs. Gloria's opinion, however, represented the opposite viewpoint. Further research needs done on the role and responsibilities of emotional support animals, to contribute to this conversation in determining if emotional support animals fit the description of assisting with disabilities. A component of this query is the perception of psychiatric, and emotional disorders as recognized disabilities.

\section{1d. Perceived need \& social impact.}

This subtheme directly relates to the previous discussion of the perceived role and responsibilities of the dog, therefore, a lot of parallels exist. Throughout the data analysis, the co-researchers, as a group, identified concern over people recognizing the value of a service dog, specifically when the disability was either unrecognized, or not 
immediately apparent, such as with PTSD or debilitating anxiety. This conclusion is a community issue as it impacts the human-to-human relationships between members of the public and dog handlers. Here are some examples supporting this theme.

Becky and Gloria both talked about how, as a society, the concept of service dogs for someone with PTSD is a relatively new concept. Becky said she had not heard about PTSD support dogs until "however many years it's been since the vets with PTSD." She attributed, "the wars" and "vets coming home with brain" and "physical injuries," for bringing service dogs "into the limelight." Through her experience fundraising for a service dog for veterans' program, Gloria said she had seen veterans learn how the dogs "can be a lifesaver" and "help them [them] life longer" with "good quality of life."

Haley's statement that "typically [with] service animals, the disability is more prevalent," represents how lack of knowledge of invisible disabilities can cause social confusion. Kevin had experience with customers in his restaurant questioning why another customer had a dog in the building. Kevin said the questioning customer had asked "That guy's not blind. Why does he have a dog?" Kevin said had "to explain...it's a service animal," and said, "People are just not aware."

Isabelle's experience supports the idea of invisible disabilities soliciting questioning. She said,

I feel like if I was blind, or deaf or had seizures, people would be like 'oh yeah, you need your service dog, bring him along,' but since I have almost like an invisible illness, people looked at me like 'are you really sick? Do you really need that?' 
The vulnerability Isabelle showed when she said, "I feel like I had to share parts of my story that I really shouldn't have had to share because my disability is invisible," represents the dangerous implications in the public's lack of knowledge of invisible disabilities because they ask unnecessary questions.

\section{Implications and recommendations.}

The implication of this subtheme is one of human-to-human interaction, whereby a gatekeeper's misguided questioning could result in discrimination of a disabled person. As with the previous subthemes, the need for education is apparent. For this theme, again, awareness needs created through education of disabilities that are not immediately visually apparent to the general public, which would coincide with increased awareness on the role and responsibilities of service dogs.

\section{1e. Accessibility.}

In general, the co-researchers agreed that service dogs are afforded accessibility rights. Adam said, "You can't be refused service at a restaurant for having a service dog." In discussing stores posting about their dog policy, Gloria said, “I don’t think there's any reason to put anything that service dogs are allowed. I think service dogs should always be allowed." Isabelle said, "a service animal is allowed to go in public places with you, even if it's not a pet friendly place." Kevin said, "if a customer has a service animal, it's discriminatory to not allow them in," and compared not allowing a person to keep their service dog with them to not allowing a person to keep their wheelchair with them.

The misunderstandings, confusion, and lack of knowledge became apparent regarding accessibility rights for emotional support and therapy dogs. As explained in 
the literature review, the ADA does not extend public accessibility rights to emotional support dogs or therapy dogs. Emotional support dogs are afforded access to airlines through the DOT and housing through the Fair Housing Act, however based on the results of the interviews, the lack knowledge regarding these mandates and how they govern different spaces is apparent.

When describing the differences between the types of assistance animals, accessibility was often used to distinguish between the three types of dogs. It is important to keep in mind that co-researcher's varied on their understanding of emotional support dogs and therapy dogs, which impacted their perceptions on accessibility. Adam recognized the potential misunderstanding when he said, "I could see the therapy dog though being the most abused (for accessibility) because it's not like a prescription you get from a physician." He recognized the accessibility concern for housing when he said, "if [someone] want[s] a certain breed and their apartment says, 'no,' then all they have to do is go to a doctor... and get a note...then the landlord can't deny them."

Becky understood for "emotional support...there's different guidelines... where you can go with them," and from her perception, "it seems like you can bring them in any store, as long as there's concrete and there's no food served." However, I understood from Becky's description of her friend who trains guide dogs experiencing people, "giving her the stink eye," and pushback when she took the dog into public spaces, that Becky perceived guide dogs to have accessibility rights. She did not differentiate for therapy dogs, but as described previously, was confused on the definition of a therapy dog. Furthermore, Becky's perception that a type of assistance dog is not allowed in certain entities because of the presence of food service, represents lack of knowledge of 
the ADA's accessibility constraints. Service dogs can be restricted access to restaurant kitchens, because they are not normally open to the public, but they cannot be restricted from areas like self-service salad bars, or dining areas. Regardless of her own lack of knowledge, Becky recognized accessibility as an issue when she described the confrontations of managers and customers over, "what kind of dog" was in the store and, "if it was allowed to be in there" she had seen.

Emily's understanding of accessibility for emotional support dogs was that, "generally you're not allowed to have them in [university] facilities, and even in campus housing, unless it's gone through the Center for Disabilities and they approved it." She understood therapy dogs were allowed "in a hospital" or "hospice" to "make home visits." Lack of knowledge, and misunderstanding was identified when Emily said, I don't think you're allowed to ask to see the paperwork if the dog has been trained. So if [the student] told me it was a therapy dog, versus an emotional support dog, I don't think I was allowed to ask her to show, to prove it.

This statement represents misunderstanding in distinguishing a service dog from a therapy dog, for accessibility rights, as well as lack of knowledge on the appropriate questions that can be asked to determine a service dog's legitimacy. As explained in the literature review, there is no universal, standardized, official paperwork to "prove" an emotional support dog or therapy dog's legitimacy.

Haley's understanding of accessibility was that housing developments can "restrict a pet" but "cannot restrict a support animal in any way." She did not know the rules were different for public accommodations, but identified the issue that landlords "are not allowed to questions" and they "just have to accept" when a renter provides a 
note stating their need for an emotional support animal. While Haley explained a new law in Kentucky has helped her in requiring the emotional support animal doctor notes, she explained it has been an issue in the past that has resulted in landlords "feeling like they are being taken advantage of."

Isabelle, said, "[an] emotional support animal... is not by law required to be allowed into any public spaces....they can't go in the stores...unless it's pet friendly.” Isabelle said, "the only thing the ADA protects emotional support animals for is housing." While Isabelle was extremely familiar with the legislation on service dogs and emotional support dogs, her statement that that ADA protects regarding housing is inaccurate. It is through the Fair Housing Act that emotional support animals are protected in housing environments.

Faith was not familiar with assistance animal accessibility rights however her interview represents the potential concern over businesses changing their dog policies. In the thirteen years Faith has been with her current company, her managers have not talked to her about their dog policy. She believed dogs were officially "not supposed to come in" the grocery store. However, as she observed "about six" dogs in her grocery store daily, and "has never known anybody to be thrown out that has a dog for any reason," she believed all dogs were welcome in the national chain grocery store. She said that if her employer changed their policy to allow "only service dogs," she said it would "turn a lot of people away from [the store] completely," and would "probably break [her] heart," she would "really want to know why." Faith is representative of the trickledown effect businesses could experience if they make changes to their dog policy, and the importance of educating not only their customers of the change, but their employees as well. 
Beyond the misunderstandings and lack of personal knowledge, the coresearchers also identified misunderstandings of the public regarding accessibility rights. As explained, Adam believed emotional support dogs should be included with service dogs, however he recognized that currently "there are a lot of places you can't go" with emotional support dogs and therapy dogs. Adam said accessibility is "all about utility..."what reason [does someone have for their] dog to be right there with [them]." He said, "it would be super cool" if he could take his dog into restaurants, but that he did "not really" have a valid reason to do so. Adam explained, however, that when he takes his therapy dog, "into a nursing home or a hospital," he "should be able to do that without anybody giving [him] the runaround for it," insinuating he perceived that as an issue.

Isabelle expressed frustration and, "fairly strong opinions" over accessibility confrontations and members of the public questioning a service dog's access. Isabelle said,

You wouldn't deny someone with a different illness access to their medication....a blind person walking with a cane, you wouldn't tell them their cane was annoying you, or that their cane was offensive. Or you wouldn't tell someone with seizures 'oh sorry, you can’t have your epilepsy medication because I don't like the bottle it's in.'

Isabelle summarized her frustration over accessibility as, "You can't deny someone access to a public space because you're sensitive.”

When talking about accessibility, almost all of my co-researchers made comments similar to Emily's comment of "I know airplanes have had some trouble with what to do with them." They did not all define the issues as pertaining to either service animals or 
emotional support animals. Regarding the airlines, nine of the eleven co-researchers made reference to the news coverage of "peacock" on an airline. Cathy said, "you've seen with the airlines....What was it, the guy with the peacock?" When I asked Kevin if they had any issues with service dogs in his restaurant, he said, "we haven't had any peacocks in here lately." Haley said she "heard something about a peacock... did they refuse service to someone who had a peacock?" Additionally, Janet said she also heard stories of "people flying with emotional support...micro pigs, snakes, chickens...bearded dragons" and other species.

\section{Implications and recommendations.}

Given the co-researcher's confusion in differentiating the differences between service dogs and emotional support dogs, this topic represents lack of understanding regarding the differences between the ADA, the ACAA, and the FHA. Based on this observation, and the previous subthemes, if the co-researchers lack the capacity to differentiate between the dogs, and are not familiar with the legislation governing individual spaces, how can they appropriately determine which dogs are allowed in their place of business? These results support the concerns identified in the media like in Gunderson's (2014) article about how businesses are affected by service dogs. Additionally, these results provide a different point of view to the findings from The Foundation for Service Dog Support's survey data (C. Betancourt, personal communication, March 22, 2018). Understanding accessibility concerns from both the service dog handlers, and the gatekeepers, is essential to making informed decisions on education and policy. 
Recommendations for this subtheme are for those creating rules, regulations, and legislation to consider the both the service dog handler's and the gatekeeper's perceptions prior to, and during policy development. Further research needs done on the existing laws and how they conflict or contradict. Based on that research, areas of confusion in legal nomenclature need to be remedied to avoid future misunderstandings. Campbell (2016), Huss (2010), and Parenti et al. (2013) also identified the need for improvements in legislation. Additionally, business owners, gatekeepers, and assistance dog handlers need educated on the existing legislation regarding accessibility rights for service dogs, emotional support dogs, and therapy dogs to ease the interactions with assistance dogs in public spaces.

\section{1f. Behavioral expectations.}

\section{Expected behavior of the dog.}

All of the co-researchers viewed a dog's behavior as an indicator of their legitimacy as a service dog. Adam described service dogs as "very mild mannered" and "do not want to be pet if they are on the job." Becky said she recently learned, "there's little things that are obvious" indicators of a true service dog, such as, "they won't go nosing under" a table. She said if those behaviors are not exhibited, "apparently it's more of an emotional support type animal." Becky said you can tell a service dog, "of course by their behavior" and provided an example of two dogs who, "were composed the whole time, very calm, very poised." When she and her co-volunteer gatekeepers saw those particular dogs, Becky said, "of course" they did not question their validity "because they're true service dogs." 
Donna observed a dog and handler practicing commands in the mall where she worked and she said she knew it was a service dog because

...the dog seemed like it was very seasoned because the whole thing came very natural....at one point they walked over to the couches and sat down for a short period and he just sat there. Didn't move, didn't bark, [and] didn't reach up to be pet, nothing.

Isabelle said recognizing a service dog "comes down to behavior." She said, a service dog "is trained to stay within so many feet of its owner; it's not going to bother you, it's not going to want attention from you; it's going to be solely focused on its job." Kevin described service dogs as, "so well-behaved, more well-behaved than any other type of dog."

When determining a legitimate service dog from a misrepresented one, Adam's statement that, "the behavior of your dog is going to tell the story" was representative of the entire group's perceptions. When Cathy saw a dog in the library wearing "a service dog thing," but the handler was repeatedly yelling at the dog to "go down," she said, "it was very clear" the dog was "not a service dog." Gloria "this one particular dog, there was no way it was a true service dog because it was barking." Janet said, "service animals know not to play, they know not to get attention, they are focused on the job they are supposed to be doing....when it's barking....that's not a service animal."

\section{Appropriate way of interacting with the dog.}

Within a discussion of behavioral expectations, the theme of appropriate ways of interacting with the working dog presented itself. In general, the co-researchers understood the public should, "respect the dog and let it have its space," as Cathy stated. 
Doing so included, "just not question[ing] it," as Adam said. Donna said the public should "not be lovey dovey" with a service dog, because it could "get the dog all excited," or make the dog "lose focus on why he was there." Faith said she noticed issues with the public "especially children....wanting to touch the dog," and has had to explain "you can't touch them," because "it's a service dog." Faith also said she was willing to facilitate a conversation between the person interested in the dog and the person with the service dog.

Gloria said she "knew you shouldn't pet" a service dog, and "you're really not supposed to touch them because they're working." She added that it was appropriate to recognize the dog by saying "what a beautiful dog" and "always [be] friendly" to the person with the dog. Gloria also explained it was appropriate to recognize when the dog was assisting a veteran and thank them for their service.

Isabelle provided another perspective of interacting with the dog through talking to the handler, which supported the other co-researchers' statements of not touching a service dog. She said, "If somebody has a real service dog, and you ask to pet the dog, they will tell you no, because the animal is working." Isabelle also provided exact questions she perceived as appropriate to ask a hander. She said she knew the questions "from having one," and they were "(a) is your dog a service animal, and (b) what task does it perform." These questions are almost exactly the questions provided in the ADA.

\section{Implications and recommendations.}

Recognition of the expected behavior of a service dog is important, particularly for service dog training facilities. While the co-researcher's perceived expectations are consistent with what I learned in my service dog training courses, there is concern over 
how these perceptions could negatively affect perceptions of a service dog in-training. As Becky explained, service dogs in training are "not perfect." From experience, I know the dogs are learning leash skills, learning to ignore distractions, and learning all of their commands. Therefore, a recommendation would be to clearly mark service dogs intraining so that when members of the public observe those dogs in the learning process, they will not see "mistakes" a dog in-training might make, and project those behaviors onto service dogs as a whole. Additionally, this realization is important for dog handlers who are taking their dogs in public. If a dog is represented as a service dog, the public expects to see the appropriate correlated behaviors, and if your dog does not meet those expected standards, its legitimacy might be questioned.

Regarding the appropriate ways of interacting with a service dog, the coresearchers appeared to understand petting a service dog as unacceptable. However, based on personal experience, like Faith, I have observed people approaching and petting service dogs. Therefore, a recommendation for this subtheme is again, education. Donna explained the goal of this education when she said, "the public...they [need to] have [a] basic understanding of the behavior that you are supposed have towards a service dog, so the dog doesn't lose focus as to why it's there or doesn't become sidetracked." As Donna shared, she did "not know how their brain works," but she understood enough to question "how exciting a dog would be a good thing."

As with Donna, the public does not need to understand how petting a service dog can distract the dog from its work, they just need to know that petting the dog is not an acceptable interaction. Future research needs to be done on whether or not people petting and touching service dogs is a genuine concern and issue for service dog handlers. 


\section{1g. Uniform expectations.}

As presented in the literature review, there are conflicting laws on service dog uniform expectations. Therefore, I was not surprised to hear the co-researchers had varying expectations on what a service dog should, or should not wear as a uniform. In general, it was from their experiences of what they had seen that influenced their expectations. Becky, Haley, Gloria, and Kevin's experiences and expectations showcase the diversity represented regarding uniforms expectations.

Becky recognized the confusion over uniforms when she questioned, "What is the difference in how you prove that it if there's not actually something to look at? I don't know what the guidelines are for that." To her, the "jacket" was used for "guide dog[s]" to communicate it should not be pet. Haley said the dogs she saw usually had "a vest or something like that," and when she saw that, she did not question if it is a legitimate service dog. Gloria recognized the service dog vest as a "burden" to the dog but acknowledged the vest's importance in communicating to the dog, when the have the vest on, "it's time to go to work." Kevin, who perceived service dogs as an umbrella term for all assistance dogs, said, "usually the emotional support animals have some kind of insignia...like a scarf or something that is clearly marked and labeled." When he and his staff see that they "make the assumption that it's legitimate."

All of the co-researchers were aware of the service dog vests available to order offline. I will discuss this more in the section on misrepresentation. However, it is important to note here the awareness they had on uniform procurement, and the recognition that uniforms did not necessarily come from a service dog training facility. 


\section{Implications and recommendations.}

Given the variety of service dog uniforms the co-researchers had seen, it is difficult to presume one particular design as the most effective for communicating a dog is a service dog. Additionally, since the ADA states service dogs are not required to wear any form of a uniform, if a service dog is not wearing one, the possibility of a gatekeeper questioning its legitimacy is highly possible.

Recommendations resulting from these themes are for future research. An inspection into the existing uniforms needs to be done to develop a holistic understanding of what uniforms are being used. Additionally, research needs done on the purpose of the uniform, how handlers decide to outfit their dog in a particular uniform, and why those decisions are made. Furthermore, research needs to focus on existing legislation regarding service dog uniforms, and the conflicting legislation regarding those uniforms need to be rectified. Wisch (2016) addressed some of the conflicts in existing legislation on assistance dog uniforms. Additional research needs to done update the available data to provide a state-by-state comparison. Until a consensus on uniform has been reached, gatekeepers and service dog handlers need to be made aware that uniforms are not necessarily a valid form of confirming a dog's role and responsibilities.

\section{1h. Certification/registration expectations.}

In addition to uniform expectations, the data presented various expectations on certification and registration requirements of service dogs. As discussed in the literature review, the ADA states "covered entities may not require documentation, such as proof that the animal has been certified, trained, or licensed as a service animal, as a condition for entry" (DOJ, 2011a, p. 1). Additionally, on their website, the DOJ acknowledges the 
presence of "individuals and organizations that sell service animal certification or registration documents online" (DOJ, 2015, p. 1), but clarifies "these documents do not convey any rights under the ADA and the Department of Justice does not recognize them as proof that the dog is a service animal" (DOJ, 2015, p. 1). The results of this study confirm the presence of those "individuals and organizations," and present misunderstandings regarding certification and registration of service dogs.

Cathy said she "think[s] there are some" existing registries. Even though she admitted she did not know "as much on that stuff." Cathy also said the guide dog program, to whom she donates money, "are pretty rigorous about their ID," implying the importance of identification is stressed in that particular organization. Gloria's said, I love how people are taking their dogs everywhere, don't get me wrong, but I don't want someone to go out and wrongly call their dog a service dog if they haven't been through the training and a true certification. You can tell the difference.

Through this statement, it is understood that Gloria viewed certification and training in connection to service dog legitimacy.

Kevin shared that "someone told [him] that you can go online and register a service animal, pay like $\$ 300$ and get a certificate." He said he did "not know if that's true," but was "curious to know the legitimacy of that and if that's really a thing." As a business owner, Kevin wondered if the "service animal industry" was "vetting" and "straightening [that] out." From what he was told, Kevin "guess[ed] it's an emerging thing." Another component of the confusion in this subtheme was the expectations of certification for therapy dogs. 
Both Adam and Emily said therapy dogs "have certification processes." Adam said there are "a couple of organizations that are nationally accredited," and those organizations all have "certification processes" in place. The existence of recognized therapy dog certification processes is a concern, because if people do not clearly understand the differences between service dogs and therapy dogs, it is not plausible to expect them to understand the differences in certifications for either type of assistance $\operatorname{dog}$.

The conflicting state-to-state legislation on this topic was discussed in the literature review, and Isabelle's statement support the idea that confusion has resulted from the laws. She said, "Federally there isn't a standardization but each state can interpret that how they want to and each state is free to enforce certifications at their level." This is a misunderstanding because each state cannot enforce laws that further restrict the ADA (1990).

Isabelle also provided clear examples of the confusion for Kentucky: Recently Kentucky actually changed their laws...you can no longer certify your own animal as a service dog. You have to have sign off from a registered animal trainer that certifies your dog for you, where previously you could certify your own dog.

Isabelle's statement implies that certification of a service dog is mandatory. Isabelle said, If you Google 'Kentucky service animal law' you can see where the law's been changed, but they've done a very poor job of outlining what exactly is needed. They just say a certified trainer must certify your dog, but they don't have a list of what certifications. 
This comment brings to light a valid aspect of confusion for service dog handlers. If the legislation does not also provide details about the expectations, they are leaving the law open to interpretation. It should be noted, Isabelle was the only co-researcher familiar who mentioned this law. I believe her statements provide good examples of confusion and misunderstanding in this subtheme, however, when I looked for the law Isabelle referenced, I did not find it. The only Kentucky law found on service dogs was included in the Assistance Animals, housing law Haley talked about.

\section{Implications and recommendations.}

The implications of these conclusions are multiple. First, if the working public incorrectly expects service dogs to be certified, or registered, they are likely going to be asking for proof of those of those certifications and registrations. This is an issue for businesses because it is in direct violation of the ADA. Second, if gatekeepers continue to ask for proof of certification and registration, non-recognized organizations will continue to sell unofficial identifications, which is an unnecessary financial strain on the service dog handler. Third, if individual states do not remove the requirements for certification or registration from their bylaws, they are not only further restricting the regulations of the ADA, but they are also contributing to the confusion regarding certification and registration requirements.

Recommendations resulting from these themes are for future research. Similar to Wisch's (2016) research, a study, or multiple studies, needs to be done on the existing laws specifically for certification and registration processes of service animals. Campbell (2016) suggested improvements to the process of acquiring documents of identification for service dog handlers, in the form of a universal identification system. Future research 
can look at the feasibility of Campbell's suggestion, in concordance with the current legislation. The results of those studies will highlight the areas of concern, including state laws that restrict the ADA, or conflict with one another. Politicians and service dog organizations can use those results to make informed decisions regarding certification/registration processes, to correct existing legislation, and to develop cohesive future legislation. As for a more immediate, community-based solution, regarding all aspects of this theme, companies need to implement the use of signage in their spaces to educate gatekeepers on the correct processes for determining service dog legitimacy in regards to accessibility. Given the complexity of this topic, the signage needs to clearly present the two questions employees of public facilities are permitted to ask in determining service dog accessibility according to the ADA

\section{Summary of Theme 1}

The biggest theme of this research study's conclusions was this theme of misunderstanding, confusion, and lack of understanding. The subthemes of this main theme were (a) terminology; (b) characteristics; (c) role/responsibility of the dog; (d) perceived need and social impact; (e) accessibility; (f) behavioral expectations; (g) uniform expectations; and (h) certification/registration expectations. In describing each of these subthemes, I presented examples of identified misunderstandings, confusion, and lack of knowledge, and how those examples impact the working public's perceptions of service dogs. Additionally, within each subtheme, I discussed the cultural implications of the observed perceptions and made recommendations for change or future research. The results of this study contribute to the existing literature done by Schoenfeld-Tacher et al. (2017), and Schoenfeld-Tacher and Kogan (2017) on the perceptions of service dogs; and 
compliment the results of the Foundation for Service Dog Support's (C. Betancourt, personal communication, March 22, 2018) survey on perceived accessibility concerns as experienced by service dog handlers.

\section{Theme 2: Dogs in Society}

In addition to misunderstandings, confusion, and lack of knowledge, the theme of gatekeeper's perceptions of dogs as a part of our society presented itself. This theme relates to the research objectives as it provides valuable insight into the co-researchers' perceptions of dogs in general, which could influence their opinions on, and perceptions of, service dogs. Included in this main theme are the subthemes of (a) personal experiences \& opinions of dogs; (b) thoughts and emotional responses to service dogs; (c) respect for training; and (d) zeitgeist (see Figure 5). The first and second subtheme present the relationship identified in the co-researcher's perceptions of dogs in general and their general perceptions of assistance dogs.

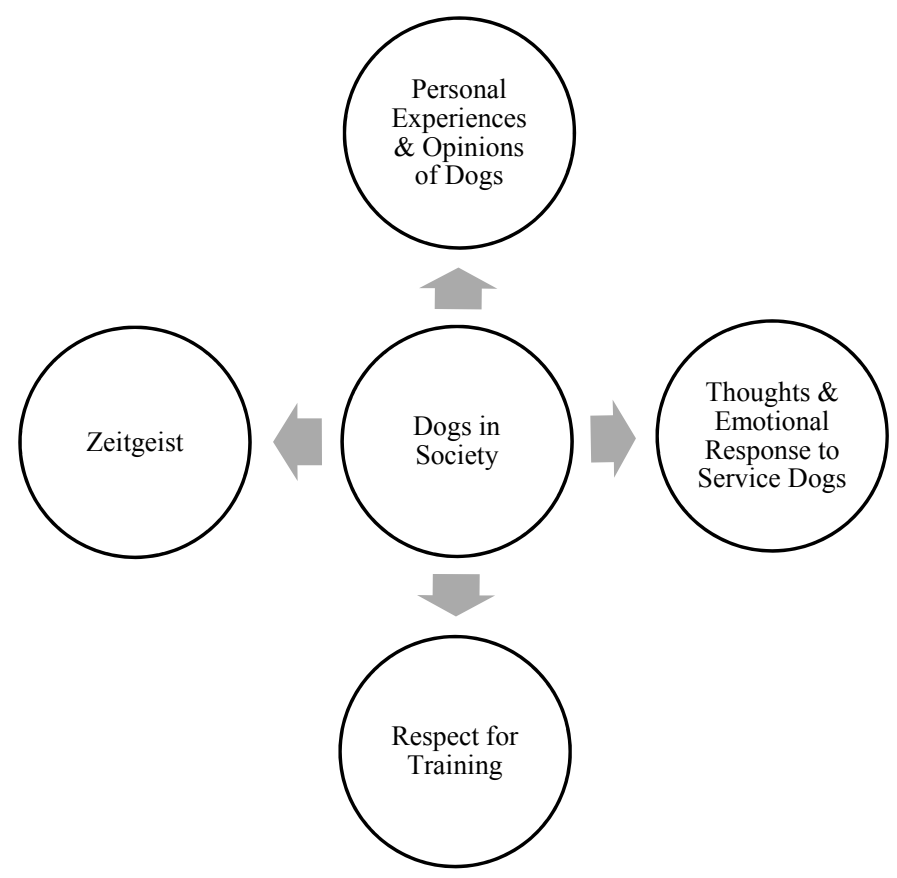

Figure 5: Main theme 2: Dogs in society, and related subthemes. 


\section{2a. Personal experiences and opinions of dogs.}

All of the eleven co-researchers in this study had a pet dog at one time in their lives. Of the eleven, seven co-researchers had pet dogs at the time of the interview and they proudly talked about their dogs and the dog's importance in their lives. Adam described one of his dogs as, his "best friend," and said, "animals just put [him] on a different wavelength." Becky described dogs as "the best creatures ever." In describing her dogs' value in her life, Cathy said she, "always had to have one" and "each and every time it's like that's your one true dog, you think this is once in a lifetime dog, and then it happens again." Haley lovingly talked about her dog, who she takes to work and was

present at the interview, when she said her dog, "just turned six this weekend." Janet said she did, "not think [she] could survive without a dog or cat in the house." Faith, Gloria, Isabelle, and Janet in some way all said they, "loved animals," or "loved dogs."

Of the eleven, four (Faith, Emily, Donna, and Kevin) did not have a pet dog at the time of the interview. Faith said the only reason she did not currently have a dog was because she and her kids are "just too busy" to properly care for a dog. She said, "Most people have dogs because they want a companion, or they're missing that," and that she will, "probably...get a dog" when her kids go to college because she is "going to miss" them. Emily said she, "would have a dog if [she had] someone to help [her] take care of it," and if she "could figure out what to do [with the dog] on the weekends when [she] want[s] to go outdoors." She also said her, "family wasn't big pet people," and said she "likes the [dogs] that are important to [her] friends," but she did "not know if [she is] a huge animal person." 
Of the eleven co-researchers, four (Adam, Becky, Donna, and Kevin) experienced trauma related to dogs. Adam and Becky's experiences happened when they were children and they wanted dogs their fathers did not necessarily want. Adam said he "would do anything to keep [his] dog," and responded to his dad's reaction by learning to train his dog. Adam realized he had a natural inclination for dog training, which he was using to train his current dog. Becky said her father "didn't have much patience," and "if [their pet dog] barked too much" her dad would get rid of it. She made the connection between her dad's behavior and her desire to "give [the dogs] a chance. Once she "became an adult," and "could choose her own," Becky said she has had a plethora of pets she has "loved."

Donna and Kevin were the two researchers who experienced trauma and did not have a dog at the time of the interview. Donna "had a dog growing up" but "when he passed away," she "became bitter towards dogs." She said, "the whole experience...was very traumatic and heart wrenching, so after that [she has] not had a dog since." She said because of the experience, she is "not really a dog person anymore," and said, ...it's not natural for me to bend down [to pet a dog] like most people who are big animal lovers...I don't react that way to animals. I might put my hand down and pat its little head but that's about the extent of what happens.

Nonetheless, because of her experiences with retired, rescued Greyhounds, Donna said, "if [she] were to get a dog" she "would get a Greyhound." The only qualm she mentioned with Greyhounds was "all the shedding. I can't stand all of the hair," she said. As a child "newspaper boy", Kevin "was chased and bitten by dogs." In describing the experience, he was very nonchalant and said he "kind of sloughed it 
off....didn't let [him] scar [him] for life or anything like that." What Kevin described as traumatic was "having a dog as part of the family, and losing it, and seeing what it does to the children." He, his wife, and their children had two dogs, both of whom died tragically. He attributed those experiences as the reason he did not currently have a dog. Going through that has "been kind of a hard process," he said. Nonetheless, Kevin said dogs have been his "go to" animal, and he viewed his daughter's dog as "part of [the] family." He described her dog as "the most loving, caring, therapeutic animal," and made a correlation between that dog and a service dog. He said, "even though she's not a service dog, or has been trained as a service dog, she's just very therapeutic to the whole family."

\section{Implications and recommendations.}

What this result shows is that previous experiences with dogs might have an impact on level of comfort around assistance animals. Dog ownership was not one of the qualifying factors in finding co-researchers. All of the eleven co-researchers, however, did have a pet dog at one point in their lives, and, even in the event of trauma, it was understood that they all had at least one positive personal experience with a dog. Recognition of this commonality presented the question if the results of the study would have been different with co-researchers who had never had a pet dog. Schoenfeld-Tacher et al. (2017) research on the public's perceptions of assistance animals, restricted the population to people who did not have any sort of assistance animal. As explained previously, in this study, Adam had a therapy dog in-training, and Isabelle had an emotional support dog. Therefore, recommendations for future research are to conduct studies on perceptions of assistance dogs, restricting the population in each study based 
on the participants' dog ownership. The results of such parameters could provide insight into correlations between exposures to dogs in general, ownership of assistance animals, and perceptions of assistance animals.

\section{2b. Thoughts and emotional response.}

This subtheme emerged as co-researcher's described their mental and emotional responses to seeing service dogs in public spaces. In general, their reactions were positive. Adam said when he sees a service dog in public he, "want[s] to know as little as possible," and "take[s] it at face value." He said the purpose of the dog is, "none of [his] business at all" but supports the presence of the dog, and thinks, "You go, dog." Adam added that it, "always warms [his] heart to see an animal giving a contribution out of the love that animals have for us."

Despite Donna's “indifference” towards dogs, Donna said when she sees a service dog, she "wonder[s] what their role is with the person they are with. It strikes curiosity" and she gets excited to know "why do they have this dog." Gloria had "nothing but wonderful things to say about service dogs," and "love[s] to see" them. Gloria said when she sees a service dog with a veteran, she views it as an opportunity to say "thank you for your service," which she has found to be a welcomed reaction.

\section{Implications and recommendations.}

What this subtheme reveals is that the working public's mental and emotional responses to seeing a service dog in public places varies. More research needs done on the working public's thoughts and emotional responses to service dogs. Research should specifically focus on people's overall experiences with dogs as they relate to their perceptions of service dogs. Findings could show if a correlation exists between general 
exposure to dogs and level of comfort around service dogs. Data would help inform animal organizations, and service dog organizations to the potential value in community related events to increase exposure to dogs.

\section{2c. Respect for training.}

As discussed previously, a dog's behavior was viewed as an important component in recognizing legitimate service dogs. Oftentimes, the behaviors the co-researcher's noted were results of training, such as sitting when a handler stops walking, or tucking under a table at a restaurant. The results of this study revealed the co-researcher's experiences with, and respect for, service dog training and dog training in general. Becky said she has "a lot of respect for people who can incorporate [service dog training] into their life." Donna was impressed by the training session she watched in the mall. In talking about service dogs detecting seizures or insulin drops, Faith said she "thought it was awesome how [service dogs] are trained to know that." Gloria said she had visited a service dog training facility and described it as "intense" and "a big deal." Gloria said she "give[s] a lot of respect to the dogs that have gone through that training."

Adam, Cathy, and Isabelle all had experience training their own dogs. Both Adam and Cathy used technical verbiage in describing their training experiences. Adam used "positive reinforcement," and Cathy used "approximation of a behavior and intermittent reinforcement." Isabelle was "involved in a community of service dog handlers who've trained their own service animals," and she talked about the financial aspects of training a service dog.

In discussing dog training, Adam brought up the point that "people that don't have an education about it, expect dogs to just stay with other dogs, but it's actually not a 
good idea if you've got a dog you're trying to train out a lot of those instinctive behaviors." Adam said dog parks are potentially dangerous for dogs because "you don't know what other people are training their dogs for, or if they are even training their dogs."

\section{Implications and recommendations.}

The overall respect for dog training represented in this subtheme supports the previously established respect for the work of assistance dogs. In all of these examples, the co-researchers had personally witnessed a dog, or service dog in training, which resulted in a respect for the training process and work the dog has done. Therefore, I believe there is value in educating the public about the processes involved in dog training, specifically assistance dog training. These results support the value in the existence of the service dog training programs discussed in the literature review on college and university campuses in Indiana, Kentucky, Ohio, Pennsylvania, and West Virginia (4 Paws for Ability University Program, n.d.; Humanimal Bond, n.d.; Susquehanna Service Dogs, n.d.). Given the fact that colleges and universities do not reach all populations, I encourage service dog training organizations to purposefully include members of the working public who may not have the opportunities to learn through existing college or university programs. As represented here, awareness and respect for a dog's behavior comes from knowledge of training.

\section{2d. Zeitgeist.}

Based on the literature review, the zeitgeist, or current sprit of the times, is that

dogs are becoming increasingly popular in our society (Walther et al., 2017). The results of this study support the current literature on the increasing popularity of dogs, and value 
of pet ownership. Adam said, "if you think about it, we've been breeding dogs and trying to get dogs to fulfill certain purposes for us for generations and generations...As far as them being a certified part of society, like monitored in some way," he said is "probably pretty new or at least that being taken seriously is pretty new."

Becky talked about a cultural change of "seeing more dogs out than [she] used to." Becky said she has been surprised when she has seen dogs in public spaces, but thinks "okay if they are good, what the heck" and why not welcome them in. Cathy observed a "surge in therapy dogs" on a university campus and speculated it to be "nearly [a] 400\% increase." When asked if there was anything she attributed the increase to, she said, "there were more...they were just more visible." Gloria's comments also supported that theory that dogs are increasing in popularity. She said, "dogs are becoming more common, whether it be service, therapy, whatever...more people are learning about them, so it's not a surprise for people to see a dog walking." Regarding working dogs like police dogs, and drug sniffing dogs, Janet noted seeing "more dogs at the airport." Isabelle's comment that "people are taking their pets everywhere" supports the American Pet Products Association's (2018) finding that that Generation Y pet owners were more likely to take their dog with them on errands than to leave the dog at home.

Some of the comments regarding the current mood highlighted the negative aspects of the current culture. Becky said, “you can’t get people to just have common sense and consideration." Janet said she perceived an increase over "the last three years" of people looking for emotional support animals who do not actually need one. She attributed the increase do "selfishness" and "people [have] learned to manipulate the system." 
Contrary to the existing literature, some of the co-researchers did not perceive an increase in the number of dogs they saw in public spaces. Haley said she "tend[s] to notice dogs just because [she] love[s] them," but did not "perceptively....notice an increase." Kevin explained that when people started bringing their pet dogs with them to the restaurant, he started allowing pet dogs on the outdoor patio space. However, he said he did not notice a particular increase in the number of dogs, at least "not any frequency that [he] could even measure."

\section{Implications and recommendations.}

The implications of this subtheme are mainly social and cultural. If there is in fact an increased number of dogs being brought into public spaces, and not all spaces are dog friendly, it is important, especially for the gatekeepers in service dog only facilities, to understand how to recognize a service dog from other dogs. Based on these observations and conclusions, one recommendation for future research is an inspection of the number of dogs seen in public facilities. Results from such research could be used to communicate with business owners the need to educate their employees on the company's policies and ADA regulations.

Another recommendation for future research is to collect data on the proliferation of a dog's presence in the media, including television shows, commercials, and advertisements. As explained in the literature review, and supported by the majority of the co-researchers, dogs are becoming "more common." It would be interesting to see if dogs have become more common in the media as well. 


\section{Summary of Theme 2}

The theme of dogs in society naturally developed as the co-researchers shared their experiences with, and perceptions of, all types of dogs. The subthemes of this main theme were (a) personal experiences \& opinions of dogs; (b) thoughts and emotional response to service dogs; (c) respect for training; and (d) zeitgeist. In describing each of these subthemes, I presented examples from co-researchers in support of the subtheme. Additionally, within each subtheme, I discussed the cultural implications of the observed perceptions and made recommendations for change or future research. This theme related to the research objectives as it illuminates the co-researcher's perceptions of dogs in general, which appeared to influence their opinions and perceptions of service dogs.

\section{Theme 3: Misrepresentation}

Misrepresentation of all three types of assistance dogs presented itself as an important component in the co-researcher's perceptions of service dogs. For the purposes of this study, misrepresentation is when someone claims their dog is a type of assistance dog, but the dog is not trained for that purpose. Included in this discussion are the reasons co-researchers identified as reasons for people misrepresenting their dogs (why); the manners in which co-researchers perceived people misrepresented their dogs (how); their opinions on misrepresentation of assistance animals; and discussion of how misrepresentation of a service animal impacts communities from a social/cultural perspective. The results of this theme contribute to the existing literature on misrepresentation of service animals (Elliot and Hogle, 2013; Schoenfeld-Tacher et al., 2017). This section presents the co-researchers perceptions through the following subthemes of misrepresentation: (a) why it is done; (b) how it is done; (c) opinions; a 
look into the influence of the news on misrepresentation in (d) bad news sells; and (e) implications; social/cultural impact and potential harm (see Figure 6). Recommendations are for the entire theme in the summary.

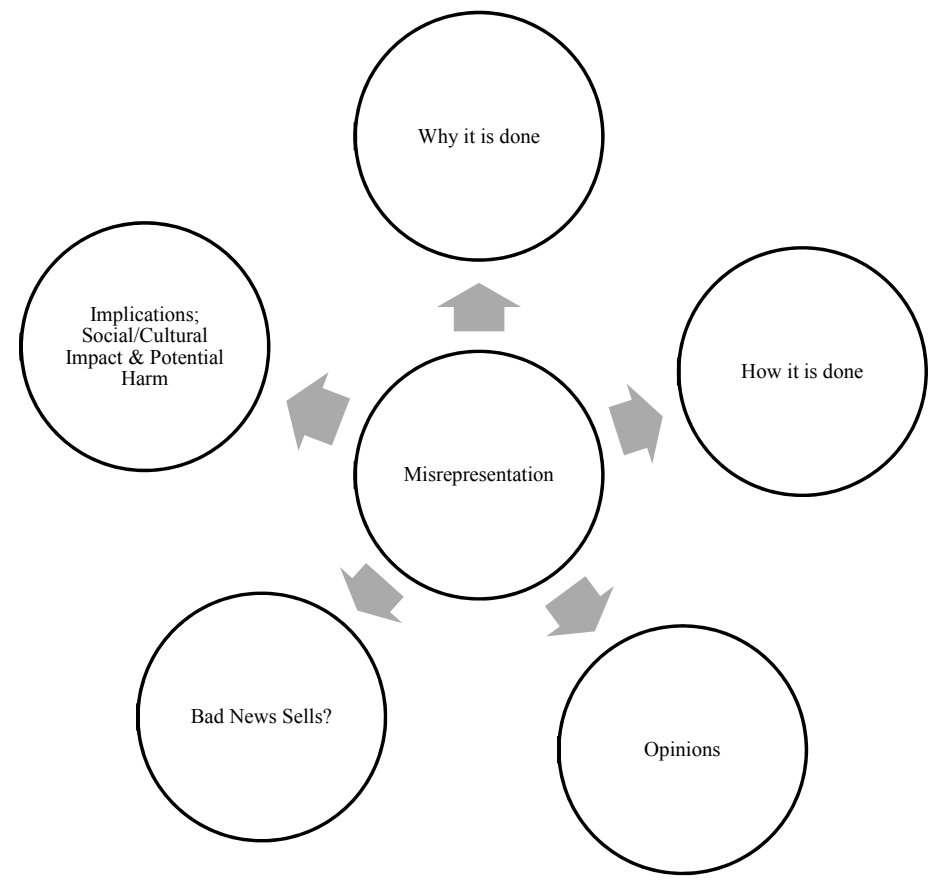

Figure 6: Main theme 3: Misrepresentation, and related subthemes.

\section{3a. Why it is done.}

The overwhelming response from the co-researchers as to why someone would misrepresent their dog as type of assistance animal, was to obtain access to places the dog is not normally permitted. Cathy said people were misrepresenting their dogs as emotional support dogs by having their "doctor write a note so they could have their dog living with them" in housing where pet dogs are not welcome. Additionally, she said people were using "therapy dog labels" to take pet dogs with them "to class.... [and] to enter businesses such as grocery stores and restaurants." It should be noted that within this statement is another example of misunderstanding on either the differences between service dogs and therapy dogs, or accessibility rights of therapy dogs. Gloria's 
perceptions on the reason someone would misrepresent their dog as a service dog were similar to Cathy's. Gloria said, "There's got to be a reason that people are doing this," and speculated the reason was people "just want to bring their pets everywhere." From her experience working as a gatekeeper at a food festival, Becky made the general statements that "people want their dogs with them," and "people sometimes will jump on a bandwagon just because they can get away with it." These results support the statements from Oliver Knsel that misrepresentation "relates to people wanting public access for their pets" (American Veterinarian, 2017, 0:42).

Haley, Isabelle, and Janet all said people misrepresent their dogs as either emotional support or service dogs to "avoid fees" related to housing. As Haley explained, landlords “can't charge any fees for assistance or service animals." Janet said another reason behind misrepresentation happens when housing developments have breed restrictions on the type of dogs that are allowed. Janet said, if people want a "certain breed" that is restricted, they will "go to the doctor and get a note and the landlord can't deny them." Though Haley did not see that as a common reason, she recognized the possibility. Haley said she believed the reason is "typically more to avoid the fee, but it does certainly help that, whereas we can restrict a pet, we cannot restrict a support animal."

\section{3b. How it is done.}

The co-researchers identified a variety of ways as to how people misrepresented their dog as an assistance dog. Adam, Janet, Gloria, and Cathy talked about people “ordering" a vest, patches, or harnesses that have "service dog" embroidered on them item, and putting the item on their dog to gain access to public places. Adam said when 
someone does that, gatekeepers "can't be questioning [them]." Janet said she was surprised when she first learned about the plethora of "service dog" and "service animal" items available online. She was also "shocked" when "people told [her]" they "just ordered it off of [online retailer] and now [they] can take [their dog] anywhere." Gloria shared Adam and Janet's perceptions. Gloria said, "you can just go online and buy [a uniform]." Gloria described misrepresenting a service dog as a simple, but disrespectful act; she said, "People just assume they can slap a harness on and call it a service dog." Gloria's use of the words 'just' and 'slap' indicated her perceived disregard on the part of the person with the misrepresented dog. Cathy said she "discovered that the internet now made it easy to buy a service dog harness and businesses were prevented from requiring verification about it."

Cathy and Becky both worked the same food festival as gatekeepers. Cathy said when festival attendees "realized" all they had to do to take their dog into the festival was say their dog was one of the approved assistance animals, they would lie and say, "Well I'm signing that. That is what my dog is." She said people changed their statements on the spot. Cathy said, "they just lied." Becky said so many people were lying about their dogs being assistance animals that she felt "like somehow word got out that you could bring your dog in if you just do it."

Cathy, Haley, and Janet all discussed that "people simply had their doctor write the medical excuse" so they could take their dogs places. Cathy said people were proud of the fact that they "did not have genuine need" for the dog, but they had the note. Haley said before the law was introduced requiring more detailed doctor notes, people would "go online and pay money to have [their] support animal registered, which," Haley 
said, "is completely fake, and not necessary." She said she heard people say "Oh I spent $\$ 75$ [and now] my dog has a vest; they mailed it to me." Even though she told them, "That's not really how this works," they still did it.

Isabelle said misrepresentation of service animals happens "because there's no system for checking whether or not it's truly needed, landlords aren't educated on what the policies are, [and] they're just trying to keep themselves out of lawsuits." From her perceptions, Isabelle said landlords will 'just say 'yes, I'll accept your paperwork' out of fear of being sued." Janet described all the entire process of how someone misrepresents an assistance animal as "people have learned to manipulate the system."

\section{3c. Opinions.}

Consistent with the literature review, and opinions represented in the news articles, some of the co-researchers expressed strong opinions on misrepresentation. Cathy described the current ease with which someone can misrepresent their dog as an assistance dog as "really bad." Haley was careful to "not sound negative about it because [she did] think there's a true benefit (to assistance animals)" but acknowledged misrepresentation has made it "hard...to sort out legitimate and illegitimate."

Adam said “you shouldn't be able to just put a vest on our dog, it shouldn't be that easy." Adam said he tries to avoid reading stories about misrepresentation because just seeing the headline makes him think "why would you pass a dog off as a seeing eye dog, like what is wrong with you?" He said, "It frustrates [him] to no end that somebody would do that." Adam equated the service dog to "the white cane," and questioned the motives of someone misrepresenting their dog. He asked, "why would you go out and pretend to have a dysfunction or an issue treatable by the dog, or by whatever, and 
pretend that you need that?" He also equated misrepresentation of a service dog to giving "the illusion that [someone] is a doctor" by "dress[ing] up in a lab coat." He said, "that's a very, very terrible thing to do, and it's also illegal to give people that impression." Adam said the same protections should exist to protect people who need service dogs. Gloria said her "biggest thing [she is] very passionate about is dogs not being labeled service or therapy when it hasn't been through the training and had the proper identification." Gloria said she was "very frustrated" about the amount of people who will misrepresent their dogs as service dogs without having "gone through the training". She said, "there's a lot of fakes," and the lack of training was her main concern. In Gloria's perception, people misrepresent their dogs as service dogs primarily so they can "take them on the planes." Gloria said she understood that desire, and it did "not bug [her]....but that means everyone should be able to do that."

\section{3d. Bad news sells?.}

Schoenfeld-Tacher et al. (2017) questioned if misrepresentation of service dogs in the news was actually a condition of bad news sells. The results of this study supported the fact that misrepresentation is an issue, however neither supported, nor refuted the inquiry as related to the news. Therefore, the results substantiated the need for further research on the topic.

As explained above, the co-researchers did view misrepresentation of an issue, however they did not attribute the news for their information on the topic. The news stories they recalled were primarily related to species of animals, other than dogs, and airline travel. Adam said he had seen "headlines" about misrepresentation, but he did intentionally did not read them. Cathy said she did not think was a case of bad news 
sells, but rather "a symptom of the me first society." Faith said she had not seen any dogs she believed to be misrepresented, but had "thought about it." Her opinion was that it was "wrong" but she countered with her opinion that she did "not see any harm in it." Her reasoning was "if it's not a service dog, then it's a dog....what's it going to harm somebody for having a dog in a grocery store? I mean, what's the harm of it?" Kevin did not directly say he had read about misrepresentation of assistance animals via the news, but he was "suspect that some people may abuse the whole service animal privilege" and if misrepresentation was actually happening. He mentioned having heard of "People traveling on airplanes and want[ing] to bring a bird, a service bird or a service monkey," and that he was "curious as to if that's a real thing."

\section{3e. Implications; social/cultural impact and potential harm.}

As co-researchers discussed the topic of misrepresentation, larger concerns became apparent. The concerns discussed have potential to impact our societies in social and cultural ways, including the risk of potential harm. The implications, and concerns identified regarding misrepresentation are discussed in the following sections of (a) reputation of service dogs and service dog handlers; (b) harm to the assistance dog; (c) reputation of the person misrepresenting their dog; and (d) impact on public entities.

\section{Reputation of service dogs and service dog handlers.}

The first area of concern is how misrepresentation affects the reputation of service dogs and service dog handlers in general. As Adam described, when someone labels their dog as a service dog, the risk is that when the misrepresented "dog give[s] bad behavior, it makes all service dogs look bad." He said the result is "people are going to be skeptical when somebody comes in that really needs their dog with them." Janet 
shared this opinion when she said, "If they keep abusing it, it's really bad for the people who really need them."

Cathy described misrepresentation of a service dog as "an insult" and "terribly demeaning to the people who have to have one." She explained that misrepresented dogs devalue the benefits of being able to have a pet. As Cathy described, service dog handlers "would like to just have a dog. They would like to just have a pet."

Gloria talked about the personal offense the service dog handlers she personally knew took to seeing misrepresented dogs. As she explained, if members of the public have "a bad experience with a dog who truly wasn't going through training," it made them "look down [on]" service dogs as a whole. Which, as she described, negatively impacts the legitimate service dog being "recognized as a positive part of the community."

Haley brought up the issue as it has impacted property owners and managers, and their perceptions of potential tenants when the tenant says they have an "emotional support animal." Because of the amount of people misrepresenting their dogs to either "avoid fees," or gain access to otherwise restricted housing, Haley said she "feel[s] like the general gist...the sense [she] gets, is that people (property owners and managers) are just kind of over it." The harmful side effect of this realization, for our communities, is that when property owners and managers hear renters "say ...emotional support animal," they instantly feel like "people are just trying to take advantage of them," and could potentially discriminate against someone with a legitimate need for an assistance animal. 


\section{Harm to the assistance dog.}

Another potentially harmful result of misrepresentation is what could happen if an assistance dog is attacked by a misrepresented service dog. Adam discussed this concern and his statements coincided with those seen in news articles from the literature review. Adam described the potential situation as, "traumatic" for the assistance dog "because that hurts [their] ability to do [their] job.” As he explained, even if the legitimate assistance dog is not physically hurt in the confrontation, they can be mentally scared, because they are "not made to handle that."

When I started data collection, I was aware of this potentially harmful side effect of misrepresentation. Personally, while I was participating in the training of one particular service dog, the dog was attacked by another non-service dog, and despite having completed almost two years of training, the service dog could no longer continue his work as a service dog. We tried for months to help him overcome the traumatic event, however, the damage was permanent. Therefore, even though Adam was the only co-researcher to discuss this concern of misrepresentation, I feel it is important to include it in the results as one of the potentially harmful side effects of misrepresentation.

\section{Reputation of the person misrepresenting their dog.}

When talking about misrepresentation, Adam said, "You can set something up to be this untouchable thing, doesn't mean people won't mess with it, but boy! How rough do you look if you're caught doing something like that when everybody has a respect for these animals." As Cathy talked about misrepresentation, she comments supported the harmful idea that “American people aren't going to follow the rules, they're just not. They're going to abuse them." Granted, some of this speaks to the co-researchers' 
general thoughts on the trustworthiness of others, but as they described these feelings in relation to their opinions of misrepresentation, they have been included in the analysis. From these viewpoints, the implications of misrepresenting an animal as a service dog conveys disrespect and lack of willingness to follow the rules of a society on the part of the person doing the misrepresenting.

\section{Impact on public entities.}

As Becky described her experiences with misrepresented dogs, she said, "it's obvious it was a comfort dog, it's wasn't a dog that can offer support, but what are you (the gatekeeper) going to do?" She felt like there were no other options than to “either...open it up to [all] dogs or...don't, because when you start letting a guide dog in, that's when you get the conflict." From this viewpoint, misrepresentation is a result of pet policy restrictions.

Both Becky and Cathy volunteered for a community social event, a food festival, at which a local animal rescue organization offered on site, free dog daycare for attendees. From their experiences as gatekeepers, the animal rescue organization possibly will not participate in the event in coming years because, as Cathy said, "it was a waste of time" since "the vast majority of people just took their [pet] dogs in anyway." They felt their contributions were "not even worth it." From this viewpoint, misrepresentation negatively impacts social events in our communities. The work of the animal rescue organization was to be helpful, but because of the amount of people who "just lied," as Cathy said, they felt their "place was not needed," and as a result, might not participate in the future. 
Both Becky and Isabelle recognized an increase in the number of misrepresented dogs on university campuses, and they discussed the impact these dogs have on the university, professors, and students. In thinking about her professor friend who was "allergic to dogs" and had a student repeatedly bring a misrepresented dog to his office, Cathy said, "People shouldn't have to be around it... [A] professor needs to know that that dog should be in the class... who should have one and who shouldn't." While her friend's allergy would still be an issue around a service dog, as she explained, the frustration with the situation was because he did not have to be "subjected to [it]. Isabelle said the situation of misrepresentation "wasn't so bad when [she] first started taking [her] service dog on campus, and then it seems like the last year, to year and half, it has really, for lack of a better term, exploded with fake service dogs." She described the current situation as "a lot more problematic." Isabelle explained that misrepresented dogs can "distract" or be "disruptive" for legitimate service dogs and handlers.

As for the impact on the community as a whole, Isabelle explained she "was told by a doctor that at [the local university] both psychiatric and student health services no longer write notes for emotional support animals." She assumed the reason for the change was the "influx of students just looking for emotional support paperwork and not actual mental health help." Based on the assumptions that university physicians do not have long term relationships with their patients, and that someone with a disability will likely have a long-term care physician to whom they can turn for proper documentation, an increase in students going to their university physicians for emotional support paperwork supports the idea that misrepresentation is happening for accessibility reasons. 
The implications of this viewpoint are that people who legitimately needed a note for their emotional support animal could experience unnecessary pushback from their doctors or housing companies when seeking assistance.

\section{Summary of Theme 3}

As revealed in this theme, misrepresentation is a complex topic, with varying points of view on the issue as a whole, and, if it is happening, why it is being done, how it is being done, and the impact it has on our communities. This main theme of misrepresentation was presented through the subthemes of (a) why it is done; (b) how it is done; (c) opinions; the impact of the news media on misrepresentation in (d) bad news sells; and (e) implications; social/cultural impact and potential harm. The results of this study showed that co-researchers viewed misrepresentation as valid concern. The implications of this concern, and recommendations for future research are presented in the following section and pertain to the entire theme of misrepresentation.

\section{Implications and recommendations.}

Misrepresentation of any type of assistance animal can negatively impact our communities. Recommendations for journalists specifically, are to focus on positive stories of service dogs helping their handlers. Additionally, use the outlet you have to create awareness of assistance animals, and how they benefit the people in our communities. Through education and increased awareness, people can learn about assistance animals, and where they might see them. Campbell (2016) described the need for increased awareness "to the current issue of service animal and ESA fraud" for the purpose of "discourage[ing] individuals from continuing to bend the loose federal and state laws" (p. 92). This awareness opens the door to respecting the work these animals 
do for humans, and in turn, helps people realize the negative impacts misrepresenting an animal as an assistance animal can cause.

Undoubtedly, additional research needs to be done on the various components of this theme. Recommendations for future research include an inspection into how misrepresentation has been presented in the news. Schoenfeld-Tacher et al. (2017) discussed the possibility that "the media may be over-representing... allegations of assistance animal fraud" (p. 642), because the results of their study showed relatively low rates of assistance dog misrepresentation. The results of this research study, however, showed the majority co-researchers viewed misrepresentation as a legitimate concern. Therefore, more research needs done to determine if misrepresentation is a widespread issue, and to develop a deeper understanding on the topic of misrepresentation overall. Studies need to be done on the frequency with which people misrepresent their dogs as assistance animals, and why they do so. Furthermore, research needs to be done on how service dogs are received in public spaces, and how service animals and emotional support animals are received in areas governed by the Fair Housing Act and the Air Carrier Access Act. Given the lack of existing empirical research on misrepresentation, researchers need to consider how they can contribute to the literature from specific to their field and line of work.

\section{Theme 4: Desire for Standardization}

Co-researchers were asked for their suggestions on improving areas they identified as needing change. From their suggestions, the two themes of standardization (theme 4) and education (theme 5) evolved. Presented in these themes, are insights into recommendations from the gatekeeper's perspective. The desire for standardization is 
organized into the following subthemes: (a) reasoning; (b) legalization and implications; and (c) certification/registration and uniforms (see Figure 7). Naturally, these subthemes coincide with some of the previously identified areas of misunderstanding, confusion, and lack of knowledge. The first subtheme of reasoning describes why standardization is needed. The remaining two subthemes are discussions of how standardization can take place in regards to legalization, uniforms, and certification or registration of assistance animals. The results of this theme support Schoenfeld-Tacher et al.'s (2017) discussed need for research on the public's perceptions of assistance animals and creation of "standardization in language and definition for these types of animals" (p. 11). Implications and recommendations are included within the subthemes.

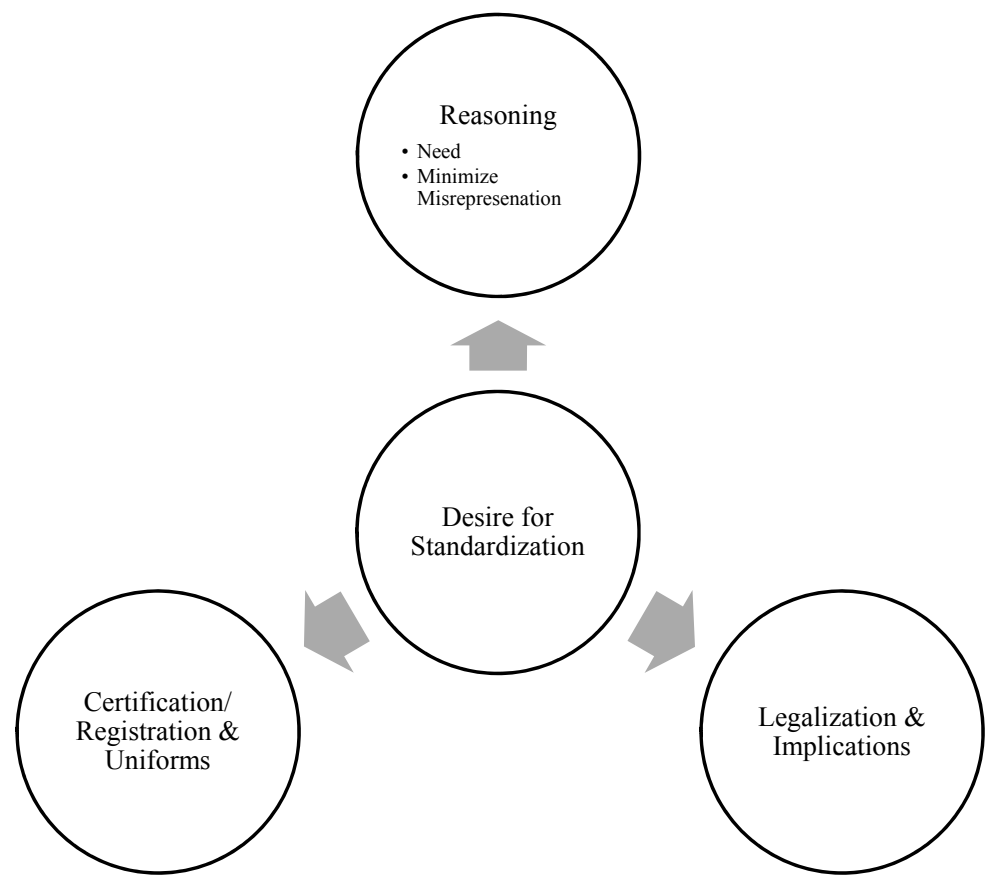

Figure 7: Main theme 4: Desire for standardization, and related subthemes. 


\section{4a. Reasoning.}

\section{Need.}

To introduce the theme of standardization, it is important to highlight what the coresearchers said about standardizing in general, and how they said it. Adam described standardization as a "consensus." He said, "there needs to be some sort of uniform consensus." Haley and Kevin both used the term "uniformity" when describing standardization. From the housing point of view, Haley said "it would be nice if there was some uniformity." Haley added that she did "not know how it would be regulated" and that "it sound[ed] like a financial opportunity for some company who want to lobby to be at the forefront [the uniform]." What to do with the existing uniforms already available for purchase was not discussed with the majority of co-researchers, however Adam said he liked the idea of removing them offline and "regulating them out on the market."

From the view point of business owners, Kevin said, "uniformity would be helpful." He said, "official uniformity" would provide "consistency" and help business owners and gatekeepers to "know [what] to look for." Kevin saw value in a standardized visual item and related it to "the Red Cross." He said, "Everybody knows, you see a white flag with a red cross on it, you know that's the Red Cross." He did not identify a specific visual item, rather he said, "Anything that makes the process fluid for the business operator is a good thing." He explained they could see the standardized item, and without having to ask about the dog, be able to welcome the guest and their dog into the establishment. 
Becky said, "There needs to be a set of guidelines," specifically to facilitate the gatekeepers' responsibilities. She described the need for standardization being for the purpose of "people can show if they can be let in or not," which would prevent gatekeepers from being "embarrassed." As discussed in the literature review, a standardized marking, or uniform, does not exist. Becky said that "put [her and her fellow gatekeepers] in a bad situation." She feared telling attendees their dog was not allowed in the event because, as she said, "People get angry." Becky was not aware that uniform requirements vary state to state, and when she found out, she exclaimed, "That's stupid." She said "you should be able to go anywhere in the United States and see if a dog is working." Standardization across the nation would provide the ability for everyone, regardless of which state they are in, to recognize a working dog.

Also from the point view of a gatekeeper, Faith, who did "not see anything wrong" with "people bringing in regular dogs," said standardization would help her just to "definitely know" which dog is which. Faith described the value in getting to know her customers based on the dog's role in their lives. She explained it would be an "indication and people would know that's just a regular dog. That's not a service dog,"

and as she explained, petting service dogs is not an appropriate interaction, but she did not see harm in asking to pet someone's pet dog. Standardization would let the public distinguish between the two without a verbal interaction.

\section{Minimize misrepresentation.}

Another reason the co-researchers identified standardization as valuable, was to help minimize the number of misrepresented assistance animals. Kevin explained, "if word got out" that businesses could expect a standardized item, it "would probably be a 
positive thing to legitimize and make sure that people aren't abusing the system." When discussing misrepresentation, Cathy said standardization is "the part that has to change." She said, "there should be something standard" because gatekeepers "can't do anything to reinforce" their policies. She explained currently they can "just ask," and if the person with the dog says the dog is a service dog, emotional support dog, or therapy dog, "[the gatekeepers] just have to assume they are." However, "if they have something....that is all uniform across the county, and across states" that would help verify the dog's legitimacy to the gatekeeper. Haley's discussion of Kentucky's new housing assistance animal law validated Cathy's point. Haley said the new law has been "helpful" for landlords to be able to "pushback a little bit."

Gloria said "having something special...and across the nation everyone has that same thing" would allow gatekeepers to know, "this is proper documentation, that it's not a fake." She brought up the issue that people "can always make a fake ID," but said "if it's enforced, hopefully that will lessen the amount of people that are" misrepresenting their animals. She explained that having an official, "proper identification" would make it harder for people to duplicate, because they could not simply "just go get that harness" and proper identification is "probably expensive" to make. Adam also recognized the issue of illegal reproductions of a standardized item. He said, "You'd still have people bootlegging, but I think that (standardization) would make it more difficult."

Isabelle said "something standardized would help people know, when an animal walked into a business, that it was working and that it wasn't someone's pet that they decided to take to the mall today." In agreement with the other co-researchers, she said, "standardizing things will slow down the fakes." Then countered her statement, which 
was observed to be in accordance with Gloria and Adam's concerns, she said, "even if there was a standardized vest, someone out there is going to forge it." She explained people can "get a vest" online. "So as far as standardizing goes....I don't think it would make a difference as far as fake service dogs go." Isabelle explained that laws have been made "in an attempt to help reduce fake service dogs," but explained the laws do not sufficiently explain the parameters of expectations.

Regardless that she did not think a standardized uniform would help minimize misrepresentation, Isabelle placed value, in general on visual identification of assistance animals. She said, "Because everyone is taking their pets everywhere, unless you can mark that yours isn't just a pet, people are going to assume you're just bringing your pet in because you don't care about the company's policies." This comment is representative of the negative impacts misrepresentation can have on the assistance dog handler, as discussed in the theme of misrepresentation.

\section{4b. Legalization and implications.}

Since the existing accessibility allowances for assistance animals comes from federal mandates, and individual states have created laws pertaining to assistance animals, naturally the subtheme of legalization evolved within standardization. Within this subtheme is a discussion of the co-researcher's perceptions of the current legislation; as well as their perceptions on why future legislation should, or should not, be created regarding assistance animals. It is important for politicians to examine the public's perceptions of legislation on the topic so the laws can work for the benefit of our communities. 
In discussing the existing legislation on assistance animals, Adam recognized, "we do have federal guidelines. It's just that the states often want to be more restrictive than the federal guidelines." Adam suggested, "if you do a federal mandate, and maybe I sound like a big government guy, but if you do a federal mandate it should be enough to satisfy the states' recommendations...I guess not leave it open-ended for any weirdness." Adam explained,

With the American with Disabilities Act, it comes down to interpretation, and people interpret what they want to interpret from most everything they see, with their own skewed bias, and if you get a good enough attorney they can argue it for you.

To "not leave it open ended for any weirdness," Adam said the laws "would be we need to make it pretty cut and dry" to "remove any potential for abuse."

Adam's statements brought to light a few key components in this subtheme of legislation. The first, is his perception that the "states want to be more restrictive" and that the ADA "comes down to interpretation. This is similar to Isabelle's statement that, "federally there isn't a standardization but each state can interpret that how they want to, and each state is free to enforce certifications at their level." These perceptions support the existing literature of Elliott and Hogle (2013), and Parenti et al. (2013), on the identified issues resulting from contradicting laws. If politicians do not recognize these concerns, amend the existing laws, and confirm the new laws do not contradict other laws, people are going to develop a disregard for the legislation, and "interpret" the laws in various ways, as represented here. 
The second key component in Adam's statements, was his mention of sounding like "a big government guy." This ties in with disregard for legislation. While Adam did not say it as a bad thing, he implied that sounding like he supported "big government" could be viewed as a negative. Becky and Cathy also made comments that implied they were wary of governmental influence in regards to standardization. When discussing improvements to be made, Becky said, “it's like you don't want the government to take control, but there needs to be some kind of guideline..." When discussing a standardized uniform, Cathy said, "it comes through one, and I guess it has to be government, even though I don't like big government, but it would have to be, that. That has to be controlled." These viewpoints convey a cultural context of the current political moment, and the pushback some have against government participation in our societies, which could possibly be a barrier to any real change.

\section{Implications and recommendations.}

What this reveals is that more research needs done on the public's perceptions of legislation relating to assistance animals. This supports the need Huss (2010) discussed regarding clarification of laws regarding service animals. Additionally, research needs to ask if conflicting legislation has led to the public naturally pushing back against the government's involvement and influence on assistance animals.

Adam and Becky both suggested the need for laws that enforce "fines" as "punishment" for misrepresentation of a service animal. Their suggestions support Campbell's (2016) suggestions for Kentucky to pass a law on misrepresentation of assistance animals. As explained by Haley, the Kentucky housing bill on assistance animals includes fines for misrepresentation of a service animal. However, that particular 
mandate only applies when an animal is misrepresented for the purpose of obtaining access to housing (An Act Relating to Assistance Animals, 2018), and therefore does not apply to misrepresentation in public entities.

Becky and Haley both discussed the how legislation can provide backing for gatekeepers. From her gatekeeper experience, and someone without knowledge of legal provisions, Becky said,

That was the first time I was in the situation where I had to possibly refuse a person because they couldn't bring their dog in, and it made me feel really awkward not having a steadfast quote, policy or something to go back on. The situation made such an impact on Becky that she said, "I don't want to be put in that situation again without some firmer laws. People get angry." Haley, from the perspective of someone who has experience with legal provisions providing her with the ability to "pushback," said the "new provisions are extremely helpful and I don't know that I would ask for much more."

One co-researcher identified potential pushback on legislation. While one person is certainly not representative of the whole, her perspective highlighted some potential pushback politicians could face regarding legislation and certification. When Isabelle said, "standardizing things will slow down the fakes," she added that it would "also increase the cost of things for people who maybe can't afford it. She explained, "anytime you take something that is free and then you put a cost to it, and not only are you putting a cost to it, you're putting a federally mandated cost to it...someone out there is going to offended." Isabelle and Janet both made suggestions of having the cost of service animals and emotional support animals being covered by insurance. 
In discussing Kentucky's laws, Isabelle said a change was made, "Where previously you could certify your own animal as a service dog," now, "you have to have sign off from a registered animal trainer that certifies your dog for you". She critiqued the law for "creating a barrier for people with low income to that now they have to pay the hundreds and thousands of dollars to work with a trainer."

Both Isabelle and Janet discussed the financial aspects of pet ownership, and how, in general, people do not understand how much a dog can cost. Isabelle was the only coresearcher, in this study, who had gone through the process of obtaining a service dog. Therefore, she was the only one with knowledge of the financial aspects of the process. Hence, recommendations for future research are to look into the costs related to obtaining various types of assistance animals, specifically service dogs and emotional support dogs. A review of both legally required and non-required, but necessary items, needs to be included. The results from those studies can be used to help educate organizations, and people, looking for assistance dogs on the financial aspect of the treatment. Such research would complement Collins' (2004) findings that compared the economic status of service dog handlers to those who were waiting for a service dog. Additionally, this information will compliment research on legislation regarding assistance animals, particularly in areas where handlers are required to pay for services.

Furthermore, as service dogs are only one possible option available for mitigating disabilities, research needs to be done delineating the benefits of a service dog as compared to other disability training, such as echo-location for the blind, or stressreduction techniques for PTSD. The results of such research could provide valuable insight for service dog training organizations to understand why a person with a disability 
would choose a service dog over other available support systems, and would help guide people in selecting most appropriate support system for their disability. Additionally, such information could teach us ways in which service dogs could be trained to participate with the existing support systems for the betterment of their handler.

\section{4c. Certification/registration, and uniforms.}

In addition to legislation, when the co-researchers were asked what would help them, and the public in general, embrace service dogs, emotional support dogs, and therapy dogs, standardization of both uniforms; and certification, or registration processes were identified. This subtheme includes a discussion of both the physical uniform and certification, or registration, suggestions. The two go hand-in-hand because often certification or registration processes result in a physical proof of legitimacy, such as a uniform. In regards to the physical uniforms, the co-researchers preferred standardized identification and/or vests.

In describing the visual component of the uniform design, Adam said, "it needs to be some sort of verifiable marking they could wear," for the purpose of "let[ing] you know" the dog's role. Becky said the uniform needs to be "Something to designate by just visually looking at them." Emily said, "something very obvious would be helpful and easy," and suggested "some sort of universal emblem of some sort, just like a credential for a person that we know to expect and a certain thing from that credentialed professional." Isabelle agreed that visually identifiable uniforms will help ease the interaction in public space.

Adam and Kevin both agreed the uniform should be on the dog, and "not something the handler carries". Adam said the issue with a handler having to carry 
something is that it requires the gatekeeper to ask for the item. Which, he said, is "too personal to get into that in depth of a conversation," and "would be more stigmatizing." Neither Adam, nor Kevin had a preference on the actual uniform item. Adam suggested "a badge" or "some kind of patch that would go on the vest." Kevin talked about how "service vests...the collar, the bandanna or...scarf" reminded him "of Boy Scouts or Girl Scouts, when they have the color, or little badge, or some kind of insignia." Which he said, "usually is a pretty good indicator that it's legitimate. It kind of looks like a uniform, not just something plain."

Kevin's reasoning for the uniform being on the dog was, "the dog is the service animal, not the handler." He added that "it would be great" if the handler had something to "correspond with the dog," but that if customers have to "go in their purse" to pull out an ID it would be troublesome. In the event the standardized item was a form of identification, Kevin suggested putting the identification in a "lanyard" gatekeepers could see without having to ask for it.

In support of a certified identification, Becky said, "There needs to be a set of guidelines, or some kind of certification...like a license of some sort, so people can show if they can be let in or not." Becky explained that the identification could be in the form of a dog tag, and "just having a little dog tag...like we have rabies tags that would be perfect." She felt "Jackets are nice as well but that [dog tag] would be something that would suffice" to help gatekeepers.

Cathy suggested the need for a "uniform monitoring system, like a registry." She explained through the official registry, people could get "a standard little thing on your driver's license." Cathy explained the item needs to be standardized and needs to have "a 
chip in it so it's official." She said doing so, would mean the gatekeepers "would never have to embarrass" the handler by asking them questions beyond asking to see their identification. "Everybody" would learn "that's a routine practice to ask," she said.

Gloria was also in support of a standardized identification. She said it needed to be "some sort of proper identification just like we would have an ID." Gloria explained the value of standardized identification would be mainly for travel purposes, specifically flying. In her perception, an identification would not help "going to malls" or "just shopping," because she doubted gatekeepers would "actually...check it." However, in regards to air travel, she said "TSA knows how to deal with that kind of thing." Also in support of the idea of standardized identification, Isabelle said "if we went the route of standardizing both," meaning uniforms and identification, she felt the identification should be "standardized" and "government issued." "Like a driver's license," Isabelle explained.

Cathy, Faith, Haley, Gloria, Isabelle, and Janet all specifically suggested a vest for the standardized uniform. Cathy said it should be one design for service dogs, and distribution of the designed vest "has to be controlled." Faith said a vest would help with the issues she saw of people wanting to pet service dogs. As she described, "it would let them know, it's a service dog. There's a reason why that dog has that vest on." Gloria valued the vest because the dog "know[s] they are working with it on." As for her preference, she said she did not have one "as long as it's the typical harness that you see that has "service dog." Isabelle said, "the dog should be vested with, like if it's a service dog, I think it should say "service dog" clearly on the vest." Janet also preferred to see the patches that say "service dog" or "do not pet me, I'm working." She explained a 
standardized uniform would help educate people on proper interactions with the service $\operatorname{dog}$.

Of the uniform colors discussed, Emily, Isabelle, Janet, and Kevin all mentioned red. Haley and Kevin mentioned yellow. Some of the co-researchers provided reasoning behind their color suggestions. Emily and Kevin's suggestions on color came from what they recalled having seen previously. Isabelle described red as "very official," and said the uniform should be "brightly colored." Emily described yellow as "bright" like "caution tape, and reflective gear, and things that would catch your eye."

Some of the co-researchers acknowledged the possibility that a visually identifiable uniform could be perceived as discriminatory, or stigmatizing, because it let the public know the handler has a disability. Adam's response to the concern was, "at the end of the day, we have to find a consensus that is going to work for everybody and also protect the people that need the dog in the first place." Isabelle said, "Speaking from personal experience, the second you walk into a business that isn't pet friendly, with your dog, it's out there that you have a disability. There's no hiding a 70 pound golden retriever." She explained that when handlers do not mark their dogs, and they "walk into a non-pet friendly establishment," they might be "asked why [they are] bringing [their] pet in, and [they will] have to explain.” The explanation could be just that the dog is a service dog, or, if the gatekeeper is not aware of the appropriate questions they can ask, the handler might be asked questions regarding training, proof of identification, or even their disability. As Isabelle said, "it's going to cause you less hassle to just mark your dog." These perceptions provided valuable insight from the two co-researchers who had personal experience with assistance dogs. 
Faith explained another benefit for service dog handlers when marking their dogs as service dogs. As she said, "if people know about it, and know exactly what you've got, then if something happens to you, somebody can call $911 \ldots$ and it can save somebody's life!" Faith's reasoning represents the potential benefit to service dog vests being a vehicle to members of the community being able to help one another.

\section{Implications and recommendations.}

In general, the co-researchers shared the opinion that a uniform provided a visual way for people to identify assistance animals. As discussed in the literature review, the ADA does not require service dogs to wear a marking, or uniform, and verbal questions asked of the dog handler are provided to determine legitimacy (DOJ, 2011a).

Nonetheless, the results of this study showed that gatekeepers were not familiar with the questions included in the ADA provision, and they identified uniforms, along with behavior, as to how they determined a dog's legitimacy. These results compliment Elliott and Hogle's (2013) suggestions for required certification processes resulting in stateissued identification tags for service dogs.

The information contained in this subtheme can be used to develop research on assistance dog uniform and certification/registration preferences. The results of this study were not able to be conclusively divided by service dog type, because of the misunderstandings, confusion, and lack of knowledge previously discussed. Therefore, recommendations for future research include research specifically focused on each type of assistance animal with participants who correctly distinguish between the assistance animals. Research also needs to be on what uniforms are being used, by whom, and why. Additionally, more research needs to be done on both the public, and the dog handler's 
uniform preferences. These studies could look at design preferences including item, shape, color, texture, and signage. Research also needs to be done on the aspect of the uniform as a component of the dog's training.

Furthermore, as uniforms requirements are included in some of the state laws on assistance animals, as discussed in the literature review by Wisch (2016), more research needs done all of the current existing laws and how those laws either compliment, or conflict with each other, and/or the federal guidelines. Regarding certification and registration, research needs to be done on existing registries and certification processes, and the validity of the programs. Research also needs to be done on the messages assistance dog training organizations are communicating about certifications and registrations.

\section{Summary of Theme 4}

Theme 4, standardization, presented the co-researchers' suggestions for improvements through standardization. Included in this theme was a discussion of why standardization is important, and how the co-researchers perceived standardization would benefit assistance dog handlers, gatekeepers, and public entities. This information was presented in three subthemes: (a) reasoning; (b) legalization and implications; and (c) certification/registration and uniforms. Recommendations for future research were included, as appropriate, in each subtheme.

\section{Theme 5: Education}

The results of this study have revealed a significant need for education. In this chapter, the need for education was discussed heavily in the first theme of misunderstanding, confusion, and lack of knowledge, as well as throughout the rest of the 
themes in the form of implications and recommendations. When co-researchers were asked for their suggestions on improving areas they identified as needing change, they identified standardization and education. Their recognition of the need for education is in line with the literature review, and data analysis from their own interviews. Presented in this theme are insights into the gatekeeper's recommendations regarding education. This theme is organized into the following subthemes: (a) perceived need and focus of education; (b) mode of delivery; and (c) information procurement, a discussion of how the co-researchers gained their own knowledge, and developed their perceptions, which were at the heart of this research study (see Figure 8).

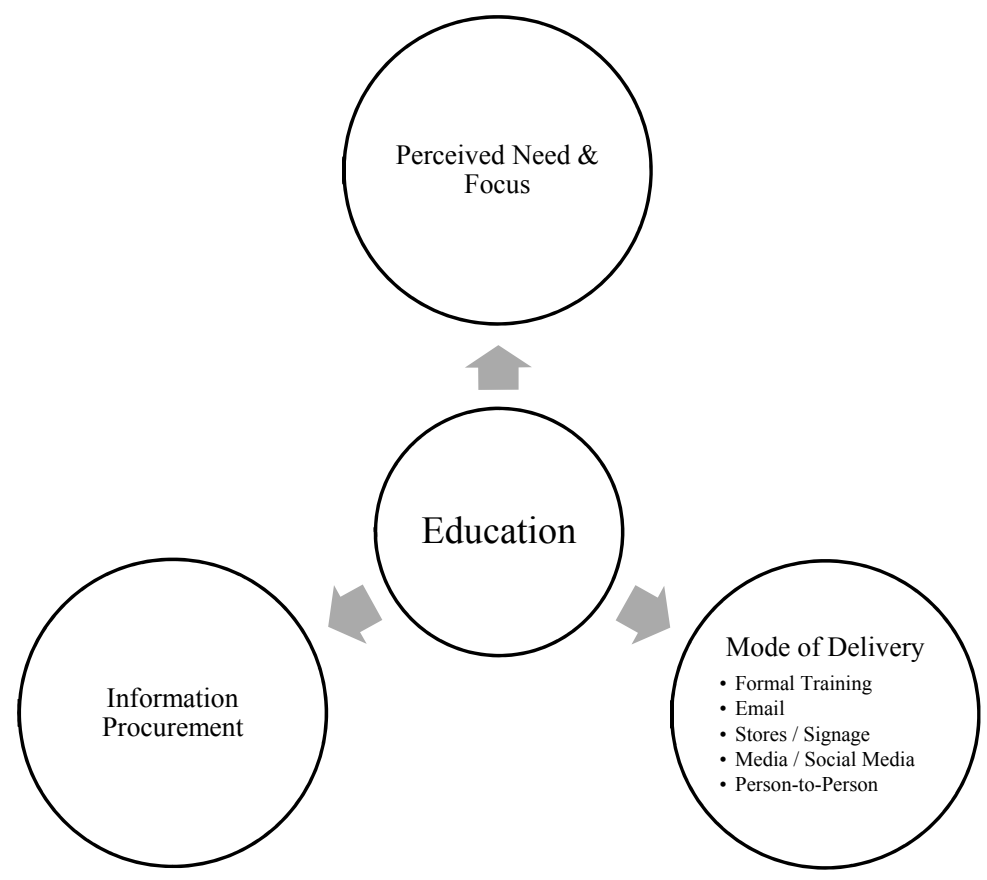

Figure 8: Main theme 5: Education, and related subthemes.

\section{5a. Perceived need \& focus of education.}

In each of the interviews, co-researchers brought up education as a necessary catalyst for change. The data analysis revealed a lot of overlap in areas identified as 
needing education. Included in this subtheme are some examples the co-researchers' stated need for education, as well as a discussion of the topics on which the needed education should be focused.

In his discussion on why he believed emotional support dogs are as important as service dogs, Adam said, "I think emotional support and service dogs are the same thing... and people just haven't realized the importance of mental health yet." $\mathrm{He}$ supported his opinion with both professional observations, and with medical research. From his professional observations, Adam had seen "how hard it is for people to struggle, and have every bit of a degree of emotional pain that somebody has physical pain." $\mathrm{He}$ explained that medical research on the "brain" has shown, "pain is pain. The same areas light up whether it's emotional [pain] or physical [pain], so that kind of adds credit to those being very valid disorders that need treatment." Adam explained that if a dog helps alleviate that pain, people should be allowed to have their dog with them. Adam's justification and statement that "people just haven't realized" the value of emotional support animals yet support the ideas found in Bourland's (2009) and Hernandez-Silk's (2018) research on emotional support animals.

While discussing accessibility rights for emotional support dogs and therapy dogs, Adam said, "you could probably get away with it in a lot of places because people are so uneducated about it." This statement represents the need to educate gatekeepers on the differences between the three types of assistance animals, service, emotional support, and therapy. Adam also discussed the need for educating "any mental health clinician" about how they could incorporate assistance dogs, "especially therapy dogs" into their work so that more people could benefit from the work of therapy dogs. 
Isabelle and Janet also discussed the public's lack of education regarding the differences that differentiate assistance animals. Isabelle said they "have a lot of people that come into [their] shelter looking for service dogs, and then [she or the other employees]" have to "educate them on what the different criteria for those are." She explained that "not everyone we work with is clear on what all of the stipulations and guidelines are," which further supports the need for educating the public, including anyone who works with the public.

Becky and Cathy's statements support the need for public education regarding accessibility. Becky made the suggestion to "make the public more aware," so people do not misrepresent their dogs as service dogs. Cathy said assistance dog handlers "need to stand up and educate us, seniors, in schools, kids, all over" about how misrepresentation makes them feel.

Cathy's personal experiences as a teacher further represent the need for education in regards to misrepresentation and accessibility. As she explained, students did not see the harm in misrepresenting their dog as an assistance animal for housing purposes. Cathy said, "They never really thought about it from that other person's perspective, [that] maybe it could be a little bit an insult." She talked to them about it, and helped them learn and "have a little more empathy." Cathy's experiences are an example of how education can open the door for empathy and subsequently, decrease misrepresentation of assistance animals.

Donna explained the need for educating "the public [is] so that they have basic understanding of the behavior that you are supposed have towards a service dog." Inappropriate interactions with the dog, such as petting them, can cause them to "lose 
focus as to why [they are] there, or... become sidetracked," which can be dangerous if it distracts them in a moment they need to be helping their handler. Isabelle also recognized this need for education when she said, "with increased education, people would teach their kids not to touch service dogs." Similarly, Becky explained parents needed to know what to do around service dogs "because we are teaching the next generation.” These statements support the need for education focused on appropriate interactions with service dogs, emotional support dogs, and therapy dogs.

Faith explained the need for education relating to businesses. She explained that if a standardized vest was created, along with a "manual" for businesses, and someone questioned why a dog was inside the facility, they could use the manual to educate their patrons on "why that dog is there." Education in this format would not only teach awareness of how service dogs assist people with disabilities, but also help facilitate the gatekeepers' interactions with inquiring customers.

Kevin had personal experience with "guests who are wondering why there's a dog" inside the restaurant. He said, "most people know about service dogs, but some people are ignorant, so you have to explain." Based on these experiences, the responsibility of educating the public falls on business owners, and their employees. Therefore, it is necessary for business owners to have knowledge regarding assistance animals, and to share that with their staff.

In Gloria's interview, she discussed how service dogs are "still somewhat a new thing," particularly for PTSD support service dogs. She stated, "I think there should be more education about service dogs," and "there's a lot of education that's lacking to the public." She explained that education focusing on the ways service dogs change people's 
lives can protect service dog handlers' and their dogs' reputations. Gloria said, "I hope that type of information goes out so people can treat service dogs with respect, and treat the people that have the dogs with respect as well." Gloria explained that without education, people "turn their nose up at them," which leads to negative social interactions.

Gloria also discussed how increased education not only teaches people "how to determine whether this is truly a service dog or not," but helps people realize if they could benefit from having a service dog. Gloria talked about how "pride" could keep someone from realizing how a service animal could improve their quality of life. To increase awareness, Gloria suggested that service dog training organizations and people with service dogs "go on the news" and share "what they [the dogs] do" or "how you could apply to get a service dog."

Haley discussed the need for education in regards to housing. Haley explained she "encountered a lot of people" who were unaware that landlords cannot charge fees for assistance animals. She also had experience with landlords who appeared to be uneducated on the legal aspects of assistance animals and housing. She explained that she often feels the need to educate them on the regulations.

Also related to housing, Isabelle said "homeowners...landlords, and property owners" need "educate[d]...on what their rights are, as well as... what it means to have an emotional support animal, and what that entails." She also said education would "help decrease fraudulent ones." Additionally, Isabelle recognized the need for "increase[d] education, not just for service animals and emotional support animals, but across the board." As she and Janet explained, people could benefit from education on all aspects 
of assistance animal, and pet ownership, including legal, medically, physical, and financial responsibilities.

\section{5b. Mode of delivery.}

Included in this discussion are suggestions the co-researchers made for delivering information and educating the public. Modes of delivery included formal trainings; email; in stores, or with signage; through media outlets, including television and social media; and person-to-person. At least two co-researchers made a suggestion for each of the outlets suggested. No one outlet was suggested by all co-researchers. The most popular suggestions were through social media, and person-to-person interactions.

\section{Formal trainings.}

The suggestions for formal trainings came from Adam and Haley. Adam's suggestion for formal training was specific to education related to therapy dogs. Adam said, "because most counseling agencies need continuing education credits offered for any mental health clinician," he suggested "have a seminar" and teach them "about" therapy dogs, what their "value" is, "what are their uses," and help counselors learn if they could incorporate therapy dogs into their work.

Haley's suggestion was specific to the housing industry. Haley stated, "Fair housing laws are really important, and people should be trained at least annually on fair housing, and how to make sure that we are providing equal opportunities for everyone."

She suggested that education on assistance animals be "covered under that training," and be updated as necessary. 


\section{Email.}

The suggestions made for disseminating information through email came from the two business owners in the group of co-researchers, Gloria and Kevin. Gloria explained that as far as learning about legislation on assistance animals, she is "so laid back about" dogs being in her store, that it was not a major concern for her. She did, however, offer multiple suggestions and one of those was email. She suggested professional organizations, like the chamber of commerce, send out an email with "the information and a phone number to call if [she] needed anything."

Kevin's suggestion was also for professional organizations, specific to the restaurant business, to send out an email with the information. He explained the restaurant organization he belonged to already sends "informative emails," so the content would be cohesive. Kevin described "the thing [he] like[d] about emails" was that he did not have to delete them, and if he wanted to, he could "go back" and reference old emails. He added that, from his perspective, magazines are "never looked at," and are not beneficial modes for spreading information.

\section{Stores/signage.}

Faith, Haley, and Donna mentioned stores and signage as ways to disseminate information. From her experience in the grocery store, Faith said, "most people put something up at a grocery store." She explained that it can be challenging to get people to pay attention to signs, but if it was big, and "bright... something to catch your eye," it could work. As discussed in the previous subtheme, Faith also suggested creating something for restaurants. She said she "know[s] there's people who go in the restaurant that have dogs," and a "little manual" with "symbols that tell that is a service dog, [and] 
this is what that dog does," would help educate not only restaurant employees, but also the public. Haley recognized that she had seen "businesses typically have signs that say, 'service animals only'," and suggested "signage like that" for other facilities as well.

Donna discussed education as it related to stores, but focused on educating the employees. She explained that, in general, she did not think "if the stores put something like in a manual that the employee would ever read it." Donna shared, that in her experience, "Most people" do not read the employee handbook, or manual. She said the

one exception would be for businesses that were "mission based," because employees of mission based companies know the company is often "animal friendly" and "when they put something out, it's something they believe wholeheartedly and...they put a lot of effort into what they are supporting." In those companies, Donna said the information would be "received well" coming straight from the company.

\section{Media/social media.}

Gloria and Haley both mentioned television as a potential way to disseminate information. Gloria said, "some of these organizations are [already] going on the news, and they're doing all of this stuff," and they "probably won't get charged...to put out...that type of information." Therefore, she suggested they use the news outlets to “educate people." Haley was unsure of her suggestion, but mentioned "advertisements, [and] TV ads" with her other ideas.

Seven co-researchers suggested social media as the best mode of information delivery and educating large numbers of people. Donna said,

I think probably one of the strongest platforms that people can learn things on is social media. Because it literally, I think runs our country. I mean everybody is 
in their phone. Everybody is down and active in this new level of communication.

Within social media, she suggested "videos" or one of "those active writings... where each screen is different [and the message] is written on the screen as it goes." She explained that people "are more apt to watch something, or look at something that's a photograph, than [read] a long written out post." Donna did not discuss who should create or post the videos.

Faith said, "Definitely put something on Internet, because so many people nowadays, they look at the internet, even the paper on internet." Gloria said, "social media is your number one way to do it." She explained she did not know "what organization," but she thought "usually the ones that are training... have something out there" and would "know to share [the information]." She also suggested "people that actually have dogs" disseminating information on social media.

Haley suggested, "a Facebook ad at this point...where we're all on Facebook." She added, "a lot of people do get there a news, sadly, from that medium." Isabelle said, "Any social media because everybody checks their social media. Twitter, Instagram, snapchat, any type of social media." Janet added, "Facebook. Everybody checks Facebook." Kevin said, "I think you should have a website, and a Facebook page, and Twitter, and Instagram, and all that stuff, because that's how people get their information these days." Kevin explained, "that's the best way to get information out there, for both the service community and for the... Restaurant operators, and for people that are in need of a service animal." Social media was not only the most popular suggestion, but coresearchers made the suggestion with confidence. 


\section{Person-to-person.}

The last method the co-researchers suggested for education was person-to person. Adam suggested taking the "most glowing examples" of service dogs, and emotional support dogs, "with the most seniority," and with "a little bit of material, like handouts or something....do a door-to-door campaign...a good faith visit.” Adam also suggested going in person with the dogs and material to visit and educate business owners.

Cathy said education is, "going to have to be human to human." She suggested "community events that teach training" in the "library." Cathy also suggested having "a little march for... groups of people with service dogs," and using the march as an opportunity for the service dog handlers to educate people from their point of view.

Gloria’s suggestion was similar to Cathy's. She said, “where people truly get impact [is] not just hearing from the organizations, but from the people themselves that have dogs, and why they are so necessary." Gloria reasoning was because "that's where [her] friends learned," and she believed "just hearing the stories" would be beneficial to other people as well.

Isabelle talked about person-to-person education as being done by those who work daily with animals. She perceived that, "animal shelters, in general, do a much better job at going into the community and educating people," and "people see [them] as the beacon of animal knowledge." Therefore, Isabelle suggested "shelters can have programs where they go to...college student housing developments, or large housing developments... or invite all of them" to "a presentation," or, she added, "go to those communities and educate them on what their rights are." Isabelle also suggested 
If people are wanting [or] maybe thinking about getting an ESA, have like a coffee hour and educate them on what it takes to have an emotional support animal, the care aspect, and what their rights are as pet owners and emotional support animal owners.

Based on Isabelle and Janet's comments that some of their co-workers were uneducated on the differences in assistance animals, the first step to these suggestions would be educating the shelter employees.

\section{5c. Information procurement.}

Included in this subtheme is a discussion of how the co-researchers gained their own knowledge, and developed their perceptions, which were at the heart of this research study. This subtheme is important as it brings to light how gatekeepers have been learning about assistance animals. Additionally, areas where educational programs should exist but do not, are discussed.

Adam, Becky, Cathy, Donna, Emily, and Isabelle all shared experiences related to assistance animals and educational settings. Of these, only one, Donna, recalled receiving information about assistance animals from her school, and she was not positive. Donna said, "the basis of information that I know probably came from my psychology degree. I'm sure at one point we...probably touched based on all three of these." Donna said she does not watch the news and did not recall seeing any coverage of service dogs on social media. The rest of her knowledge came from her experiences volunteering at a local clinic, where a service dog was present, and the other woman around shared information with her. Donna also said the amount of information someone needs 
"depend[s] on the level of contact that [they] are going to have with these service dog," and emphasized the need of education for people working in retail with the public.

When Emily was confronted with a student wanting to bring "her emotional support dog to class," she said she found and learned about the university's policy on assistance animals. Emily described her process of learning as she "went through the hierarchy and asked what the policies were, and then found the university-wide ones." When Emily talked to her superiors in her college about the policy, they told her "they would maybe put one out [a policy] for the [specific school]." However at the time of our interview, she had not seen any changes. Emily described the responsibility for learning about assistance animals as, "it's not something someone says one day, 'let me go research what exactly this involves." That recognition presented a problem in that people only learn about assistance animals when they must.

Adam was positive that the "seven years" he spent working on his undergraduate in sociology, and master's degree in clinical mental health counseling, "it never came up one time, in either degree program." Adam also said he had "never known there to be any [training], even in the counseling office [he] worked in." Given the increase in the number of therapy dogs Emily described seeing in the hospitals, and the increase in the number of people asking their doctors for medical notes to obtain an assistance animal, all students in any medical field need to be educated about assistance animals.

In discussing searching for information, Adam shared that he used dog organization websites, therapy dog training organizations, in addition to online journals, and his dog trainer. In describing the information procurement process, Adam said, "It's just something you learn if you want to," and "you kind of have to hunt for the stuff 
yourself." He described the unfortunate reality of the situation as each person is "responsible for learning about something that [they] may not even care about." That was not an issue for him, as he said he was "hungry for knowledge. He wants to learn as much about anything as [he] can, but the dogs in particular." Of the co-researchers, Adam was the most knowledgeable about therapy dogs. This was understandable as he had a therapy dog in-training. Adam said, "you will find what you're looking for, and the more we look for positive stories about how these animals can affect people's lives, the more that's going to be focused on by folks." This statement supports the recommendation made for journalists to focus on publishing positive stories instead of negative ones.

Becky’s knowledge on assistance animals came primarily from her guide dog raising friend, watching television, and her experiences as a volunteer with a local animal shelter. Regarding the responsibility to learn about "any law or legislation", Becky said it, "would be [her] responsibility to know about it." Becky explained that she also has gained information from talking to the local animal shelter volunteer coordinator, by reading about it herself, and having overall awareness.

Cathy's knowledge came from a variety of sources. Of the co-researchers, she was one of the more out-going and described the various conversations she had with people about assistance animals. Cathy was also very involved in her community and had a lot of connections. Some of the ways Cathy obtained her knowledge were through doing her own research, listening to the radio, from service dog training organizations, and numerous conversations with veterinarians, dog trainers, people who had service 
dogs, or service dogs in-training, people working in different organizations, the public in general, as well as friends and family.

Faith, like Cathy, was very outgoing and comfortable talking to a lot of different people. As she explained, most of her knowledge came from talking to people who brought their dogs in the grocery store, from her personal experiences, and learning "completely on [her] own." Faith said that when she gets curious she goes online to "Google stuff...read about it, and get more familiar." Faith did not recall seeing anything about assistance animals in the news or social media. Additionally, in the thirteen years Faith had been with her company, she has never received any training on assistance dogs officially or from her managers.

Gloria said she did "not even know how [she] started learning about [service dogs], because [she] didn't grow up with service dogs." Gloria said she felt like she "didn't really know that much about them," however, when she "was a physical therapist...in the hospitals they would teach [her] about them.” As she explained, the majority of the knowledge she shared in her interview came from her experiences volunteering with a service dog training organization.

Haley's knowledge came primarily from her professional membership to a housing association, and the CEO of her management company. While Haley understood the laws regarding assistance animals and her industry well, she acknowledge the concern that her colleagues are not necessarily as educated. Regarding education, Haley said she "hope[s] that people, if they don't have the right answer, know where to get...the right answer." However, she was not sure they all knew where to look. 
Of the co-researchers, Isabelle appeared to have the most amount of knowledge on legislation regarding service dogs and emotional support dogs. This was not surprising as she had one and had gone through the processes necessary to have her dog with her while in school, and at work. Isabelle had seen news articles concerning negative interactions with assistance animals and the public, however her knowledge of service dogs and emotional support dogs came from other sources. She said, "all of my stuff came from me having an emotional support animal, that was then trained to become a service animal." Isabelle explained that as a, "college student," and coming from "pretty much a middle class family," she had "the ability to afford the doctor end of things to get [her] treatment, but [they] couldn't afford the multiple thousands of dollars it took to get a service animal." Therefore, she learned "how [she] could meet [her] needs without spitting up thousands of dollars that our insurance wasn't going to cover." Learning how to meet her needs meant she did "a lot of online research, using government websites, state and local and federal." Isabelle described the research process she went through as "It mostly made me feel crazy." Isabelle's experience, and resulting knowledge, support the need for education that is presented in an understandable, and accessible manner.

Janet's knowledge came from personal experiences, observations, talking to people with assistance animals, and the internet. Janet's knowledge also came from an episode of 20/20 on the television. Like Janet, Kevin's knowledge came from personal experiences, observations, and verbal conversations. Additionally, Kevin credited a presentation on service dogs that was done for his daughter's community youth organization for his knowledge. As a business owner, Kevin expressed interest in 
learning the "real nomenclature," including "what [business owner] rights... [and] obligations [are] as associated with service animals," and checking the accuracy of his perceptions and understandings.

\section{Summary of Theme 5 with Implications and Recommendations}

What this theme reveals is the overwhelming need for education, across all social groups. This call to action for education is in line with the suggestions made in existing literature (Elliot and Hogle, 2013; Huss, 2010; Schoenfeld-Tacher et al., 2017; Schoenfeld-Tacher and Kogan, 2017). Furthermore, while the focus of the education can vary depending on the audience, all members of the public need education on appropriate interactions with assistance animals. Additionally, business owners, managers, gatekeepers, and assistance dog handlers, need to be educated on each person's rights, and the regulations surrounding accessibility. Organizations can use the suggestions presented here to inspire and inform change within their businesses.

Recommendations for future research are to look into the feasibility, and effectiveness, of different teaching methods, and modes of delivery, as they relate to this topic. Furthermore, since the ADA provision includes service dogs, but excludes emotional support dogs and therapy dogs, research needs to be done to develop educational materials for the purpose of training, and teaching, business owners, managers, and gatekeepers on service dogs, accessibility, and the process of determining legitimacy, as well as the differences between the three types of assistance animals.

\section{Summary of Chapter V}

This chapter presented the results of the data analysis from this research study. The results included a discussion of the conclusions, interpretations, and implications of 
the results of five main themes, each of which included subthemes. Additionally, recommendations were made within each theme for service dog training organizations, politicians, business owners, and for topics of future research. The following chapter is a broad summary of the results, conclusions, and recommendations. 


\section{CHAPTER VI}

\section{Summary \& Conclusions}

The purpose of this study was to understand the working public's experiences with, and perceptions of, service dogs in public places as a way of identifying the primary aspects of the phenomenon from the gatekeeper's point of view. The existing literature on the public's perceptions of assistance animals, including service dogs, is limited. Therefore, the results of this research study are meant to contribute to the existing literature, and to identify areas needing further research.

As discussed in detail in chapter five, the results of this research study naturally formed into five themes, each with subthemes, within and across the interviews (see Table 4). This chapter includes a summary, and discussion, of those themes as they relate to the research questions. Additionally, this chapter includes a summarized presentation of the recommendations and my personal reflection statement.

\section{Research Questions 1 and 2}

1. What are the experiences of the working public with service dogs and service dog teams in public places?

2. How does the working public perceive service dogs?

\section{Conclusions.}

The results of this study showed that the co-researchers had varied experiences with service dogs, and service dog teams in public places, and since the experiences of the co-researchers greatly influenced their perceptions, it is valuable to discuss the conclusions of these two research questions together. In general, the experiences and the perceptions went hand-in-hand. 
Table 4

Themes and Subthemes of Data Analysis Results

\begin{tabular}{|c|c|c|c|c|c|}
\hline$\frac{\mathscr{E}}{\mathscr{E}}$ & $\begin{array}{l}\text { Misunderstanding, Confusion, } \\
\text { and Lack of Knowledge }\end{array}$ & Dogs in Society & Misrepresentation & $\begin{array}{l}\text { Desire for } \\
\text { Standardization }\end{array}$ & Education \\
\hline \multirow{8}{*}{$\begin{array}{l}\stackrel{0}{E} \\
\stackrel{0}{\Xi} \\
\stackrel{\Xi}{\Xi} \\
\tilde{\Xi}\end{array}$} & Terminology & $\begin{array}{l}\text { Personal experiences \& } \\
\text { opinions of dogs }\end{array}$ & Why it is done & Reasoning & Perceived need \& focus \\
\hline & Characteristics & $\begin{array}{l}\text { Thoughts \& emotional } \\
\text { response to service } \\
\text { dogs }\end{array}$ & How it is done & $\begin{array}{l}\text { Legalization \& } \\
\text { implications }\end{array}$ & Mode of delivery \\
\hline & Role/responsibility of the dog & Respect for training & Opinions & $\begin{array}{l}\text { Certification/ } \\
\text { registration \& uniforms }\end{array}$ & $\begin{array}{l}\text { Information } \\
\text { procurement }\end{array}$ \\
\hline & $\begin{array}{l}\text { Perceived need \& social } \\
\text { impact }\end{array}$ & Zeitgeist & Bad news sells? & & \\
\hline & Accessibility & & $\begin{array}{l}\text { Implications; social/ } \\
\text { cultural impact \& } \\
\text { potential harm }\end{array}$ & & \\
\hline & Behavioral expectations & & & & \\
\hline & Uniform expectations & & & & \\
\hline & $\begin{array}{l}\text { Certification/registration } \\
\text { expectations }\end{array}$ & & & & \\
\hline
\end{tabular}




\section{Misunderstanding, confusion, and lack of knowledge.}

The major findings related to these two research question are in the first theme of regarding the co-researchers' misunderstandings, confusion, and lack of knowledge. The results of this research study showed that members of the working public's experiences with and perceptions of service dogs have both created, and been affected by their widespread misunderstandings, confusion, and lack knowledge regarding these dogs.

It was found that many of the co-researchers were confused and misunderstood how to differentiate service dogs from other dogs. In addition, they lacked knowledge, or had misunderstandings regarding service dog uniforms, and certification or registration expectations. Moreover, they lacked knowledge regarding the terminology used for labeling service dogs and other assistance dogs. It was also found that the co-researchers misunderstood a dog's breed or size was indicative of their legitimacy as a service dog, and that they did not perceive a small dog as a possible legitimate service dog based solely on its size. Furthermore, it was concluded that both co-researchers and other members of the public were under the misunderstanding that service dogs only assist people with prevalent disabilities, which shows a lack of knowledge regarding invisible disabilities such as PTSD or epilepsy.

These findings are consistent with the literature and are concerning for multiple reasons. First, if a gatekeeper has inaccurate perceptions of what a service dog, or a service dog team looks like, and a service dog team enters their place of business looking differently than those expectations, the gatekeeper could unintentionally discriminate against someone with a legitimate service dog, which is not only offensive to the disabled person, but also, if they deny the person access based on their perceptions, it puts the 
business in violation of the American's with Disabilities Act. Second, if gatekeepers are unable to clearly differentiate and recognize service dogs from other dogs, they lack the capacity to consistently, clearly, and confidently enforce current accessibility regulations. Again, this is concerning because it puts the business in a precarious position of potentially violating the federal accessibility provisions for service dogs.

\section{Dogs in society.}

Another conclusion related to these research questions was found in the theme of the co-researchers' experiences with, and perceptions of dogs in society. It was found that the co-researchers' exposure to service dog training procedures increased their respect of service dogs and the work the dog performs for their handler. Furthermore, the co-researchers with first-hand experiences with other types of assistance dogs showed the most clarity in differentiating service dogs from other dogs. Therefore, the results of this research study suggested that a person's exposure to dogs in general, training procedures, and other assistance dogs, could impact their perceptions of, and level of comfort around service dogs, which could, in turn, influence their opinions on service dogs being welcomed into public spaces.

Dog ownership was not one of the qualifying factors for the co-researchers, however, it was interesting to note that all of the eleven co-researchers had a pet dog at one point in their lives, and, even in the event of trauma, it was understood that they all had at least one positive personal experience with dogs. Realizing this made me wonder if the results of the study would have been different with co-researchers who had never had a pet dog at all, or if the positive experiences with dogs influenced their overall 
perceptions of service dogs. Certainly, more research needs to be done to determine the correlation of experiences with dogs in general as it relates to perceptions of service dogs.

\section{Research Question 3}

What are the working public's understandings of accessibility regulations as they relate to service dogs and public places?

\section{Conclusion.}

In general, the co-researchers understood that service dogs are afforded public accessibility rights, however, given their confusion with differentiating service dogs from other dogs, they were unable to consistently determine which dogs were service dogs and which were not. Additionally, the results showed that the majority of the co-researchers had not received training on how to properly navigate the situation when a patron entered with a service dog, and they were unaware of the appropriate questions they could ask to determine if the dog was a service dog. Furthermore, it was found that the co-researchers lacked knowledge regarding the differences between the Americans with Disabilities Act and the Air Carrier Access Act, and how those differences impacted their own responsibilities versus what they heard about in the media.

These conclusions on the working public's understandings of accessibility regulations further illustrated the component of confusion as it related to the coresearchers' understandings of accessibility regulations. While it is encouraging that the co-researchers understood service dogs have accessibility rights, the findings that coresearchers have not received training, are unaware of the appropriate gatekeeper questions outlined in the Americans with Disabilities Act, and are unable to determine service dogs from other dogs presents again, a concerning situation. The conclusion was 
made that when a gatekeeper is tasked with the responsibility of determining whether a dog should be allowed on the premises or not, if they have not received training, and they lack knowledge of what they can legally ask to determine accessibility, they could easily ask inappropriate questions and/or discriminate against someone with a disability. In this manner, the answer to this research question directly relates to the discussion of the first two research questions.

\section{Research Question 4}

What, if any, are the issues the working public identify in and around the topic?

\section{Conclusion.}

The results of this research study showed the working public identified misrepresentation of a service dog, lack of standardization, and need for education as the main issues in and around this topic.

\section{Misrepresentation.}

Regarding misrepresentation of a service dog, the co-researchers perceived misrepresentation as an issue that was prevalent and not one over-represented in the news, as was suggested in the literature. Within misrepresentation, they perceived it as negative because of how it could harm legitimate service dogs, as well as negatively impact the reputation of the person doing the misrepresenting. Furthermore, findings showed that the co-researchers felt misrepresentation negatively impacted businesses' involvement in community events because when they were responsible to act as gatekeepers, a large majority of people would try to pass their pet dog off as a service dog, which since they were unable to determine which dogs were service dogs and which 
were not, the gatekeepers were put into uncomfortable situations they did not feel prepared to circumnavigate.

In relation, the overwhelming response from the co-researchers as to why someone would misrepresent their dog as a type of assistance dog was to obtain access to places the dog is not normally permitted such as public events, retail spaces, school campuses, and airlines. They also identified the desire for obtain housing or avoiding housing pet fees as motivation for why they perceived someone would misrepresent their dog. In most situations, the co-researchers did not perceive the misrepresentation as being maliciously, rather it was happening because people were not aware of how their actions could impact others. Nonetheless, some of the co-researchers expressed strong negative opinions of anyone who misrepresents their dog as a service dog.

The co-researchers identified a variety of ways as to how people misrepresented their dog as an assistance dog, which included verbal statements, use of uniforms, and documentation, including medical notes. In general, they said people would just lie to obtain the various means with which they were misrepresenting their dog. The availability of service dog paraphernalia for purchase was identified as an influencing factor in misrepresentation, as well as an issue that needs regulation.

The co-researchers also identified lack of education on the part of the gatekeeper an issue because they perceived not knowing how to determine which dogs are service dogs and which are not has aided in the successful attempts of misrepresentation for accessibility purposes. 


\section{Lack of standardization.}

The co-researchers identified lack of a standardized visual identifier as one component of their issues in recognizing service dogs. Conclusions were made that they preferred consistency in either what the dog would wear (the uniform) or the paperwork the handler carries (proof of certification or registration). As for the item, they varied on their opinions, but shared the desire that it be a visual identifier that did not require additional questioning.

Additionally, the co-researchers valued standardization as a way to minimize the issue of misrepresentation because the uniforms and paperwork would be regulated, and therefore more difficult for someone without an assistance animal to obtain.

Furthermore, the co-researchers expressed desire for a universal monitoring system with punishments for those who broke the rules. Despite some pushback of government involvement, the co-researchers felt that the standardized item or process needs to be regulated by a large governing body, like the government, that can enforce penalties.

Overall, they viewed standardization as a means to help all gatekeepers in their responsibilities of making service dog accessibility decisions. The conclusion was made that standardization would alleviate the embarrassment and stress of interactions because everyone would know the expectations and requirements related to obtaining access to public places with a service dog.

\section{Need for education.}

Throughout the entire data collection and analysis, a significant need for education was revealed. Not only is education needed based on the conclusions of the 
gatekeeper's misunderstandings, confusion, and lack of education, but the co-researchers themselves also identified the lack of education as one issue regarding this topic.

In describing what it was like for them to gain their own knowledge, they said it was something they learned because they had the desire. Only one of the co-researchers recalled receiving information from an educational setting, and none of them received training from their current employer. The findings showed that when they wanted to know about service dogs, they had to ask or do the research themselves. The majority of the co-researchers utilized internet web searches to find their information, which given the expansive amount of opinion-based information available through those searches, it was concluded that their own information procurement methods could be one of the influencing factors of their misunderstandings.

The co-researchers also talked about how different groups of people can benefit from increased education on the different types of assistance animals, their roles, and accessibility allowances. Suggestions were made for various groups, and in relation to the aspect of service dogs and gatekeepers, conclusions were made that gatekeepers need to be educated on the existing legislation and appropriate questions they can ask regarding a service dog's legitimacy when determining accessibility.

Related to their discussion of the issue of lack of education, the co-researchers discussed what they perceived as the best way to communicate this information with the public. No one outlet was suggested by all of the co-researchers, however the most popular suggestions were through social media and person-to-person interactions. 


\section{Research Question 5}

Based on the data obtained, what are the important issues and areas that need further research?

\section{Conclusion.}

Overall, there were a lot of areas identified for needing further research. In chapter five, I discussed recommendations within each theme, and when fitting, within each subtheme. Given the lack of literature and research on people's perceptions of service dogs, this was not surprising. Therefore, the results of this research study can help guide future researchers in defining their own research focus. Additionally, included below are recommendations for different groups of society based on the conclusions of this research study.

\section{Recommendations for future research.}

Here is a compiled list of recommendations for future research:

- Inquiry into the preferred terminology of different types of assistance dogs from the handler's perspective, including inspection of why certain labels are preferred or used more than others

- Conduct a research study that asks service dog handlers what main tasks/work their service dog performs related to their disability. Results from such a large collection of data could be used to help create awareness and educate people on the various ways in which service dogs of different breeds mitigate disabilities.

- Additional research is needed on the public's perceptions of assistance dogs, including: 
o Further research into the perceptions of the differences between the types of assistance animals;

o Research from a large population and sample;

o Inspection into the perceptions of different demographic groups;

o Inspection into the perceptions of how service animals and emotional support animals are received in areas governed by the Fair Housing Act or the Air Carrier Access Act;

o Inquiry into how those perceptions were created;

o Identification of what needs to change to provide clarity and increased awareness of service dogs;

o Inquiry into how experiences with dogs in general influences perceptions of service dogs;

o Inquire into how exposure to other types of assistance animals influences perceptions of service animals.

- Additional research needs done on the role and responsibilities of emotional support animals, and the suggestion that they be considered equal to service dogs.

o There is existing literature on this topic that also states more research needs done; the findings of this research study support their statements.

o A component of this query is the perception of psychiatric, and emotional disorders as recognized disabilities.

- Additional research needs done analyzing the existing legislation regarding assistance animals, determining which laws are conflicting and which further restrict those of the ADA. 
- Analyze the existing uniforms being used for service dogs to develop a holistic understanding of what is being used including:

o The purpose of the uniform;

o Why the handler decided to use a particular uniform;

o How the handler decided on a particular uniform;

o Service dog training organization influence on the uniform choice;

o Why organizations use particular uniforms;

o The public's perceptions of particular uniforms.

- Collect data on the existing service dog registries and certification processes, including the organization/business behind the company and what is required of the service dog handler.

- Conduct a study to identify if there has been an increase in the number of service dogs seen in public places. Results from such research could be used to communicate with business owners the need for educating their employees on the company's policies and how to adhere to the ADA regulations.

- Conduct a study analyzing the proliferation of the representation of dogs in the media, including television shows, commercials, and advertisements.

- Additional research needs done on the complex topic of misrepresentation, including:

o Conduct a study analyzing the media's presentation of misrepresentation of service animals.

o Inquire if misrepresentation is a widespread issue or centralized to demographic regions; 
o Collect data on existing arrests or fines in relation to misrepresentation of a service animal.

- Conduct an inquiry into the costs related to obtaining the different types of assistance animals, specifically service dogs and emotional support dogs. A review of both legally required and non-required, but necessary items, needs to be included. The results from those studies can be used to help educate organizations, and people, looking for assistance dogs on the financial aspect of the treatment.

- Analyze the feasibility, and effectiveness, of different teaching methods, and modes of delivery, as they relate to this topic.

- Using research, develop educational materials for the purpose of training, and teaching, business owners, managers, and gatekeepers on service dogs, accessibility, and the process of determining legitimacy, as well as the differences between the three types of assistance animals.

\section{Recommendations for social groups}

The following is a list of recommendations for different social groups in our communities:

- For service dog organizations and service dog handlers:

o Openly share your knowledge and experiences with how service dogs help mitigate disabilities.

- Share how service dogs mitigate a variety of disabilities, including invisible disabilities; 
- Share the various ways in which service dogs of various breeds and size mitigate disabilities;

- Clearly mark service dogs in-training so that when members of the public observe those dogs in the learning process, they will not see "mistakes" a dog in-training might make, and project those behaviors onto service dogs as a whole.

o Continue incorporating different members of our communities into the service dog training process to increase awareness and respect of service dogs.

o Adopt a standardized taxonomy.

o Working with politicians, create a nationally recognized standardized service dog uniform, or certification, or registration process.

- For business owners:

o Establish and incorporate an educational program to help gatekeepers and/or other individuals understand their role and responsibilities regarding assistance animals and accessibility in your place of business;

o Implement the use of on-site signage educating gatekeepers on the two questions they are allowed to ask according to the Americans with Disabilities Act regarding service dogs and determining accessibility.

- For politicians:

o Take into consideration both the service dog handler's and the gatekeeper's perceptions prior to, and during policy development; 
o Amend existing legislation that conflicts or contradicts the federal regulations;

o Identify areas in which legislation conflicts or contradicts nearby state legislation;

o Implement fines for misrepresentation of a service animal, and educate law enforcement officers on how to determine which dogs are misrepresented;

o Adopt a standardized taxonomy;

o Working with service dog training organizations, create a nationally recognized standardized service dog uniform, or certification, or registration process;

o After standardization, restrict the availability of non-standardized items available for purchase.

- For journalists:

o Focus on positive stories of service dogs helping their handlers;

o Use the outlet you have to create awareness of assistance animals, and how they benefit the people in our communities. Through education and increased awareness, people can learn about assistance animals, and where they might see them. This awareness opens the door to respecting the work these animals do for humans, and in turn, helps people realize the negative impacts misrepresenting an animal as an assistance animal can cause;

o Be aware of potentially over-representing misrepresentation in the news. 


\section{Recommendations summary.}

As I said, the existing literature is very limited on regarding perceptions of service dogs. Some of the results in this study supported the existing literature and others represented a different viewpoint. However, there is still a large gap in the literature. Increased research and education are necessary catalysts for change and further understanding of how we can incorporate service dogs into our communities.

\section{Reflection Statement}

As I reflect on this research process and how it has changed me as an individual, I am humbled by my own lack of knowledge. Despite having been actively researching this topic for the better part of five years, and gaining an incredible amount of knowledge, it still feels like there is so much to learn. Almost every day I realize I have learned something new regarding the nuances in the labels of assistance animals, changes in legislation, or notice a new area in which service dogs are being represented in the media.

For example, the day after my dissertation defense I attended another colleague's dissertation defense and learned that the label of "therapy dog" is currently a topic of conversation in assistance dog communities. I was aware that therapy dogs participate in structured therapeutic plans, created by a counselor or therapist, to be implemented in a controlled setting. I also thought the label of therapy dog was meant to refer to the dogs who visited places like university campuses or nursing homes to provide therapeutic benefits through their visits, however, I learned that my use of therapy dog for those dogs is not necessarily correct. From my understanding, the current consideration is to label those particular dogs as "visitation dogs" and not "therapy dogs" since they do not 
participate in a structured therapy process, rather they simply visit locations to make people feel better. Upon this realization, I felt very close to how my co-researchers must have felt when the recognized their own confusions. Even after months of working so closely with this data, I was shocked to hear that my own use of the label was not fully correct, and came to the realization that until a standardized taxonomy is adopted, figuring out the nuances of terminology is a non-stop responsibility.

Another seemingly unrelenting responsibility is that of awareness of the legislation regarding assistance animals. At numerous points throughout this research process, I found myself having to go back and update my literature review because new legislation was created, or other ones were amended. For example, when I started designing this research study, neither West Virginia, nor Kentucky had laws regarding service dogs. Nonetheless, in the spring of 2018, West Virginia proposed an amendment to their White Cane Law to implementation a penalty for misrepresentation of a service animal (Article 15. White Cane Law). The amendment passed in the summer of 2018. Likewise, in the summer of 2018, Kentucky implemented a law regarding assistance animals in housing, which included a penalty for misrepresentation of a service animal (An Act Relating to Assistance Animals, 2018). It passed in the summer of 2018, and was amended with more detailed descriptions and penalties in January of 2019. During my literature review, this piece of legislation was not yet created, and I therefore learned about this law from Haley. Upon researching it myself, noticed that the penalty for misrepresentation applied solely to misrepresentation for the purpose of obtaining housing, which made me wonder when a similar law will be created in Kentucky for misrepresentation to obtain access to public facilities. As per my research, one has not 
yet been created, however, my experiences have shown me that could change any day. Additionally, after concluding that Kentucky does not currently have legislation regarding service dogs for public spaces, as Isabelle had said, I wondered if Isabelle misunderstood the legislation for housing as applicable to public spaces as well; a confusion I could easily understand.

Another example of how I have been humbled by my own lack of knowledge and the constant changes regarding legislation happened just days before my dissertation defense when I visited the Department of Transportation's website and noticed a change in their service animal and emotional support animal policies. As discussed in my literature, their website previously stated that their policy was under review, however, during my most recent inspection, I noticed the Department of Transportation made revisions to their policy which includes the statements that "most service animals tend to be dogs and cats," and "Airlines are never required to accept snakes, reptiles, ferrets, rodents, sugar gliders, and spiders" (United States Department of Transportation [DOT], 2018b, para. 2). Since I had not heard about the changes myself before specifically looking them up, I found myself wondering as to how the DOT informed their decisions and how other members of the public are learning about the changes, or if they are aware of them at all.

Recognizing the seemingly constantly changing aspects of this topic has been both exciting and daunting. I am excited that people are talking about service dogs, and that they appear to be gaining in popularity, however, I feel that the numerous changes, and lack of standardization are simply going to further complicate the existing confusion regarding service dogs. Additionally, I empathize with business owners who actively try 
to educate their employees on service dogs and accessibility, because learning about this topic, and staying current with my knowledge, has at times felt like a full-time job. Therefore, when I think about how the results of this research study can be immediately implemented, I believe the main concern for business owners is to educate their employees on the two questions they can ask, as per the ADA. Until the rest of the details are standardized, the important thing to know is that they are constantly changing. This research study evolved in ways I did not foresee, and led me to learn about more aspects of this phenomena than I anticipated. Additionally, this process has made me aware of my own biases, and how to bracket those biases, and it has helped me see this phenomena from the perspectives of others. In reflection, I am more aware of my own understandings and expectations, and how those could differ from other members of my community. Furthermore, even though I am just as passionate about dogs as I was at the start of this research study, I have a greater appreciation for understanding how others perceive dogs, and how that understanding can inform the design of improvements to educational training programs, research, and legislation. It is my hope, that through education, research, and collaboration, we can continue to improve and work together as a united community, to incorporate, celebrate, and support the important work of service dogs. 


\section{REFERENCES}

4 Paws for Ability University Program. (n.d.) Retrieved from https://4pawsforability.org/4-paws-university/

Allen, K., \& Blascovich, J. (1996). The value of service dogs for people with severe ambulatory disabilities: A randomized controlled trial. Jama, 275(13), 1001-1006.

Allen, R. E. S., \& Wiles, J. L. (2016). A rose by any other name: participants choosing research pseudonyms. Qualitative Research in Psychology, 13(2), 149-165. doi:10.1080/14780887.2015.1133746

American Pet Products Association (2018). The 2017-2018 APPA National Pet Owners Survey. Retrieved from https://www.americanpetproducts.org/pubs_survey.asp

American Sheltering (2018). Pets by the numbers. U.S. pet ownership estimates. Retrieved from https:/www.animalsheltering.org/page/pets-by-the-numbers

American Veterinarian. (2017, September 4). Fraudulent emotional support animals [Video file]. Retrieved from https://www.americanveterinarian.com/videos/fraudulent-emotional-supportanimals

Americans with Disabilities Act of 1990. 42 U.S.C.A. § 12101 et seq. (West 1993).

An Act Relating to Assistance Animals. KRS § 383.085, HB032910.100 - 1415, State of Kentucky. (2018).

An Act Relating to Assistance Animals. KRS § 383.1-085, HB041120.100 - 1838 State of Kentucky. (2019).

Article 15. White Cane Law. § 5-15-9, SB397, State of West Virginia. (2018).

Ary, D., Jacobs, L. C., Irvine, C. K. S., \& Walker, D. (2014). Introduction to Research in Education (9th ed.). Belmont, California: Wadsworth, Cengage Learning.

Baby Name Wizard. (n.d.) [Graph illustration of baby name popularity and trends by decade]. Baby Names Popularity - Name Voyageer: Baby Name Wizard Graph of Most Popular Baby Names. Retrieved from http://www.babynamewizard.com/voyager\#prefix=\&sw=both\&exact=false

Beacham, C., \& Shambaugh, N. (2010). Translating Design Thinking for Scientists. Psychology of Thinking, 1-15.

Beck, A. M. (2006). The use of animals to benefit humans: Animal-assisted therapy. In Handbook on Animal-Assisted Therapy (2nd ed., pp. 21-40): Academic Press.

Bergin, B., \& Hogan, S. (2006). Teach your dog to read: Crown Archetype. 
Bersani, H., \& Lyman, L. (2009). Governmental policies and programs for people with disabilities. Disability and Public Health. Washington, DC: American Association on Intellectual and Developmental Disabilities, 79-104.

Blattner, B. (2015). Helping paws throughout history: The evolution of the service dog. Veterinary Heritage, 38(1), 17-24.

Bomkamp, S. (2018, February 9). Emotional support animals - from dogs to peacocks, real or fake - present challenges for businesses. Chicago Tribune. Retrieved from https://www.chicagotribune.com/

Bourland, K. M. (2009). Advocating change within the ADA: The struggle to recognize emotional-support animals as service animals. University of Louisville Law Review, 48, 197-220.

Boyd, C. O. (2001). Philosophical foundations of qualitative research. P. Munhall (Ed.), Nursing research: A qualitative perspective, 65-90.

Bremhorst, A., Mongillo, P., Howell, T., \& Marinelli, L. (2018). Spotlight on Assistance Dogs-Legislation, Welfare and Research. Animals : an open access journal from MDPI, 8(8), 129. doi:10.3390/ani8080129

Brown, T., \& Katz, B. (2011). Change by Design. Journal of Product Innovation Management, 28(3), 381-383.

Burgoyne, L., Dowling, L., Fitzgerald, A., Connolly, M., Browne, J. P., \& Perry, I. J. (2014). Parents' perspectives on the value of assistance dogs for children with autism spectrum disorder: a cross-sectional study. BMJ Open, 4(6), e004786, doi: 10.1136/bmjopen-2014-004786

Campbell, K. (2016). Supporting Adoption of Legislation Criminalizing Fake Service and Emotional Support Animals. Journal of Animal \& Environmental Law, 8(1), 73-93.

Cohen, J. (2011, August 8). Assistance dogs: Learning new tricks for centuries. History. Retrieved from https://www.history.com

Cole, L. (2017, June 5). Who was the first person to use a guide dog?. Canidae. Retrieved from https://www.canidae.com/blog/2017/06/who-was-the-first-person-to-use-aguide-dog/

Collins, D. M., Fitzgerald, S. G., Sachs-Ericsson, N., Scherer, M., Cooper, R. A., \& Boninger, M. L. (2006). Psychosocial well-being and community participation of service dog partners. Disability and Rehabilitation: Assistive Technology, 1(1-2), 41-48. doi:10.1080/09638280500167183

Combs, M. (2018, July 26). Fake service dogs: 'One of the most hideous things I've ever seen'. WKYT. Retrieved from https://www.wkyt.com/ 
Copen, R. G. (1992). Insomnia: A phenomenological investigation. (Doctoral dissertation). Retrieved from ProQuest Dissertations \& Theses Global. (AAT 9311957).

Creswell, J. W. (1998). Qualitative inquiry and research design: Choosing among five tradition. Thousand Oaks, CA: Sage.

Cutt, H., Giles-Corti, B., Knuiman, M., \& Burke, V. (2007). Dog ownership, health and physical activity: A critical review of the literature. Health \& Place, 13(1), 261272.

Daniels, V. (2005). Lecture on phenomenology [online notes]. Retrieved from http://web.sonoma.edu/users/d/daniels/phenomlect.html

Davis, K. (1992). Therapy dogs: Training your dog to reach others. New York, New York: Howell Book House.

Denzin, N. K. (1989). Interpretive interactionism. Newbury Park, CA: Sage.

Donalek, J. G. (2004). Phenomenology as a qualitative research method. Urologic nursing, 24(6), 516-517.

Douglas, M. R. (2011). The arts-integrated curriculum (AIC) and its possible impact on the self-concepts of adolescent girls and their perceptions of beauty: A phenomenological study (Doctoral dissertation). Retrieved from ProQuest Dissertations \& Theses Global. (AAT 3530525).

Eagleton, T. (2011). Literary theory: An introduction: John Wiley \& Sons.

Eddy, J., Hart, L. A., \& Boltz, R. P. (1988). The effects of service dogs on social acknowledgments of people in wheelchairs. The Journal of Psychology, 122(1), 39-45. doi:10.1080/00223980.1988.10542941

Edelman, A. (2018, May 5). Collared: New laws crack down on fake service dogs. NBC. Retrieved from https://nbcnews.com

Elliott, D., \& Hogle, P. S. (2013). Access rights and access wrongs: Ethical issues and ethical solutions for service dog use. International Journal of Applied Philosophy, 27(1), 1-14. doi:10.5840/ijap20132716

Fairman, S. K., \& Huebner, R. A. (2001). Service dogs: A compensatory resource to improve function. Occupational Therapy in Health Care, 13(2), 41-52. doi:https://doi.org/10.1080/J003v13n02_03

Fishman, G. A. (2003). When your eyes have a wet nose: the evolution of the use of guide dogs and establishing the seeing eye. Survey of Ophthalmology, 48(4), 452458. doi:10.1016/S0039-6257(03)00052-3 
Fitzpatrick, R. B. (1991). Americans with Disabilities Act of 1990. Journal of the National Association of Administrative Law Judiciary, 11(1), 13-24.

Food and Agriculture Code. $§$ 30850-30854. State of California. (2004).

Glick, F. (2018, May 25). Robley rex VA hospital will train staff to identify fake service animals. WDRB. Retrieved from https://www.wdrb.com

Groenewald, T. (2004). A phenomenological research design illustrated. International Journal of Qualitative Methods, 3(1), 42-55. doi: 10.1177/160940690400300104

Gunderson, L. (2014, July 22). Everything you need to know about service dogs, their owners and how businesses are affected. The Oregonian. Retrieved from https://www.oregonlive.com/

Harris, K. I., \& Sholtis, S. D. (2016). Companion angels on a leash: Welcoming service dogs into classroom communities for children with Autism. Childhood Education, 92(4), 263-275.

Heasley, S. (2019, February 6). New emoji include people with disabilities. Disability Scoop. Retrieved from https://www.disabilityscoop.com/2019/02/06/new-emojiinclude-disabilities/26001/

Heidegger, M. (1977). Basic writings. In (E. Krell, Ed. ed.). New York: Harper \& Row.

Henderson, A. (2018, June 4). A law restricting the impersonation of a service dog is now being enforced in West Virginia. WBOY. Retrieved from https://www.wboy.com/

Hernandez-Silk, C. (2018). They say emotional support dog, we say service dog: Why the americans with disabilities act should recognize emotional support dogs as service animals. Richmond Public Interest Law Review, 21(3), 313-340.

Humanimal Bond (n.d.). Hearts of gold. Retrieved from https://humanimalbond.org/heartsofgold/

Huss, R. J. (2010). Why context matters: Defining service animals under federal law. Pepperdine Law Review, 37(4), 1163-1216.

Hycner, R. H. (1985). Some guidelines for the phenomenological analysis of interview data. Human Studies, 8(3), 279-303.

Jennings, L. B. (1997). Potential benefits of pet ownership in health promotion. Journal of Holistic Nursing, 15(4), 358-372.

Kegel, A. (2016). Service dogs for the mind: Psychiatric service dogs for the treatment of posttraumatic stress disorder and alcohol use in veterans: A quantitative study (Doctoral dissertation). Retrieved from ProQuest Dissertations \& Theses Global. (AAT 10666876). 
Kogan, L. R., Schaefer, K., Erdman, P., \& Schoenfeld-Tacher, R. (2016). University counseling centers' perceptions and experiences pertaining to emotional support animals. Journal of College Student Psychotherapy, 30 (4), 268-283. doi:10.1080/87568225.2016.1219612

Kosar, M. A. (2018, May 28). Lack of federal regulation leads to spike in fake service dogs. ABC News 5 Cleveland. Retrieved from https://www.news5cleveland.com/

Krauss, S. E. (2005). Research paradigms and meaning making: A primer. The Qualitative Report, 10(4), 758-770.

Leduc, J. K. (2017). Misrepresentation of a Service Animal [PDF]. (Report No. 0255). Connecticut General Assembly. Office of Legislative Research. Objective Research for Connecticut's Legislature. Retrieved from

Lengyel, K. (2017, March 20). State news: Misrepresenting service animals may soon be illegal in massachusetts. American Veterinarian. Retrieved from https://www.americanveterinarian.com/

Loughlin, S. (2018, April 14). Doggone confusion over service, support animals. Tribune-Star. Retrieved from https://www.tribstar.com/

Loviglio, D. (2012, May 9). Picking pseudonyms for your research participants [web log]. Firefox $U X$. Retrieved from https://blog.mozilla.org/ux/2012/05/pickingpseudonyms-for-your-research-participants

McNicholas, J., \& Collis, G. M. (2000). Dogs as catalysts for social interactions: Robustness of the effect. British Journal of Psychology, 91(1), 61-70.

Michigan State University. (n.d.). Fraudulent Service Dogs. Retrieved April 13, 2019, from https://www.animallaw.info/content/fraudulent-service-dogs

Miles, M. B., \& Huberman, M. A. (1994). Qualitative data analysis: An expanded sourcebook. Thousand Oaks, CA: Sage Publications, Inc.

Morse, J. M. (1994). Designing funded qualitative research. In N. K. Denzin \& Y. S. Lincoln (Eds.) Handbook of Qualitative Research (pp. 220-235). Thousand Oaks, CA: Sage Publications, Inc.

Moustakas, C. (1994). Phenomenological research methods. Thousand Oaks, CA: Sage Publications, Inc.doi:10.4135/9781412995658

Norman, D. (2013). The design of everyday things: Revised and expanded edition: New York, NY: Basic Books.

Odendaal, J. S. (2000). Animal-assisted therapy—magic or medicine?. Journal of Psychosomatic Research, 49(4), 275-280. 
Ollove, M. (2017, October 16). These 19 states are cracking down on fake service dogs. PBS News Hour. Retrieved from https://www.pbs.org/

Parenti, L., Foreman, A., Meade, B. J., \& Wirth, O. (2013). A revised taxonomy of assistance animals. Journal of Rehabilitation Research and Development, 50(6), 745-756. doi:10.1682/jrrd.2012.11.0216

Patton, M. Q. (2002). Qualitative research methods and evaluation. Thousand Oaks, CA: Sage Publications, Inc

Raina, P., Waltner-Toews, D., Bonnett, B., Woodward, C., \& Abernathy, T. (1999). Influence of companion animals on the physical and psychological health of older people: An analysis of a one year longitudinal study. Journal of the American Geriatrics Society, 47(3), 323-329.

Rhoads , S. (2018, April 14). Missouri house approves pain capable unborn child protection act (HB 1266). Howell County News. Retrieved from https://www.howellcountynews.com/

Rothberg, B., \& Collins, E. (2015). A service dog in group. International Journal of Group Psychotherapy, 65(2), 307-315. doi:10.1521/ijgp.2015.65.2.307

Sachs-Ericsson, N., Hansen, N. K., \& Fitzgerald, S. (2002). Benefits of assistance dogs: A review. Rehabilitation Psychology, 47(3), 251.

Schoenfeld-Tacher, R., \& Kogan, L. (2017). Professional veterinary programs' perceptions and experiences pertaining to emotional support animals and service animals, and recommendations for policy development. Journal of Veterinary Medical Education, 44(1), 166-178. Doi: 10.3138/jvme.0116-003R

Schoenfeld-Tacher, R., Hellyer, P., Cheung, L., \& Kogan, L. (2017). Public perceptions of service dogs, emotional support dogs, and therapy dogs. International Journal of Environmental Research and Public Health, 14 (6), 642. doi:10.3390/ijerph14060642

Serpell, J. (1991). Beneficial effects of pet ownership on some aspects of human health and behaviour. Journal of the Royal Society of Medicine, 84(12), 717.

Shah, S. (2018, Oct 30). Netflix is getting a documentary series about dogs. Engadget. Retrieved from https://www.engadget.com/2018/10/30/netflix-is-getting-adocumentary-series-about-dogs/

Smith, T. (2018, June 4). Websites sell unneeded service animal certifications. ABC 6 WATE. Retrieved from https://www.wate.com/

Sokolowski, R. (2000). Introduction to phenomenology. New York, NY: Cambridge University Press. 
Stateline, M. O. (2017, October 16). These 19 states are cracking down on fake service dogs. PBS. Retrieved from https://www.pbs.org/

Storms v. Fred Meyer Stores, Inc. No. 55288-1-I (Wash. Ct. App. 2005)

Susquehannah Service Dogs. (n.d.) Roar for more at penn state. Retrieved from http://www.keystonehumanservices.org/susquehanna-service-dogs/campuspuppy-raising-programs/roar-for-more-at-penn-state.php

The Foundation for Service Dog Support, Inc. (2015) Public Access Challenge Report Form [introductory page]. Retrieved from http://servicedogsupport.org/publicaccess-report-form/

The Foundation for Service Dog Support, Inc. (n.d.). Public access challenge report form [interactive document]. Retrieved from https://docs.google.com/forms/d/e/1FAIpQLSc2Z61tzaRB6UYeRbEINZ6MfZqF z9ESa_rL8oWKKiuFpnP4fQ/viewform

United States Department of Justice. (1991) ADA title III technical asssitance manual covering public accommodations and commercial facilities. Americans with Disabilities Act. Retrieved from https:/www.ada.gov/taman3.html

United States Department of Justice. (1999) Americans with disabilities act technical assistance letters. Civil Rights Division. Retrieved from https://www.justice.gov/crt/americans-disabilities-act-technical-assistance-letters36

United States Department of Justice. (2011a) Public accomodations and commercial facilities (Title III). Information and Technical Assistance on the Americans with Disabilities Act. Americans with Disabilities Act. Civil Rights Division. Retrieved from https://www.ada.gov/ada_title_III.htm

United States Department of Justice. (2011b) Revised ADA requirements: Service animals [PDF] Americans with Disabilities Act. Civil Rights Division. Disability Rights Section. Retrieved from https://www.ada.gov/service_animals_2010.htm

United States Department of Justice. (2015) Frequently asked questions about service animals and the ADA. Civil Rights Division. Disability Rights Section. Retrieved from https://www.ada.gov/regs2010/service_animal_qa.html

United States Department of Transportation. (2018a). What's new: Latest news. Retrieved from https:/www.transportation.gov/airconsumer/latest-news

United States Department of Transportation. (2018b). What's new: Latest news. Retrieved from https://www.transportation.gov/individuals/aviation-consumerprotection/service-animals-including-emotional-support-animals 
Von Bergen, W. C. (2015). Emotional support animals, service animals, and pets on campus. Administrative Issues Journal: Connecting Education, Practice, and Research, 5(1), 15-34.

Walther, S., Yamamoto, M., Thigpen, A. P., Garcia, A., Willits, N. H., \& Hart, L. A. (2017). Assistance dogs: Historic patterns and roles of dogs placed by ADI or IGDF accredited facilities and by non-accredited U.S. facilities. Frontiers in Veterinary Science, 4(1). doi:10.3389/fvets.2017.00001

Weiss, E., \& Greenberg, G. (1997). Service dog selection tests: Effectiveness for dogs from animal shelters. Applied Animal Behaviour Science, 53(4), 297-308. doi:10.1016/S0168-1591(96)01176-8

Willens, J. S. (2013). Animal-assisted therapies are becoming more common. Pain Management Nursing, 14(4), 183. doi:10.1016/j.pmn.2013.10.001

Wilson, C. C. (1998). Companion animals in human health. Thousand Oaks, CA: Sage Publications, Inc.

Winkle, M., Crowe, T. K., \& Hendrix, I. (2012). Service dogs and people with physical disabilities partnerships: A systematic review. Occupational Therapy International, 19(1), 54-66. doi:https://doi.org/10.1002/oti.323

Wisch, R. (2016). Table of state assistance animal laws. Michigan State University. Retrieved from https://www.animallaw.info/topic/table-state-assistance-animallaws

Yamamoto, M., Lopez, M. T., \& Hart, L. A. (2015). Registrations of assistance dogs in california for identification tags: 1999-2012. PLOS ONE, 10(8), e0132820. doi:10.1371/journal.pone.0132820

Yount, R., Ritchie, E. C., Laurent, M. S., Chumley, P., \& Olmert, M. D. (2013). The role of service dog training in the treatment of combat-related PTSD. Psychiatric Annals, 43(6), 292-295.

Zetwick, T. D. (2016). Service dog registration: Necessary discourse or distorted issue of inconvenience?.(Doctoral dissertation). Retrieved from ProQuest Dissertations \& Theses Global. (AAT 10252582).

Zucker, H. G. (1978). The variable nature of news media influence. Annals of the International Communication Association, 2(1), 225-240. 
APPENDIX A:

Cover Letter 
Dear Participant (Name),

As a Kentucky public worker, you are a vital part of our community. As your company serves the public in (Lexington or Louisville), you are part of the ongoing pursuit of growth and improvement in Kentucky. One critical aspect in our continuing to grow and improve is understanding the experiences and perspective of our public workers.

I am Angela Dial, a graduate student in the School of Design and Community Development at West Virginia University; and under the direction of my advisor, Dr. Harry Boone, Professor and Chair in the Davis College of Agriculture, Natural Resources and Design, we are conducting this research study to understand Kentucky's working public's experiences with service dogs. The study will also identify potential areas for improvement concerning training, accessibility and service dogs in public places. The results of this study will be used to prepare a dissertation to partially fulfill the requirements for a Doctorate in Human and Community Development.

We are contacting members of the working public in the Lexington and Louisville areas of Kentucky for this study. The results will provide insight for many groups of people in our community, including politicians, business owners, public workers, and service dog training organizations. The results will be used to assist communities in making informed decisions regarding training, regulations and legislation. Please consider participating in this research study.

Participation in this research study is completely voluntary and all information you provide will be held as confidential as possible. The interview should take approximately an hour, with potential follow-ups if needed. Your participation is crucial to the success of this study. You may skip any question that you do not wish to answer and you may discontinue at any time. You must be 18 years of age or older to participate. Your interview will be audio-recorded and data will be coded for your privacy. All data will be kept on a password-protected, private computer and a pseudonym will be used in the dissertation so individual responses will not be identifiable. Data will be kept securely locked and protected for three years, after which time data will be destroyed. West Virginia University's Institutional Review Board acknowledgement of this project is on file.

I hope that you will participate in this research project, as it could be beneficial in improving our community. Thank you very much for your time. Should you have any questions about this letter or the research project, please feel free to contact me, Angela Dial at (304) 3191934 or by e-mail at amdial@mix.wvu.edu. Thank you for your time and help with this project.

Sincerely,

Angela Dial

Doctoral Student 
APPENDIX B:

Phone Script 
Participant (Name),

I am Angela Dial, a graduate student in the School of Design and Community Development at West Virginia University; and under the direction of my advisor, Dr. Harry Boone, Professor and Chair in the Davis College of Agriculture, Natural Resources and Design, we are conducting this study to understand the working public's experiences with service dogs in Kentucky.

As someone who has firsthand experience with a service dog coming into your place of business, your participation in this project would be extremely valuable. We are contacting members of the working public in the Lexington and Louisville areas of Kentucky for this study. The results will provide insight into the topic of service dogs and accessibility from the working public's perspective. The results will be used to assist communities in making informed decisions regarding training, regulations and legislation.

Participation in this research study is completely voluntary and all information you provide will be held as confidential as possible. The interview should only take an hour, with potential followups if needed. You must be 18 years of age or older to participate. Your interview will be coded for your privacy and a pseudonym used in the dissertation. You may skip any question that you do not wish to answer and you may discontinue at any time. West Virginia University's Institutional Review Board acknowledgement of this project is on file.

I hope that you will participate in this research project, as it could be beneficial in improving our community. Thank you very much for your time. Should you have any questions please feel free to contact me, Angela Dial at (304) 319-1934 or by e-mail at amdial@mix.wvu.edu

Thank you for your time and help with this project.

Sincerely, Angela Dial 
APPENDIX C:

Interview Schedule 
Interview Questions

What has been your experience with service dogs in your workplace?

Describe the setting in which the dog came into your workplace.

What time of day did the interaction occur?

How many service dogs have you experienced coming into your workplace?

Describe any differences in the interactions.

How did you identify the dog as a service dog?

Describe the dog's appearance.

What was the dog wearing? Describe in as much detail as possible.

What, if any, training did you receive regarding service dogs?

In what context did your receive this training?

What was your thought process when you saw the dog entering your store?

What feelings did you experience when the dog entered your facility?

What, if any, dialogue was exchanged?

As a gatekeeper, how did you make your decisions?

What do you need to help you make your decisions?

What improvements would you like to see?

What suggestions do you have?

What has been your experience with service dogs outside of your work?

What has been your experience with animals in your life?

Probing questions to be used when appropriate:

Describe that to me.

Can you explain that more?

Can you help me understand? 
APPENDIX D:

IRB Approval Letter 


\section{W. West VirginiaUniversity. \\ Office of Research Integrity and Compliance}

886 Chestnut Ridge Road Morgantown, WV 26506

Acknowledgement of Exemption

$09 / 20 / 2018$

To: Harry Boone

From: WVU Office of Research Integrity \& Compliance

Protocol Type: Exempt

Submission Type: Initial

Funding: N/A

WVU Protocol \#: 1809271455

Protocol Title: Working Public's Experiences with Service Dogs
Approval Date: 09/20/2018

Expir ation Date: 09/19/2021

The West Virginia Univ ersity Institutional Review Board has rev iewed your submission of Exempt protocol 1809271455 . Additional details regarding the rev iew are below:

- This research study was granted an exemption because the Research inv olves educational tests, survey procedures, interv iew procedures or observation of public behav ior and (i) information obtained is recorded in such a manner that human subjects cannot be identified, directly or through identifiers linked to the subjects, and (ii) any disclosure of the human subjects responses outside the research could not reasonably place the subjects at risk of criminal or civ il liability or be damaging to the subjects financial standing, employability, or reputation [45 CFR 46.101(2)]. All exemptions are only good for three years. If this research extends more than three years beyond the approved date, then the researcher will hav e to request another exemption. The following documents have been acknowledged for use in this study and are av ailable in the WVU+kc system:

The following documents were reviewed and approved for use as part of this submission. Only the documents listed below may be used in the research. Please access and print the files in the Notes \& Attachments section of your approv ed protocol.

- 1809271455 Phone Script.docx

- 1809271455 Interv iew Questions. docx

Protocol \#: 1809271455

FWA: 00005078

IORG: 0000194
Phone : $304293-7073$

Fax: $304293-3098$

Email: IRB@mail.wu.edu 
- Cover Letter-Revised docx

WVU IRB acknowledgement of protocol 1809271455 willexire on 09/19/2021.

If the study is to contimue beyond the expiration date, a renewal application rous tbe sub rutted wo later than two (2) weeks prior to expiration date. It is your responsib ility to sub mit your protocol for renewal.

Once you begin your human subjects research, the following regulations apply.

1. Uhantix inated or serious adverse everts andior side effects encourtered in this re search study must be reporte d to the IRB withinf ive (5) days, using the Notify IRB action in the electronis protocol.

2. Ary modif ications to the study protocol should be submitted only if there will be am ince ase inrisk to subjects ac comparying the proposed change(s).

3. You may not use a modif i d information sheet until it has beenreviewe d and achorwle dged by the WUU IRB prior to implementation.

The Office of Research Integrity and Cormpliance will be glad to provide assistance to you throughout the research process. Flease feel fiee to contact us by phone, at 304.293 .7073 or by email at IRB@mail.wn edu.

Sincerely,

$$
\begin{aligned}
& \text { Lile Ast } \\
& \text { IRB Admisistrator }
\end{aligned}
$$

Frotool H: $1809171+55$

FWR: 00005078

IORC: 000019
Phow: $304-293-7073$

Fax: $304-293-3098$ Emsil: IFFOmsil.movedn 
VITA 


\section{Angela Dial}

Education

Ph.D.

West Virginia University, Morgantown, WV
Davis College of Agriculture, Natural Resources and Design
Doctorate in Human and Community Development
Dissertation: The Working Public's Perceptions of Service Dogs: A
Phenomenological Investigation of Gatekeepers' Experiences

2019

Certificate West Virginia University, Morgantown, WV

Teaching and Learning Commons

Certificate in University Teaching

M.A. DOMUS ACADEMY, Milan, Italy

Fashion Design

Thesis: Dream Reality - streetwear collection with EASTPAK

Validation: University of Wales

B.S.

WEST VIRGINIA UNIVERSITY, Morgantown, WV

Davis College of Agriculture, Forestry and Consumer Science

Textiles, Apparel and Merchandising; Design Emphasis

Major G.P.A 4.0; Cumulative G.P.A. 3.85

Summa Cum Laude

Professional Experience - Academic/Teaching

Tennessee Technological University

Adjunct Instructor, Human Ecology, Merchandising and Design

West Virginia University

Graduate Teaching Assistant, Fashion, Dress and Merchandising

Visiting Assistant Professor, Fashion Design and Merchandising

Mars Hill University

Adjunct Instructor, Apparel and Interior Merchandising
January 2019 -

May 2019

August 2014 September 2016 January 2011 May 2013

January 2014 May 2014

\section{Professional Experience - Academic/Teaching - Courses Taught}

Tennessee Technological University

School of Human Ecology

Human Ecology, Merchandising \& Design

Merchandising II (HEC 4360)

Enrollment: 10 senior level students

In this course, students explored the concepts and

principles of merchandising, including merchandise

planning and decision making. Emphasis was on the role of 
the buyer. This course was taught online and coursework included discussions, team work and individual assignments, critical thinking activities, and a case study project simulating a merchandise buyer's responsibilities.

\section{West Virginia University}

Davis College of Agriculture, Natural Resources, and Design

School of Design and Community Development, Fashion Dress and Merchandising

Unless otherwise noted, my responsibilities for the following courses included all requirements as the primary course instructor.

\section{Introduction Fashion Business (FDM 110)}

Enrollment: 75 first or second year students

This course was part of the university's general education classes and introduced students to the business of fashion through the exploration of production and distribution systems with a focus on basic merchandising, design, marketing and retail concepts. This introduction provided a foundation for both upcoming courses and a wide range of careers available throughout the fashion industry. In addition, the concepts covered in this course were equally applicable to the merchandising and marketing of other fashion-influenced goods, such as beauty/cosmetics and home furnishing collections.

\section{Product Development (FDM 235)}

Enrollment: 60 second year students

In this course, merchandising specific students explored the concepts and principles of apparel production and postconsumer alternatives. This course was designed specifically around student-centered learning where the student learned and practiced the product development cycle as it related to merchandising roles. Class meetings included discussion, team work, hand-on experiences, and critical thinking activities. Students completed a semesterlong project developing a product for an existing retailer.

\section{Flat Pattern Design (FDM 250)}

Enrollment: 10 senior-level students

In this course, creative expression through pattern design was studied using the flat pattern method. Original apparel was designed and constructed. This was a 3 credit hour, lecture and studio class that introduced the principles of pattern design through the creation and manipulation of basic flat patterns. Course emphasis was on the relationships between two and three-dimensional shapes and the interpretation of design concepts into patterns. Through demonstration, lecture, studio work, assignments and projects, students learned the processes included in
Fall 2012, Spring 2013

Fall 2011, Fall 2014, Fall 2015 (cotaught)

Spring 2012, Spring 2013 
translating body measurements to pattern making and subsequently garment design and construction. Introduction to body scanning technology, Adobe Photoshop, collaboration with textile design, and piecework construction was included.

\section{Mentoring (FDM 293S)}

Fall 2012

\section{Enrollment: 70}

This course was designed to help students learn and practice habits to help them succeed in the major and university. Coursework included job research, schedule planning, oral presentation practice, and guest speaker presentations.

\section{Practicum (FDM 310)}

Summer 2015, Enrollment: 30 Summer 2016

This was a prearranged, supervised work experience providing practical insight into the apparel profession and fashion industry. In this course students secured summer employment and worked at least 120 hours over 6 weeks.

\section{Fashion Study Tour (FDM 311)}

Spring 2013

\section{Enrollment: 20}

In this course, students studied textile, apparel, and retail industries through visits to historic costume collections, apparel firms, design showrooms, and retail establishments. This course included a week-long field trip to New York City where students experienced the fashion industry firsthand. Additionally students had the opportunity to meet FDM alums during an alumni meet-and-greet.

\section{Draping (FDM 350)}

Enrollment: 10

In this course students used the draping method to develop creative and technical garments. Muslin fabric was used to drape basic and complex designs, in addition to practicing pattern transferring methods, and refining construction processes. Students continued to hone their designing skills from former construction courses.

Internship (FDM 491)

Summer 2015, Enrollment: 40

Spring 2011, Spring 2012, Spring 2015, Spring 2016

This course was a prearranged, supervised work experience providing students practical insight into the apparel profession. In this course students secured summer Summer 2016 (co-taught both semesters) employment working at least 240 hours over 8 weeks. This was a capstone course and required a formal written and verbal presentation of work.

\section{Fashion Show Production (FDM 493A)}

Spring 2013 
Through the application of merchandising and design principles, students in this course learned all steps involved in the production of a fashion show. Students implemented techniques applicable to, but not restricted to, project-based group work, model casting, sponsorship, planning, peer review and professionalism. The course final was the production of a WVU FDM fashion show featuring FDM designs.

\title{
SPTP: Historic Inspiration Fashion Show (FDM 493M) Lead Faculty: Dr. Lynn Barnes \\ Enrollment: 15 \\ In honor of the 100 year anniversary of the Titanic, students in this course designed, planned, and carried out a themed dinner complete with time appropriate food, presentations and fashion show. All garments were designed around historic 1912 garments of the social class and constructed with haute couture techniques.
}

\section{Mars Hill University}

Apparel \& Interior Merchandising

\section{Apparel Design Applications (AIM 332)}

\section{Enrollment: 5}

Apparel Design Applications encouraged the use of innovative ideas and creativity in apparel design. Students employed analysis, reasoning, and manipulative skills to translate design concepts into half-size patterns and garment samples. This course provided an introduction to product development using the latest Adobe Creative Suite.

\section{Publications/Conference Proceedings}

\author{
International Textiles and Apparel Association (ITAA) \\ ATEXINC Award for Innovation in Textile Instruction \\ Integrating Textile Design in Apparel Construction through a Joint-Class \\ Project
}

\section{Professional Experience - Industry}

$\begin{array}{lll}\text { J.Crew } & \text { Merchandise Processor } & \text { December } 2013 \\ \text { Distribution } & \text { Responsibilities: Packed, inspected, re-ticketed and inventoried } & \text { - March 2014 } \\ \text { Center } & \text { merchandise for shipment; performed data entry via PC/RF; } & \\ \text { Arden, NC } & \text { achieved production and quality standards; worked with team } & \\ & \text { members in support of shipments and inventory; understood } & \\ & \text { team objectives and goals. }\end{array}$

Skier Trash Technical Designer

Morgantown, WV Responsibilities: Created specification sheets; developed grading charts; researched fabrics, materials, and findings; analyzed competition.
January 2011 -

December 2011 


\begin{tabular}{|c|c|c|}
\hline Silpada Designs & Jewelry Representative & December 2007 \\
\hline Morgantown, WV & $\begin{array}{l}\text { Responsibilities: Designed and distributed mailings and } \\
\text { advertisements; processed inventory and online data entry; } \\
\text { organized client and order information; established and } \\
\text { managed customer service relations. }\end{array}$ & - January 2009 \\
\hline The Finery & Sales Associate/ Intern & August 2007 - \\
\hline Morgantown, WV & $\begin{array}{l}\text { Responsibilities: Designed and executed in-store and window } \\
\text { displays, processed inventory, assisted with seasonal buys, } \\
\text { maintained merchandise quality through steaming routine } \\
\text { inspections, processed purchases. }\end{array}$ & December 2007 \\
\hline Victoria's Secret & Sales Associate & November 2006 \\
\hline Morgantown, WV & $\begin{array}{l}\text { Responsibilities: Consistently met established sales goals, } \\
\text { provided fashion and beauty consultations to individuals and } \\
\text { groups along with bra fittings, developed creative } \\
\text { merchandising and visual displays as provided by Limited } \\
\text { Brands Corporate, operated the sales counter, processed } \\
\text { shipment, conducted physical inventory counts, attended } \\
\text { training seminars. }\end{array}$ & $\begin{array}{l}\text { - December } \\
2007\end{array}$ \\
\hline Classic Bridal & Bridal Consultant & May $2000-$ \\
\hline Morgantown, WV & $\begin{array}{l}\text { Responsibilities: Provided personalized bridal consultations } \\
\text { including fittings and alterations; mixed textile dye } \\
\text { combinations; developed custom embroideries; designed } \\
\text { window displays and floor layouts; stylized photo shoots; } \\
\text { created and modeled in runway shows; prepared promotional } \\
\text { and advertising materials; cooperated in website design; } \\
\text { negotiated product assortments and vendor contracts, } \\
\text { organized paperwork. }\end{array}$ & $\begin{array}{l}\text { July } 2002 \\
\text { August } 2003- \\
\text { November } 2005\end{array}$ \\
\hline
\end{tabular}

Research

West Virginia University

Principles of Flat-Pattern Design, $4^{\text {th }}$ ed. Summer

Research Assistant

2008

Responsibilities: Compared and contrasted existing patterning

sources, measured and recorded body and form measurements, designed and drafted patterns. Supervisor: Nora MacDonald

West Virginia University Office of International Programs

Research Assistant

Responsibilities: Researched, organized, filtered and presented reports on competing study abroad programs, for the purpose of the study abroad committee and development of WVU Design in Italy; managed email and phone communications apparent to the research; provided educated opinions on the launch of the WVU Design in Italy program with NABA. 
University/Community Service

$\begin{array}{lll}\text { Lexington } & \text { Volunteer } & \text { Spring 2018 - } \\ \text { Humane Society } & \text { Responsibilities: Patriciate in setting up, maintaining, and } & \text { Present } \\ & \text { removal of shelter merchandise displays and sales during } & \\ & \text { community events. Provide socialization for adoptable animals } & \\ & \text { through visits with local community groups. Assist with daily } & \\ & \text { shelter activities. }\end{array}$

Fashion

Faculty Advisor

Business

Association

West Virginia University

August 2012 -

May 2013

(FBA)

Betty Puskar

Faculty Volunteer

Fall 2011,

Fashion Show

Responsibilities: Organized West Virginia University student

Fall 2012 volunteers. Supervised volunteers for fashion show set-up and production.

oneSHIRT

Volunteer

Clothing Drive

WVU and SustainU National Collegiate Clothing Drive

Spring 2011 